\title{
Detecting and Modeling the Changes of Land Use/Cover for Land Use Planning in Da Nang City, Viet Nam
}

\section{Dissertation}

zur Erlangung des mathematisch-naturwissenschaftlichen Doktorgrades "Doctor rerum naturalium" der Georg-August-Universität Göttingen im Promotionsprogramm Geographie der Georg-August University School of Science (GAUSS)

vorgelegt von

Nguyen, Hoang Khanh Linh aus Hue, Viet Nam

Göttingen, 2013 
Betreuungsausschuss:

\section{Prof. Dr. Martin Kappas}

Department Cartography, GIS and Remote Sensing, Institute of Geography

\section{Prof. Dr. Renate Bürger-Arndt}

Department of Nature Conservation and Landscape Management, Institute of the Faculty of Forest Sciences and Forest Ecology

Mitglieder der Prüfungskommission:

Referent: Prof. Dr. Martin Kappas

Korreferent: Prof. Dr. Renate Bürger-Arndt

Weitere Mitglieder der Prüfungskommission:

1. Prof. Dr. Karl-Heinz Pörtge

2. Prof. Dr. Christoph Dittrich

3. Prof. Dr. Heiko Faust

4. Prof. Dr. Hans Ruppert

Tag der mündlichen Prüfung: 21.10.2013 


\section{Dedication}

To my beloved mother, who has sacrificed all her life for my progress in study. 


\section{Acknowledgements}

One of the joys of completion is to look over the windy journey and keep in mind all people who have helped and supported me to complete this dissertation.

This dissertation presents my work at the Cartography, Remote Sensing, and GIS department, Georg-August University Göttingen, Germany. The study has been carried out in the period from October 2009 to September 2013, under the supervision of Professor Dr. Martin Kappas. I would like to exhibit my heartfelt gratitude to my supervisor, Prof. Dr. Martin Kappas, who is kindness, sympathy, and the true embodiment of a mentor. He always encouraged and patiently provided me the vision and sensible advices through my doctoral pursuit. It helped me to stay on track. My gratitude goes out as well to Prof. Dr. Renate Bürger-Arndt, my second supervisor, for her instructive comments. I am greatly indebted to Dr. Stefan Erasmi for his critical comments, which helped me hone my research. Many thanks to my colleagues both staff and students at department in past and present, for their friendship and assistance: Hong Quang Nguyen, Cesar Revilla, Alexander Winz, Jan Degener, Michael Klinge, Timo Pascal Lehmann, Yi Li, Martina Beck, Pavel Propastin, and Eike Stefan Dobers.

The most enjoyable fact during my working is that I have been met wonderful researchers from over the world, doing on related subjects. They were almost available every time I need the help and I could always receive nice emails. Their guidance lets me improve the practical skills. Thank you for sharing your expertise and knowledge: Dr. Morton Canty at Central Resarch Jülich IBG-3, Dr. Wilbert van Rooij at Plansup, Msc Sebastian Günthert at Department of Geography, University of Education Heidelberg, and Mr. Duc Tri Nguyen at Sub-National Institute of Agricultural Planning and Projection (SubNIAPP).

I would not have contemplated this road if I did not have financial support from the German Academic Exchange Service (DAAD) and Vietnamese Ministry of Education and Training, especially the Vietnamese Overseas Scholarship ProgramProject No.322. I would like to express my thankfulness to both organisations for their generous support.

Thanks also to my best friend Ai Nhung Nguyen for being by my side all these hard years, sharing with me all the good and the bad times, and keeping my smiles. "A true friend is hard to find, difficult to leave, and not easy to forget”. And I will not forget all of my Vietnamese friends, especially those in Rosenbagweg 13, who warmed me up by their sentiments during my stay in Göttingen.

The last and the most important, I would like to present my sincere appreciation to my dearest mother, who did anything that kept my mind on own work. I could not able to finish this hard work without love and encouragement of my husband Ngoc Khiem Tran, and my little son Nguyen Khang Tran. I would also like to thank my aunt's family for their great affections during my stay in Germany. This achievement is dedicated for their mute sacrifice. You are the reasons why I always keep the spirit to finish things that I have started.

Finally, my PhD is over. Yeaaaaahhhhhhh!

Nguyen, Hoang Khanh Linh

Göttingen, September 2013 


\section{Abstract}

Da Nang City is located in the south central coast region of Viet Nam, between $15^{\circ} 55^{\prime} 19^{\prime \prime}$ to $16^{\circ} 13^{\prime} 20^{\prime \prime} \mathrm{N}$ and $107^{\circ} 49^{\prime} 11^{\prime \prime}$ to $108^{\circ} 20^{\prime} 20^{\prime \prime} \mathrm{E}$, and covers an area of approximately 1,283.42 $\mathrm{km}^{2}$, including Paracel Island (Hoang Sa) of $305 \mathrm{~km}^{2}$. Since its adoption of the DOI MOI policy in economy of the national assembly in 1986, which was changing from a centrally planned economy to a market oriented economy, Da Nang has developed in many aspects. Da Nang has been known as one of five independent municipalities of Viet Nam, after separating from Quang Nam Province on January $1^{\text {st }} 1997$. From then, it has asserted its position at the national level and today constitutes as the Key Economic Zone in central Viet Nam. Consequently, rapid industrialization and urbanization have caused the incessant change of land use/cover (LULC) in Da Nang city. However, less attention has been paid to assess the longterm development and driving forces of LULC changes. In this context, the study aims to (1) detect, quantify and characterize the changes of LULC in Da Nang City region by using multi-temporal images from 1979 to 2009; (2) explore the effects of LULC changes on landscape structure through spatial landscape metrics; (3) simulate the changes of LULC under different scenarios by the integration of SD model and DynaCLUE model.

The results of this thesis show that a total of 35689.79 ha or $37 \%$ of the total land has undergone change. The analysis indicates a notable decrease of agriculture, forest, barren, and shrub due to the expansion of urban. The speed and transformation trends of LULC varied in different research periods. Before being separated from Quang Nam Province (1979-1996), the LULC in Da Nang City changed gradually. However, after becoming an independent municipality, the LULC changed with rapid speed, especially urban area. Within thirteen years (1996-2009), urban area grew up 86.6\% of net increase of urban area. This could be caused by strong focus of economic development. From the following urban area, agriculture, and forest had a high rate of change, with a decreasing trend. In the meantime, key landscape indices were performed to further understand the spatial distribution of three main classes, including urban, agriculture and forest. The dynamic change of landscape indices at agriculture class revealed the break-up of the area into smaller patches. However, except agriculture, patches of forestry, and urban tended to have a uniform landscape configuration.

To simulate the future changes of LULC at Da Nang City from 2009 to 2030, three scenarios with different missions were developed, namely, scenario A “development as usual”, scenario B “aggressive development”, and scenario C "optimal development". All scenarios give a continuous increase in urban area, and a gradual decrease in agriculture, barren, and shrub area. The change of urban area in 2030 is the highest under B scenario with 17152.7 ha $(99.16 \%)$ and the lowest under C scenario with 9794.23 ha $(56.62 \%)$. The B scenario results in the most loss of agricultural area 6098.96 ha $(83.61 \%)$, while the C scenario shows the least loss of agricultural area 1996.98 ha (27.40\%) during the simulated period. Particularly, forest areas decrease by 5269.19 ha (9.1\%) and 5125.59 ha (8.85\%) under scenario A and B, respectively; meanwhile, the $\mathrm{C}$ scenario, emphasized the environmental issue, shows no change in forest (57936.2 ha) during the simulated period.

Keyword: land use/cover change, land use planning, landscape, simulate, Da Nang 


\section{Zusammenfassung}

Da Nang City liegt in der südlich zentralen Küstenregion von Viet Nam, zwischen $15^{\circ} 55^{\prime} 19^{\prime \prime}$ bis $16^{\circ} 13^{\prime 2} 20^{\prime \prime} \mathrm{N}$ und $107^{\circ} 49^{\prime} 11^{\prime \prime}$ bis $108^{\circ} 20^{\prime} 20^{\prime \prime} \mathrm{E}$, und umfasst eine Fläche von ca. 1,283.42 km², einschließlich des Bezirks Paracel Islands mit $305 \mathrm{~km}^{2}$. Seit der wirtschaftlichen Kontrolle durch die DOI MOI Politik in der Nationalversammlung im Jahre 1986, wurde die zentrale Planwirtschaft in eine marktorientierte Wirtschaft verändert, wodurch sich Da Nang in vielen Aspekten entwickelt hat. Am 1. Januar 1997 ist Da Nang offiziell eine von fünf selbstständigen Gemeinden in Viet Nam geworden. Seit dem hat sie ihre Position auf nationaler Ebene ausgebaut und ist heute Key Economic Zone in Zentral-Viet Nam. Folglich haben die rasche Industrialisierung und Urbanisierung einen unaufhörlichen Wandel der Landnutzung/Bodenbedeckung (LULC-Land use/land cover) in Da Nang Stadt verursacht. Allerdings ist wenig Aufmerksamkeit auf die langfristige Entwicklung und die treibenden Kräfte der LULC Veränderungen gelegt worden. In diesem Zusammenhang soll diese Studie (1) zum Erfassen, zum Quantifizierten und zum Charakterisieren der Veränderungen durch LULC in Da Nang City mit multi- temporalen Bildern von 1979 bis 2009, (2) zum Untersuchung der Auswirkungen der LULC Änderung auf die Landschaftsstruktur durch Raumlandschaftsmetriken und (3) zum Simulieren der Veränderungen der Landnutzung / Bodenbedeckung unter verschiedenen Szenarien durch die Kombination von SD -Modell und Dyna- CLUE Modell dienen.

Die Ergebnisse dieser Arbeit zeigen, dass insgesamt 35.689,79 ha oder 37\% der gesamten Landfläche von Veränderungen betroffen sind. Die Analyse ergab, dass ein deutlicher Rückgang der landwirtschaftlicher Fläche, des Waldes sowie unfruchtbarer Gebiete und Strauchvegetation auf den Ausbau der Städte zurückzuführen ist. Die Geschwindigkeits und Transformations Trends der LULC variiern in verschiedenen Forschungsperioden. Bevor Da Nang von der Provinz Quang Nam (1979-1996) abgetrennt wurde, änderte sich die LULC nur allmählich. Doch nachdem die Stadt zur eigenständigen Gemeinde wurde, änderte sich die LULC besonders im Stadtgebiet mit rasanter Geschwindigkeit. Innerhalb von 13 Jahren (1996-2009) wuchs das Stadtgebiet mit einen Netto-Zunahme der städtischen Bereiche von 86.6\%. Dies kann durch die starke Konzentration auf wirtschaftliche Entwicklung verursacht worden sein. Durch die urbanisierte Fläche ergab sich eine hohe Veränderungsrate für landwirtschaftlicher Fläche und Waldgebiete, mit abnehmender Tendenz. In der Zwischenzeit wurden Indizes für die Landbedeckung festgelegt, um die räumliche Verteilung der drei Hauptklassen, Stadt, Landwirtschaft und Wald ab zu leiten. Die dynamische Veränderung der Landschaft Indizes von Landwirtschaft Klasse zeigte die Aufspaltung der Flächen in kleinere Segmente. Dennoch lässt sich mit Ausnahme der Landwirtschaft, eine einheitliche Tendenz in der Landschaftskonfiguration für Wald und Stadtgebiete erkennen.

Um die zukünftigen Veränderungen der LULC bei Da Nang von 2009 bis 2030, vorherzusagen wurden drei Szenarien mit unterschiedlichen Annahmen entwickelt, nämlich: Szenario A "normale Entwicklung" , Szenario B "aggressive Entwicklung" und Szenario C "optimale Entwicklung". Alle Szenarien ergeben einen kontinuierlichen Anstieg im städtischen Bereich, und eine allmähliche Abnahme der landwirtschaftlicher Fläche, sowie der unfruchtbaren Gebiete und in Bereichen mit Strauchvegetation. Die 
Veränderung im städtischen Gebiete bis zum Jahr 2030 ist am höchsten im Szenario B mit 17.152,7 ha (99,16\%) und am niedrigsten im Szenario C mit 9.794,23 ha (56,62\%). Im Szenario B ergibt sich der größte Verlust an landwirtschaftlicher Fläche mit 6098,96 ha (83,61\%), während im Szenario C der geringste Verlust landwirtschaftlicher Fläche, mit 1996,98 ha (27,40\%) zu verzeichnen ist. Ein Verlust von Waldgebieten zeigt sich besonders in den Szenarien A und B mit 5.269,19 ha (9,1\%) bzw. 5.125,59 ha (8,85\%), während im Szenario C, welches den ökologischen Aspekt betont, keine Veränderung der Waldgebiete (57.936,2 ha) bis 2030 zu verzeichnen ist.

Schlagwort: Bodennutzung/Bodenbedeckung, Wandel, Raumplanung, Landschaft, simulieren, Da Nang 


\section{Table of contents}

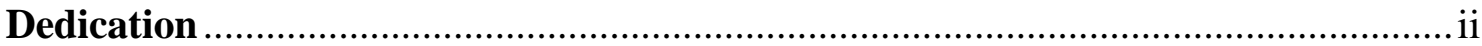

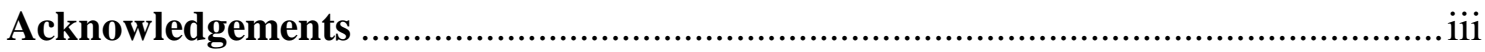

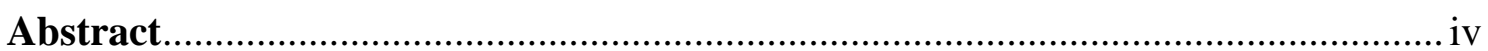

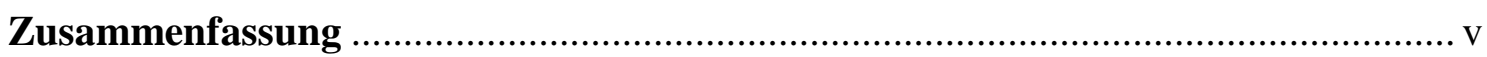

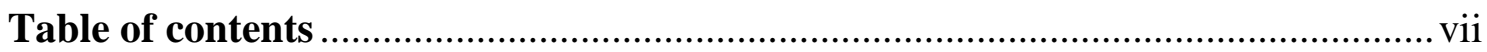

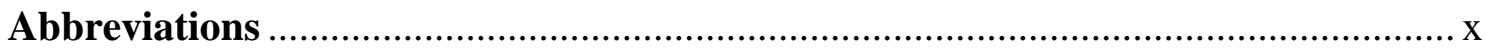

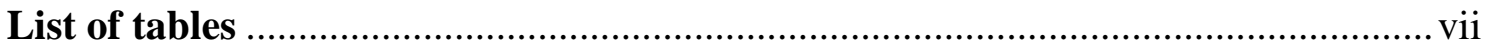

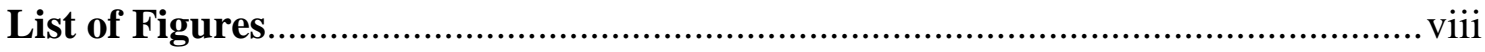

\section{Chapter 1: Introduction}

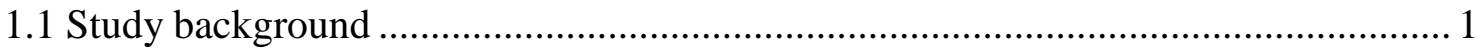

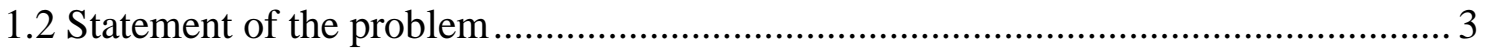

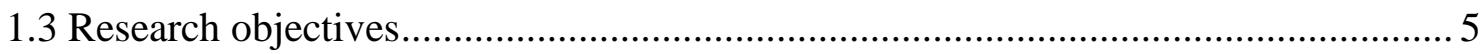

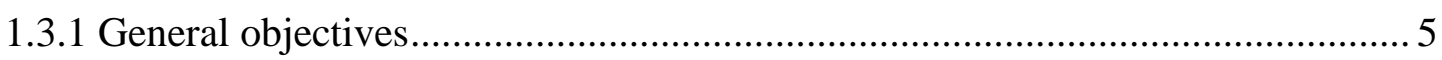

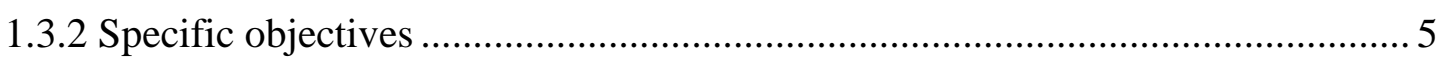

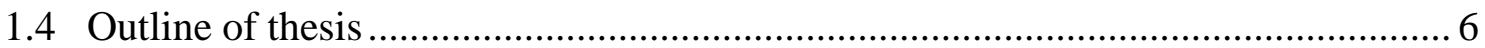

\section{Chapter 2: Theoretical Background}

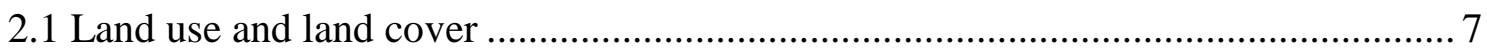

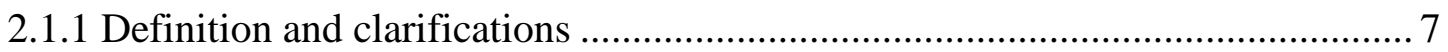

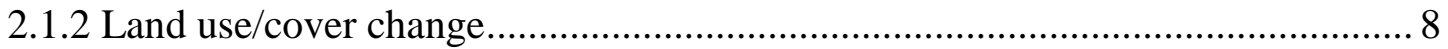

2.1.3 Land use/cover change causes and consequences ............................................. 9

2.1.4 Driving factors of land use/cover change ...................................................... 9

2.2 Combination of remote sensing and geographic information systems (GIS) ........... 10

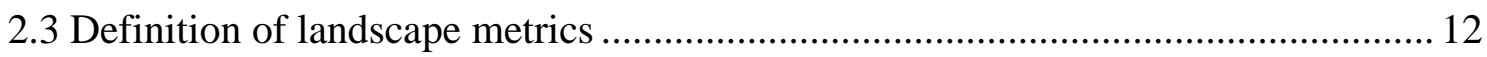

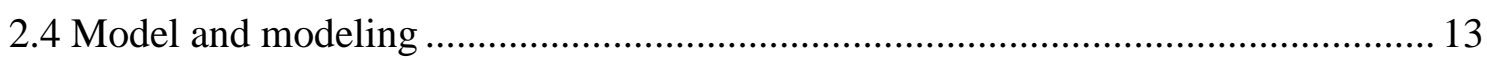

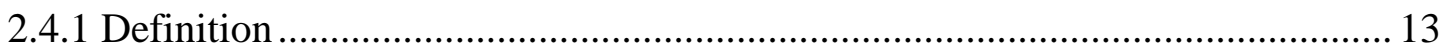

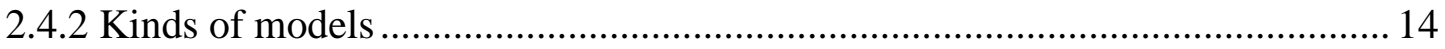

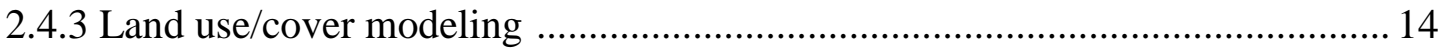

\section{Chapter 3: Study Area}

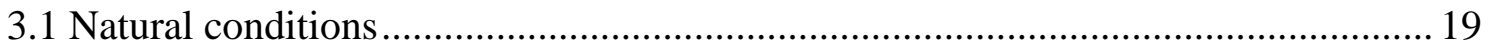

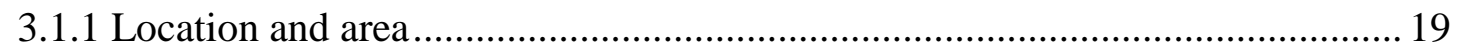


3.1.2 Topography 21

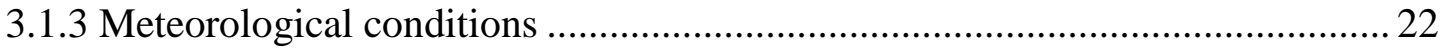

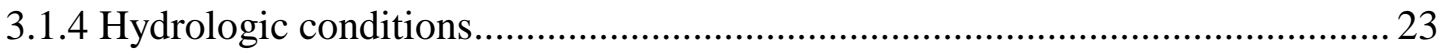

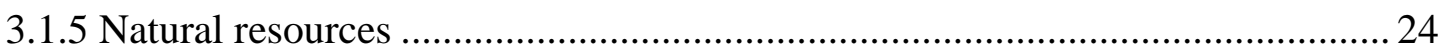

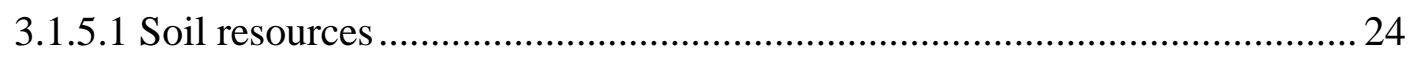

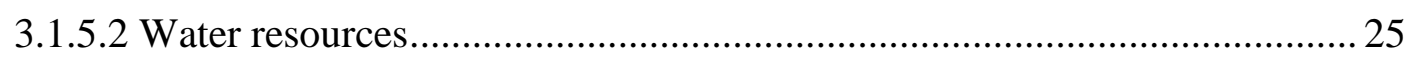

3.1.5.3 Forestry and floristic cover resources ...................................................... 26

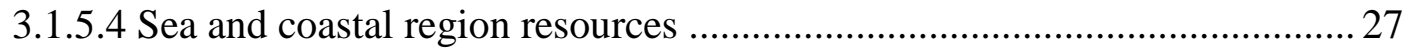

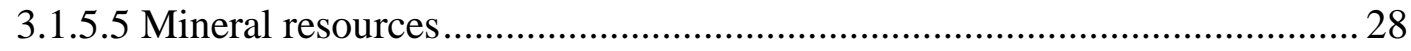

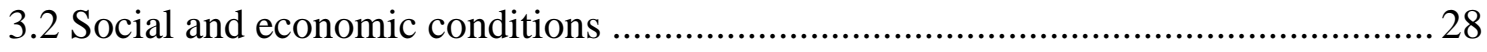

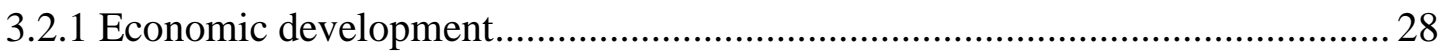

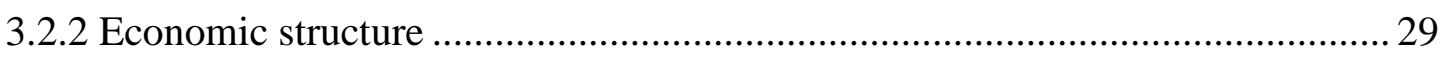

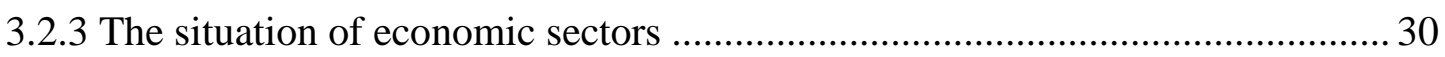

3.2.3.1 Agriculture, forestry, and fishery sector ................................................... 30

3.2.3.2 Construction and industry sector ............................................................ 31

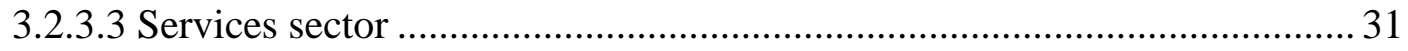

3.2.4 Population, labor, employment, and income …............................................... 32

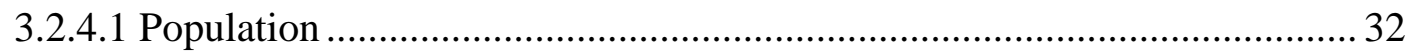

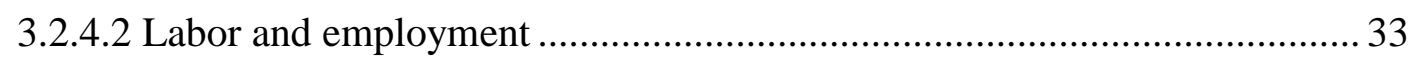

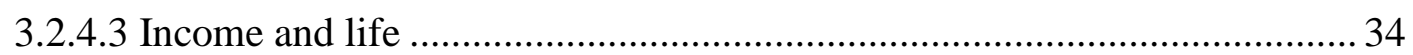

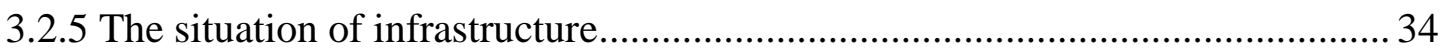

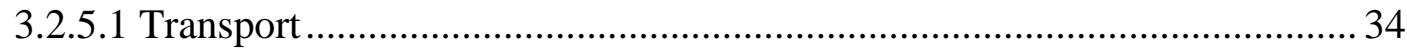

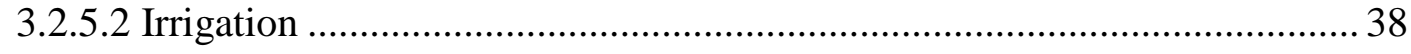

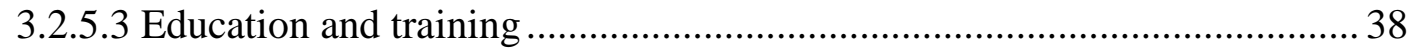

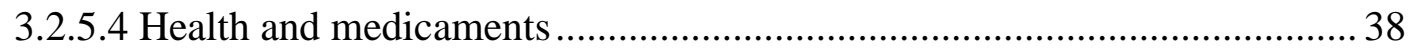

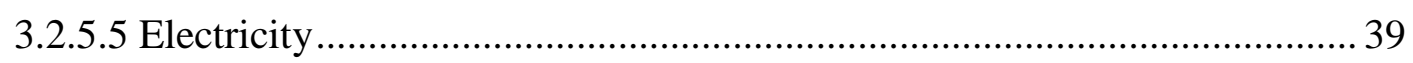

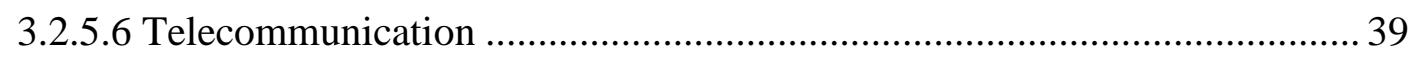

3.3 General assessment of natural, socio-economic condition .................................... 39

\section{Chapter 4: Data and Methodology}

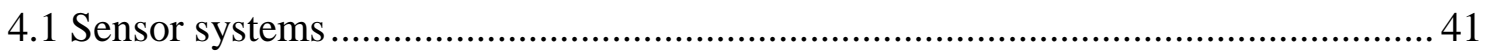

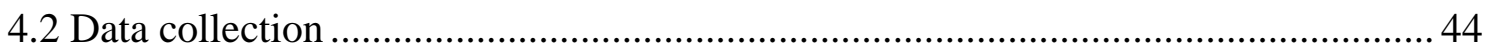

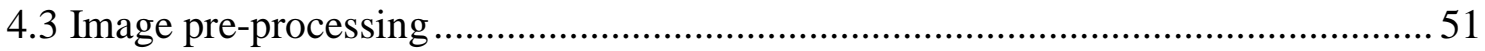

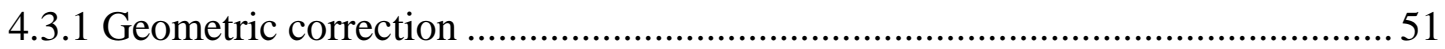

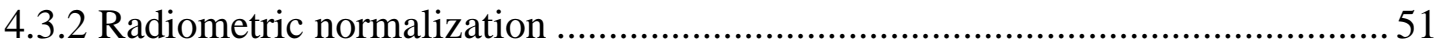

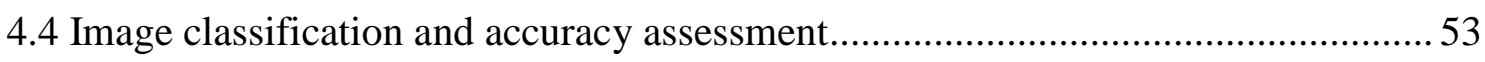




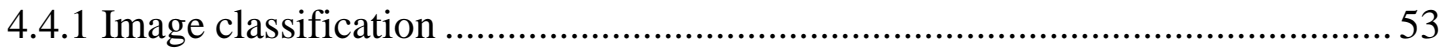

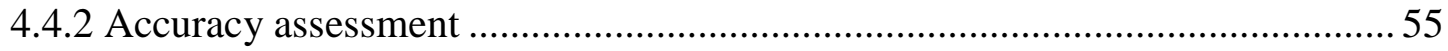

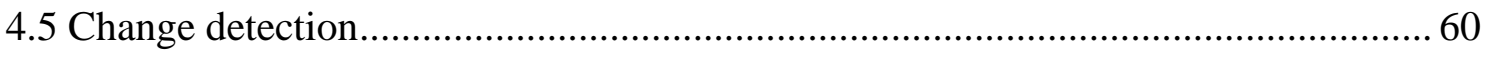

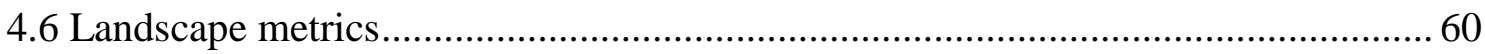

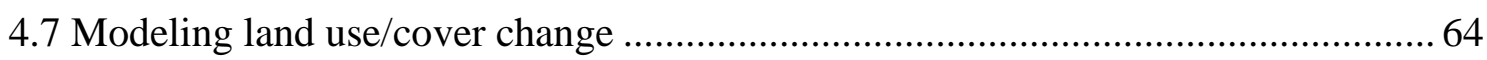

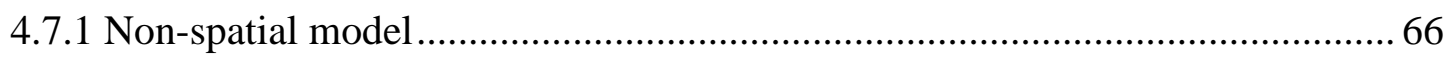

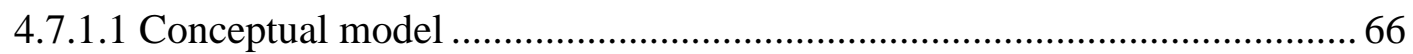

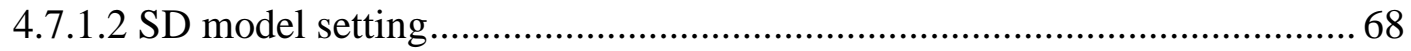

4.7.1.3 SD model calibration and validation ...................................................... 77

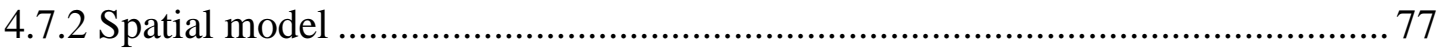

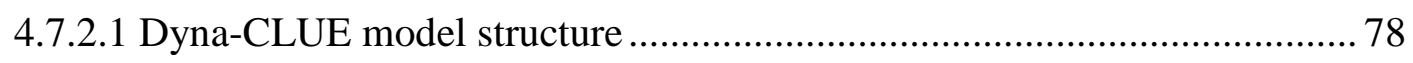

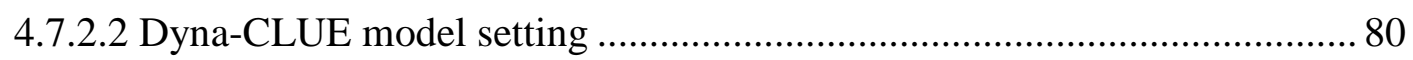

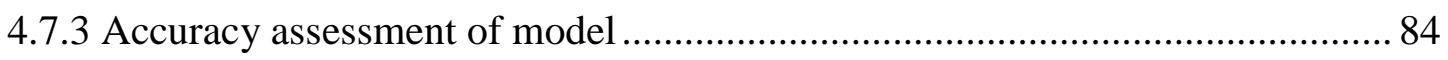

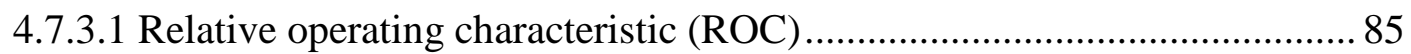

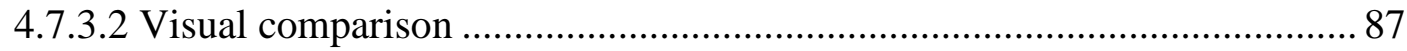

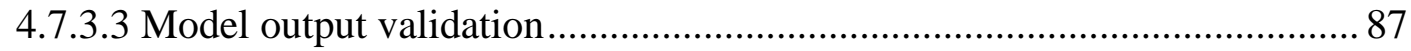

4.8 ANOVA analysis for landscape metrics under scenarios ....................................... 91

\section{Chapter 5: Land use/cover Changes}

5.1 Spatial-temporal dynamics and evolution of LULC changes .................................. 92

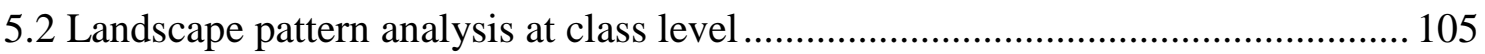

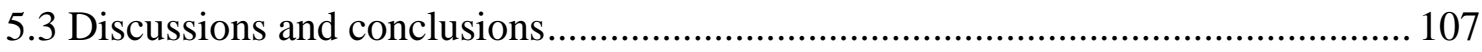

\section{Chapter 6: Modeling Land use/cover}

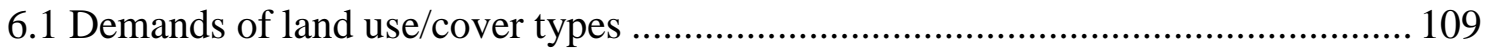

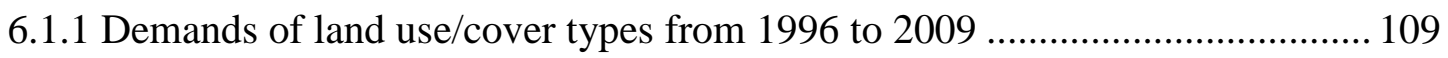

6.1.2 Demands of land use/cover types from 2009 to 2030 .................................... 112

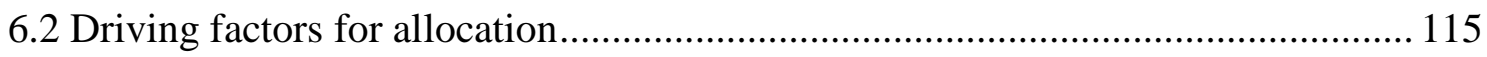

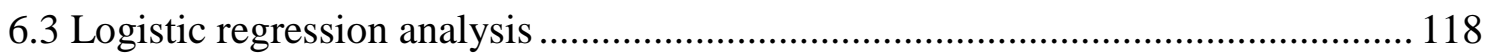

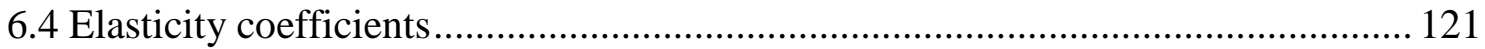

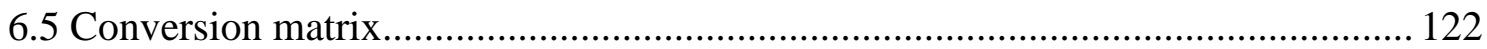

6.6 Validation output from the Dyna-CLUE model .................................................... 122

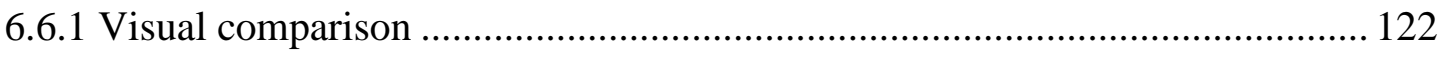

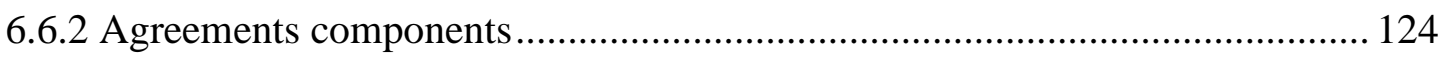

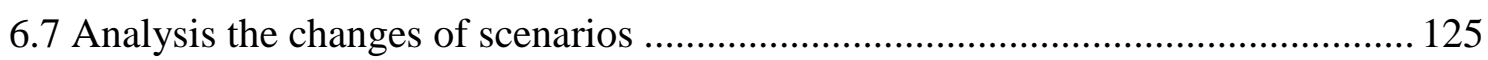

6.7.1 Land use/cover changes under different scenarios ......................................... 125 
6.7.2 Land use/cover changes according to administration boundary ..... 132

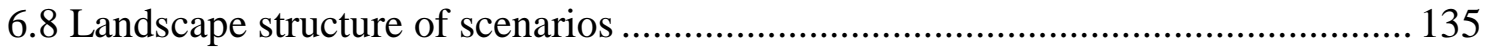

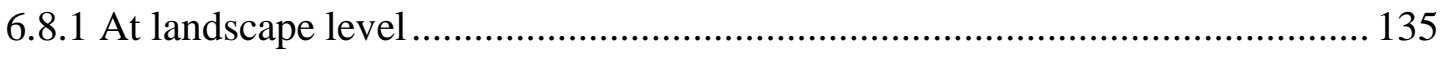

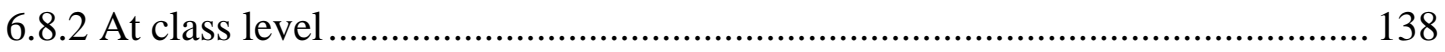

6.8.3 Efffects of land use scenarios to landscape structure ..................................... 146

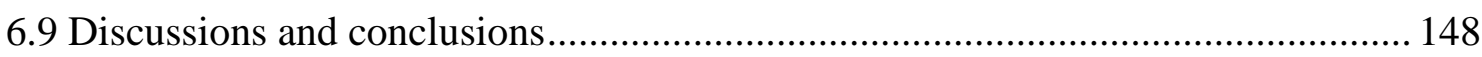

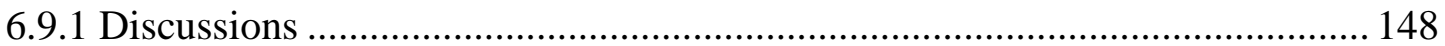

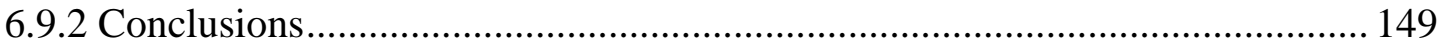

\section{Chapter 7: Conclusions}

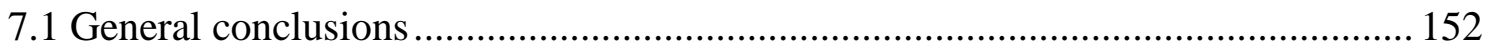

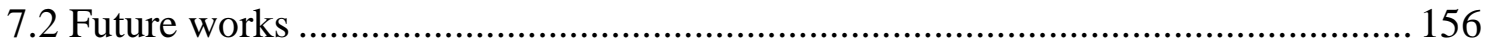

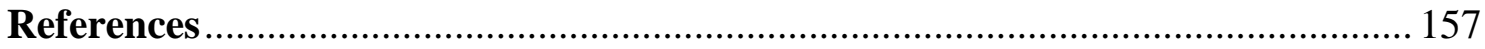

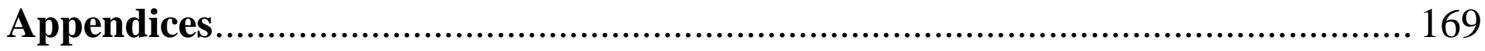

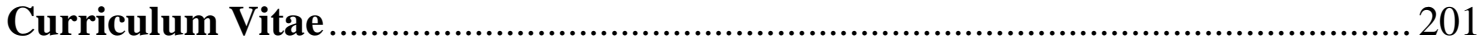

\section{Abbreviations}

ASPRS American Society for Photogrammetry and Remote Sensing

ANOVA Analysis of Variance

ASTER Advanced Space-borne Thermal Emission and Reflection Radiometer

AUC Area under the curve

CCD Charge Coupled Detector

CLUE Conversion of Land Use and its Effects

DEM Digital Elevation Model

DN Digital Number

Dyna-CLUE Dynamic Conversion of Land Use and its Effects

ETM+ Enhanced Thematic Mapper Plus

FAI Fixed-assets investment of construction

FAO Food and Agriculture Organization of the United Nations

FPR False Positive Rate 


\begin{tabular}{|c|c|}
\hline GDP & Gross Domestic Product \\
\hline GIS & Geographic Information System \\
\hline GloVis & Global Visualisation \\
\hline GOI & Gross output industry \\
\hline GSPs & Ground Control Points \\
\hline IDS & Institute of Development Studies \\
\hline IFOV & Instantaneous Field of View \\
\hline IR-MAD & Iteratively Re-weighted Multivariate Alteration Detection \\
\hline LULC & Land use/ Land cover \\
\hline MAD & Multivariate Alteration Detection \\
\hline MCK & Map Comparison Kit \\
\hline MERN & Multiple date Empirical Radiometric Normalization \\
\hline MLC & Maximum likelihood classification \\
\hline MSS & Multispectral Scanner \\
\hline NASA & National Aeronautics and Space Administration \\
\hline PCA & Principal Component Analysis \\
\hline PIFs & Pseudo Invariant Features \\
\hline RMSE & Root Mean Square Error \\
\hline ROC & Relative Operating Characteristic \\
\hline SD & System dynamics \\
\hline SLC & Scan Line Corrector \\
\hline SPOT & System Probatoire d’Observation de la Terre \\
\hline SWIR & Short Wave Infrared \\
\hline TM & Thematic Mapper \\
\hline TPR & True Positive Rate \\
\hline USGS & United States Geological Survey \\
\hline UTM & Universal Transverse Mercator \\
\hline VND & Vietnamese Dong \\
\hline VNIR & Visible and Near Infra-Red \\
\hline WGS 84 & World Geodetic System 1984 \\
\hline WTO & World Trade Organization \\
\hline
\end{tabular}




\section{List of Tables}

Table 2.1 Overview of land use/cover model 18

Table 3.1 GDP and development of economics in period 2000-2010 29

Table 3.2 Economic structure in period 2000-2010 _................................................... 30

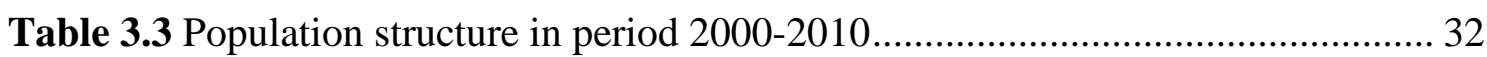

Table 3.4 Quantity of transported passengers and goods by airlines ............................ 35

Table 3.5 Quantity of transported passengers and goods by train......................................36

Table 3.6 Quantity of transported goods by waterway ............................................... 37

Table 4.1 Characteristics of Landsat sensors ................................................................... 43

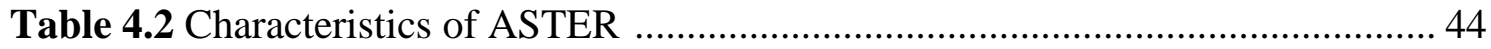

Table 4.3 Characteristics in satellite datasets used .................................................... 50

Table 4.4 Illustration of error matrix with j classes and $\mathrm{N}$ reference samples............... 55

Table 4.5 Formulas of quantity disagreement and allocation disagreement indexes..... 59

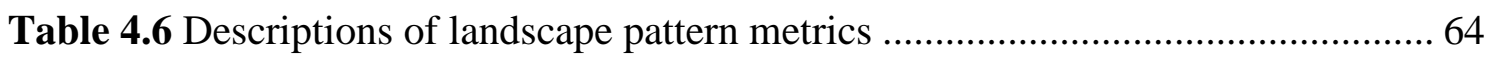

Table 4.7 Example of conversion matrix with three land use types ............................. 84

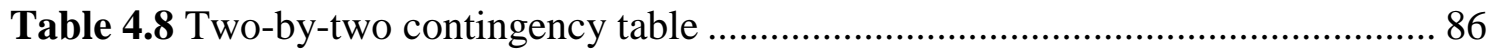

Table 5.1 Kappa scores obtained from assessment of four different land use maps...... 93

Table 5.2 Land use/cover in Da Nang City from 1979 to 2009 ................................... 94

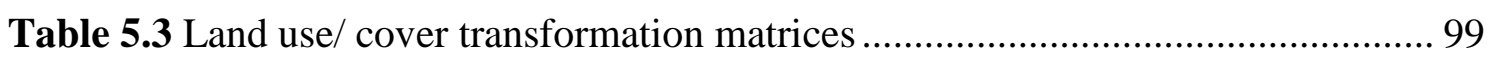

Table 5.4 Measuring the changes of urban area in different districts ......................... 100

Table 5.5 Metrics of landscape structure at the class level ....................................... 105

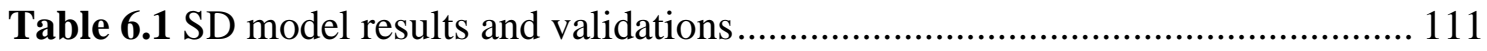

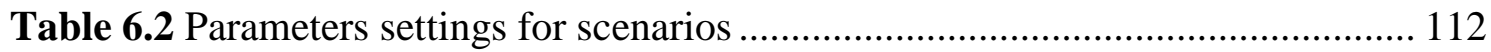

Table 6.3 Temporal simulation of land use/cover system in Da Nang city ................. 114

Table 6.4 Logistic regression of land use/cover type................................................ 118

Table 6.5 Elasticity coefficient of land use/cover type ............................................. 121

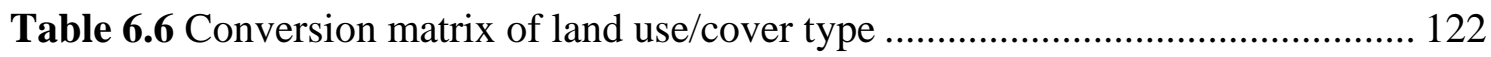

Table 6.7 Accuracy assessment indices of land use change modeling ........................ 124

Table 6.8 Comparison of land use/cover changes in 2030 under three scenarios......... 131

Table 6.9 Comparison of land use/cover types in 2030 under three scenarios according to administration boundary 135 
Table 6.10 One-way ANOVA for the effects of land use/cover changes on landscape structure

Table 6.11 Descriptive values of landscape metrics obtained with one-way ANOVA.....

\section{List of Figures}

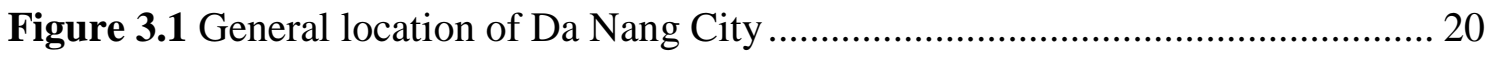

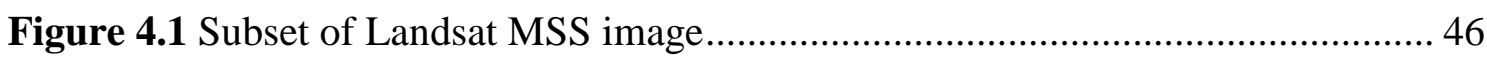

Figure 4.2 Subset of mosaic Landsat TM images...................................................... 47

Figure 4.3 Subset of mosaic Landsat ETM+ images ................................................ 48

Figure 4.4 Figure 4.4 Subset of ASTER image ........................................................ 49

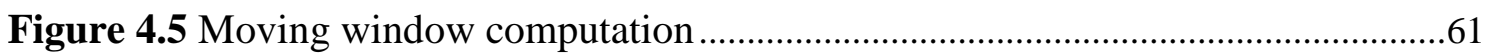

Figure 4.6 Flowchart of modeling land use/cover changes used in study ..................... 65

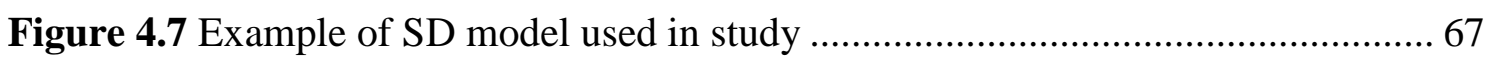

Figure 4.8 The SD model for simulating the demands of land use/cover in Da Nang

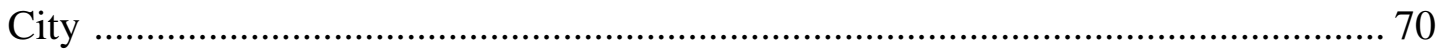

Figure 4.9 Framework of the Dyna-CLUE model ....................................................... 79

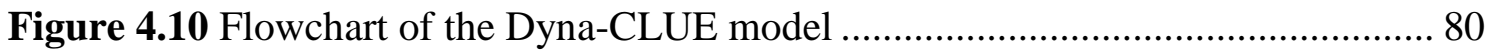

Figure 4.11 Example of ROC curve $=0.970$, area under the curve (forest) ................. 84

Figure 4.12 Flowchart of calibration and validation process..................................... 91

Figure 5.1 Percentage of land use/land cover extracted from remote sensing data....... 94

Figure 5.2 Trends of land use/covers from multi-temporal images and statistic data: a) agriculture; b) barren; c) urban; d) forest; e) shrub and forest; f) water ................... 95

Figure 5.3 Classified land use/cover maps from multi-temporal images ..................... 97

Figure 5.4 Gross Domestic Product and its growth in Da Nang City from 1990-2009

Figure 5.5 Development of the economic structure in Da Nang City from 1997 to 2009.

Figure 6.1 Comparison between actual and predicted values of Population, Gross

output industry, and Fixed-assets investment construction 110

Figure 6.2 Comparison between actual and predicted values of land use/cover area 
Figure 6.3 Driving factors a) Urban rate, b) Mean density of population, c) Slope, d) Elevation

Figure 6.3 (continued) Driving factors e) Distance to urban, f) Distance to water, g)

Distance to road

Figure 6.4 Visual comparison between the pairs of maps 123

Figure 6.5 Simulated LULC maps in scenario A 126

Figure 6.6 Simulated LULC maps in scenario B 127

Figure 6.7 Simulated LULC maps in scenario C ..................................................... 128

Figure 6.8 Land use/cover types under different scenarios 129

Figure 6.9 Comparisons of land use/cover in three scenarios: a) Agriculture, b) Barren,

c) Urban, d) Forest, e) Shrub, and f) Water 130

Figure 6.10 Landscape metrics at landscape level under scenarios (a) number of patches, (b) patch density, (c) mean proximity, d) mean patch area, (e) interspersion and juxtaposition index, (f) largest patch index, and (g) largest shape index 136

Figure 6.11 Landscape metrics at agriculture class under scenarios (a) number of patches, (b) patch density, (c) mean proximity, (d) mean patch area, (e) interspersion and juxtaposition index, (f) largest patch index, and (g) largest shape index

Figure 6.12 Landscape metrics at barren class under scenarios (a) number of patches, (b) patch density, (c) mean proximity, (d) mean patch area, (e) interspersion and juxtaposition index, (f) largest patch index, and (g) largest shape index 141

Figure 6.13 Landscape metrics at urban class under scenarios (a) number of patches, (b) patch density, (c) mean proximity, (d) mean patch area, (e) interspersion and juxtaposition index, (f) largest patch index, and (g) largest shape index

Figure 6.14 Landscape metrics at forest class under scenarios (a) number of patches, (b) patch density, (c) mean proximity, (d) mean patch area, (e) interspersion and juxtaposition index, (f) largest patch index, and (g) largest shape index 143

Figure 6.15 Landscape metrics at shrub class under scenarios (a) number of patches, (b) patch density, (c) mean proximity, (d) mean patch area, (e) interspersion and juxtaposition index, (f) largest patch index, and (g) largest shape index

Figure 6.16 Landscape metrics at water class under scenarios (a) number of patches, (b) patch density, (c) mean proximity, (d) mean patch area, (e) interspersion and juxtaposition index, (f) largest patch index, and (g) largest shape index. 145 


\section{CHAPTER 1}

\section{Introduction}

\subsection{Study background}

As stated in Competitive Cities in the Global Economy (OECD, 2006) and State of the World's Cities 2008/2009: Harmonious Cities (UN, 2008), urbanization is a global phenomenon that is expected to continue for the next few decades. According to the United Nations, roughly half of the world's population lives in urban areas, and, in 2030 , it will have increased to $60 \%$. This increase in urbanization will mainly happen in developing countries (OECD 2010). As pointed out by Elvidge et al. (2004), human beings tend to live in spatially limited habitats, called urban environment, where most people live and work. Hence, urban areas concentrate not only people but also economic density and productivity (OECD, 2009), which is the reason for: changes in lifestyles, high consumption of energy, transportation, infrastructure, and production of waste, etc. (Angel et al., 1998; Collier, 1997; Collier and Löfstedt, 1997; DeAngelo and Harvey, 1998; Harvey, 1993; Lambright et al., 1996; McEvoy et al., 1999; Wilbanks and Kates, 1999).

Urbanization is believed one of the most prevalent anthropogenic causes of arable land loss, habitat devastation, and natural vegetation cover loss (Dewan and Yamaguchi, 2009). As a matter of course, rural areas have been converted into urban areas through development with an unprecedented rate, which has had a noted effect on 
the natural functioning of ecosystems (Turner, 1994). In other words, "the phenomenon of urban development is one of the major forces driving land use change” (Wu et al., 2006). What is more, urban growth is a very complex process that is jointly influenced by social, economic, historical, and biophysical factors. Hence, a profound understanding of land use/cover change is very important be able to have proper land use planning and sustainable development policies (Braimoh and Onishi, 2007).

To fulfill a sustainable development plan, Myint and Wang (2006) asserted that such plan must be summarized from numerous factors extracted from various data sources. These factors could represent the physical, biological and social settings of areas in the continued spectrum of spatial and temporal domains. Therefore, it is important to have an effective spatial dynamic tool, which is used to understand the changes of land use and land cover (LULC).

Since the launch of the first Earth Resources Technology Satellite in 1972 (ERTS-1, later renamed Landsat 1), remote sensing has become an important research branch in mapping and monitoring environmental changes due to anthropogenic pressures and nature processes (Treitz and Rogan, 2004). In the last three decades, the technologies of remote sensing have incessantly evolved, including a suite of sensors operating at a wide range of imaging scales, lower data price and high resolution (Rogan and Chen, 2004). Hence, remote sensing data offers spatially consistent data sets of large areas with high spatial detail and high temporal frequency. Undoubtedly, remote sensing is an ideal mean for providing consistent historical time series data which can be seen as the "unique view" of spatial and temporal patterns in the process of land use/cover change (Xiao et al., 2006). Accordingly, remote sensing is well known as a technique used in detecting and monitoring the change at various scales with useful results (Stefanov et al., 2001; Wilson et al., 2003). In addition, with strong development, geographic information systems (GIS), a powerful spatial analysis function, can be used to convert the discrete statistical data and survey data into spatially continuous distribution data. GIS effectively reflects the spatial difference by using certain spatial calculation methods (Peng and Lu, 2007). Of the many technological and conceptual approaches to spatial data analysis, GIS, the most promising tool, can give reliable information for both planning and decision-making tasks (Michalak, 1993). 
Landscape ecological studies have been focused as the new dimension of land management in recent years. The recognition of the importance of "landscape perspective” is growing (Apan et al., 2000). Studying landscape change is absolutely necessary for sustainable management; it helps the decision makers obtain a complete view of the land use/cover change system and its components (Keleş et al., 2008). Regarding this term, ecological perspectives have been addressed by the questions: "How does urbanization influence land-ecosystem services, and, How does urbanization impact landscape structures/land architecture?” (Fragkias, 2012). To answer these questions and to increase effectiveness in managing environmental sustainability, it is necessary to understand the links between LULC and landscape pattern (Antrop and Van Eetvelde, 2000). What is more interesting is that spatial metrics could be a useful tool to characterize the differences between plan and design alternatives. As a result, spatial metrics are required for land use planning and design (Lin et al., 2007).

According to Jat et al. (2008), for balanced development after monitoring to know how the land is currently used, the municipal authorities or decision maker must assess future demand and take steps to assure adequacy of future supply. Hence, to answer the question as how LULC is likely to move in the next several years to come, a modeling approach is believed to be a useful tool. Simulating land use/land cover dynamics by models can help municipal authorities or decision makers perceive the characteristics and interdependencies of the components that constitute spatial systems. This could give valuable insights into possible LULC configurations in the future (Koomen, 2007). Consequently, the policy makers could evaluate different scenarios of LULC change and their effects, which are used to support land use planning and policy (Rafiee et al., 2009).

\subsection{Statement of the problem}

Da Nang, the fourth largest city of Viet Nam and the largest urban area in the Central region, is in a favorable geographical location, including the national transport axis with road, railroad, sea and air transportation links as well as serving as the gateway to the Central Highlands (Nguyen, 2003). 
In the late 80s and early 90s, the Vietnamese government adopted the economic reform policy (namely, DOI MOI), changing from a centrally planned economy to a market oriented one (Que and Phuc, 2003). However, Da Nang had not been able to grow its economy compared to Ho Chi Minh City (HCMC) and Ha Noi Capital. On January $1^{\text {st }} 1997$, Da Nang was separated from Quang Nam province and officially became one of five independent municipalities of Viet Nam that directly belong to the government (The Statistics department, 2005). This marked an important turning point in the socio-economic development of Da Nang because the government would like to push the city into an economic hub to boost the development of the Central region (Nguyen, 2003). During this development period, Da Nang has experienced its highest economic growth rates, with an annual increase of the gross domestic product (GDP) of $11.43 \%$. Together with the growth of the economy, rapid industrialization and urbanization have caused the incessant change of LULC in Da Nang city.

With this change, Da Nang has asserted its position of importance at the national level and today constitutes the Key Economic Zone in central Viet Nam. Nevertheless, as the Institute of Development Studies report (IDS, 2007), Da Nang City has been confronted with many environmental problems and natural disasters that impact not only socio-economic development but also the environment. Different conflicts have been arising, such as the conflict between land resources and demand for development versus the vulnerability of the coastal zone (Ding et al., 2007; Huang et al., 2010; Käyhkö et al., 2011; Lyons et al., 2012; Quan et al., 2006; Shalaby and Tateishi, 2007; Weng, 2002). Like other provinces in Viet Nam, the land use planning in Da Nang City was generated basically on the increase of population, the development of economics, characteristics of topography, and experiments of local planners without scientific support. Thus, sustainable development is put at risk due to inadequate planning, increasing human activity, inter-agency conflicts and lack of a coordinated management approach. Consequently, it is necessary to obtain complete measures to arrest and reverse the declining environmental conditions (IDS, 2007). In this case, a complete research study in assessing and simulating land use/land cover dynamics in Da Nang city is needed to help the local decision-making processes and influence land managers to carefully consider land use planning and design. 


\subsection{Research objectives}

\subsubsection{General objectives}

Guided by the matters stated above, the objectives of this dissertation are to address and simulate the changes of land use/cover in Da Nang City. A deep understanding of the complex changes over time could support land use planners or decision makers in the formulation of locally adapted policy interventions. It is expected to have an efficient land use/over management manner that benefits both local and national economy.

The proposed research will be guided by the following questions:

- What is the current system of land use/cover in Da Nang City and how has the spatial and temporal distribution altered overtime?

- What are the driving factors of land use/cover changes within Da Nang City? What are the critical developments, and can the effects of change over time be quantified? How to identify the local effects of vulnerable and sustainable components to interacting perturbations?

- How does the trend of spatial land use help political decision-making variables and land use planning?

\subsubsection{Specific objectives}

In order to achieve the general objective the above, these operational steps are formulated as:

- Assessing the change of land use/cover, in particular urban land use under the impacts of urbanization by using time series remotely sensed images from 1979 to 2009;

- Analysing patterns of changes in landscape within the study area during the last three decades;

- Determining the underlying and proximate causes of land use/land cover changes; 
- Simulating and locating the changes of land use/cover within the study area during the period 2009 to 2030;

The outcome of this study is to support the sustainable development of urbanization. Understanding of the complex interactions of these changes over time could assist local decision makers in the formulation of regionally adapted policy interventions.

\subsection{Outline of thesis}

In the framework of the dissertation, this research consists of seven chapters that discuss the major components. Chapter 1 defines the problem statements and the main objectives of study. Chapter 2 reviews shortly the conceptual background often used in assessing the change of land use/land cover and landscape structure. In addition, this chapter also includes a brief literature review on land use modeling approaches. Chapter 3 introduces an overview of study area based on its biophysical and socio-economic characteristics. In Chapter 4, data used for research are presented. Importantly, this chapter fully discusses the applied methods for processing the remote sensing dataset, the approaches for detecting the changes of land use/cover and landscape structure, and the modeling techniques. The dynamics of land use/cover and landscape structure within the study area over the last three decades are presented in Chapter 5 . The resulting output of modeling, the validation results, as well as landscape structure analysis under different land use/cover scenarios are detailed in Chapter 6. Finally, the general conclusions and recommendations are outlined in Chapter 7. 


\section{Theoretical Background}

This chapter introduces and provides some of the fundamental terms related to land use/cover concepts, remote sensing, GIS, combination of remote sensing and GIS in land use/cover change analysis, landscape metrics analysis, and land use/cover modeling.

\subsection{Land use and land cover}

\subsubsection{Definition and clarifications}

FAO (1995) defined land as:

"Land is a delineable area of the earth's terrestrial surface, encompassing all attributes of the biosphere immediately above or below this surface including those of the near-surface climate the soil and terrain forms, the surface hydrology (including shallow lakes, rivers, marshes, and swamps), the near-surface sedimentary layers and associated groundwater reserve, the plant and animal populations, the human settlement pattern and physical results of past and present human activity (terracing, water storage or drainage structures, roads, buildings, etc.)." 
Land use/cover is one of the important pieces of information for land use planning and management. The concepts "land use" and "land cover" have a close relationship to each other; therefore, in many cases, they are often confused and have been used interchangeably (Anderson et al., 1976b; Zhan, 2003). As a matter of fact, "land cover and land use are two linked components” (Müller, 2003).

As mentioned by Campbell (1996, 2002), land use is defined as the use of land by humans and refers to how the land is being used, which often refers to the use of land for economic activities. On the other hand, land cover designates the visible evidence of land use or refers to the biophysical materials found on the land that can be directly observed, such as roads, buildings, parking lots, forest, rivers, etc. Hence, land use is an abstract term while land cover is a concrete one without economic function. For example, a state park may be used for recreation but have a deciduous forest cover. One method of organizing land use/cover information is to use a classification system.

Many different classification systems, based mainly on various requirements of planners or other businesses, have been created in different countries. These classification systems are actually quite detailed and not suitable for applying remote sensing or visual aerial-interpretation (Zhan, 2003). To have useful information from remote sensing data for different applications, therefore, a proper standardized land use or land cover classification scheme must be organized (Jensen, 2000). For this reason, the first "Land use/Land cover classification system for use with remotely sensed data" was developed by Anderson et al.,(1976b). After that, it was modified by USGS in 1992 with four system levels (I-IV). The main source of this classification system at that time was the Landsat MSS with $79 \mathrm{~m}$ spatial resolution (Zhan, 2003). Up to now, despite the adapted classification system for high-resolution images (0.5 $\mathrm{m}$ to $4 \mathrm{~m})$, the classification of USGS is still useful for coarse and medium spatial resolution remotely sensed images.

\subsubsection{Land use/cover change}

In order to detect the dynamics of land use/cover, it is necessary to differentiate the types of change. Regarding land cover, the change that can be distinguished as two types: conversion and modification (Lambin et al., 2003; Turner et al., 1995). 
Land cover conversion is known as the completely transforming of one cover type to another. Whereas land cover modification replaces structure or function from one type to another without a total change, which could cause the changes in productivity, biomass or phenology (Sloke, 1994) (i.e. forest succession under slash-and burn cultivation) (Lambin et al., 2001).

Likewise, land use conversion may be understood as the transformation of one type of land use to another one. The changes in land use modification involve the intensity of the use and the alterations of their qualities or attributes (e.g. the use of suburban forest is changed from natural conservation to recreation purpose with remaining unchanged in area) (Orekan, 2007).

\subsubsection{Land use/cover change causes and consequences}

To improve the models or projections of land use and land cover, it is important to understand the causes of changes (Committee on Global Change Research, 1999). Land use/cover change is the consequence of human activities in a direct or indirect manner. It is known as a complex process by the mutual interactions between environmental and social factors on different spatial and temporal scales (Jokar Arsanjani, 2012). Lambin et al. (2001) summarized the changes of land use and land cover for the following reasons: "tropical deforestation, rangeland modifications, agricultural intensification and urbanization”.

Changes in land cover and land use are so pervasive; therefore, when aggregated globally, they significantly affect the functioning of the Earth's systems (Lambin et al., 2001), such as: directly impacting biotic diversity worldwide (Sala et al., 2000), contributing to local and regional climate change (Chase et al., 2000) or global climate warming (Houghton et al., 1999), being the primary source of soil degradation (Tolba and El-Kholy, 1992) and affecting the ability of biological systems to support human needs by altering ecosystem services (Vitousek et al., 1997).

\subsubsection{Driving factors of land use/cover change}

As pointed out by (Priyanto, 2010), the perspective regional planning is used to manage human activities development to reduce the impacts of environmental degradation and 
achieve sustainable development. In order to have a practical planning, the driving forces behind the changes of land use/cover in the past patterns should be clarified.

There are a variety of driving forces on land use/cover changes relate to environmental, social and economic variables, Turner et al. (1995) categorized the forces into following groups: “(a) Factors that affect the demands that will be placed on the land: population and affluence; (b) Factors that control the intensity of exploitation of the land: through technology; (c) Factors that are related to access to or control over land resources: the political economy; (d) Factors create the incentives that motivate individual decision makers: the political structure attitudes and values”.

To investigate the interrelation between the drivers of land change, a thorough knowledge of methods and effective variables from the natural and social sciences is required, such as: climatology, soil science, ecology, environmental science, hydrology, geography, information systems, computer science, anthropology, sociology, and policy science (Ellis, 2010).

\subsection{Combination of remote sensing and geographic information systems (GIS)}

Wilkinson (1996) ascertained that there are three different approaches for integrating remote sensing and GIS technologies to enhance each other.

(1) Remote sensing data can be seen as input datasets for use in GIS

From remote sensing data, thematic information can be extracted to create GIS layers via three different methods as Campbell (2007) summarizes. First, after interpreting remote sensing images, a set of maps depicting boundaries between categories of land use are digitized to make appropriate input digital files for GIS. Second, by using automated methods, paper maps and images generated from analyzing and classifying digital remote sensing data are digitized for data entry in GIS. Finally, after analysis and classification, digital remote sensing data are converted directly into GIS.

The automated extraction of cartographic information is also an important application of remote sensing for GIS. By using pattern recognition, edge extraction, 
and segmentation algorithms lines, polygons, other geographic features are generated. Therefore, satellite images have been recognized as great information provider in creating and revising base maps. In addition, satellite images have been demonstrated as cost-effective sources to update GIS databases and maps by their temporal resolution. This could be used to detect changes within a particular area. Moreover, the fourth application of remote sensing imagery as an input of GIS is cartographic representation (Weng, 2010).

(2) GIS datasets are one piece of ancillary information used in remote sensing

GIS datasets can be applied to remote sensing image processing at various stages. First, GIS datasets (vector polygons) are used to select the area of interest to restrict the area of an image to be processed. This will make the image processing much more efficient due to the faster processing time (Weng, 2010). The second use of GIS datasets such as vector points, polygons and digital elevation model (DEM) is for applying geometric and radiometric correction at the stage of image pre-processing (Hinton, 1996). At the stage of image classification, independent ancillary datasets are useful in assisting the selection of training samples (Mesev, 1998). Moreover, GIS technology also offers a flexible environment for entering, analyzing, managing and displaying digital data from various sources to enhance the functions of remote sensing image processing at various stages (Weng, 2010).

(3) Remote sensing and GIS are applied as input of modeling

According to the studies of many authors (Ehlers et al., 1990; Harris and Ventura, 1995; Treitz et al., 1992; Weng, 2002), the integration of remote sensing and GIS has been widely used as an effect tool for analysis and modeling of the changes of land use/cover in general, urban in particular. Multi-temporal images are processed in order to understand and monitor the change of land use/cover and then the data area can be abstracted into suitable form of GIS. Based on this information, different models of geographic space can be conceptualized more easily (Weng, 2010). 


\subsection{Definition of landscape metric}

In general, the studying in spatial structure and pattern is known as central to many types of geographic research. Many approaches have been implemented to analyze the spatial structure as well as pattern, including spatial metric method. This perspective is used to measure the spatial configuration of vegetation in natural landscapes. Hence, spatial metrics are also known under the name of landscape metrics (Herold et al., 2005). A definition of landscape metrics is portrayed in work of McGarigal and Mark (1995), where the landscape metrics (indices) are numeric measurements that are used to quantify the spatial pattern of land cover patches, land cover classes, or entire landscape mosaics of a geographic area. The metrics have been applied in landscape ecology (Forman and Gordon, 1986) to specify the important relationships in ecology (Bhatta, 2010).

Recently, the combination of remote satellite imagery and spatial metrics has been widely examined. Analyzing the changes in spatial metrics can help to broaden the knowledge of spatial configuration and change processes and, therefore, can support the modeling processes for guiding planning and management efforts (Bhatta, 2010).

Landscape metrics are supposed to numerically interpret the spatial structure of landscape, by which we can be well aware the effects of structure system to heterogeneous landscape (O'Neill et al., 1999; Turner, 1989; Turner et al., 2001). Also, studying landscape structure can help the scientific transition from an inductive to deductive logic model, in which the hypotheses can be formed and tested (Curran, 1987; Dietzel et al., 2005). Commonly, landscape structure has two basic components: (a) composition and (b) configuration. According to Leitao and Ahern (2002), composition metrics are a non-spatially-explicit characteristics. They measure landscape characteristics (e.g., richness, evenness, dispersion, contagion, etc.) instead of reflecting patch geometry or geographic location. In contrast, configuration metrics refer to spatially explicit characteristics of land cover types in a given landscape, which display the geometry or the spatial distribution of patches. They measure spatial characteristics (e.g., size, shape, perimeter, perimeter-are ratio, fractal dimension, etc.). 
Many studies showed that landscape metrics can be utilized for examining the change of spatial heterogeneity in the degree when they were applied to multi-scale or multi-temporal datasets (Dunn et al., 1991; Herold et al., 2005; Wu et al., 2000). The work of O'Neill et al. (1988) showed many different metrics which were tested, modified and developed (Hargis et al., 1998; McGarigal et al., 2002; Riitters et al., 1995). These metrics can be found in the statistical package FRAGSTATS (McGarigal et al., 2002).

\subsection{Model and modeling}

\subsubsection{Definition}

When searching for the definition of model, many concepts of this term can be found. According to Webster's Dictionary, a model is defined as “a description, a collection of statistic data, or an analogy used to help visualize often in a simplified way something that cannot directly observed (as an atom), or a theoretical projection in detail of a possible system of human relationships”.

A similar definition of model can be also read in the Collins English Dictionary, in which a model is understood as a simplified representation or description of a system or complex entity, especially one designed to facilitate calculations and predictions. From these definitions, Liu (2009) ascertained that a model is generally a simplified representation of reality, and modeling, therefore, is the process or behavior of producing models.

In geographic terms, model and modeling were mentioned in the 1960s. As pointed out in Integrated models in geography (Chorley and Haggett, 1967, 2013), a model could be a theory, a law, a hypothesis of data, a word, a map, a graph or some type of computer or laboratory hardware arranged for experimental purposes. However, this definition was narrowed to "any device or mechanism which generates a prediction” (Haines-Young and Petch, 1986). Consequently, modeling is "an activity that enables the theories to be examined critically” (Haines-Young, 1989). 


\subsubsection{Kinds of models}

In general, there are two kinds of models: hardware and mathematics. Hardware models represent the real work situations as scaled-down versions. This model is applied when it is impossible to use the mathematical one due to the complexity, uncertainty or the lack of knowledge. Conversely, mathematical models are much more common, which are used to express the states and rates of change based on mathematical rules. Hence, mathematical models can encompass from simple equations through to complex software codes with various equations and rules over discrete areas of time and space. This kind of model can separated into empirical, conceptual or physical based.

In empirical models, only observed behaviors between variables are described by the simplest mathematical function wherein physical laws or assumptions about the relationships between variables on the basis of observations are not considered. Therefore, empirical models are much better at predicting than explaining and have the capability to generalize data. The conceptual models describe the same behavior, but under different values of parameter, which reveal the observed relationship between the variables. This means that conceptual models have slightly greater explanatory depth but are not as general as empirical models. Physically based models are based on the deduction of physical principles and produce results. These models tend to have good explanatory power but low prediction power and often need to be calibrated against observations. In the case that they are not highly calibrated to observed data and have an appropriate and flexible structure, physically based models can generalize better than empirical models (Mulligan and Wainwright, 2004).

\subsubsection{Land use/cover modeling}

Models on land use/cover change are believed to be powerful tools that can be used to reveal and analyze the links between socio-economic processes associated with land development, agricultural activities and natural resource management strategies (Roy and Tomar, 2001). In other words, the modeling of land use/cover change tries to solve at least one of the following questions: "(1) Which socio-economic and biophysical variables cause the change of land use/cover - why? (2) Which locations are affected by 
land use changes - where? (3) At what rate does land use/cover change progress when?” (Lambin, 2004).

In addition, techniques using computers have erupted dramatically over the past few decades. As a result, research on modeling has increased exponentially. There are hundreds of land use/cover models which have been described in the literature on "landscape ecology, geography, urban planning, economics, regional science, computer science, statistics, geographic information science and other fields” (Brown et al., 2004). To bridge the information gap that many users must face when selecting a dynamic model, many authors tried to arrange or systematize the available land use/cover models (Agarwal et al., 2002; Lambin et al., 2000; Mondal et al., 2012; Verburg et al., 2004). In this situation, a new classification scheme of models was developed by Silva and Wu (2012). Accordingly, a comprehensive review of the models showed that models of land use/cover change could be arranged based on six important benchmarks: modeling approaches, level of analysis, spatial scales, temporal scales, spatial contexts, and planning tasks.

In the first benchmark, different modeling approaches were distinguished based on the methods of the models: mathematical/statistical models, GIS based-models, cellular automata based models, agent-based models, rule-base models, and integrated models. Besides the traditional mathematical/statistical modeling approaches, there is an increasing number of dynamic models that use cellular automata or are agent based (M. Batty et al., 1999). Similar to GIS based-models, the new modeling approaches, rulebased models, also rely on the knowledge of experts and are based on explicit decision rules in which the model users can specify how the model will behave (Silva and $\mathrm{Wu}$, 2012).

The second benchmark categorizes all models into three different levels: macro level, micro level, or cross level (or multilevel). The macro level models were developed based on macroeconomic theory or system approach. These models focus mainly on the macro process of urban land use change and hardly consider the micro level interactions (Silva and Wu, 2012). According to Verburg et al. (2004), micro level models are used to simulate the behavior of individuals and the up-scaling of this behavior, through which changes of land use/cover can be revealed. 
Similar to the second benchmark, models in benchmarks 3, 4 and 5 were categorized based on the scales of the simulated phenomena in terms of size of the application area and the prediction time. The group models of spatial scale were divided into four levels: regional (or national) scale, metropolitan scale, local scale, and multi scale. Depending on the time of the simulation, the temporal scale groups were divided into long-term models (more than fifty years), medium-term models (from ten to fifty years), and short-term models (from zero to ten years). In considering the spatial characteristic, models can be categorized into three groups:

(a) Spatial-oriented models: focusing on geographical patterns of land use/cover processes;

(b) Non-spatial-oriented models: focusing on the interaction of commodity demand, production and trade;

(c) Integrated models: concerning both geographic and socioeconomic aspects;

According to popular designed planning tasks, models were classified into five groups: land use/cover change, urban growth, transportation land use, impact assessment, and comprehensive projection (Silva and Wu, 2012). An overview of land use change models are summarized in Table 2.1.

\begin{tabular}{|c|c|c|c|c|c|c|c|}
\hline \multirow{2}{*}{ Model name } & \multicolumn{6}{|c|}{ Benchmark } & \multirow{2}{*}{ Total } \\
\hline & 1 & 2 & 3 & 4 & 5 & 6 & \\
\hline Agent-LUC & $\mathrm{x}$ & & & $\mathrm{x}$ & & $\mathrm{x}$ & 3 \\
\hline BabyLOV & $\mathrm{X}$ & $\mathrm{x}$ & & & $\mathrm{X}$ & $\mathrm{x}$ & 4 \\
\hline CARLOS & & & $\mathrm{x}$ & & & $\mathrm{x}$ & 2 \\
\hline CUF & $\mathrm{X}$ & & $\mathrm{x}$ & & & $\mathrm{x}$ & 3 \\
\hline CUFM & $\mathrm{X}$ & $\mathrm{x}$ & $\mathrm{x}$ & & & $\mathrm{x}$ & 4 \\
\hline CURBA & $\mathrm{x}$ & $\mathrm{x}$ & $\mathrm{x}$ & & $\mathrm{x}$ & $\mathrm{x}$ & 5 \\
\hline CLUE & $\mathrm{x}$ & $\mathrm{x}$ & $\mathrm{x}$ & $\mathrm{x}$ & $\mathrm{x}$ & $\mathrm{x}$ & 6 \\
\hline Community Viz & $\mathrm{x}$ & & $\mathrm{x}$ & & & $\mathrm{x}$ & 3 \\
\hline CVCA & $\mathrm{x}$ & $\mathrm{x}$ & $\mathrm{x}$ & $\mathrm{x}$ & $\mathrm{x}$ & $\mathrm{x}$ & 6 \\
\hline DG-ABC & $\mathrm{x}$ & $\mathrm{x}$ & $\mathrm{x}$ & $\mathrm{x}$ & $\mathrm{x}$ & $\mathrm{x}$ & 6 \\
\hline DRAM & $\mathrm{x}$ & & $\mathrm{x}$ & & & $\mathrm{x}$ & 3 \\
\hline DELTA & $\mathrm{x}$ & $\mathrm{x}$ & $\mathrm{x}$ & $\mathrm{x}$ & $\mathrm{x}$ & $\mathrm{x}$ & 6 \\
\hline DUEM & $\mathrm{x}$ & & $\mathrm{x}$ & & & $\mathrm{x}$ & 3 \\
\hline EMPIRIC & $\mathrm{x}$ & & & & $\mathrm{x}$ & $\mathrm{x}$ & 3 \\
\hline $\begin{array}{l}\text { Environmental } \\
\text { Explorer }\end{array}$ & $\mathrm{x}$ & $\mathrm{X}$ & $\mathrm{x}$ & & $\mathrm{x}$ & $\mathrm{x}$ & 5 \\
\hline GEOMODE2 & $\mathrm{x}$ & $\mathrm{x}$ & $\mathrm{x}$ & & & $\mathrm{x}$ & 4 \\
\hline GSM & $\mathrm{x}$ & $\mathrm{x}$ & $\mathrm{x}$ & $\mathrm{x}$ & & $\mathrm{x}$ & 5 \\
\hline INDEX & $\mathrm{x}$ & & & & & $\mathrm{X}$ & 2 \\
\hline
\end{tabular}




\section{Chapter 2. Theoretical background}

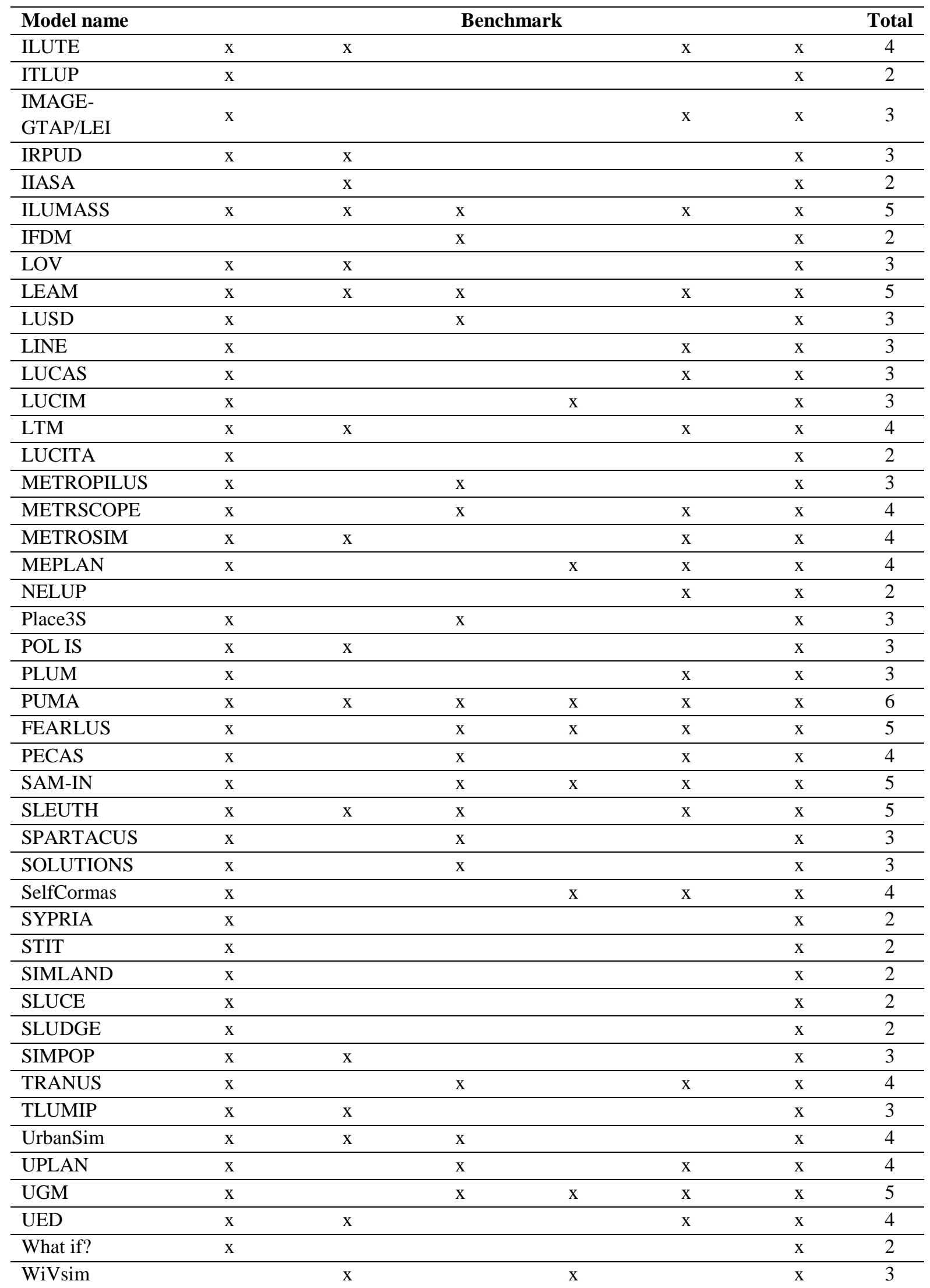

Table 2.1 Overview of land use/cover model, Source from Silva and Wu (2012) 
In terms of the main characteristics, only twelve of the total of sixty-four models seem to cover up to six of the main benchmarks defined for the analysis of the models, whereas the majority of the models cover only three benchmarks (and in many case, only two). After reviewing relevant literature, the Conversion of Land Use and its Effects (CLUE) model was chosen to estimate the changes of land use/cover area in the near future of Da Nang City. Orekan (2007) and Khoury (2012) showed some reasons motivated the choice of using CLUE model:

- CLUE is a hybrid model using the parameters from the estimation models (scenarios) to simulate simultaneously the changes in spatial term of multiple land use/cover types;

- CLUE uses empirically quantified relation between variable factors of land use/cover change and statistical methods;

- CLUE can be used at continental, national, and regional scales to define the change of land use/cover based on biophysical and socio-economic factors;

- CLUE can simulate cartographically the future land use/cover map as the continuation of the former one;

- CLUE modeling was performed in different regions of the world and across various ranges of land use/cover change scenarios, such as "agricultural intensification, deforestation, land abandonment, and urbanization” (Verburg and Overmars, 2007);

- The output of CLUE may be used as a reference for land-use planners to decide the way developing for a desired land use/cover in the future;

More details of the CLUE modeling approach will be presented in the chapter 4 . 


\section{CHAPTER 3}

\section{Study Area}

\subsection{Natural conditions}

\subsubsection{Location and area}

Da Nang is located in central coast region of Viet Nam, between $15^{\circ} 55^{\prime} 19^{\prime}$ to $16^{\circ} 13^{\prime} 20^{\prime \prime}$ north latitude and $107^{\circ} 49^{\prime} 11^{\prime \prime}$ to $108^{\circ} 20^{\prime} 20^{\prime \prime}$ east longitude. It covers an area by approximately $1,283.42 \mathrm{~km}^{2}$, including Paracel Island (Hoang Sa) of $305 \mathrm{~km}^{2}$. It is next to Thua Thien Hue Province to the north, Quang Nam Province to the south and west, and is washed by the Eastern Sea, along its $92 \mathrm{~km}$ seashore. Da Nang is located in the middle of the country and it is $764 \mathrm{~km}$ far from Ha Noi, the northern Capital and $964 \mathrm{~km}$ far from Ho Chi Minh City on the south (Figure 3.1). Sitting on the north-south road (National Road 1A), rail, sea, and air routes, Da Nang is an important gateway to the Central Highlands of Viet Nam, and to the North East Asian countries (Laos, Cambodia, Thailand, Myanmar) through economic corridor running East-West and the Tien Sa Seaport. In addition, Da Nang is in the center of the well-known world cultural heritage sites, including the ancient capital of Hue, the ancient town of Hoi An and My Son Holy Land, and Phong Nha - Ke Bang National Forest. As one of the sea-lanes and international air routes, Da Nang's geographical location is particularly convenient for rapid development and sustainability (Danang Info, 2012). 


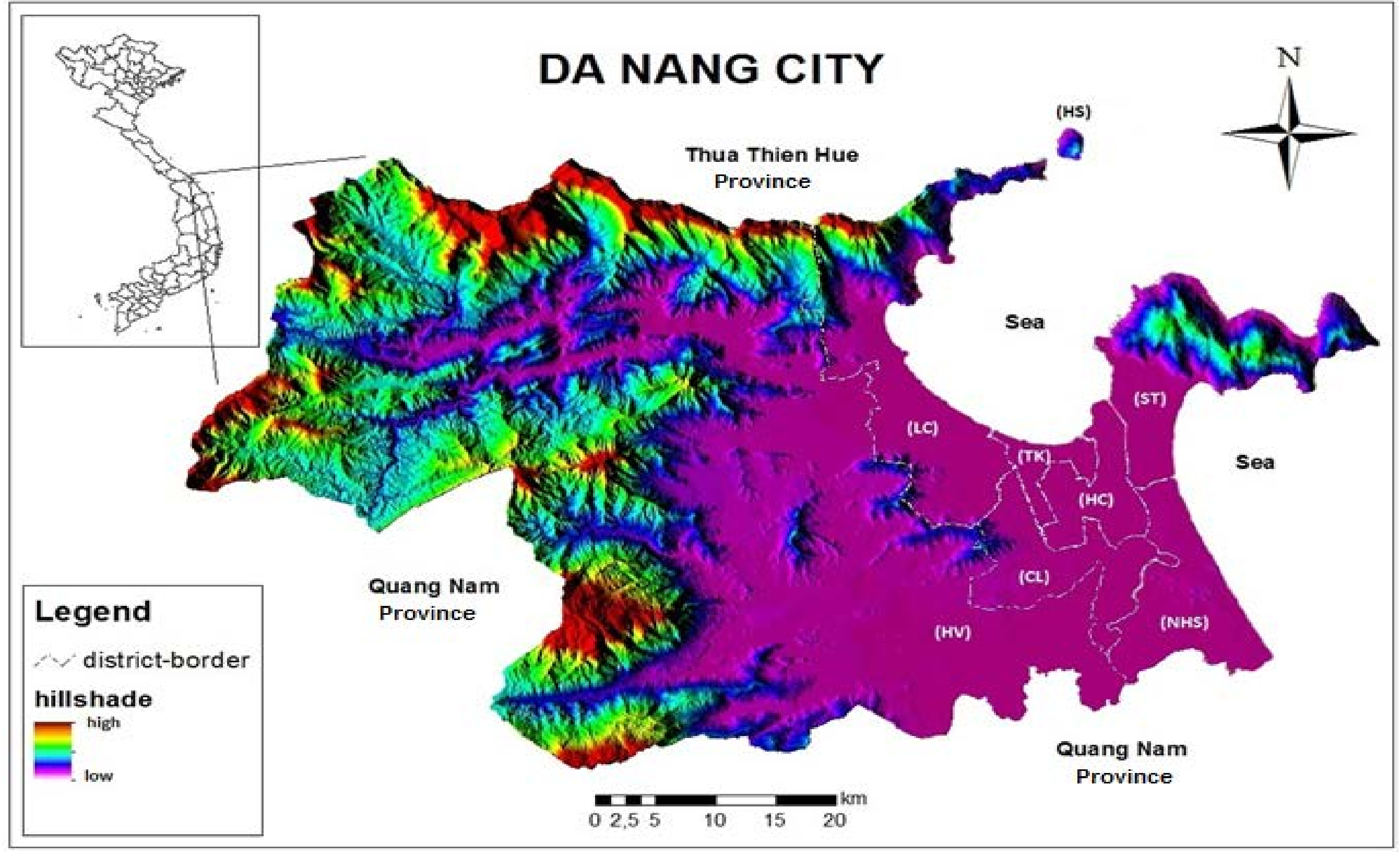

Figure 3.1 Location of Da Nang City, Viet Nam

(Source: Own calculation) 
The city is divided into seven mainland districts and one island district, namely, Cam Le (CL), Hai Chau (HC), Hoa Vang (HV), Lien Chieu (LC), Ngu Hanh Son (NHS), Son Tra (ST), Thanh Khe (TK), Hoang Sa (HS). According to the Statistical Yearbook of Da Nang City in 2009, the total population of Da Nang city was about 890,490 and the population density was approximately 693.84 people per $\mathrm{km}^{2}$, with $86.9 \%$ population in the urban area. The average annual population growth rate was 2.39\%. It was the highest rate in the North and South Central Coast regions and the sixth highest in the country (Danang' statistical office, 2009).

\subsubsection{Topography}

The topographic structure of Da Nang City is multiform and strongly separated. Its direction of dip is from the northwest to southeast. It can be divided into three main types of topography: high and steep mountains, hills and mountains, low-lying coastal plains. High and steep mountains range in the west and northwest of the city (in Hoa Bac, Hoa Lien, Hoa Ninh, Hoa Phu communes) with average altitude from 500 to 1500 $\mathrm{m}$, including continuous ranges running into the sea. Some valleys are broken by high mountains, such as Ba Na (1,487 m), Hoi Mit (1,292 m), Nui Mam (1,712 m). This area is primarily covered by forest with high value of biodiversity, natural resources, ecosystems, and environmental protection. Hills and mountains are located in the west and northwest of the city, including communes: Hoa Lien, Hoa Son, Hoa Nhon, Hoa Phong, and a part of Hoa Khuong, Hoa Ninh of Hoa Vang district. Hills and mountains are the area with a transition from high mountains to plains. Mountains in this area are specified by an inverse bowl shape with soil exhaustion and stones, average altitude changing from 50 to $100 \mathrm{~m}$, slope from 3 to $8^{\circ}$. It is appropriate for developing fruit gardens and orchards.

Mainly in the eastern side of the city and along the coastal area and big rivers, such as: Song Yen, Tuy Loan, Cam Le, Cu De and Han, low-lying plains are separated by rivers as small and narrow areas, including many directions of dip. There are many large sand dunes along coastal region, such as: Xuan Thieu, Hoa Khanh, Bac My An. The topography of this area is fairly low. Hence, residential quarters, agriculture services, industrial factories, and the functional area of government are mostly concentrated in this area. 


\subsubsection{Meteorological conditions}

Da Nang is in a typical tropical monsoon region with high temperature and equable climate. The weather of city is a combination between climatic features of northern and southern Viet Nam. There are two seasons: the wet season is from August to December and the dry from January to July. Occasional cold spells occur in winter but they are not severe and short. According to the statistics of Da Nang weather station at coordinates of $108^{\circ} 12^{\prime}$ east longitude and $16^{\circ} 3^{\prime}$ north latitude after 50 years, climatic weather of Da Nang city has been characterized as:

The annual average temperature is $25.6^{\circ} \mathrm{C}$. The highest average temperature is about $29.8^{\circ} \mathrm{C}$ in June and July, and the lowest average temperature is $22.7^{\circ} \mathrm{C}$ in December and January. The absolute high temperature is $40.9^{\circ} \mathrm{C}$ and the absolute low temperature is $10.2^{\circ} \mathrm{C}$. The 1,500 meter high mountain $\mathrm{Ba} \mathrm{Na}$ has an average temperature of $20^{\circ} \mathrm{C}$.

The average moisture is $82 \%$ and the average humidity is $83.4 \%$. The highest humidity appears in October and November, the average humidity of these months is about $85.67 \%$ to $87.67 \%$, and the lowest humidity appears in June and July, average humidity of these months is about $76.67 \%$ to $77.33 \%$.

The average rainfall in many years in Ba Na Mountain is 2,642 mm, in Da Nang is 2,185 mm, in Tien Sa is 2,456 mm. The highest rainfall is $550-1,000 \mathrm{~mm}$ per month in October and November and the lowest 23 - $40 \mathrm{~mm}$ per month in January, February, March and April.

The annual average sunshine hours are 2.158, with the maximum in May and June of 234 - 277 hours per month and the minimum in November and December of 69 -165 hours per month. Gross annual radiation is $147.8 \mathrm{kcal} / \mathrm{cm}^{2}$. Total sunshine hours in a year is 2.272 hours in average, the average evaporation is $1,048 \mathrm{~mm}$.

Based on measured data on wind speed, the frequency corresponding to $0.5 \%$, the strongest wind speed is $52 \mathrm{~m} / \mathrm{s}$, with a frequency of $1 \%$, wind speed is $47 \mathrm{~m} / \mathrm{s}$, with the frequency of $5 \%$, wind speed was $39 \mathrm{~m} / \mathrm{s}$. 


\subsubsection{Hydrologic conditions}

Within the city's territory, there are four large rivers, three of which are in the southeast of city, namely Vu Gia - Thu Bon river basin, including Vinh Dien river, Yen river, and Tuy Loan river. All of these rivers run to Han River before reaching the Da Nang gulf at the Han river mouth; basin area of $\mathrm{Cu}$ De river is $472 \mathrm{~km}^{2}$ and this river flows from west to east.

+ Han River: Han river mouth is contiguous to the sea therefore it is strongly influenced by the tide. The Han River is the confluence of the Cau Do River and the Vinh Dien River. The highest water level is $+3.45 \mathrm{~m}$ (1964), the lowest water level is $+0.25 \mathrm{~m}$.

+ Cu De River rises from the south of the Hai Van mountain pass, $38 \mathrm{~km}$ in length and $426 \mathrm{~km}^{2}$ in area. Cu De River has the highest water level at $+4.0 \mathrm{~m}$ and the lowest water level at $+0.3 \mathrm{~m}$. It includes two branches running in a west-east direction. The hydrograph/ hydrographic varies swiftly according to the rains.

+Vinh Dien river is the confluence of Thu Bon river and Han river. The hydrograph varies according to the seasons. This is one of the rivers which caused formidable floods in Da Nang City during the last several years.

Topographical separation of the city was created to distinguish two river basins, the $\mathrm{Cu}$ De river basin in the North and Vu Gia - Thu Bon river basin in the South. Among eight districts, there are six districts in $\mathrm{Vu}$ Gia - Thu Bon river basin, accounting for 59.5\% natural area. Therefore, Vu Gia - Thu Bon river basin plays an important role in the City's development. The flood season usually starts from September and continues to December.

In general, rivers flowing cross Da Nang City have the common characteristics of rivers in the coastal region of central Viet Nam: short in length, large in depth, strongly fluctuating in water level and output, and poor alluviums. Da Nang Bay Sea has semidiurnal irregular tidal regime, on average, there are three diurnal tidal days in a month, the maximum month has eighth diurnal tidal days and the minimum month has one diurnal tidal day. Tidal amplitude at Da Nang port is $90 \mathrm{~cm}$ on average, the largest is 
170 cm. Da Nang has many scattered small lakes, notably: Xuan Ha, Thac Gian-Vinh Trung, Khue Trung, Bau Mac, Bau Vang, Bau Tram, Bau Gia Thuong, Bau Gia Ha, etc. These lakes are generally small, with a surface area from 1 to 10 ha; the water level depends on the city's water level and season.

\subsubsection{Natural resources}

\subsubsection{Soil resources}

+ Sandy-bank and sandy-dunes group: this group is in the coastal region or in the river mouth, created by the influence of wind. The sandbank and sand dunes can be stable or mobile, located mainly in Lien Chieu, Son Tra and Ngu Hanh Son districts. The sandbank and sand dunes occupy about 10\% of total area of Da Nang City. They are mainly in low-lying plains and used particularly in non-agriculture: exploiting for infrastructure constructing, tourism, and habitat.

+ Salt soil group: this group is created from the penetration of the sea in the surface or artesian area. This kind of soil appears in sunken areas and concentrates in coastal regions or river mouths. The soil has brown-grey color, a salt layer in the surface, reaction from low aluminous to neuter, the mechanical composition from mix-sand to soil, the layer is deep from 50 to100 cm.

+ Alkaline and salt soil group: due to the disintegration of dead ocean animals in lowlying area, this kind of soil has brown, brown-grey color. This group is distributed in Hoa Xuan, Hoa Quy commune of HoaVang district. This group occupied about 2\% of total area, mainly in low-lying plains, and most can be used for agriculture.

+ Alluvial soil group: mainly in lower sections of rivers streams. This kind of soil is appropriate for producing agriculture and occupied about 9\% of total area of Da Nang City.

+ Slope gathering soil group: this kind of soil is normally distributed in the valleys. It is a thick layer with many organic substances. The fertility of the soil is good. This kind of soil has grey-brown, grey-black color; the mechanical composition includes softly soil to medium soil. It occupies about $1.8 \%$ of total area of Da Nang City and is good 
for agriculture. However, it has a scattered distribution across many complicated topographical areas and so can be difficult to access.

+ Yellow and red humus soil group: this kind of soil distributed mainly in high mountains of Hoa Lien commune.

+ Yellow and red soil group: is the product of Feralit processes. The soil is created from weathered magma rock products; therefore it has a red-yellow or yellow-red color. These soils are distributed in high mountains (including Hoa Vang and Son Tra districts) and occupied about 56.1\% of total area of Da Nang City. They mostly used in forestry and a little bit for agriculture.

\subsubsection{Water resources}

+ Water surface: the water for Da Nang City is supplied mainly from Cu De and Han Rivers.

- $\quad \mathrm{Cu}$ De River is $38 \mathrm{~km}$ in length with total average of water volume of 0.7 billion $\mathrm{m}^{3} /$ year. The quality of water is quite good and now supplying for habitat activities and manufacturing in the north and northwest of city.

- Han river is the confluence of Cau Do and Vinh Dien rivers. Total average of the water volume is about 7.6 billion $\mathrm{m}^{3} /$ year. It is mainly used for supplying water in habitat activities and agricultural production.

In addition, the water supply in Son Tra peninsula might be used for life activities, however, the reserves is quite low and depends on the seasons.

+ Underground water: According to the survey results of Planning Water Resource Association 709, the underground water in Da Nang City is quite shallow, various and complicated. The underground area exploited for water supplying are in Hoa Hai and Hoa Quy commune with the depth about 20-35 m and the total average water volume of 5,000-10,000 $\mathrm{m}^{3} /$ day, in Hoa Khanh with the depth about 30-90 $\mathrm{m}$ and total average water volume of $20,000,000 \mathrm{~m}^{3} /$ day for industrial places.

In general, the water source of Da Nang City is quite plentiful. However, in the dry season (May and June), the water source is salted because of tidal influence. The 
quality of water was quite good and might be used for life activities and developing economics.

\subsubsection{Forestry and floristic cover resources}

+ Forestry resource: Forest area occupied 59,127.27 ha, about 46.02\% of total area. Natural forest in Da Nang City is at the confluence of north and south floras of Viet Nam. All the trees are tropical evergreens and could be seen as the "Green Lung" of city. Ecological characteristic of forest is abundant and diversified, including:

- Protected forest, for the preservation of water resources, the prevention of erosion, natural disasters, climatic risks, and the overall protection of environment (8,624.55 ha);

- Special use of forest to conserve nature, plant and animal species, to research, and protect historic, cultural, and tourist sites (35,288.68 ha);

- Production forest, for supplying timber and other forest products, and associated with the other types of forest to protect environment (15,239.04 ha);

\section{+ Floristic cover resources:}

- Mountains: due to the natural conditions, the ecology in the mountains is highly diverse, and covered with many kinds of flora. However, the floristic cover resource has been strongly devastated because of the war and the exploitation by humans. At this time, the floristic cover has not been recovered to cover all the bare mountains yet. It can be divided into four levels:

- Floristic cover of evergreen: this is created from big standing timber and is green all year around. Therefore, the moisture in this area is high. In addition, floristic cover of evergreen supplies large amount of organic substance for soil.

- Floristic cover of sapling forestry: because of the war and the strongly exploitation by humans, the forestry area was heavily devastated. For covering the mountains, many forest plantation programs were implemented in the late of 1990s. Hence, the forest trees are still small, that is why the 
floristic cover of this forestry is thinner and the moisture is lower than that of the floristic cover of evergreen.

- Floristic cover of bamboos: besides sapling forestry, bare mountains are covered also by species of bamboo. However, the floristic cover is thinner and the moisture is lower than floristic cover of sapling forestry.

- Floristic cover of shrub: this area is contiguous to plains. Instead of trees, the surface in this area is covered by many kinds of shrub: Rhodomyrtustomentosa(L.),

MelastomadodecandrumLour (L.), Melastomacandidum D. Don. (L.), Imperatacylindrical(L.). However, the layer of this cover is too thin which was caused by soil erosion when the rain falls down. Hence, it is difficult to plant in this area.

- Low-lying plains: is an agriculture area. The floristic cover includes mainly short-day crops, and fruit trees. Because of the change in agricultural activities, the cover of this area is abundant and diversified. This area is closely connected with human life.

- River-mouth area: the area is covered by Pinophyta, Poplar, Willow or Halophyte trees. There are also many kinds of alga or seaweed in the river-bed or the sea-bed which are affected directly by human activities in the environment, in particular the water environment.

\subsubsection{Sea and coastal region resources}

Da Nang city has a coastal line over $92 \mathrm{~km}$ in length, with a deep-water bay of $200 \mathrm{~m}$ and continental shelf outstretched over $125 \mathrm{~km}$, which provides suitable conditions for developing maritime economics and doing business with foreign countries. According to the survey, the territorial seas of Da Nang City have high reserves of seafood, about 60,000-70,000 tons/year can be exploited (distributing in water at $50 \mathrm{~m}$ depth 31\%, 50 200 m depth 48\%, over 200m depth 21\%). In addition, coastal region of Da Nang city is the right place for rearing aquatic products, such as fish and lobster in Tho Quang commune, shrimp in Nai Hien Dong, Hoa Hiep commne, Son Tra district. 
Besides, various nice beaches with wonderful natural landscape along coastal line, such as Non Nuoc, My Khe, Pham Van Dong, Thanh Khe, Xuan Thieu, Nam O are good conditions for developing tourism.

\subsubsection{Mineral resources}

According to the survey documents, there is little mineral resource in Da Nang City, including stone for constructing in Hoa Nhon, Hoa Phat, Hoa Son commune, granite in Non Nuoc commune, gold in Hoa Bac commune, white sand and peat in Hoa Khanh commune, However, the mineral reserve is negligible. The continental shelf promises petroleum and gas complex.

\subsection{Social and economic conditions}

\subsubsection{Economic development}

The economics of Da Nang City had many positive changes and obtained a remarkable growth rate, which met the basic demands in the short term and created impetus for development in the next years. In the period from 2001 to 2010, the city made many achievements in developing economics:

+ From 2001 to 2005 stage: the city gradually promoted the advantages of the new economic policy, mobilized all human and financial resources to give an impulse to trade and producing, and then could overcome all the difficulties of financial crisis. All economic indices of Da Nang City in this period achieved or exceeded the indices of the proposal. The annual development rate of GDP was about 12.89\%, in which Agriculture, Forestry \& Fishery increased 6.3\%, Construction and Industry increased 18.95\%, and Services increased 8.34\%. The average GDP of each person in 2005 was 940 USD.

+ From 2006 to 2010 stage: in this period, there were many opportunities and challenges, such as Chanchu and Xangsane storms, and disease epidemics. Consequently, the price of raw materials increased, which heavily influenced to production and human life. Being an official member of World Trade Organization (WTO) has given many chances for investment, developing production, economic development and changing the economic structure of Viet Nam in general, and of Da 
Chapter 3. Study area

\begin{tabular}{|c|c|c|c|c|c|c|c|}
\hline \multirow[b]{2}{*}{ Index } & \multirow[b]{2}{*}{ Unit } & \multirow[b]{2}{*}{2000} & \multirow[b]{2}{*}{2005} & \multirow[b]{2}{*}{2010} & \multicolumn{3}{|c|}{ Rate (\%) } \\
\hline & & & & & $\begin{array}{l}2001- \\
2005\end{array}$ & $\begin{array}{l}2006- \\
2010\end{array}$ & $\begin{array}{l}2001- \\
2010\end{array}$ \\
\hline 1.Population & 103 people & 716.3 & 781.0 & 926.09 & 1.69 & 3.44 & 2.47 \\
\hline $\begin{array}{l}\text { 2. GDP } \\
\text { (1994 price) }\end{array}$ & billion VND & 3,390.2 & $6,214.3$ & $10,275.45$ & 12.89 & 10.31 & 11.74 \\
\hline $\begin{array}{l}\text { - Agriculture, } \\
\text { forestry \&fishery }\end{array}$ & - & 276.3 & 373.5 & 308.12 & 6.30 & -5.11 & 1.19 \\
\hline $\begin{array}{l}\text { - Construction\& } \\
\text { Industry }\end{array}$ & - & 1,347.9 & $3,207.4$ & $4,043.13$ & 18.95 & 4.93 & 12.72 \\
\hline - Services & - & $1,766.0$ & $2,633.4$ & $5,924.20$ & 8.34 & 17.53 & 12.42 \\
\hline 3. GDP/people & & & & & & & \\
\hline - 1994 prices & $\begin{array}{c}106 \\
\text { VND/person }\end{array}$ & 4.73 & 7.97 & 11.56 & 11.00 & 6.73 & 9.10 \\
\hline - Current prices & - & 6.91 & 15.01 & 35.87 & 16.83 & 16.82 & 16.82 \\
\hline - In USD & USD/person & 488.0 & 940.0 & 1795.0 & & & \\
\hline
\end{tabular}

Table 3.1 GDP and development of economics in period 2000-2010

\section{Source from (People's committee Danang city, 2010)}

Nang City in particular. The annual development rate of GDP in this period was about 10.31\%, in which Agriculture, Forestry \& Fishery decreased 5.11\%, Construction and Industry increased 4.93\%, and Services increased 17.53\%. The average GDP of each person in 2010 was 1795 USD. In general, from 2000 to 2010, the economics of Da Nang City achieved the annual rate at $11.74 \%$, in which Construction and Industry increased 12.72\%, Services increased 12.42\%, and Agriculture, Forestry \& Fishery increased $1.19 \%$. The average income of each person was increased clearly, higher after each year. The average GDP was 488 USD/person in 2000, 940 USD/person in 2005 and 1,795 USD/person in 2010 (increased 5 times than in year 2010 and 1.91 times in year 2005).

\subsubsection{Economic structure}

During the period (2000-2010), the economic structure of Da Nang City has changed. The value of GDP in Constrictive and Industry, Services increased strongly. The economic structure moved in both quality and quantity from “Agriculture, Forestry \& 
Unit: \%

\begin{tabular}{llll}
\hline Index & $\mathbf{2 0 0 0}$ & $\mathbf{2 0 0 0 5}$ & $\mathbf{2 0 1 0}$ \\
\hline Total & 100 & 100 & 100 \\
- Construction \& Industry & 41.3 & 50.19 & 44.58 \\
- Services & 50.9 & 44.68 & 51.51 \\
- Agriculture, Forestry \& Fishery & 7.9 & 5.13 & 3.91 \\
\hline
\end{tabular}

Table 3.2 Economic structures in period 2000-2010

Source from (People's committee Danang city, 2010)

Fishery - Construction \& Industry - Services” to "Construction \& Industry - Services Agriculture, Forestry \& Fishery”, which satisfied the inherent demands of Da Nang City. As can be seen from Table 3.2, the value of GDP in Agriculture section decreased regularly from $7.9 \%$ (in 2000) to 3.91\% (in 2010). Services section had the largest value of GDP, decreased from 50.19 (in 2000) to 44.68\% (in 2005), and then increased to 51.51\% (in 2010). The annual tempo-development of GDP in Construction and Industry section was quite good at $12.72 \%$ per year. The value of GDP in this section increased from $41.3 \%$ (in 2000) to $44.58 \%$ (in 2010).

The structure of economics by ownership also changed in a positive way. In the first period, the state owned enterprise section still played an important role with the value of GDP increased from 54.86\% (in 2000) to 58.5\% (in 2003). However, since 2004, due to the promotion of arranging, renovating and privatizing state enterprises, the value of GDP of this section decreased to 41.09\% (in 2010), whereas the value of GDP in non-state enterprises section increased gradually from 31.89\% (in 2000) to $51.89 \%$ (in 2010). Although occupied just 8\% of total GDP of Da Nang City, the foreign investment enterprises section always kept in high level, which contributed for the development of economics of Da Nang City.

\subsubsection{The situation of economic sectors}

\subsubsection{Agriculture, forestry, and fishery sector}

In period of ten years (2000-2010), the Gross output of agriculture, forestry and fishery achieved the rate at $1.19 \%$ per year. The density of this section in total GDP of Da Nang 
City decreased from $7.9 \%$ (in 2000) to 3.91\% (in 2010). The inherent structure of this section was changed by focusing on developing maritime economics, protecting the environment, increasing the density of fisheries and decreasing the density of forestry and agriculture.

With a coastal line of over $92 \mathrm{~km}$, fisheries were determined as a key in developing Agriculture, Forestry \& Fishery section by exploiting seafood in the deepsea instead of inshore fishing, investing and contributing the infrastructures and services for fish farming. Regarding Agriculture and Forestry, the decrease of agricultural area brought about the decrease in production of annual crops. Hence, the inherent structure of agriculture was changed by reducing the density in planting, raising the density in breeding. Forestry was strongly shifted from exploiting wood and forest products to protecting, afforesting, and covering the bare mountains.

\subsubsection{Construction and industry sector}

The gross output of Construction and Industry in period of ten years (2000-2010) increased at annual rate of $12.72 \%$. The density of this section in total GDP of Da Nang City increased from $41.3 \%$ (in 2000) to $44.58 \%$ (in 2010). The gross output of construction and industry section in 2010 was approximately 4,043.13 billion VND, over threefold than in 2000, which helped to shift the economic structure in trend of increasing the density of Construction and Industry. Industry was main force of Da Nang City and its gross output increased high every year. Many industrial parks and large projects have been invested. Nevertheless, the industry also faced many difficulties, and challenges because of natural calamities, diseases, the financial crisis in 2007.

\subsubsection{Services sector}

Because of the convenient geographic location and having all kinds of transportation, such as an airport, seaport and railway, Da Nang City had more advantages in transporting, importing, exporting and tourism than any provinces in Key Economics Zone of Central Viet Nam. Therefore, almost all important service providers had their headquarters in Da Nang City to supply the services not only for Da Nang, but also for the Central Zone. Including wholesale and retail trade, financial credit, real estate, 
tourism, transport, post and others, the density of Services section in total GDP of Da Nang City was always over 45\%. In the period of ten years (2000-2010), the annual GDP rate of this section was $12.42 \%$. The GDP of this section increased from $50.9 \%$ (in 2000) to $51.51 \%$ (in 2010).

\subsubsection{Population, labor, employment, and income}

\subsubsection{Population}

According to statistical yearbook 2010, the population of Da Nang City on 12/31/2010 was 942,132, in which there were 458,605 males and 483,527 females, 819,332 people in urban (86.97\% of total population), 122,800 people in rural $(13.03 \%$ of total population). The natural growth rate of population in Da Nang City was $10.09 \%$. The dweller distributed not equally between the area and districts. The highest density of people was 19,041 people $/ \mathrm{km}^{2}$ in Thanh Khe district; the lowest one was 166 people/ $\mathrm{km}^{2}$ in Hoa Vang district; the density of people in mainland was 960 people/ $/ \mathrm{km}^{2}$; the density of people in urban area was 3,364 people/ $\mathrm{km}^{2}$, over twentyfold the density of people in rural area. With the high urbanization rate, the population of Da Nang City will be further increased, which will bring about an increase in the density of people in the near future.

\begin{tabular}{clcc}
\hline Number & \multicolumn{1}{c}{ District } & $\begin{array}{c}\text { Population } \\
\text { (people) }\end{array}$ & $\begin{array}{c}\text { Density } \\
\text { (people/km²) }\end{array}$ \\
\hline 1 & HaiChau & 197,922 & 8,500 \\
2 & ThanhKhe & 179,810 & 19,041 \\
3 & Lien Chieu & 140,500 & 1,775 \\
4 & Son Tra & 135,300 & 2,280 \\
5 & NguHanh Son & 69,500 & 1,801 \\
6 & Cam Le & 96,300 & 2,852 \\
7 & HoaVang & 122,800 & 166 \\
& Da Nang City $(*)$ & 942,132 & 960 \\
\hline
\end{tabular}

Table 3.3 Population structure in period 2000-2010 (* just calculated in mainland) Source from (People's committee Danang city, 2010) 


\subsubsection{Labor and employment}

In 2010, the labor force of the whole city was 462,979 people $(49.14 \%$ of total population). In which, 440,500 people (95.14\% of labor force) with stable employment; divided as: 148,050 people (33.61\% of stable employment) working in Construction \& Industry section, 249,650 people (56.67\% of stable employment) working in Services section, 42,800 people (9.72\% of stable employment) working in Agriculture, Forestry and Fishery section.

Compared with the average standard for the whole country, the academic and technical standard of the labor force in Da Nang City was quite good. Most of the laborers were young. According to the statistics in 2010, over 83,498 laborers graduated from university and college education (18.03\% of labor force), 26,039 laborers graduated from secondary vocational qualification (5.62\% of labor force), and there were 37,914 technical workers (9.48\% of labor force). In recent years, laborers in state owned enterprises lessened strongly, whereas more and more laborers concentrated in non-state and foreign investment enterprises.

In the period of ten years (2000-2010), Da Nang City provided jobs for 2.2 thousand laborers a year. Particularly, the number of laborers got jobs significantly increase due to the adoption of the "Having Job" project. Accordingly, the rate of unemployed decreased from $5.42 \%$ (in 1997) to $4.95 \%$ (in 2005) and $4.86 \%$ (in 2010). It was assessed as a stable and reasonable condition for a developing city.

The unemployed of Da Nang City in 2010 numbered about 22,479 and most of them were in the urban area. In rural areas, the unemployment was lower. According to the statistics, the coefficient of working day was about 85\%. Da Nang City always concentrated in solving jobs for labors, combined with vocational and technical training. Therefore, the rate of educated labors increased from $21.6 \%$ (in 1997) to $24.4 \%$ (in 2000) and 50.16\% (in 2010), over 2 times than in the first period of separating province in 1997.

Generally, the labor force of Da Nang City was quite plentiful, which created good conditions for developing socio-economics and constructing infrastructure. 
Nevertheless, the educated laborers were not enough. Hence, Da Nang City must concentrate more in vocational and technical training for the demands of development.

\subsubsection{Income and life}

Based on the reformation of economic policy and its own conditions, the economic growth rate of Da Nang City in period of 2000-2010 was $11.74 \%$ and got the sixth position of the whole country after Ho Chi Minh, Ha Noi, Dong Nai, Binh Duong and Ba Ria-Vung Tau. The average income increased from 6.91 million VND/ person (in 2000) to 15.01 million VND/ person (in 2005) and 35.87 million VND/ person (in 2010).

The living conditions of all social classes were clearly improved and the comforts of life were ameliorated significantly. The $97 \%$ of households had solid or half-solid houses, only $3 \%$ of households had rudimentary houses. 95\% of households could use electricity and $93 \%$ of households had running water. The habitat area also increased noticeably; the average habitat area of low-income groups was $13 \mathrm{~m}^{2} /$ person; the average habitat area of the whole city was $20.3 \mathrm{~m}^{2} /$ person, which was quite high, compared with other provinces and the whole country (Ho Chi Minh City: 12.27 $\mathrm{m}^{2}$ /person, cities in Central Zone: $9.02 \mathrm{~m}^{2} /$ person, the whole country: $9.67 \mathrm{~m}^{2} /$ person). Therefore, Da Nang City has continued to implement the aims of the "Having House" project in order to increase the living conditions of its inhabitants.

\subsubsection{The situation of infrastructure}

After Da Nang was recognized as a centrally governed city in 1997, the city concentrated more in constructing infrastructure, improving most streets within the city. However, these measures were not enough for a big city. The infrastructure satisfied just a part of urgent demand of city.

\subsubsection{Transport}

+ Airline: far away from the center of city about 5km, Da Nang airport has an important position, compared with other airport system in Central Zone. It is used for civil and military transport, with an area of 1,100 ha, 850 ha for the airport and 37 ha for civilian use. Da Nang airport is the aid point that supplies air-traffic services for international 
flights and has capability of receiving up to 400,000 tons goods per year and 2.5 million passengers per year. Because of the location of airport in the city, there are many advantages for passengers. However, this also causes many obstacles for people living near the airport as well as the development of the city. In the long term, the noise of airplanes will significantly affect the environment.

\begin{tabular}{ccccc}
\hline \multirow{2}{*}{ Year } & \multicolumn{2}{c}{ Passenger (person) } & \multicolumn{2}{c}{ Goods (ton) } \\
\cline { 2 - 5 } & Departure & Arrival & Departure & Arrival \\
\hline 2000 & 240,024 & 233,145 & 1,092 & 1,128 \\
2001 & 338,843 & 328,651 & 2,186 & 2,089 \\
2002 & 336,170 & 321,063 & 1,601 & 2,303 \\
2003 & 314,585 & 295,385 & 2,047 & 2,484 \\
2004 & 445,994 & 404,800 & 2,727 & 3,406 \\
2005 & 524,708 & 485,561 & 2,385 & 3,932 \\
2006 & 626,577 & 580,726 & 2,779 & 4,891 \\
2007 & 613,336 & 571,818 & 2,597 & 5,902 \\
2008 & 904,426 & 797,332 & 3,410 & 6,689 \\
2009 & 791,000 & 778,000 & 3,097 & 8,976 \\
2010 & 974,189 & 937,381 & 3,057 & 7,458 \\
\hline
\end{tabular}

Table 3.4 Quantity of transported passengers and goods by airlines (Source from Da Nang's Statistical Office, Statistic Year Books)

+ Road network: Highway 1A is the communication axis running from north to south Viet Nam. Part of the highway across Da Nang City begins from the Hai Van pass to Hoa Phuoc commune at $35.5 \mathrm{~km}$ in length, and carries interprovincial traffic. It has been improved by mineral pitch concrete composition and widened to $28 \mathrm{~m}$. Highway 14B (32 km in length) runs along Son Tra and Ngu Hanh Son district, crosses Tuyen Son Bridge and comes to the cross roads of Hoa Cam, Tuy Loan, Hoa Khuong. This route connects Da Nang City with the Central Highland as well as with the overland network to Cambodia, Thailand etc. The province road network includes roads 601, 602, 604, 605 which are $83.8 \mathrm{~km}$ in length, $7 \mathrm{~m}$ wide $(601,602)$, or $15 \mathrm{~m}$ wide $(604,605)$. Most roads have been improved by mineral pitch concrete composition. The road network within the city has total of $268 \mathrm{~km}$ in length. Most of the roads were improved and fixed for traffic in the city itself. The rural road network includes district roads of $69 \mathrm{~km}$ in 
length, commune roads, $84 \mathrm{~km}$ in length and rural roads $272 \mathrm{~km}$ in length. Most of rural road network was covered by mineral pitch composition; in particular, about $90 \%$ of rural roads were concreted. In addition, there are 35 kinds of bridge have just been improved and/or constructed. As a whole, the road network of about $850 \mathrm{~km}$ in length in Da Nang City was synchronously connected, improved, fixed and renewed. Fifty per cent of the road networks are main roads, which help to develop socio-economics not only for the urban area but also for the rural and mountainous region.

+ Railway: the railway runs across Da Nang city, $36 \mathrm{~km}$ in length and has the capability of 22 couple trains/over a 24 hour period. It includes 3 main railway stations: Kim Lien station in the south of Hai Van pass, Le Trach in Hoa Tien commune (the south of city). Da Nang station in the central of city with an area of $240,000 \mathrm{~m}^{2}$ is responsible for transporting passengers and goods.

\begin{tabular}{lcccc}
\hline \multirow{2}{*}{ Year } & $\begin{array}{c}\text { Passenger departure } \\
(\mathbf{1 , 0 0 0} \text { person) }\end{array}$ & $\begin{array}{c}\text { Package departure } \\
\text { (ton) }\end{array}$ & \multicolumn{2}{c}{$\begin{array}{c}\text { Goods } \\
(\mathbf{1 , 0 0 0} \text { ton) }\end{array}$} \\
\cline { 4 - 5 } 2000 & 363.0 & 5,320 & 10,046 & 58,225 \\
2001 & 403.1 & 6,101 & 10,506 & 107,190 \\
2002 & 415.6 & 5,172 & 23,989 & 195,543 \\
2003 & 414.9 & 4,573 & 50,622 & 220,055 \\
2004 & 444.5 & 5,718 & 40,576 & 170,720 \\
2005 & 445.8 & 3,939 & 30,604 & 174,089 \\
2006 & 364.4 & 2,863 & 65,277 & 207,119 \\
2007 & 342.3 & 2,294 & 113,659 & 208,454 \\
2008 & 313.5 & 1,945 & 123,557 & 197,403 \\
2009 & 290.3 & 2,083 & 135,741 & 220,885 \\
2010 & 315.3 & 2,139 & 131,091 & 216,994 \\
\hline
\end{tabular}

Table 3.5 Quantity of transported passengers and goods by train (Source from Da Nang's Statistical Office, Statistic Year Books)

+ Waterway: the inland waterway is $60 \mathrm{~km}$ in length and can used to transport goods where is not convenient to transport by land, including Han river, Cu De, Cam Le, Yen, Tuy Loan, etc., transported goods are mainly consumer product, fuel, sand etc. Due to the convenience of the road network, transporting by inland waterway decreases with 
every passing day. Da Nang City seems to have many advantages for developing the seaport and river port. They play important role in Central Zone for domestic transport and international exporting, including Tien Sa seaport and Han river port. Han River port has an area of 3 ha, in which there are $8,000 \mathrm{~m}^{2}$ for storage area, $8,225 \mathrm{~m}^{2}$ for storehouses. The river port can accept ships with an aggregate tonnage of 5.000 tons. Tien Sa seaport is in Da Nang bay with two wharfs (183 m in length, 27,5 m in width), 3 large storehouses $\left(15,875 \mathrm{~m}^{2}\right)$ and 1 storage area (17 ha). The seaport can accept ships with an aggregate tonnage of 20,000 - 30,000 tons, which is used for container goods, over length or over weight goods.

Unit: 1,000 tons

\begin{tabular}{|c|c|c|c|c|c|c|}
\hline \multirow[b]{2}{*}{ Year } & \multirow[b]{2}{*}{ Total } & \multicolumn{4}{|c|}{ Dividing } & \multirow{2}{*}{$\begin{array}{l}\text { Turn- } \\
\text { around }\end{array}$} \\
\hline & & $\begin{array}{c}\text { International } \\
\text { export }\end{array}$ & $\begin{array}{c}\text { International } \\
\text { import }\end{array}$ & $\begin{array}{c}\text { Domestic } \\
\text { export }\end{array}$ & $\begin{array}{c}\text { Domestic } \\
\text { import }\end{array}$ & \\
\hline 2000 & $1,410.6$ & 421.6 & 333.5 & 65.9 & 589.6 & 1,847.1 \\
\hline 2001 & $1,709.8$ & 428.6 & 646.2 & 76.1 & 558.9 & $2,232.3$ \\
\hline 2002 & $2,074.0$ & 511.2 & 802.7 & 159.9 & 600.2 & $2,644.9$ \\
\hline 2003 & 2,178.6 & 554.1 & 824.3 & 231.1 & 569.0 & 2,768.8 \\
\hline 2004 & 2,308.9 & 739.9 & 724.7 & 146.0 & 698.4 & $3,086.9$ \\
\hline 2005 & $2,256.1$ & 778.4 & 595.2 & 95.4 & 787.3 & $3,021.3$ \\
\hline 2006 & $2,371.0$ & 891.6 & 414.8 & 72.2 & 992.4 & $3,145.3$ \\
\hline 2007 & $2,736.9$ & $1,241.2$ & 489.3 & 106.3 & 900.1 & $4,056.2$ \\
\hline 2008 & $2,742.3$ & $1,230.8$ & 525.9 & 85.6 & 899.9 & 4,188.1 \\
\hline 2009 & $3,150.4$ & $1,370.6$ & 630.3 & 102.0 & $1,074.5$ & 4,179.2 \\
\hline 2010 & $3,304.0$ & 1,388.0 & 645.0 & 136.0 & $1,232.0$ & $4,591.0$ \\
\hline
\end{tabular}

Table 3.6 Quantity of transported goods by waterway (Source from Da Nang's Statistical Office, Statistic Year Books)

Generally, the traffic in Da Nang City has many advantages and ability in exploiting effectively by the connection of between mountainous regions, midland, coastal region, tourism area and center city. It can be developed and integrated easily with national and international traffic. However, there are many problems which need to be solved, such as the placement of the airport and railway station in the center of the city. Although, it is convenient for passengers, there are many obstacles in developing the city and protecting environment. 


\subsubsection{Irrigation}

The irrigation systems in Da Nang City includes 2 big water reservoirs (HoaTrung, Dong Nghe), 21 medium and small water reservoirs, 27 spillways and 27 feed-pump stations, $13 \mathrm{~km}$ seawalls and $630 \mathrm{~km}$ canals (452 km interior field canals). Total capable design of irrigation systems is 12,500 ha; real capability of irrigation is 8,500 ha $(68 \%$ of total design capacity) that satisfies $72 \%$ of the cultivated area. There are $139 \mathrm{~km}$ permanent canals (71\% of total canals).

\subsubsection{Education and training}

The education and training systems of Da Nang City have all kinds of school, such as public, semi-official, private, day-boarder. These schools are distributed widely across Da Nang city. Therefore $100 \%$ of children from 6 years old come to school. Illiteracy disappeared in $100 \%$ of the communes. There are 124 kindergartens, 99 primary education schools, 55 junior high schools, 21 senior high schools, 8 technical secondary schools, 10 colleges, 5 universities. In general, the education and training network in Da Nang City developed quite well, which satisfied the demand of study for the inhabitants and supplied thousands of educated laborers for not only Da Nang city but also neighboring provinces. In addition, the education systems supported the farmer who lost cultivated land, the rural laborer, the poor, or the handicapped people who now have new jobs.

\subsubsection{Health and medicaments}

The public health of Da Nang City has 22 hospitals (including 4 private hospitals), 3 health centrals and 56 communal health stations. Total number of beds is 3,819 or there are 43 beds/ten thousand people. 56/56 (100\%) communes attained the national standard of health and medicaments. The health network in Da Nang City was carefully planned and the number of beds and physician doctors increase every year. In addition, the preventive health services were also concerned. Consequently, the disease prevention projects have been implemented and all kinds of vaccine have been widely used. 


\subsubsection{Electricity}

+ Power source: The main power source of Da Nang City belongs to the National Grid $500 \mathrm{KV}$ through transformer stations, including: $500 \mathrm{KV}$ station with two transformer machines (+500/200 KV - 450 MVA and +220/110 - 125 MVA), Xuan Ha station with two transformer machines (2x25 MVA -110/35/6 KV). In addition, there are spare diesel source in Cau Do (12 MW) and airport (3.5 MW) for supplying in peak hours.

+ Electric network: Currently, Da Nang City has 448.9 km in length of electric network (110 KV - 385 km, $35 \mathrm{KV}-63.9 \mathrm{~km}$ ), $362.37 \mathrm{~km}$ in length of supply network ( $15 \mathrm{KV}$ - $206.9 \mathrm{~km}, 6 \mathrm{KV}$ - $125.3 \mathrm{~km}, 22 \mathrm{KV}$ - $30.17 \mathrm{~km}), 29 \mathrm{~km}$ in length of step- low network ( $0.4 \mathrm{KV}$ and $0.2 \mathrm{KV}$ ) and 1310 transform machines ( 220/0.4 KV station: 19, 15/0.4 KV station: 428, 0.6/0.4 KV station: 863).

\subsubsection{Telecommunication}

The telecommunications of Da Nang City has been modernized in recent years and became the third large telecommunication center of the whole country. The network distributes widely across the whole city with 1 central post office, 4 district post offices, 57 posts, 14 communal cultural stations. Currently, the communication system includes 146 telecommunication centrals, 449 telecommunication stations, 45 switchboards with 275,218 telephones and fax machines, and 48 public telephone stations, which satisfy the communicating demand of inhabitants in Da Nang City.

\subsection{General assessment of natural, socio-economic condition}

Based on the conditions of nature and socio-economics, we can summarize the advantages and disadvantages of developing economics of Da Nang City in following statements:

+ Advantages:

- By the favorable geographical location with all kinds traffic conditions, such as national transport axis with major road, railroad, sea and air transport links and the gateway to Central Highlands as well as trans-network to East-West Economic Corridor, Da Nang City has conditions that allow easy exchange with 
other countries (Lao, Thailand, Myanmar etc.). It has the capability of being in the first position in developing economics in Central Region and Highlands.

- With a coastline of 92 km, Da Nang City has advantages in developing maritime economics as well as tourism.

- The temperate weather, together with the big potentiality of seafood and large fishing ground, is good condition to develop fisheries.

- Being the center of famous cultural and natural heritage sites such as the ancient capital of Hue, Hoi An ancient town, My Son sanctuary, and Phong Nha-Ke Bang National Forest, and having many beautiful beaches, Da Nang City attracts numerous tourists coming to visit and relax.

- Da Nang has made a good start by building hard infrastructure with multiform transport network, synchronously electricity and water systems, and modern telecommunications. These conditions attracted both domestic and foreign investments.

- There are many kinds of education and training, including university, college, technical training as well as research centers, which help to have educated laborers to high level and attract more and more research staff working in Da Nang City.

\section{+ Disadvantages:}

- In the wet season, downpours cause floods in low-lying plains, whereas, exhausted sources of water in dry season causes salty in lower river section that give troubles for farming.

- Complicated topography with high and steep mountains, in company with heavy rains is the reasons of destroying floristic cover, through landslide and erosion in the areas of Da Nang City.

- The degradation of water, soil, air has been more and more serious due to the human activities in development and construction. Like other cities in Viet Nam, Da Nang City also faces these problems. If there is not any timely solution for preventing natural degradations, it will diminish the ability in developing the economics of the city. 


\section{CHAPTER 4}

\section{Data and Methodology}

Chapter 4 presents the remote sensing collection used in this study. Computational methods applied for processing data, detecting changes in land use/cover, and landscape structure, together with modeling land use change are explained in detail.

\subsection{Sensor systems}

Initially, three satellite sensor systems were chosen for land cover mapping: Landsat, SPOT, and ASTER. However, SPOT data could not be used due to incomplete availability. Landsat satellite data were the best alternative choice owing to their long existence. The chosen Landsat scenes for this study include data of all three Landsatsystems, namely Landsat Multispectral Scanner (MSS), Landsat Thematic Mapper (TM), and Landsat Enhanced Thematic Mapper Plus $\left(\mathrm{ETM}^{+}\right)$.

According to Jensen (2000), the Landsat MSS sensor was set for Landsat satellite 1 through 5. Landsat MSS used an optical-mechanical system in which a mirror scans the terrain perpendicular to the flight direction. Energy reflected or emitted from the terrain is obtained onto discrete detector elements in scanning. Then, the radiant flux measured within each instantaneous field of view (IFOV) in the scene has been converted into an electronic signal by the detectors. The IFOV of each detector element is squared and measured in a ground resolution by approximately $79 \times 79 \mathrm{~m}$. The MSS 
scanning mirror oscillates through an angular displacement of $\pm 5.78^{\circ}$ off nadir. The $11.56^{\circ}$ field of view resulted in a swath width of $185 \mathrm{~km}$ during each orbit. Six parallel detectors sensitive to four spectrums viewed the ground simultaneously: $0.5-0.6 \mu \mathrm{m}$ (green), $0.6-0.7 \mu \mathrm{m}$ (red), $0.7-0.8 \mu \mathrm{m}$ (reflective near infrared), and $0.8-1.1 \mu \mathrm{m}$ (reflective near infrared), namely, 4, 5, 6, and 7 band, respectively.

The Landsat TM sensor was placed on the Landsat 4 and 5 platforms. This records energy in visible, reflective infrared, middle-infrared, and thermal infrared regions of the electromagnetic spectrum as an optical mechanical whisk-broom sensor. The Landsat TM sensor can obtain multispectral images with higher spatial, spectral, temporal, and radiometric resolution compared to Landsat MSS. Landsat TM has 7 bands: band 1: $0.45-0.52 \mu \mathrm{m}$ (blue), band 2: $0.52-0.60 \mu \mathrm{m}$ (green), band 3: 0.63 $0.69 \mu \mathrm{m}$ (red), band 4: 0.76 - $0.90 \mu \mathrm{m}$ (near-infrared), band 5: 1.55 - $1.75 \mu \mathrm{m}$ (midinfrared), band 6: $10.4-12.5 \mu \mathrm{m}$ (thermal infrared), band 7: $2.08-2.35 \mu \mathrm{m}$ (midinfrared). The thermal infrared band 6 has been excluded as it has a spatial resolution of $120 \times 120 \mathrm{~m}$, whereas band 1 through band 5 and band 7 have a ground projected IFOV of $30 \times 30 \mathrm{~m}$.

The $\mathrm{ETM}^{+}$sensor was launched on the Landsat-7 platform. The $\mathrm{ETM}^{+}$sensor has the same mirror and detector design, and is based on the same push-broom technology which is derived from Landsat TM. The $\mathrm{ETM}^{+}$has the same 7 bands than its predecessor TM, in which bands 1 through 5 and 7 have the same $30 \times 30 \mathrm{~m}$ spatial resolution and thermal infrared band 6 has $60 \times 60 \mathrm{~m}$ spatial resolution instead of $120 \mathrm{x}$ $120 \mathrm{~m}$.Moreover, there is a notable band with $15 \mathrm{x} 15 \mathrm{~m}$ resolution, namely panchromatic band: $0.52-0.9 \mu \mathrm{m}$. However, the $\mathrm{ETM}^{+}$Scan Line Corrector (SLC) was defected in 2003, resulting in imagery with significant missing data. Consequently, an ASTER image was used to discover the changes of land use/cover for the period after 2003 instead of Landsat $\mathrm{ETM}^{+}$. 


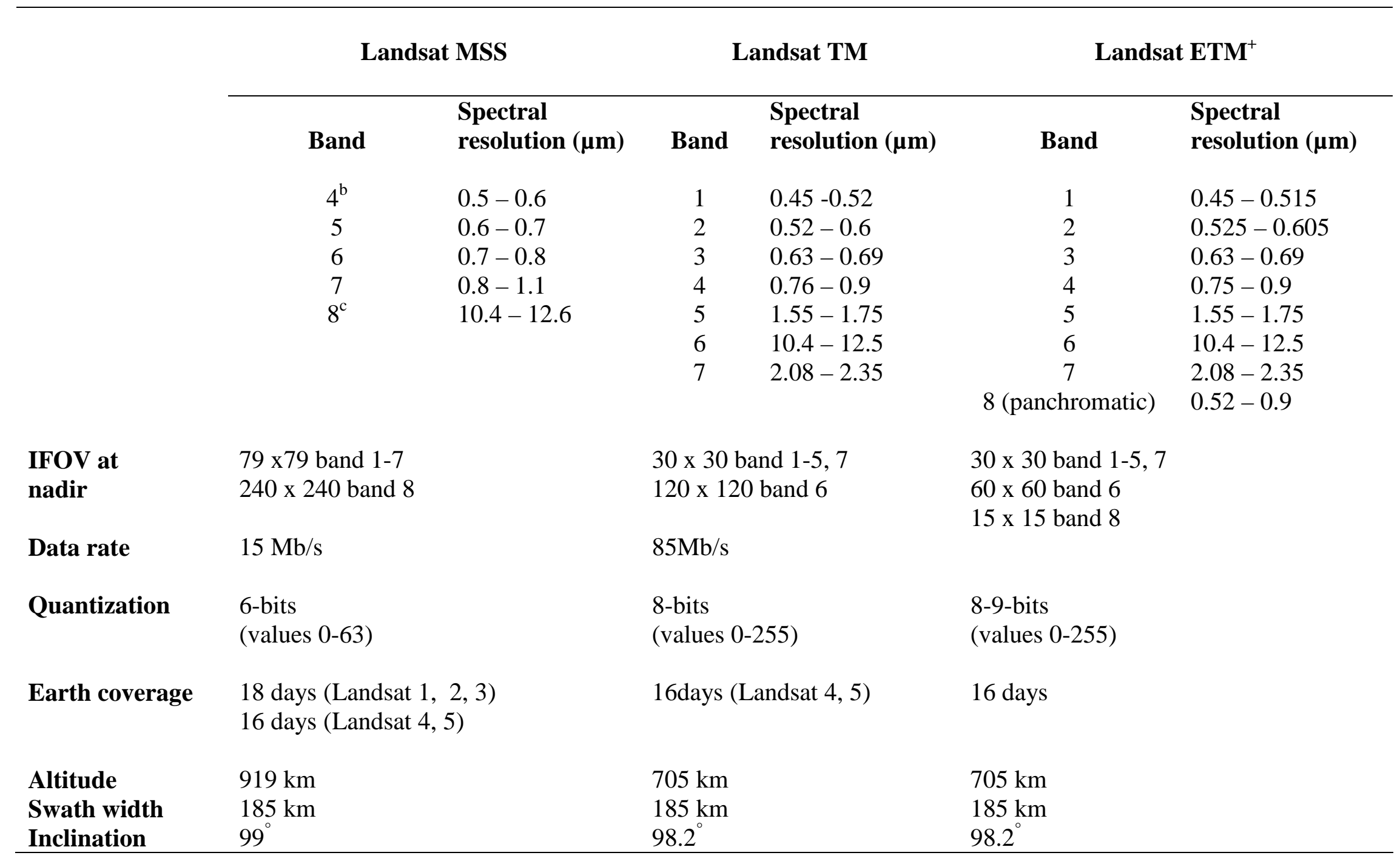

Table 4.1 Characteristics of Landsat sensors, Source from Jensen (2000) 
ASTER (Advanced Space borne Thermal Emission and Refection Radiometer) is the product of cooperation between NASA and Japan's Ministry of International Trade and Industry (JAXA). ASTER records information on land surface temperature, emissivity, reflectance, and elevation. ASTER consists of 14 bands from visible through thermal infrared regions of the electromagnetic spectrum, dividing as three separate instrument subsystems: VNIR (Visible and Near Infra-Red), SWIR (Short Wave Infrared), and TIR (Thermal Infrared). The technical details of the ASTER system are summarized in Table

4.2.

\section{Advanced Space borne Thermal Emission and Refection Radiometer (ASTER)}

\begin{tabular}{llllll} 
Band & VNIR $(\boldsymbol{\mu m})$ & Band & SWIR $(\boldsymbol{\mu m})$ & Band & TIR $(\boldsymbol{\mu m})$ \\
1 (nadir) & $0.52-0.60$ & 4 & $1.600-1.700$ & 10 & $8.125-8.475$ \\
2 (nadir) & $0.63-0.69$ & 5 & $2.145-2.185$ & 11 & $8.475-8.825$ \\
3 (nadir) & $0.76-0.86$ & 6 & $2.815-2.225$ & 12 & $8.925-9.275$ \\
3 (backward) & $0.76-0.86$ & 7 & $2.235-2.285$ & 13 & $10.25-10.95$ \\
& & 8 & $2.295-2.365$ & 14 & $10.95-11.65$ \\
& & 9 & $2.360-2.430$ & & \\
Detector & Push-broom & & Push-broom & & Whisk-broom \\
Spatial resolution & $15 \times 15$ & & $30 \times 30$ & & $90 \times 90$ \\
Swath width & $60 \mathrm{~km}$ & & $60 \mathrm{~km}$ & & $60 \mathrm{~km}$ \\
Quantization & $8-b i t s$ & & $8-b i t s$ & $12-b i t s$ \\
\hline
\end{tabular}

Table 4.2 Characteristics of ASTER

Source from Jensen (2000)

\subsection{Data collection}

In this study, four base years were defined to analyze LULC changes in Da Nang City. The determination of these base years is a result and compromise of project needs and satellite data availability. Among all available satellite data, the following scenes were chosen: Landsat-3 Multispectral Scanner System (MSS) July 24, 1979; Landsat-5 Thematic Mapper 
(TM) July 07, 1996 and Landsat-5 Thematic Mapper (TM) 14 July 1996; Landsat-7 Enhanced Thematic Mapper Plus (ETM+) March 04 and April 14, 2003; ASTER April 02, 2009. Details of these satellite images can be found in Table 4.3. Landsat images were downloaded for free from Earth Explorer (http://earthexplorer.usgs.gov/) and United States Geological Survey (USGS) Global Visualisation (GloVis) (http://glovis.usgs.gov/); ASTER images were purchased from Japan Space Systems/Earth Remote Sensing Division (ERSDAC). Nevertheless, the SWIR data (band 4-band 9) of ASTER are unusable (USGS, 2009) due to the increase of the SWIR detector's temperature after April 2007.

Because of the geographic location and the tropical climate, the area of Da Nang City is frequently covered by cirrus and cumulus clouds. As a consequence, only a limited number of cloud-free optical satellite images were available for the study area. The data acquisitions used in this study cover different seasons (dry season to wet season, which has to be accounted for in the change detection analysis due to seasonal effects. Detailed training and reference data together with local knowledge were used in order to deal with this problem (Kashaigili and Majaliwa, 2010).

The mosaic of Landsat TM images of 1996 was chosen to map the state of LULC in the study area before separating from the Quang Nam Province. In 2003, the new Land Law was approved by the national assembly and a new land use system was created. Land use in Da Nang City was inventoried for these special times by the National department of Geodesy and Cartography. Hence, land use/cover maps resulting from these inventories could be used later as reference data. 


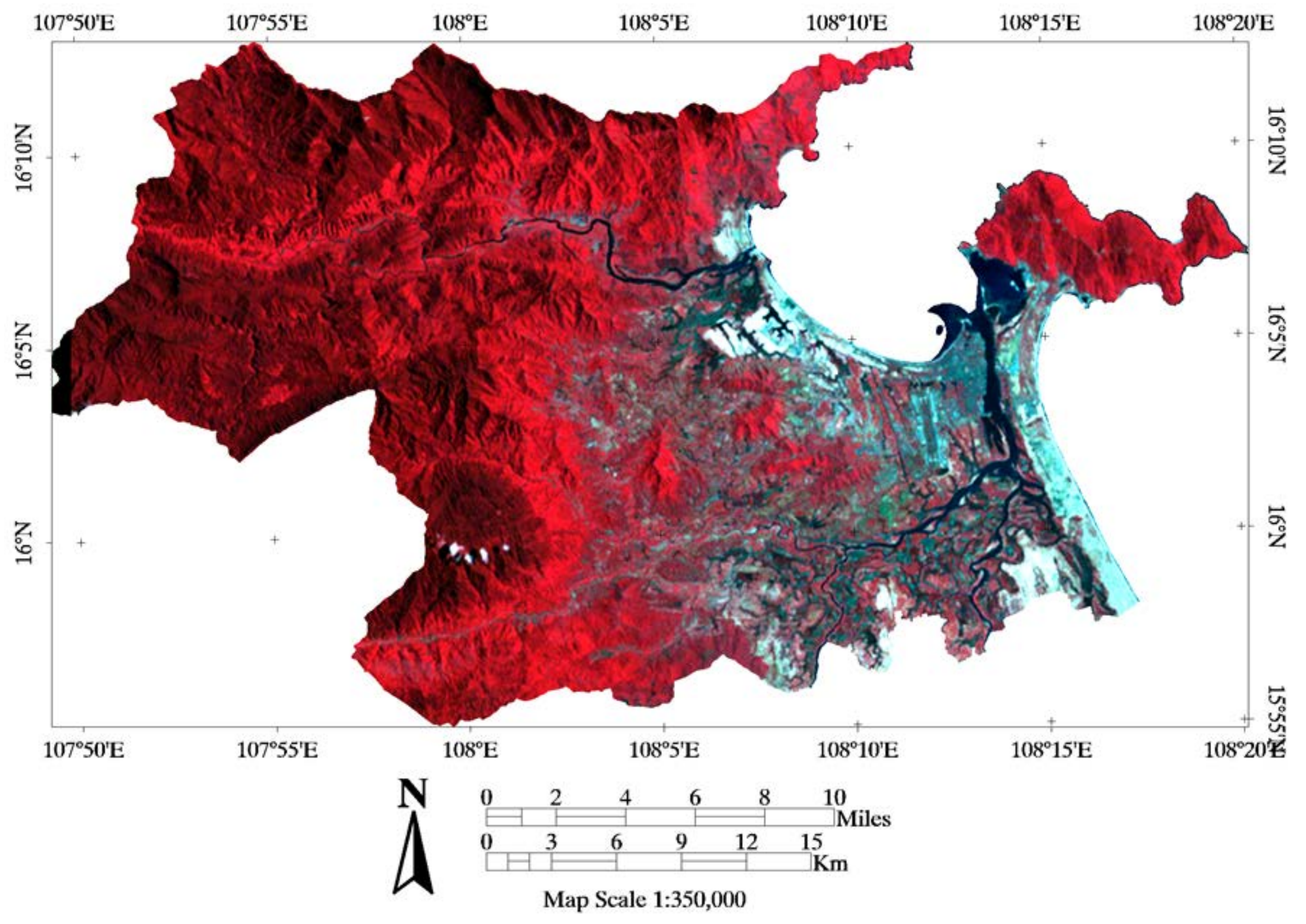

Figure 4.1 Subset of Landsat MSS image (July 24, 1979), RGB 754, (Source: Own calculation) 


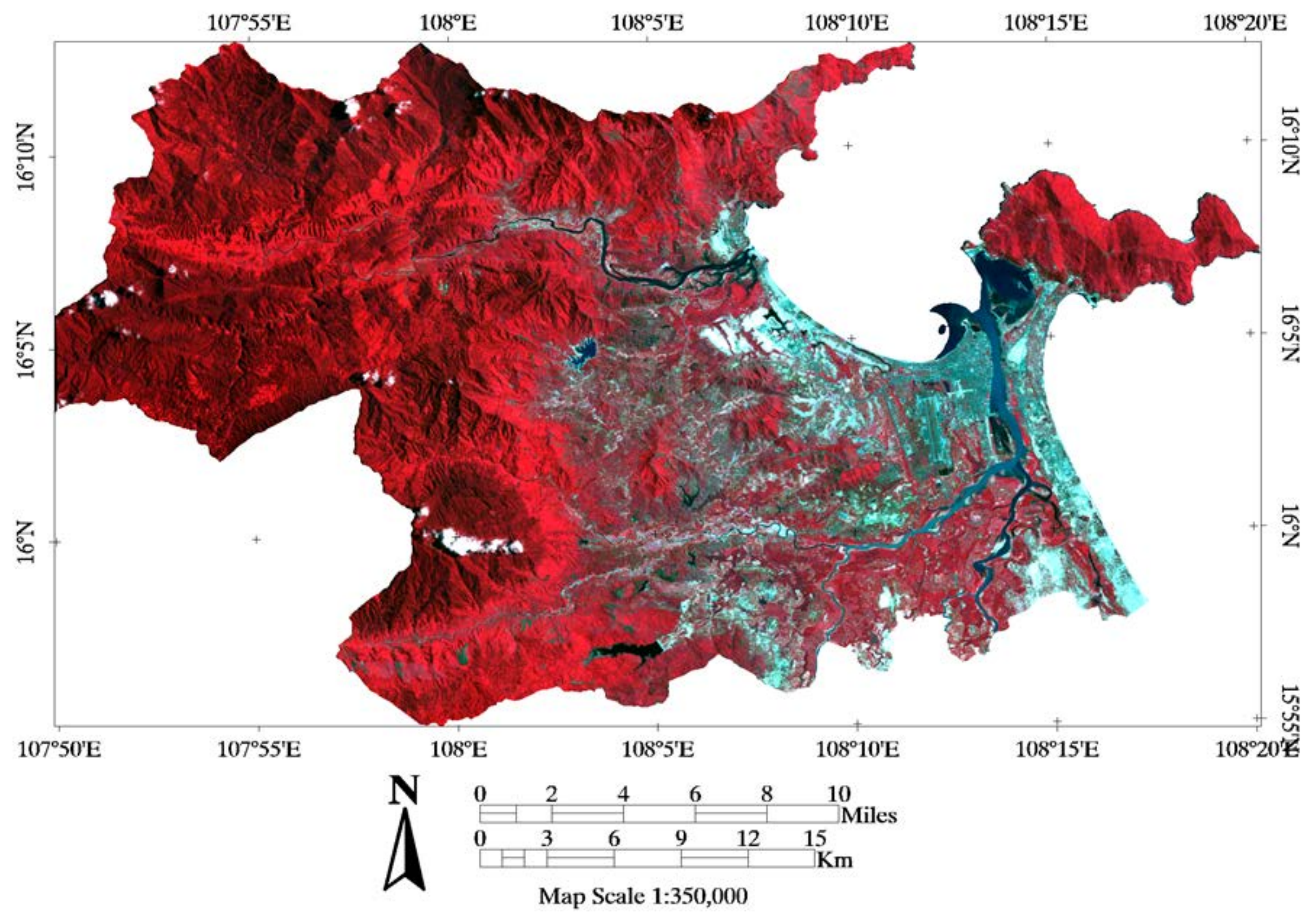

Figure 4.2 Subset of mosaic Landsat TM images (July 07 \& 14, 1996), RGB 432 (Source: Own calculation) 


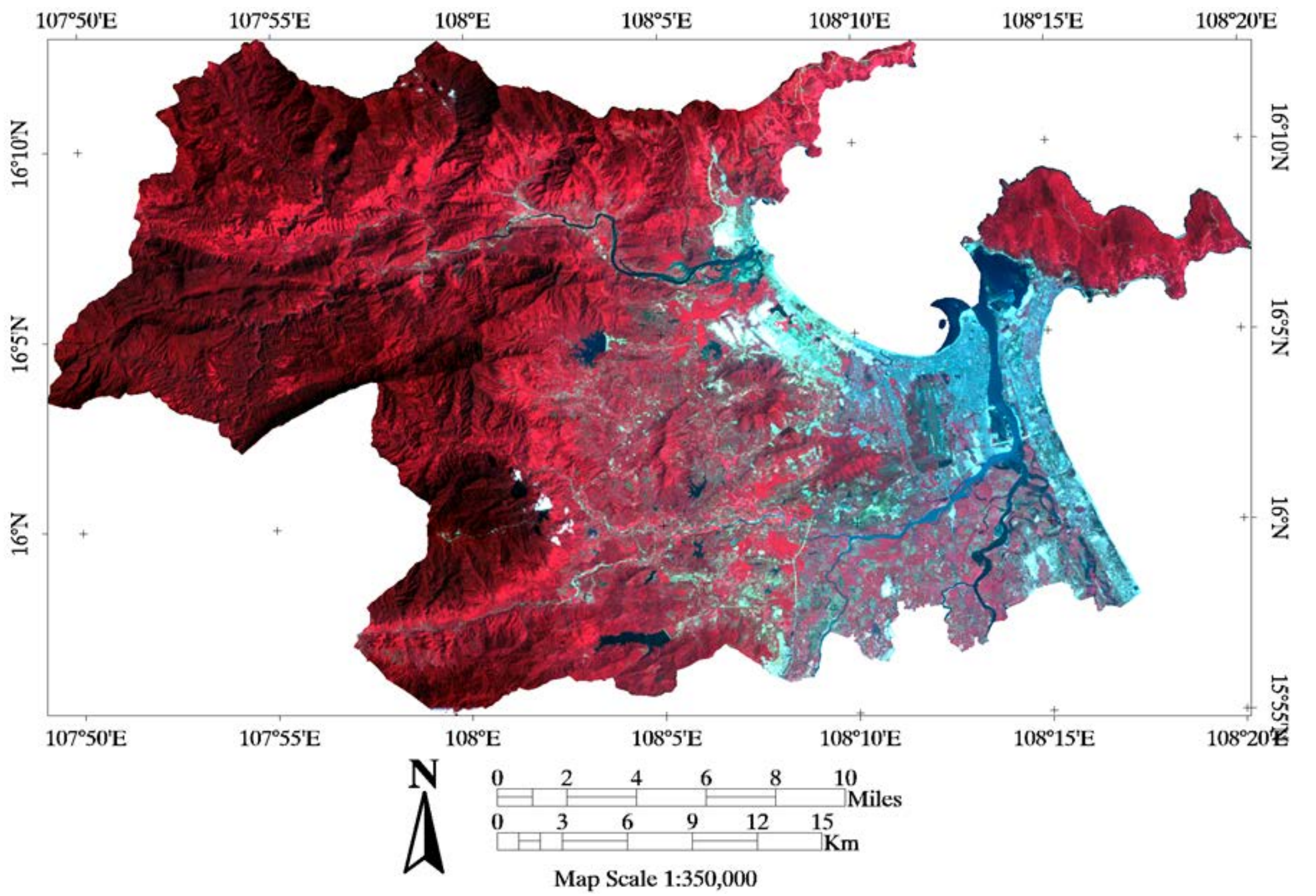

Figure 4.3 Subset of mosaic Landsat ETM+ images (March 04 \& April 14, 2003), RGB 432 (Source: Own calculation) 


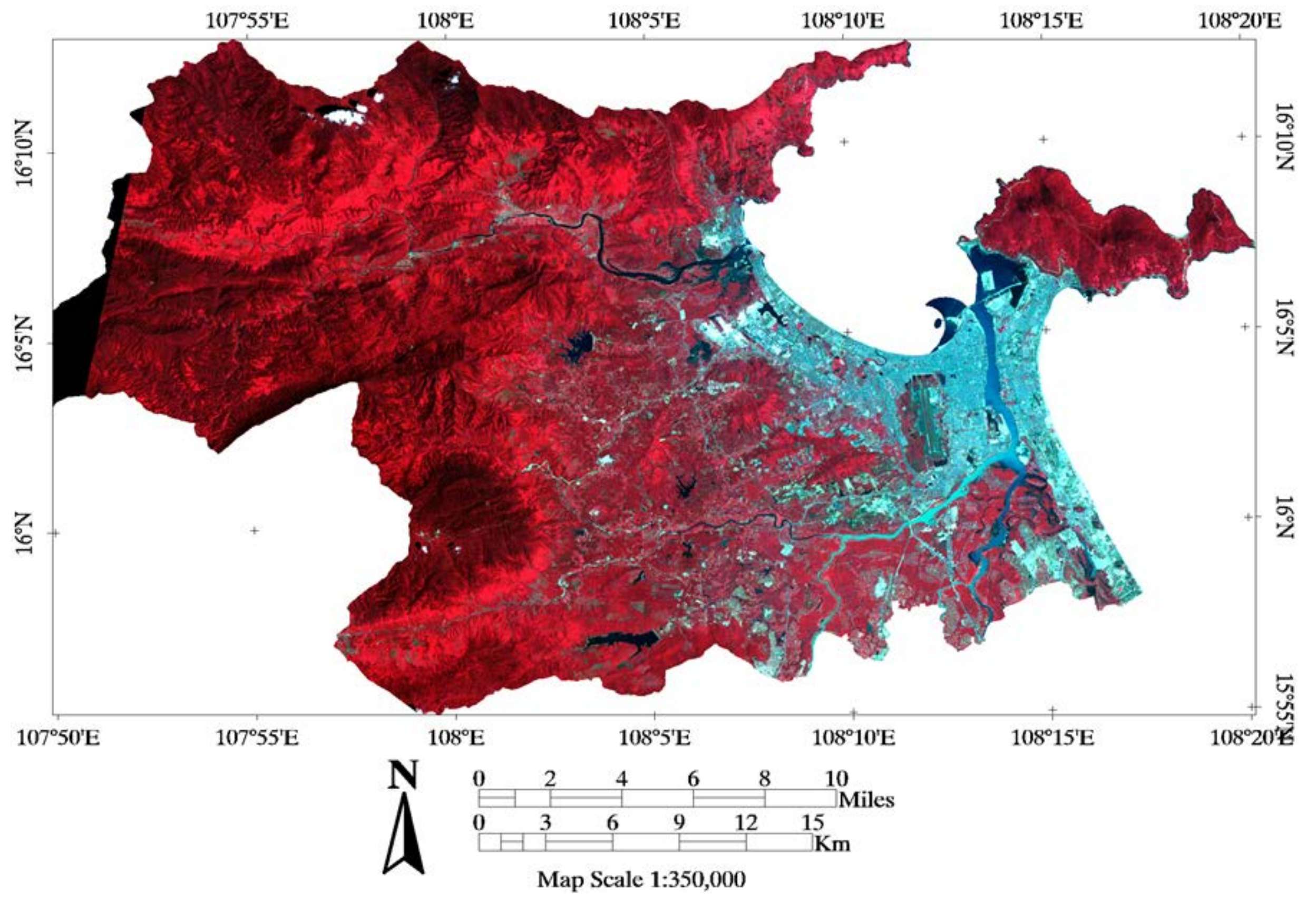

Figure 4.4 Subset of ASTER image (April 02, 2003), RGB 321 (Source: Own calculation) 
In this study, ancillary data included topographical map 2001 (scale 1:50.000), land use map 1997, 2003, 2010 (scale 1:25.000), and an administrative map. These maps were used to correct the geometry of the satellite images and assess the accuracy of land use maps. In addition, a panchromatic SPOT 5 image acquired on February 12, 2009 (2.5m) was also used as reference images for satellite images interpretation. SPOT image was purchased from Viet Nam National Remote Sensing Centre. In addition to remote satellite data, social statistics and economic data for Da Nang City were collected from Da Nang Statistics Yearbooks in different years. Due to the rapid growth of the city, the administrative boundaries of districts in this study area have been changed. In 2005, a part of Hoa Vang (HV) district was separated as one new, namely, Cam Le (CL). Consequently, social statistics and economic data were inconsistent in parts. Population data and the gross domestic products (GDP) of three sectors: agriculture, industry, and service were gathered. Also, land use planning guidelines of Da Nang City were collected to analyze the driving factors of LULC changes in Da Nang City.

\begin{tabular}{|c|c|c|c|c|c|c|}
\hline $\begin{array}{l}\text { Type of } \\
\text { sensor }\end{array}$ & $\begin{array}{c}\text { Spatial } \\
\text { resolution } \\
\text { (m) }\end{array}$ & Band & Date & Path & Row & $\begin{array}{c}\text { Average } \\
\text { cloud } \\
\text { coverage } \\
(\%)\end{array}$ \\
\hline $\begin{array}{c}\text { Landsat-3 } \\
\text { MSS }\end{array}$ & 79 & $4-8$ & July 24, 1979 & 134 & 49 & 20 \\
\hline $\begin{array}{c}\text { Landsat-5 } \\
\text { TM }\end{array}$ & 30 & $1-5,7$ & July 14, 1996 & 125 & 49 & 11 \\
\hline \multirow{3}{*}{$\begin{array}{c}\text { Landsat-7 } \\
\text { ETM+ }\end{array}$} & 30 & $1-5,7$ & July 07, 1996 & 124 & 49 & 0 \\
\hline & 28.5 & $1-5,7$ & March 04, 2003 & 125 & 49 & $34.65 *$ \\
\hline & 28.5 & $1-5,7$ & April 14, 2003 & 124 & 49 & 0.34 \\
\hline $\begin{array}{c}\text { ASTER } \\
\text { (VNIR) }\end{array}$ & 15 & $1-3$ & April 02, 2009 & - & - & 4 \\
\hline
\end{tabular}

(* Although the average cloud coverage of Landsat-7 ETM+ is very high, there is almost no cloud in study area at that time).

Table 4.3 Characteristics in satellite datasets used 


\subsection{Image pre-processing}

\subsubsection{Geometric correction}

For producing spatially corrected LULC maps through time, it is important to register multiple data imageries to a single map coordinate system (Yang and Lo, 2002). In this study, the digital topographical map 1/50.000 of 2001 was used as reference data. The ASTER image was geo-referenced to Universal Transverse Mercator (UTM) coordinate system, Datum WGS 84, Zone 48 North by image-to-map rectification. Then, the ASTER registered image was used as the base image to co-register all Landsat images. An average of 25 well distributed Ground Control Points (GCPs) was used. A first degree polynomial transform was applied to transform the image coordinates. The achieved Root Mean Square Error value (RMSE) of all transformations was below 0.5 pixels. According to Lunetta et al. (1998), an ideal RMSE of any two date images used for change detection should be less than 0.5 pixel.

Due to the different spatial resolution and seasonal acquisitions of the remote satellite imagery, a radiometric normalization was required in order to study change detection. For this reason, the nearest neighbor resampling was used to avoid changing the radiometric characteristic of original remote satellite images (Crocetto and Tarantino, 2009). All satellite images were resampled to $30 \mathrm{~m}$ pixel size.

\subsubsection{Radiometric normalization}

As pointed out by Chen (2005), radiometric correction should be performed on multi temporal images to increase the sensitivity of LULC changes and simultaneously reduce the impact of environmental and sensor factors like e.g. sensor characteristics, atmospheric condition, solar angle and sensor view angle.

Conghe Song et al. (2001) evaluated different absolute and relative radiometric normalization techniques. This preprocessing method is significant for land cover change and other studies, such as mosaicking imageries or tracking indices of vegetation over times (M. Caprioli et al., 2008). 
Chapter 4. Data \& Methods

Conghe Song et al (2001) asserted that in the absolute radiometric correction approach, the digital brightness value of a pixel have been recorded by the remote sensing system. In which, established transformation equations and atmospheric models are used to convert digital brightness value as a percent reflectance value. Thus, it needs information of both the sensor spectral characteristic and the properties of atmosphere at the time of the acquired image. According to M. Caprioli et al. (2008), data for characterization of the relevant atmosphere include "aerosols, ozone or water vapor in different atmospheric layers". However, it is impossible to determine these data for the historic satellite images, because atmospheric properties are not available (Du et al., 2002).

To overcome this problem, relative radiometric correction can be considered as an alternative approach, which is discovered by the radiometric information intrinsic of images (M. Caprioli et al., 2008). Relative radiometric correction is applied for (a) normalizing the intensities of different bands in a single-date image or (b) normalizing the intensities of different bands in multiple-date images to a standard selected image (Jensen, 2005). Yuan and Elvidge (1996) ascertained that this procedure maintains the original radiometric value of the reference image. Thus, it obviates the computation in converting image to unit of radiance or reflectance. The relative correction approach for multiple-date images have been suggested by authors, such as Jensen (2005) with Multiple-date Empirical Radiometric Normalization (MERN) or Schott et al (1988), Caselles et al. (1989), Conel (1990), Hall et al. (1991) with Pseudo-Invariant Features (PIFs). These methods involve in selecting a base image, and then the spectral characteristics of all other images recorded on different dates are transformed to have approximately the same radiometric as the standard scale. Within radiometric normalization approach, the selection of ground targets is generated from the knowledge and abilities of the analyst about local area (Janzen et al., 2006). Nevertheless, those approaches are limit with satellite imagery under climatic conditions, such as clouds or snow covers in the acquisition phase (M. Caprioli et al., 2006; Moran et al., 1992).

For ameliorating such matters, different techniques to select PIFs were developed by Heo et al.(2000). Later, Du et al. (2002) used principal component analysis (PCA) to select 
Chapter 4. Data \& Methods

PIFs. In 2004, Canty et al. raised a new automatic radiometric normalization for multitemporal satellite imagery, based on MAD transformation (Multivariate Alteration Detection) and later IR-MAD transformation (Iteratively Re-weighted Multivariate Alteration Detection), see also (Canty and Nielsen, 2008). IR-MAD transformation is known as a fully automatic approach and overcomes the above limited problems, in which "no change pixels” are identified. Based on the discussions above, IR-MAD transformation was chosen as the radiometric normalization approach for this study.

The remote satellite images used in this thesis were attained from various sensors at different dates spanning a period of thirty years. In order to have a meaningful detection of LULC change, the second step in the pre-processing images involved in compensating the inhomogeneous of the time series of satellite images. The ASTER 02/04/2009 image was selected as reference image or "target" image, which was used to correct the rest images based on IR-MAD method by means of ENVI extensions (Canty and Nielsen, 2008). As requirement of radiometric normalization approach, all images must have the same dimensions and spectral resolution. Hence, a subset of 1800 x 1100 pixels with resampled $30 \mathrm{~m}$ spatial resolution including $968.17 \mathrm{~km}^{2}$ was chosen for investigating. In addition, a composite of standard false color was applied for individual images: Landsat MSS (754); Landsat TM/ETM ${ }^{+}$(432); ASTER (321). After radiometric normalization, the multi images in the same period of years 1996 and 2003 were mosaicked as a new single seamless composite image and then the study area was extracted in the image for further analysis

\subsection{Image classification and accuracy assessment}

\subsubsection{Image classification}

According to Anderson's classification scheme Level I (Anderson et al., 1976a), six LULC classes were defined in this study: (1) agriculture, (2) barren, (3) urban area, (4) forest, (5) shrub, (6) water. The fact that there were some clouds and cloud shadows in remote satellite imagery, all potential clouds and cloud shadows were detected. However, all of these clouds and cloud shadows persisted in the northern and western parts of study area 
Chapter 4. Data \& Methods

covered by forest. Consequently, all clouds and shadow clouds categories were combined to forestry classes.

For classification, different training areas of each LULC class were delineated and verified by reference maps and the visual interpretation of each image (Bakr et al., 2010). The number of pixels for Landsat 1979, Landsat 1996, Landsat 2003 and ASTER 2009 were 11701, 16389, 11927, and 10693, respectively. Based on supervised classification using Maximum likelihood algorithm, six LULC types were derived from the classification maps of 1979, 1996, 2003 and 2009.

Due to the capability in minimizing the problems that are encountered in radiometric calibration of imagery of two days, post-classification comparison was employed for LULC maps extracted from satellite imageries to detect the changes of LULC in four interval of time: 1979-1996, 1996-2003, 2003-2009, and 1979-2009. Based on pixel-by-pixel approach, a change detection matrix of the classification results in two days was inspected, from which from-to-change of LULC types were identified. It means that the accuracy of each individually classified map decides the accuracy of change detection (Jensen, 2005). Therefore, it requires accurate geometric correction, proper radiometric correction, a good quality training sample and suitable classification methods in order to increase the image classification accuracy and improve achieve acceptable change detection results (Chen and Wang, 2010).

The second part of this study is related to investigating the change of landscape pattern, it is worthy to perceive the "salt and pepper" effect observed in per-pixel classification approach. In some cases, a single pixel could be ranged as one patch of land cover type. Such occurrence can result in scattered patches of very small sizes, which have potential in reducing the effectiveness of patch metrics to analyze landscape patterns. Thus, it is needed to generated classified LULC maps as less impact of the "salt and pepper" effect as possible by carefully evaluating and manipulating the spectral signatures of each land use/ land cover type. To do this, a 3 x 3 majority filtering of post classification was applied on the binary images to reduce the occurrences of patches with a single pixel or a small number of pixels (Ji et al., 2006). 


\subsubsection{Accuracy assessment}

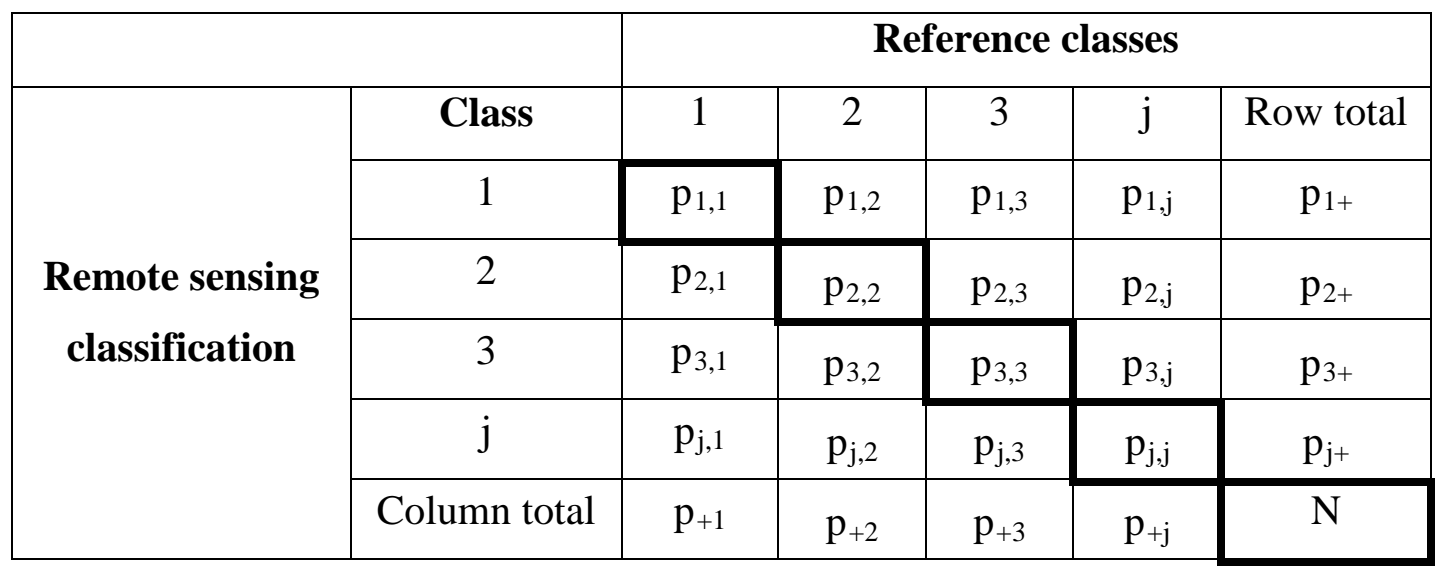

Table 4.4 Illustration of error matrix with $\mathbf{j}$ classes and $N$ reference samples Source from Jensen (2005)

As pointed out by (Johannsen et al., 2003), remotely sensed/remote sensing image data have become more and more important for environmental models at local, regional, and global scales. Many significant decisions are made throughout the world using derived information from remote sensed data (Kyriakidis et al., 2004; Muchoney and Strahler, 2002). Hence, it is needed to assess the accuracy of thematic maps and give evidence for implementing the next steps.

A total of three-hundred stratified random samples of pixels were assigned to each LULC map extracted from satellite image and then classes were checked their labels based on reference data, from which overall accuracy of each LULC map were calculated. The 1996 classified Landsat images were compared to Land use map of 1997, the 2003 classified Landsat images were compared to Land use map 2003 and topographic map 2000, the 2009 classified ASTER image was compared to Land use map 2010 and SPOT-5 images 2009. It is more difficult to assess the accuracy for the 1979 LULC map due to the lack of reference data. To overcome this circumstance, the overall accuracy of LULC map 1979 would be determined as the work of Yang and Lo (2002). Accordingly, it is believed that the comparison of LULC map 1979 to LULC map 1996 is the sufficient way to shed light on accuracy. 
Chapter 4. Data \& Methods

The comparison of samples from classification or modeling system results with the reference data prevailing at the same location on ground is accepted as the most widely approach to calculate the accuracy classification (Leinenkugel, 2010). Comparisons of both samples labeled correctly and erroneously of each class are presented in the error matrix. Through this, a tabular range of descriptive and analytical statistical accuracies of each class are computed based on commission errors and omission errors (Colgalton and Green, 1999; Leinenkugel, 2010).

The overall accuracy represents the percentage of correctly classified samples. It can be calculated by dividing the total number of sample points correctly classified using the total number of pixels in the entire error matrix (Colgalton and Green, 1999).

$$
\text { overall accuracy }=\frac{\sum_{i=1}^{j} p_{i i}}{N}
$$

Together with overall accuracy, the Kappa coefficient (K) has been believed to be a powerful tool for such a long time, which is used to indicate the level of classification accuracy compared to a classification obtained by chance. However, Pontius and Millones (2011) ascertained some of conceptual flaws with the standard Kappa and its variations. According to these authors, instead of revealing the difference from correct proportion in a manner which helps practical decisions about image classification, Kappa coefficient just gives redundant or misleading information for practical decision making. They found that the standard Kappa and its variations are complicated in computing, difficult in understanding, and unhelpful in interpreting. Thus, a more useful and simpler tool focusing on two components of disagreement between maps in terms of the quantity and spatial allocation of the categories marks the end of the use of Kappa. Quantity disagreement is defined as "the amount of difference between the reference map and classified map based on the less than perfect match in the proportions of the categories". On the other hand, allocation disagreement is defined as "the amount of difference between the reference map and classified map based on the less than optimal match in the spatial allocation of the categories”. Pontius and Millones (2011) defined five types of indices ( $\mathrm{K}_{\text {standard }}, \mathrm{K}_{\text {no }}$, $\mathrm{K}_{\text {allocation }}, \mathrm{K}_{\text {histo }}$, and $\mathrm{K}_{\text {quantity }}$ ), which are used to explore the observed agreement between the comparison map and the reference map; in which, 1 indicates that the agreement is 
Chapter 4. Data \& Methods

perfect and 0 indicates that the observed agreement is equivalent to the statistically expected random agreement. $\mathrm{K}_{\text {standard }}$ is an index that accounts for "the expected agreement because of random spatial reallocation of categories in the comparison map"; through which, the proportion of categories in the comparison and reference maps can be given without regarding the size of the quantity disagreement. $\mathrm{K}_{n o}$ is the statistical index that measures the expected overall agreement based on the randomly selection of both the quantity and allocation of categories in the comparison map. $\mathrm{K}_{\text {allocation }}$ is computed to have an index of pure allocation; in which, 1 shows optimal spatial allocation as constrained by the observed proportions of the categories, whereas 0 shows the observed overall agreement that is "equal the agreement expected under random spatial reallocation within the comparison map given the proportion of categories in the comparison and reference maps”. $\mathrm{K}_{\text {histo }}$ index defines the separation of quantity and allocation. Contrary to $\mathrm{K}_{\text {allocation, }}$, $\mathrm{K}_{\text {quantity }}$ is computed to have an index of pure quantity which defies the accuracy of the allocation. Thus, Pontius and Millones (2011) stated that these statistics could be used to answer two critical questions: "(1) How well does a pair of maps agree in terms of the quantity of cells in each category? (2) How well do a pair of maps agree in terms of the allocation of cells in each category?”. In short, how well the comparison map agrees with the reference map could be explored by these Kappa statistics (Ahmed et al., 2013).

The formulas in calculating the observed agreement indicators are briefly presented in Table 4.5. For more details about this method please see (Pontius, 2000, 2002; Pontius et al., 2004; Pontius and Millones, 2011). 


\begin{tabular}{|c|c|c|}
\hline Index & \multicolumn{2}{|l|}{ Formula } \\
\hline $\mathbf{K}_{\text {standard }}$ & $\frac{\mathbf{C}-\mathbf{E}}{\mathbf{1 - E}}=\frac{(\mathbf{1}-\mathbf{Q}-\mathbf{A})-(\mathbf{1}-\mathbf{R})}{\mathbf{1}-(\mathbf{1}-\mathbf{R})}=\frac{\mathbf{R}-(\mathbf{Q}+\mathbf{A})}{\mathbf{R}}=\frac{\mathbf{R}-\mathbf{D}}{\mathbf{R}}$ & [4.2] \\
\hline$K_{n o}$ & $\frac{\mathrm{C}-1 / \mathrm{J}}{1-1 / \mathrm{J}}=\frac{(1-\mathrm{Q}-\mathrm{A})-(1 / \mathrm{J})}{1-1 / \mathrm{J}}=\frac{(1-1 / \mathrm{J})-(\mathrm{Q}+\mathrm{A})}{1-1 / \mathrm{J}}=\frac{(1-1 / \mathrm{J})-\mathrm{D}}{1-1 / \mathrm{J}}$ & [4.3] \\
\hline $\mathbf{K}_{\text {allocation }}$ & $\frac{\mathbf{C}-\mathbf{E}}{(\mathbf{1}-\mathbf{Q})-\mathbf{E}}=\frac{(\mathbf{1}-\mathbf{Q}-\mathbf{A})-(\mathbf{1}-\mathbf{R})}{(\mathbf{1}-\mathbf{Q})-(\mathbf{1}-\mathbf{R})}=\frac{\mathbf{R}-(\mathbf{Q}+\mathbf{A})}{\mathbf{R}-\mathbf{Q}}=\frac{\mathbf{R}-\mathbf{D}}{\mathbf{R}-\mathbf{Q}}$ & [4.4] \\
\hline $\mathbf{K}_{\text {histo }}$ & $\frac{(\mathbf{1}-\mathbf{Q})-\mathbf{E}}{\mathbf{1 - E}}=\frac{(\mathbf{1}-\mathbf{Q})-(\mathbf{1}-\mathbf{R})}{\mathbf{1 - ( 1 - R )}}=\frac{\mathbf{R}-\mathbf{Q}}{\mathbf{R}}$ & [4.5] \\
\hline $\mathbf{K}_{\text {quantity }}$ & $\frac{\mathrm{C}-\mathrm{Z}}{\mathrm{Y}-\mathrm{Z}}$ & [4.6] \\
\hline In which & $\begin{array}{l}\text { (1) } \boldsymbol{p}_{i j}=\left(\frac{n_{i j}}{\sum_{j=1}^{J} n_{i j}}\right)\left(\frac{N_{i}}{\sum_{i=1}^{J} N_{i}}\right) \\
p_{i j} \text { : the estimated proportion of study area that is categor } \\
\text { map and category } j \text { in the reference map } \\
J \text { : the number of categories } \\
i \text { : category in the comparison map (ranges from } 1 \text { to } \mathrm{J} \text { ) } \\
j \text { : category in the reference map (ranges from } 1 \text { to J) } \\
N_{i} \text { : the number of pixels in each stratum } \\
n_{i j} \text { : the number of observations in row } i \text { and column } j \text { of } \\
\text { (2) } \mathbf{C}=\sum_{j=1}^{J} \boldsymbol{p}_{j j} \\
\text { C: the proportion correct } \\
\text { (3) } \mathbf{E}=\sum_{\boldsymbol{g}=\mathbf{1}}^{J} \boldsymbol{e}_{\boldsymbol{g}} \\
\text { E: the overall expected agreement of all } J \text { categories }\end{array}$ & $\begin{array}{l}\text { [4.7] } \\
\text { irison } \\
\text { [4.8] } \\
\text { [4.9] }\end{array}$ \\
\hline
\end{tabular}




\begin{tabular}{|c|c|c|}
\hline Index & Formula & \\
\hline & 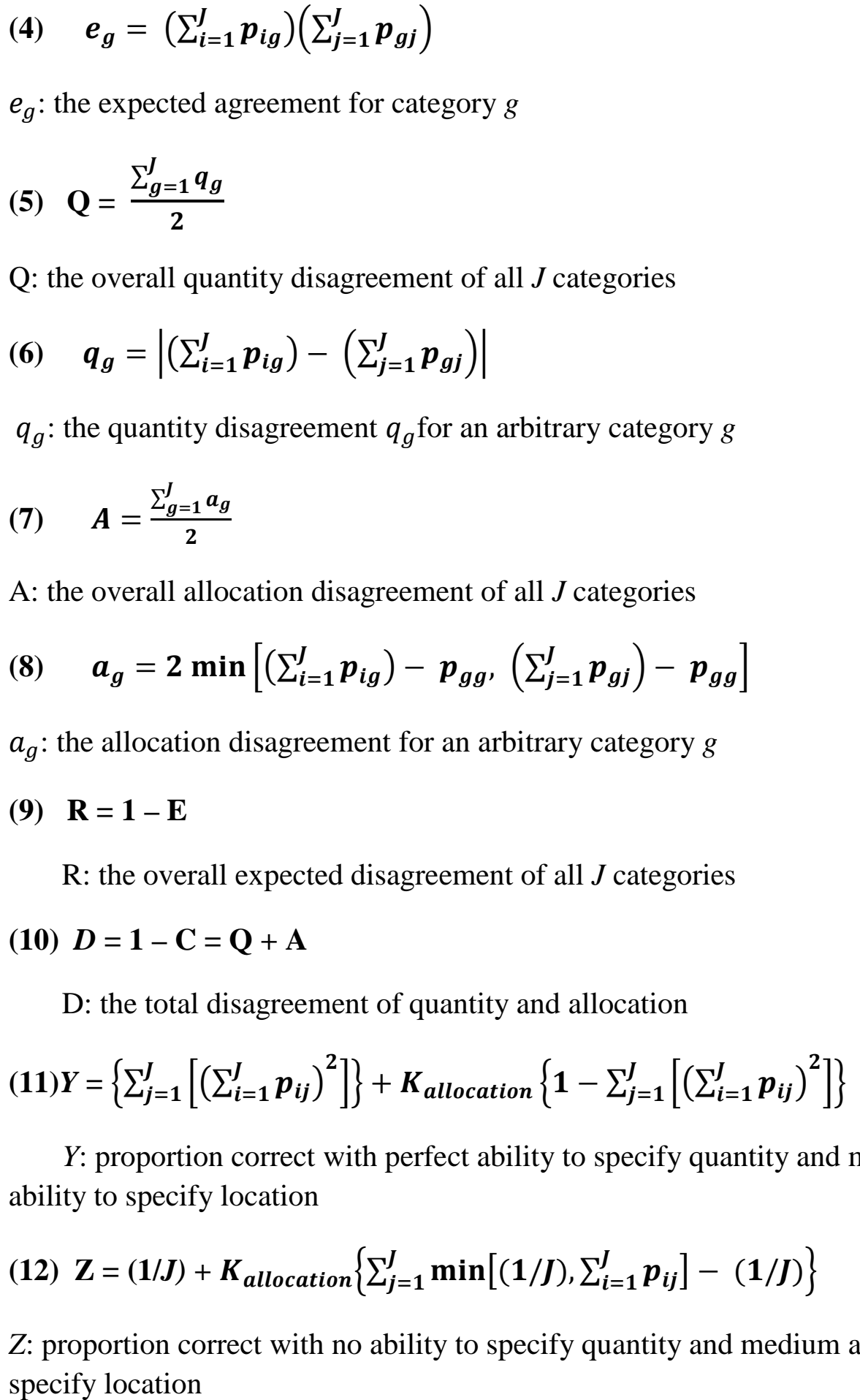 & $\begin{array}{l}\text { [4.15] } \\
\text { [4.16] } \\
\text { [4.17] } \\
\text { ledium } \\
\text { [4.18] }\end{array}$ \\
\hline
\end{tabular}

Table 4.5 Formulas of quantity disagreement and allocation disagreement indexes Adapted from Pontius and Millones (2011) 


\subsection{Change detection}

The next step is post-classification comparison which was carried out for LULC maps extracted from remote satellite imageries to detect the changes of LULC in four interval times: 1979 - 1996, 1996 - 2003, 2003 - 2009, and 1979 - 2009. Based on a pixel-by-pixel approach, a change detection matrix of the classification results was generated, from which the tendency and amount of LULC change were identified (Jensen, 2005).

\subsection{Landscape metrics}

Landscape metrics are usually used to objectively quantify landscape composition and configuration, which are main descriptions of landscape pattern (Deng et al., 2009; Lin et al., 2007; Turner et al., 2001). According to McGarigalet al.(2002), landscape composition describes the abundance and variety of patches in the landscape, whereas landscape spatial configuration characterizes the "spatial character and arrangement, position, or orientation of patches" in the landscape.

Heroldet al. (2005) evinced that the combination of remote satellite imagery and spatial metrics could give more detailed information about landscape structure and their changes than either of the methods that are used independently. In this regard, FRAGSTATS $4.1^{\circledR}$ (McGarigal, 2002), a spatial pattern analysis program, was used to evaluate the changes of landscape pattern in the study area based on the output of the remote sensing mappings. The FRAGSTATS software was developed by McGarigal and Marks (1995) of the Forest Science Department of Oregon State University. As output, a continuous landscape metric surface for statistical analysis is created by using square moving window computing technique (Figure 4.5). The selected index is calculated within each window, and then the value returned to the focal (central) cell. Continuously, the moving window goes through the grid until all valued cells containing a full window are mostly calculated. A new grid for each selected metric is the output of studying (Xinping Ye, 2008). 


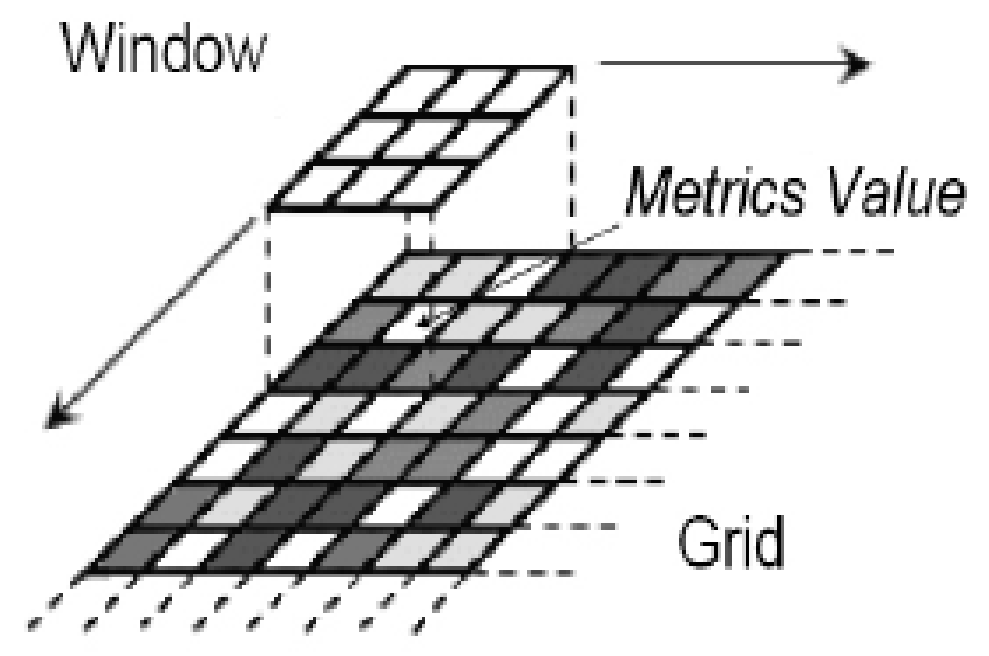

Figure 4.5 Moving window computation, Source: Xinping Ye (2008)

According to Antrop and Van Eetvelde (2000), all elements in the spatial structure of the landscape pattern are related to each other. One single metric alone cannot clarify the spatial characteristics of a landscape. So far, the few published studies have compared and suggested some different sets of metrics in analyzing landscape structure. Especially, these studies were focused more on economic landscape functions and land use/cover pattern (Herold et al., 2005). Most importantly, Parker et al. (2001) stated that there is no standard set of metrics which is best suited for a particular region because the significance of specific metrics are varied upon the objectives of research as well as characteristics of study area. Thus, the eight major landscape metrics were selected for studying based on own characteristics of study area and objectives of the thesis, including: (1) percentage of landscape, (2) number of patches, (3) largest patch index, (4) average size of patches, (5) patch density, (6) proximity index, (7) interspersion and juxtaposition index, and (8) landscape shape index (Table 4.6). These metrics were of particular interest for this study because they offer additional attributes for landscape types or region (Antrop and Van Eetvelde, 2000). In addition, their values deliver statistically meaningful information about change of land use and land cover over long period of times (Olsen et al., 2007). 
Chapter 4. Data \& Methods

According to McGarigal et al. (2012), some landscape metrics are partially or completely redundant. It means that these metrics quantify a similar or identical feature of landscape pattern. In some particular applications, metrics are used for a particular landscape under investigation instead of using to measure the same aspect of landscape pattern. In this case, the different aspects of landscape pattern are statistically correlated. However, it is also important to understand the redundancy, "because little can be learned by interpreting metrics that are inherently redundant, but much can be learned about landscapes by interpreting metrics that are empirically redundant”. In this study, we focus on the change of landscape structure between 1979 and 2009. Consequently, LULC maps of 1979 and 2009 were converted into Grid format by using ArcGIS 10.1 software for computing landscape metrics in FRAGSTATS ${ }^{\circledR}$. Further explanations and formula of the metrics are presented by McGarigal et al. (2012), as follows:

\begin{tabular}{|c|c|c|c|}
\hline Index & Unit & Description & Range \\
\hline PLAND & Percent & $\begin{array}{l}\text { Percentage of landscape-equals the sum of the } \\
\text { areas }\left(\mathrm{m}^{2}\right) \text { of all patches of the corresponding } \\
\text { patch type, divided by total landscape area }\left(\mathrm{m}^{2}\right) \text {, } \\
\text { multiplied by } 100 \text { to convert to a percentage }\end{array}$ & $\begin{array}{l}0<\text { PLAND } \\
\quad \leq 100\end{array}$ \\
\hline Formula & \multicolumn{3}{|c|}{$\begin{array}{l}P_{i}=\text { proportion of the landscape occupied by patch type (class) } i \\
a_{i j}=\text { area }\left(\mathrm{m}^{2}\right) \text { of patch } i j \\
A=\text { total landscape area }\left(\mathrm{m}^{2}\right)\end{array}$} \\
\hline NP & none & $\begin{array}{l}\text { Number of patches-equals the number of patches } \\
\text { of the corresponding patch type (class). }\end{array}$ & $\begin{array}{c}\mathrm{NP} \geq 1, \text { no } \\
\text { limit }\end{array}$ \\
\hline Formula & \multicolumn{3}{|c|}{$\begin{array}{l}\qquad \boldsymbol{N P}=\boldsymbol{n}_{\boldsymbol{i}} \\
\text { [4.20] } \\
n_{i}=\text { number of patches in the landscape of patch type (class) } i \text {; }\end{array}$} \\
\hline LPI & percent & $\begin{array}{l}\text { Largest patch index-equals the area }\left(\mathrm{m}^{2}\right) \text { of the } \\
\text { largest patch of the corresponding patch type } \\
\text { divided by total landscape area }\left(\mathrm{m}^{2}\right) \text {, multiplied by } \\
100 \text { to convert to a percentage }\end{array}$ & $0<\mathrm{LPI} \leq 100$ \\
\hline Formula & \multicolumn{3}{|c|}{$L P I=\frac{\max _{j=1}^{n}\left(a_{i j}\right)}{A}(100)$} \\
\hline
\end{tabular}


Chapter 4. Data \& Methods

\begin{tabular}{|c|c|c|c|}
\hline Index & Unit & Description & Range \\
\hline & \multicolumn{3}{|c|}{$\begin{array}{l}a_{i j}=\text { area }\left(\mathrm{m}^{2}\right) \text { of patch } i j \\
A=\text { total landscape area }\left(\mathrm{m}^{2}\right)\end{array}$} \\
\hline AREA_MN & hectares & Mean patch area-Average size of patches & $\begin{array}{l}\text { AREA_MN } \\
\geq 0, \\
\text { no limit }\end{array}$ \\
\hline Formula & \multicolumn{3}{|c|}{$a_{i j}=$ area $\left(\mathrm{m}^{2}\right)$ of patch $i j$} \\
\hline PD & $\begin{array}{l}\text { number } \\
\text { per } 100 \\
\text { hectares }\end{array}$ & $\begin{array}{l}\text { Patch density equals the number of patches of the } \\
\text { corresponding patch type divided by total } \\
\text { landscape area (m), multiplied by } 10,000 \text { and } 100 \\
\text { (to convert to } 100 \text { hectares). }\end{array}$ & $\begin{array}{c}\mathrm{PD} \geq 0 \\
\text { no limit }\end{array}$ \\
\hline Formula & \multicolumn{3}{|c|}{$\begin{array}{l}n_{i}=\text { number of patches in the landscape of patch type (class) } i \\
A=\text { total landscape area }\left(\mathrm{m}^{2}\right)\end{array}$} \\
\hline PROX_MN & meters & $\begin{array}{l}\text { Mean proximity equals the sum of patch area }\left(\mathrm{m}^{2}\right) \\
\text { divided by the nearest edge-to-edge distance } \\
\text { squared }\left(\mathrm{m}^{2}\right) \text { between the patch and the focal } \\
\text { patch of all patches of the corresponding patch } \\
\text { type whose edges are within a specified } \\
\text { distance }(\mathrm{m}) \text { of the } \\
\text { focal patch; Average proximity index for all } \\
\text { patches in a class }\end{array}$ & $\begin{array}{c}\text { PROX_MN } \\
\geq 0, \\
\text { no limit }\end{array}$ \\
\hline Formula & \multicolumn{3}{|c|}{$\begin{array}{l}a_{i j s}=\text { area }\left(\mathrm{m}^{2}\right) \text { of patch } i j s \text { within specified neighborhood }(\mathrm{m}) \text { of patch } i j \\
h_{i j s}=\text { distance }(\mathrm{m}) \text { between patch } i j s \text { and patch } i j s \text {, based on patch edge-to- } \\
\text { edge distance, computed from cell center to cell center }\end{array}$} \\
\hline IJI & percent & $\begin{array}{l}\text { Interspersion and juxtaposition index measures the } \\
\text { juxtaposition of a focal patch class with all other } \\
\text { classes }\end{array}$ & $0<\mathrm{IJI} \leq 100$ \\
\hline Form & & & \\
\hline
\end{tabular}


Chapter 4. Data \& Methods

\begin{tabular}{|c|c|c|c|}
\hline \multirow[t]{2}{*}{ Index } & Unit & Description & Range \\
\hline & \multicolumn{3}{|c|}{$\begin{array}{l}e_{i k}=\text { total length (m) of edge in landscape between patch types (classes) } \\
i \text { and } k \\
m=\text { number of patch types (classes) present in the landscape, including the } \\
\text { landscape border, if present }\end{array}$} \\
\hline LSI & none & $\begin{array}{l}\text { LSI equals . } 25 \text { (adjustment for raster format) times } \\
\text { the sum of the entire landscape boundary } \\
\text { (regardless of whether it represents 'true' edge or } \\
\text { not, or how the user specifies how to handle } \\
\text { boundary/background) and all edge segments (m) } \\
\text { within the landscape boundary involving the } \\
\text { corresponding patch type, including some or all of } \\
\text { those bordering background (based on user } \\
\text { specifications), divided by the square root of the } \\
\text { total landscape areas }\left(\mathrm{m}^{2}\right) \text {. }\end{array}$ & $\begin{array}{l}\text { LSI } \geq 1 \\
\text { no limit. }\end{array}$ \\
\hline Formula & $\begin{array}{l}e^{*}{ }_{i k}=\text { to } \\
i \text { and } k ; i \\
\text { edge seg } \\
A=\text { tot }\end{array}$ & $\begin{array}{l}\qquad \boldsymbol{L S I}=\frac{.25 \sum_{\boldsymbol{k}=1}^{m} \boldsymbol{e}_{\boldsymbol{i}}{ }^{*}}{\sqrt{\boldsymbol{A}}} \\
\text { ngth }(\mathrm{m}) \text { of edge in landscape between patch types } \\
\text { les the entire landscape boundary and some or all b } \\
\text { s involving class } i \\
\text { dscape area }\left(\mathrm{m}^{2}\right)\end{array}$ & $\begin{array}{l}\text { [4.26] } \\
\text { asses) } \\
\text { kground }\end{array}$ \\
\hline
\end{tabular}

Table 4.6 Descriptions of landscape pattern metrics

Adapted from (Keleş et al., 2008; McGarigal et al., 2012)

\subsection{Modeling land use/cover change}

The flowchart of the methodology used to simulate the changes of land use/cover in this study is presented in Figure 4.6. It includes two main parts: simulating temporal demand of land use/cover under various scenarios (non-spatial analysis) and simulating the allocation of land use/cover depending on scenarios (spatial analysis). 
Chapter 4. Data \& Methods

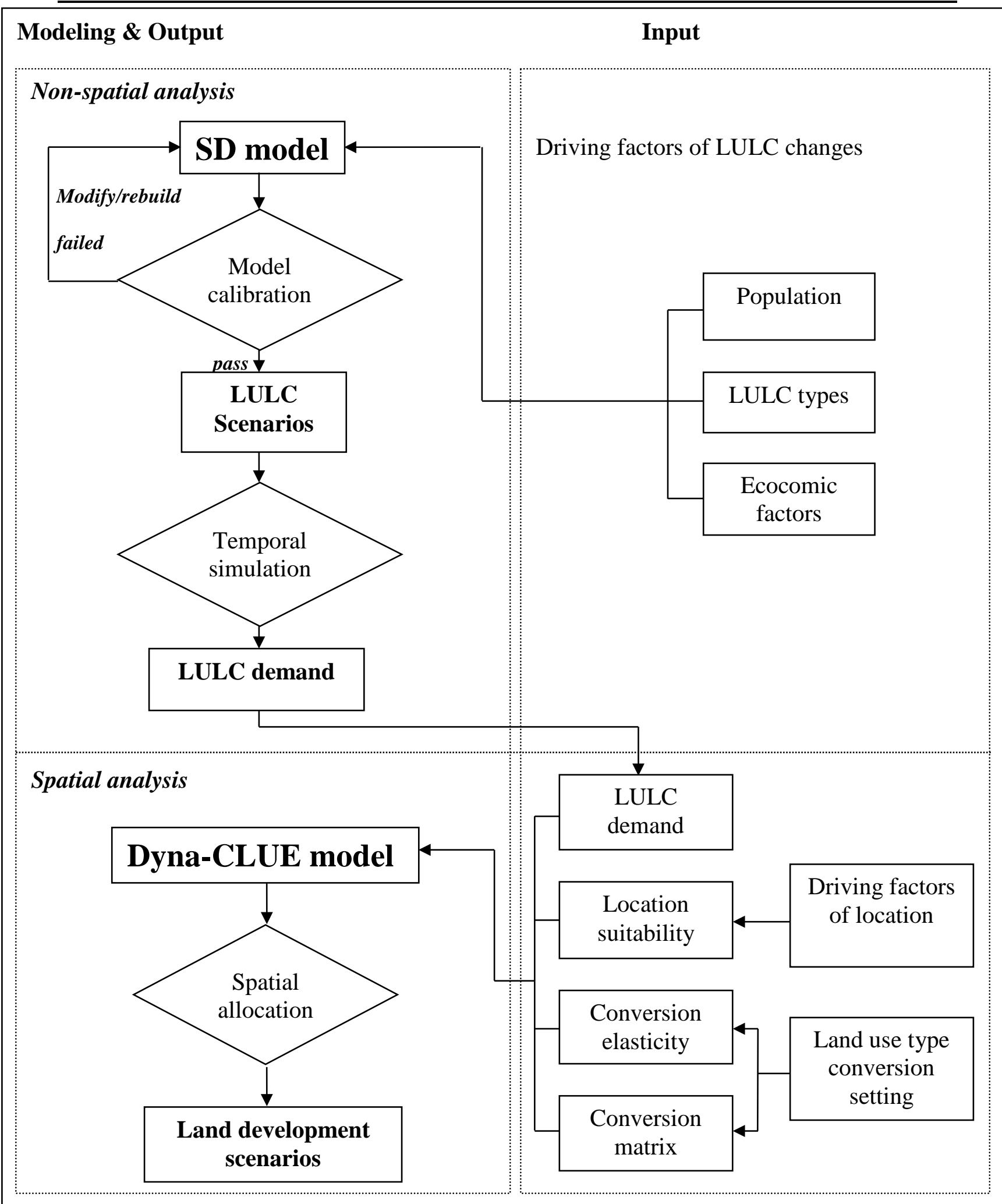

Figure 4.6 Flowchart of modeling land use/cover changes used in study

Adapted from Zheng et al. (2012) 
Chapter 4. Data \& Methods

According to Verburg and Overmars (2007), the demands for land use/cover types are calculated by the user in advance with different techniques, ranging from simple trend extrapolation (e.g. linear trend) to advanced models (e.g. macro-economic modeling changes). In this study, the system dynamics (SD) model is chosen for setting various control factors which allows observing and predicting the changes of land use/cover. Zheng et al. (2012) asserted that the SD model can help to answer the questions "When and how much does the land development take place according to different scenarios?”. In contrast to this, the Dyna-CLUE (Dynamic Conversion of Land Use and its Effects) model is applied to solve the question "Where does the land development possibly take place?" due to its capacity in describing the microcosmic and spatial factors. Consequently, the DynaCLUE model is created as a way of bridge building between temporal land demand and spatial supply.

\subsubsection{Non-spatial model}

\subsubsection{Conceptual model}

As pointed out by Radzicki and Taylor (2008), the system dynamic (SD) is a methodology and mathematical model technique to frame, understand, discuss, and simplify complex problems over time. This method was originally developed by JayForrester (1961) of the Massachusetts Institute of Technology, in which the interactions among various components of the system are studied by internal feedback loops and time delays. They are the two important components that reflect the behavior of the entire system. In SD model, the real-world is represented in terms of causal loop diagrams, flow and stock diagrams, and different equations. A causal loop diagram is a simple map of a system which is used to visualize all its constituent components and their interactions. Hence, it is possible to discover the system's behavior over a certain time period (Meadows, 2008). The correlational relationship between variables can be symbolized by arrows in positive or negative directions. It is indicted that in positive arrow two nodes changes in the same direction; meanwhile, the two nodes change in opposite directions in negative arrow. For more detailed quantitative analysis, a stock and flow diagram is performed. A stock is considered as any entity that accumulates or depletes over time; meanwhile, a flow is 
considered as the rate of change in a stock (Steven N. Durlauf and Blume, 2008). Once the model is structurally established, it needs a set of equations to describe each relationship. The equation is a simple algebraic expression to calculate the values of a specific variable, defining one variable in terms of others that are causally connected (http://vensim.com/docs/). An example of SD model is presented in Figure 4.7.

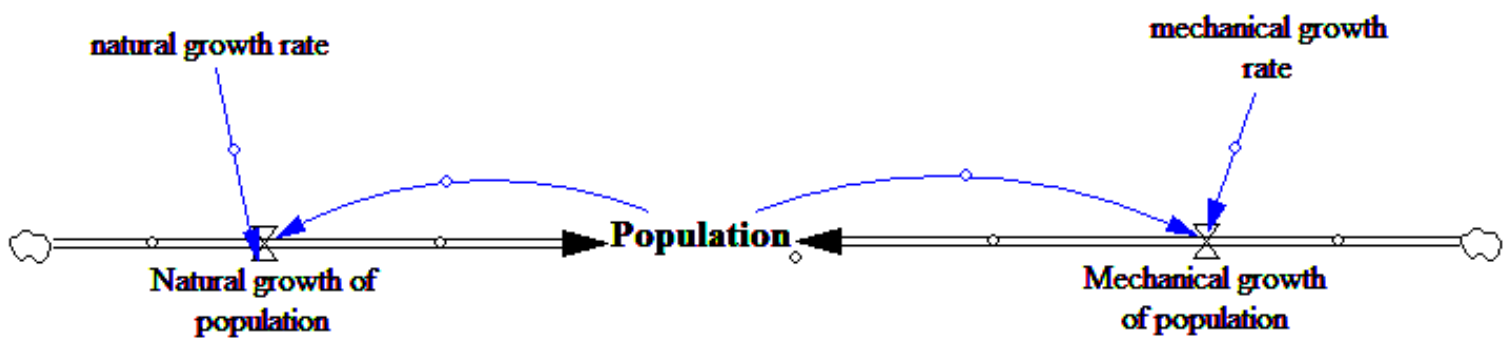

Figure 4.7 Example of SD model used in study (Source: Own calculation)

In which:

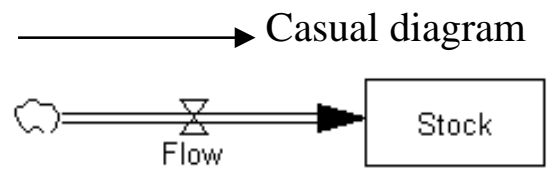

To look at the sketch view, mechanical growth rate has no cause; hence, it is a Constant in the model and has a numerical value. Mechanical growth of population is calculated as follows:

\section{Mechanical growth of population $=$ Population $*$ mechanical growth rate [4.27]}

User-friendly SD software was developed by the 1990s and has been applied in a wide range of areas, such as: population, environmental management, ecosystem assessment or economic systems. Some researchers have recently applied SD to predict the demands of land use/cover for land use planning and management by using socialeconomic conditions (Luo et al., 2010), for example: He et al. (2006) modeling urban expansion by using system dynamics model and cellular automata model in Beijing, China; Lee et al. (2009) coupling system modeling and spatial system modeling for simulating land use change of Taipei metropolitan area; Wang et al. (2011) applying SD model for changes in land use patterns under drought scenarios. It proves that the SD model is a useful tool to analyze the demand of land use/cover. 
Chapter 4. Data \& Methods

Generally, the SD model simulates the demand of land use/cover types based on natural and social-economic parameters. The natural driving forces may cause climate, landform conditions, distance conditions, and water availability (Wang et al., 2011); socialeconomic driving forces, including population density, population growth rate, economic factors, marketing conditions or technology advances, and macro-policy constrains (Luo et al., 2010). The natural factors are more stable and have a cumulative trend; socio-economic factors are more active in contrast (Wang et al., 2011). According to Lambin et al. (2001), the changes of land use/cover types in short term are mostly dominated under human activities. In this sense, only socio-economic factors are supposed to affect land use/cover changes.

\subsubsection{SD model setting}

The Ventana Vensim PLE v6.1 program (http://vensim.com) is used to construct system variables in different scenarios for the study. The SD model includes three subsystems, namely, Population, Economic factors, and Land use/cover types. As showed in Figure 4.8, population is the main social factor that affects the land use system from many aspects because of human life demands. The increase of population causes by the growth of builtup areas for residential demand or constructing factories. The larger population requires the higher demand of primary products, e.g. meat, food, water; hence, demanding areas for breeding and cultivation are increased (Zheng et al., 2012). In this study, the economy subsystem relates to the growth rate of Gross Output Industry (GOI) and Fixed-Assets Investment of construction (FAI). The increase in rate of GOI and FAI could lead mostly to the growth of demand in land use for construction. Generally, urban areas are expanded more and more at the expense of other land use/cover types, such as agriculture or forestry. Consequently, changes of population and economic subsystem result the increment or decrement in area of each dependent land use/cover type. More details about the relation among three kinds of subsystem are presented in Figure 4.8.

\section{(1) Predicted population}

The future population of Da Nang City is simulated as extrapolative approach according to natural and mechanical growth (Da Nang' s committee, 2012): 


$$
\boldsymbol{P}_{(t)}=\boldsymbol{P}_{(0)} \cdot e^{r t}
$$

In which:

$P_{(t)}$ : the simulated population at given time (2030)

$P_{(0)}$ : the population at the start of the simulation (1996)

$e=2.718$ (Euler's number)

$r$ : growth rate of population

$t$ : 35 years of simulation (from 1996 to 2030)

Figure 4.8 shows that the increase of population in Da Nang City is calculated based on the natural growth rate and mechanical growth rate of population. In which, natural growth rate is the rate of birth and death; mechanical growth rate is the rate of immigration and transmigration.

\section{(2) Cultivated area demand}

The demand of cultivated area can be obtained based on food security. The required number of land resources is achieved under the circumstances of ensuring the healthy life of the total population and the food demand in their basic development (Yang Long-fei et al., 2010). The calculation formula is given as follows:

$$
A_{d}=\frac{P_{t} \cdot F_{c} \cdot D_{s}}{Y_{a} \cdot R_{s}}
$$

In which:

$$
\begin{aligned}
& A_{d}: \text { regional land demand (ha) } \\
& P_{t}: \text { the total population (person) } \\
& F_{c}: \text { the per capita food demand ( } \mathrm{kg} / \text { per capita) } \\
& D_{s}: \text { the food self-sufficiency ratio }(\%) \\
& Y_{a}: \text { yearly food yield per unit area }(\mathrm{kg} / \mathrm{ha}) \\
& R_{s}: \text { rate of grain sowing }(\%)
\end{aligned}
$$




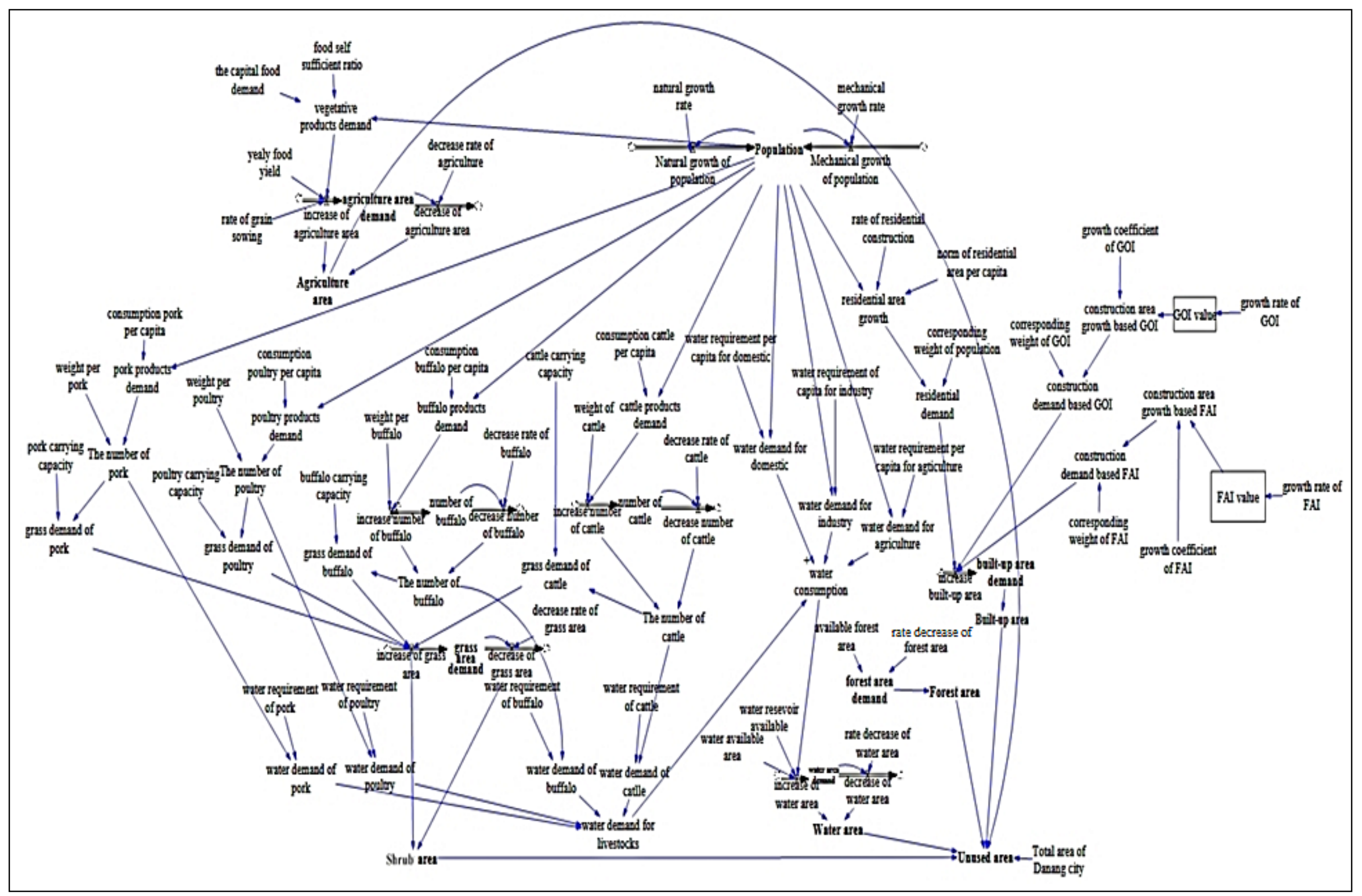

Figure 4.8 The SD model for simulating the demands of land use/cover in Da Nang City (Source: Own calculation) 
As can be seen from the formula [4.29], the demand of cultivated area $\boldsymbol{A}_{\boldsymbol{d}}$ depends on many indexes $\left(\boldsymbol{P}_{\boldsymbol{t}}, \boldsymbol{F}_{\boldsymbol{c}}, \boldsymbol{D}_{\boldsymbol{s}}, \boldsymbol{Y}_{\boldsymbol{a}}, \boldsymbol{R}_{\boldsymbol{s}}\right)$. In which, the total population index and per capita food demand index define the total food demand; whereas the yearly food yield per unit area and rate of grain sowing define the food production capacity of cultivated land. Thus, under the setting of the food self-sufficiency ratios, the regional land demand for agriculture primarily obtained from the total food demand and the food production capacity of cultivated land (Yang Long-fei et al., 2010).

\section{(3) Shrub area demand}

In this study region, livestock are generally grazed in shrub area instead of special grassland. Thus, demanding of shrub area can be simulated based upon the calculation of grassland. The demand of grassland is calculated by dividing the number of grazed livestock using the livestock carrying capacity of the grassland, as follows (Wang et al.,

$$
\text { 2011): } \quad S=\frac{N}{L}
$$

In which:

$S$ : the area of grass land

$N$ : represents the number of livestock

$L:$ the livestock carrying capacity of the grassland

\section{(3.1) Number of grazed livestock - $N$}

Consumption of livestock product can be estimated based on the population size. From which, we can compute the number of standard heads of grazed livestock by diving the consumption of livestock product using standard livestock units (Wang et al., 2011).

\section{(3.2) The livestock carrying capacity of the grassland - $\mathbf{L}$}

The livestock carrying capacity of the grassland can be calculated based on four indices: the grass production per unit area of grassland, the grassland utilization rate, the number of grazing days, and the number of grazing days, as follows (Wang et al., 2011):

$$
\boldsymbol{L}=\frac{\boldsymbol{B} \cdot \boldsymbol{E}}{\boldsymbol{D} \cdot \boldsymbol{F}}
$$


In which:

$B$ : the grass production per unit area of grassland

$E$ : the grassland utilization rate

$D$ : the number of grazing days

$F$ : the number of grazing days

(4) Residential and industrial area demand

According to Wang et al. (2011), the demand of residential and industrial area can be calculated from population, gross output industry and fixed-assets investment of construction factors, which are mutually influenced and restricted to each other. The residential and industrial land can be obtained according to formula:

$$
U=U_{1} R_{1}+U_{2} R_{2}+U_{3} R_{3}
$$

In which:

$U$ : the area of residential and industrial land

$U_{1}, U_{2}, U_{3}$ : represents the area of urban construction predicted as a function of (respectively) population size, gross output industry, fixed-assets investment of construction

$R_{1}, R_{2}, R_{3}$ : the corresponding weights of population, gross output industry, fixed-assets investment of construction, respectively

(4.1) Calculate construction area based on population size - $\boldsymbol{U}_{\mathbf{1}}$

According to (Shao et al., 2006), construction demanding area can be obtained from formula:

$$
U_{1}=\frac{A}{a_{0}}
$$

In which:

A: total residential area

$\mathrm{a}_{0}$ : rate of residential construction

Where: 
$\mathrm{A}=$ normalization of residential area per capita ( $\mathrm{m}^{2} /$ person). Population (person)

$$
\mathbf{a}_{0}=\frac{\text { construction area }\left(m^{2}\right)}{\text { urban area }\left(m^{2}\right)}
$$

(4.2) Calculate construction area based gross output industry - $\boldsymbol{U}_{2}$

$$
\boldsymbol{U}_{2}=\boldsymbol{q} \cdot \boldsymbol{t}
$$

In which:

q: gross output industry (bill VND)

$t$ : growth coefficient of gross output industry (ha/bill VND)

(4.3) Calculate construction area based fixed-assets investment of construction $-\boldsymbol{U}_{3}$

$$
\boldsymbol{U}_{3}=\boldsymbol{Q} \cdot \boldsymbol{T}
$$

In which:

Q: fixed-assets investment (bill VND)

$T$ : growth coefficient of fixed-assets investment (ha/bill VND)

(4.4) Calculate the corresponding weights $\boldsymbol{R}_{\mathbf{1}}, \boldsymbol{R}_{\mathbf{2}}, \boldsymbol{R}_{\mathbf{3}}$

Grey's correlation analysis can be used to calculate the corresponding weights by quantitatively compare correlations among factors in system. In this approach, the closeness of correlation is distinguished by the degree of similarity of the geometrical shapes of different time series. Thus, the more similar the curves are, the closer the correlation is. The calculation steps of urban area using grey's correlation analysis are given as follows (Men Ke-pei and Kai, 2010):

a) Establish the reference and comparison sequences. Firstly, residential and industrial demand is determined as reference sequence as following equation:

$$
X_{0}=\left\{x_{0}(1), x_{0}(2), \ldots, x_{0}(n)\right\}
$$

In which:

$n$ : the number of indexes

Then, the comparison sequence of related factors is determined as:

$$
\boldsymbol{X}_{\boldsymbol{i}}=\left\{\boldsymbol{x}_{\boldsymbol{i}}(\mathbf{1}), \boldsymbol{x}_{\boldsymbol{i}}(\mathbf{2}), \ldots, \boldsymbol{x}_{\boldsymbol{i}}(\boldsymbol{n})\right\},(\text { with } i=1,2, \ldots, m)
$$


In which:

$i$ : the number of comparison sequence

$m$ : comparison objects

b) Calculate the initial value of each sequence. Each object has its own unit of measurement. Thus the following formula is used to eliminate the impact of the units of measurement among the sequences of number.

$$
\begin{aligned}
\qquad \boldsymbol{X}^{\prime} & =\frac{\boldsymbol{X}_{\boldsymbol{i}}}{\boldsymbol{x}_{\boldsymbol{i}}(\mathbf{1})}=\left\{\boldsymbol{x}_{i}^{\prime}(\mathbf{1}), \boldsymbol{x}_{i}^{\prime}(\mathbf{2}), \ldots, \boldsymbol{x}_{\boldsymbol{i}}^{\prime}(\boldsymbol{n})\right\} \\
\text { (with } i & =1,2, \ldots, m \text { ) }
\end{aligned}
$$

c) Calculate the evaluation of maximum and minimum difference.

$$
M=\max _{i} \max _{k} \Delta_{i}(k), \boldsymbol{m}=\min _{i} \min _{k} \Delta_{i}(k)
$$

Where: $\Delta_{i}(\boldsymbol{k})=\left|\boldsymbol{x}^{\prime}{ }_{\mathbf{0}}(\boldsymbol{k}), \boldsymbol{x}^{\prime}{ }_{\boldsymbol{i}}(\boldsymbol{k})\right|$

(with $k=1,2, \ldots, n ; i=1,2, \ldots, m$ )

d) Evaluate the correlation coefficient

$$
\gamma_{0 i}(k)=\frac{m+\xi M}{\Delta_{i}(k)+\xi M^{\prime}}
$$

(with $k=1,2, \ldots, n ; i=1,2, \ldots, m$ )

$$
\xi \in(0,1) \text { is the resolution coefficient, generally, } \xi=0.5
$$

The mean of each correlation coefficient sequence is calculated based on equation [4.41]:

$$
\bar{\gamma}_{0 i}=\frac{1}{n} \sum_{k=1}^{n} \gamma_{0 i}(k)
$$

(with $i=1,2, \ldots, m)$

e) Calculate the stability formula which is given by:

$$
S\left(\gamma_{0 i}\right)=\sqrt{\frac{1}{n} \sum_{k=1}^{n}\left(\gamma_{0 i}-\bar{\gamma}_{0 i}\right)^{2}}
$$

$$
\text { (with } i=1,2, \ldots, m \text { ) }
$$

f) Evaluate the grey similarity correlation degree: 


$$
\boldsymbol{R}_{0 i}=\frac{\gamma_{0 i}}{1+S\left(\gamma_{0 i}\right)}
$$

(with $i=1,2, \ldots, m$ )

The degrees of correlation $\boldsymbol{R}_{\boldsymbol{i}}$ among the influences of population, gross output industry and fixed-assets investment of construction and the area of residential and industrial demanding area range from 0 to 1 . These values are used as corresponding weights to calculate residential and industrial area demand in formula [4.32]. All correlations are computed by the aid of MATLAB 7.0.

(5) Water area demand

In order to simulate water area, the water demand for all needs is firstly examined. The future water demand includes the purposes of agricultural, industrial, domestic activities, and livestock activities. The method of demand forecasting of water is based on the method of Lawgali (2008) as follows:

$$
W=W_{A}+W_{I}+W_{D}+W_{L}
$$

In which:

$W$ : the total water demand

$W_{A}, W_{I}, W_{D}, W_{L}$ : the water demand for the purposes of agricultural, industrial, domestic use, and livestock, respectively

Where:

$W_{A}, W_{I}, W_{D}=f$ (population, water requirement per capita for agricultural, industrial, domestic use, respectively)

$W_{L}=f$ (number of livestock, water requirement per livestock)

(6) Forest area demand

Generally, the forest area can be determined based on the assumption of forest products demand as the approach which was described by (Brooks et al., 1995). According to Kangas and Baudin (2003), this approach benefits because it involves all aspects, 
including consumption, production, imports, and exports. It is solved by the following system of equations:

$$
\begin{aligned}
\mathbf{Q}^{D_{D}} & =\mathbf{f}\left(\mathbf{P}_{\mathrm{d}}, \mathbf{P}_{\mathrm{m}}, \mathbf{D}^{\mathbf{D}}\right) \\
\mathbf{Q}^{\mathbf{M}} & =\mathbf{f}\left(\mathbf{P}_{\mathrm{d}}, \mathbf{P}_{\mathrm{m}}, \mathbf{D}^{\mathbf{M}}\right) \\
\mathbf{Q}_{\mathrm{S}}^{\mathbf{D}} & =\mathbf{f}\left(\mathbf{P}_{\mathrm{d}}, \mathbf{P}_{\mathrm{x}}, \mathbf{S}^{\mathbf{D}}\right) \\
\mathbf{Q}^{\mathrm{X}} & =\mathbf{f}\left(\mathbf{P}_{\mathrm{d}}, \mathbf{P}_{\mathrm{X}}, \mathbf{S}^{\mathrm{X}}\right)
\end{aligned}
$$

In which:

$\mathrm{Q}^{\mathrm{D}}{ }_{\mathrm{D}}$ : demand for domestically-produced goods,

$\mathrm{Q}^{\mathrm{M}}$ : import demand,

$\mathrm{Q}^{\mathrm{S}}{ }_{\mathrm{D}}$ : supply to domestic markets $\left(\mathrm{Q}^{\mathrm{S}}{ }_{\mathrm{D}}=\mathrm{Q}^{\mathrm{D}}{ }_{\mathrm{D}}\right)$

$\mathrm{Q}^{\mathrm{X}}$ : supply to export markets,

$\mathrm{P}_{\mathrm{d}}$ : the price in domestic markets,

$\mathrm{P}_{\mathrm{m}}$ : the import price,

$\mathrm{P}_{\mathrm{x}}$ : the export price,

$\mathrm{D}^{\mathrm{D}}$ : demand shifters for the domestic market,

$\mathrm{D}^{\mathrm{M}}$ : demand shifters for import demand,

$S^{D}$ : supply shifters for the domestic market,

$\mathrm{S}^{\mathrm{X}}$ : supply shifters for the export market,

However, due to the unavailability and complexity of these data, the rate decrease of forest area obtained from Statistical Year Books is chosen to calculate demand of forest area as alternative approach for this study. Detailed information could be seen in Figure 4.8.

(7) Unused area

After defining the demands of agriculture, forest, urban, shrub, and water area, it is possible to estimate the unused area by the following equation: 


$$
\mathbf{U}_{\mathrm{s}}=\mathbf{T}-\mathbf{A}_{\mathbf{d}}-\mathbf{U}-\mathbf{F}-\mathbf{S}-\mathbf{W}
$$

In which:

$\mathrm{U}_{\mathrm{s}}$ : unused area,

T: total area of Da Nang City (excluding area of Paracel islands, $\mathrm{T}=96817.2$ ha)

$\mathrm{A}_{\mathrm{d}}$ : agricultural area

$\mathrm{U}$ : urban area

F: forest area

S: shrub area

W: water area

\subsubsection{SD model calibration and validation}

Before using the results of the SD model as the input of Dyna-CLUE, it is necessary to assess whether the SD model predicts the demand of land use/cover correctly (Pontius et al., 2004). In this case, calibration and validation are also required. Calibration is the process of "estimation and adjustment of the model parameters and constraints to improve the agreement between model output and a data set", while model validation is "a demonstration that a model within its domain of applicability possesses a satisfactory range of accuracy consistent with the intended application of the model” (Rykiel, 1996).

From the data of initial year 1996, population, economic factors, and land use cover/types each year in Da Nang City are calculated based on formulas mentioned above. In this study, historical statistics obtained from Statistical Yearbook of Da Nang city are used to calibrate the SD model, and data obtained from classified LULC maps in year 2003 and 2009 are employed to validate the results of SD model.

\subsubsection{Spatial model}

The CLUE (Conversion of Land Use and its Effects) modeling frame work was first created by Veldkamp and Fresco (1996). The empirical model is used to define the processes in changing spatial pattern and estimate possible future changes of land 
use/cover. This modeling level was specifically developed through the spatially explicit analysis between land use/cover and its driving factors under different scenarios conditions (Verburg and Overmars, 2007).

Originally, the CLUE model was applied to national, e.g., Costa-Rica (Veldkamp and Fresco, 1996), Ecuador (de Koning et al., 1999), China (Verburg et al., 2000) and supra-national, e.g., Central-America (Kok and Winograd, 2002) extent with coarse spatial resolutions varying from $7 \times 7$ kilometers to $32 \times 32$ kilometers to identify the critical areas of land use/cover changes. Consequently, this could lead to large biases in land use/cover definition because of the diminishing or increasing of class proportions as the pixel size (Verburg et al., 2002). Because of the increasingly requirement in impacts assessment of land use/cover change through landscape pattern, high spatial resolution represented by homogeneous spatial unit is more suitable. Moreover, it is needed to know exactly where the allocations of land use/cover changes are (Verburg and Overmars, 2007). Hence, later versions of CLUE model, the CLUE-S model and Dyna-CLUE (Dynamic Conversion of Land Use and its Effects) model were developed by Peter Verburg and colleagues at Wageningen University and worldwide (Verburg and Overmars, 2009; Verburg et al., 1999; Verburg et al., 2002). These models have been applied to regional extent with spatial resolution ranging from 20 x 20 meters to $1,000 \times 1,000$ meters, in which each pixel is used as one type of land use/cover (Verburg and Overmars, 2007).

In this study, Dyna-CLUE is chosen for modeling the changes of land use/cover in Da Nang City. The following subsections describe more in details the structure and functioning of Dyna-CLUE model, through which the processes of setting up the model are presented.

\subsubsection{Dyna-CLUE model structure}

The Dyna-CLUE is an upgraded version of the CLUE-S methodology, in which the spatial allocation of land use/cover demands are defined as individual grid cells (Verburg, 2010). In Dyna-CLUE model approach, “the top-down allocation of land use/cover change is combined with a bottom-up determination of conversions for 
specific land use transitions to grid cells”. This method is particularly suitable for land user/cover types where the demand is mutually affected by driving factors.

As showed in Figure 4.9, the first analysis starts in regional level in determining land use/cover are considered or separated as two groups: those demand-driven and those which are not aggregate. As the result, the net change of the demand-driven land use/cover is correspondingly with the overall change in area of no-aggregate group. Afterwards, the land use/cover demands are allocated into individual grid cells at local level through the iteratively comparing the allocated area of the individual land use/cover types with the demanded areas for a given simulation year until getting a satisfactory model solution (Verburg and Overmars, 2009). Figure 4.10 presents the flowchart of allocation procedure in Dyna-CLUE model, which determines location (i) of land use/cover type $(l u)$ at time $(t)$ with the highest total probability (Ptot $\left.{ }_{i, t, l u}\right)$. The total probability is computed as the sum of the location suitability ( $\operatorname{Ploc}_{i, t, l u}$ ), neighborhood suitability $\left(P n b h_{i, t, l u}\right)$, conversion elasticity (elas $\left.{ }_{l u}\right)$ and competitive advantage (comp $\left.\mathrm{c}_{t, l u}\right)$ as follows (Verburg and Overmars, 2009):

$$
\text { Ptot }_{i, t, l u}=\text { Ploc }_{i, t, l u}+P_{n b h} h_{i, t, l u}+\text { elas }_{l u}+\operatorname{comp}_{t, l u}
$$

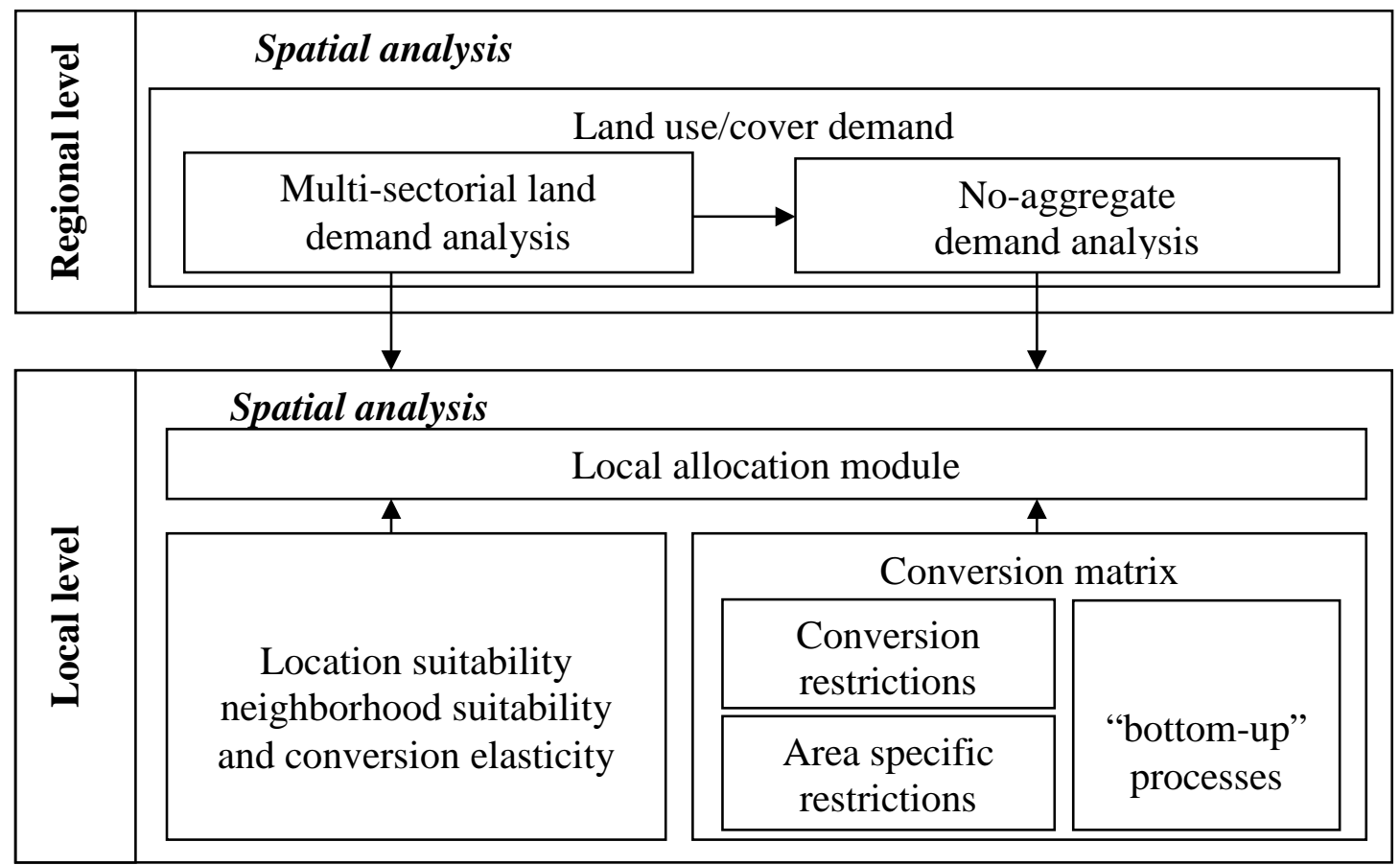

Figure 4.9 Framework of the Dyna-CLUE model

Adapted from Verburg and Overmars (2009) 


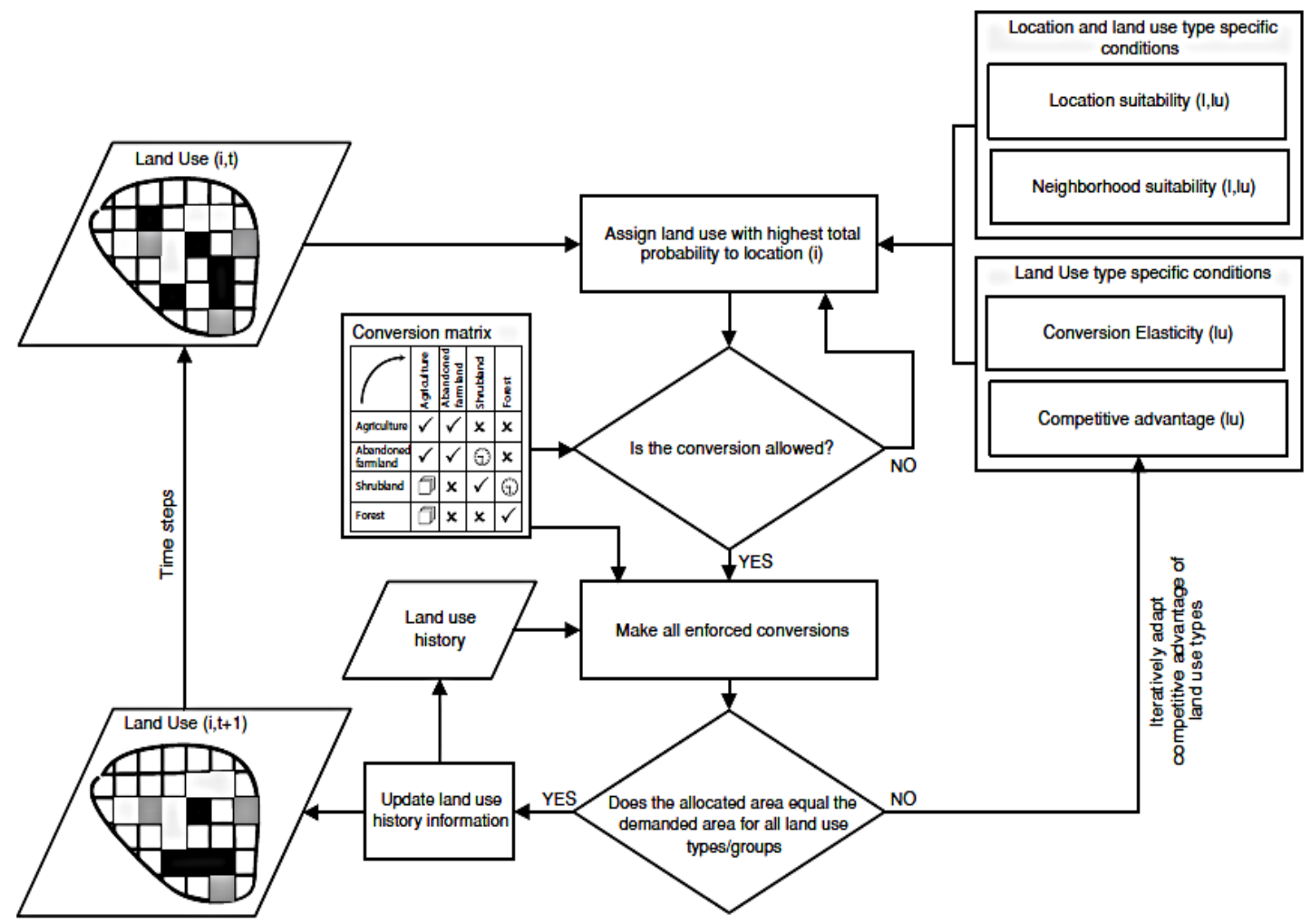

Figure 4.10 Flowchart of the Dyna-CLUE model

Source from Verburg and Overmars (2009)

According to Verburg and Overmars (2009), location suitability (Ploc $i, t, l u$ ) and neighborhood suitability $\left(P n b h_{i, t, l u}\right)$ are obtained based on empirical methods as well as process and expert knowledge, and the dynamic analysis of neighborhood interactions. The conversion elasticity ( $\operatorname{elas}_{l u}$ ) measures the expense of one land use/cover type to another. This parameter is assigned to those locations where the land use/cover type is found at the time $t$. In contrast to this, the competitive advantage $\left(\operatorname{comp}_{t, l u}\right)$ is iteratively applied to all land use/cover types during procedure. Based on conversion matrix, the maximization of the total probability $\left(\right.$ Ptot $\left._{i, t, l u}\right)$ is controlled at each individual location.

\subsubsection{Dyna-CLUE model setting}

\section{(1) Location suitability - Ploc $i, t, l u$}

As pointed out by Lambin et al. (2001), land use/cover changes result from a set of explanatory factors, such as socio-economic and biophysical drivers as well as the place-based, and human environment conditions. In Dyna-CLUE, land use/cover 
conversion involves a change from one cover type to another which is taken place at locations that have the highest "preference" of suitability at the moment in time. The preference of a location is generally determined by the explanatory factors which are chosen from the knowledge of user about the dominant factors caused the change of land use/cover in the study area. The preference is calculated as follows (Verburg et al., 2008):

$$
R_{k, i}=a_{k} X_{1, i}+b_{k} X_{2, i}+\cdots+n_{k} X_{n, i}
$$

In which:

$R_{k, i}$ : the preference to devote location $i$ with land use type $k$

$X_{1,2}$ : biophysical or socio-economical characteristic of location $i$

$a_{k}, b_{k}, n_{k}$ : the relative impact of these characteristics on the preference for land use type $k$

However, the preference $R_{k, i}$ cannot be computed directly. Thus, the relative probabilities in finding the difference of land use/cover types at that location upon biophysical and socio-economic factors are calculated as the alternative. A logistic model (Binary Logistic Regression) is presented as follows (Verburg et al., 2005):

$$
\log \left(\frac{P_{i}}{1-P_{i}}\right)=\beta_{0}+\sum_{j=0}^{n} \beta_{j} X_{j, i}
$$

In which:

$P_{i}$ : the probability of a grid cell for the occurrence of the considered land use type on location $i$

$X_{, j, i}:$ the $j$ location factor affecting the suitability of land use type $i$

$\beta_{n}$ : regression values, obtained from the binary logistic regression model

The coefficient $\left(\beta_{n}\right)$ is estimated by logistic regression procedure of SPSS Statistics package 20; in which, each type of land use/cover is dependent variable, and the expected driving factors are independent variables. For selecting the relevant factors from the list of expected driving factors, a stepwise regression of logistic regression 
model is setup correctly. Variables without significant contribution to the change of land use/cover types are excluded from the final regression formula (Verburg et al., 1999). In addition, it is needed to evaluate the goodness of model fit. However, the least squares regression $\left(R^{2}\right)$, which is commonly used for measuring the model fit, is not suitable for logistic regression (Verburg et al., 2005). Instead, the Relative Operating Characteristic (ROC) method is therefore chosen for this purpose (Pontius and Schneider, 2001). More details on this method and its utility are presented in model validation.

(2) Neighborhood suitability - Pnbh $\boldsymbol{h}_{i, t, \mathbf{l u}}$

The conversion of land use/cover type can be exerted partly by the neighborhood of a location relative to the occurrence of this land use type/cover type through the enrichment factor $(F)$, which is given as follows(Verburg et al., 2005):

$$
F_{i, k, d}=\frac{n_{k, d, i} / n_{d, i}}{N_{k} / N}
$$

In which:

$F_{i, k, d}$ : characterizes the enrichment of neighborhood $d$ of location $i$ with land use type $k$ $n_{k, d, i}:$ the number of cells of land use type $k$ in the neighborhood with size $d$ of cell $i$

$n_{d, i}:$ the total number of cells in the neighborhood

$N_{k}$ : the number of cells with land use type $k$ in the whole raster

$N$ : the total number of cells in the raster

In Dyna-CLUE model, the relations between the probabilities $P$ of a location $i$ and the enrichment factors are computed as a logit model. It is similar to the logit model of socio-economic and biophysical location factors:

$$
\log \left(\frac{P_{i}}{1-P_{i}}\right)=\beta_{0}+\sum_{j=0}^{n} \beta_{j} F_{j, i}
$$

The coefficient $\left(\beta_{n}\right)$ is calculated from the enrichment factor. 


\section{(3) Conversion elasticity - elas lu}

Conversion elasticity, known as one of the specific coefficients of Dyna-CLUE model, is used to determine the resistance of each land use/cover type to the conversions (Khoury, 2012). This coefficient is specified by the user upon the expert knowledge or observed manner of each land use/cover type in the recent past and ranges from 0 (easy conversion) to 1 (irreversible change) (Verburg, 2010). In other words, the closer the value of conversion elasticity comes to 0 , the easier the land use/cover conversion is; the closer the value of conversion elasticity comes to 1 , the harder the land use/cover conversion is (Khoury, 2012). Verburg (2010) explained the possible values of the conversion elasticity as follows:

0: All changes of land use/cover type are permitted.

$>0>1$ : Land use/cover type is permitted to convert. In which, the higher the value indicates the more difficult in converting land use/cover type given in a special location. Generally, this setting relates to the high conversion costs of land use/cover types.

\section{1: Land use/cover type can never change.}

\section{(4) Competitive advantage - comp $_{t, l u}$}

During the iterative procedure, competitive advantage is defined for all kinds of land use. This value is increased in case allocated area is smaller than demanded area. Conversely, it is decreased when allocated area goes beyond the demanded area. If demand of a certain land use/cover type increases, the value of the competitive advantage also increase; whereas, it gets lower values in case the demand of one land use type decreases. In case of group land use/cover types, there is only a value of competitive advantage which is set for the whole group. This is because the demands of areas are not specified for any individual land use/cover type within the group (Verburg, 2010). 


\section{(5) Conversion matrix}

In Dyna-CLUE model, a conversion matrix is defined to indicate the converted capability of land use/cover types and their temporal dynamic of characteristics (Verburg, 2010). This matrix is created from the number of land use/cover types available in the study area, where rows and columns denote the present and potential future land use/cover types, respectively. At each corresponding cell of matrix, the value " 1 " is assigned if the land use/cover type can be converted, if not, it is assigned as value "0" (Khoury, 2012). An example of conversion matrix with three land use type would be found in Table 4.7.

\begin{tabular}{cccc}
\hline Land use/cover & Forest & Agriculture & Grassland \\
\hline Forest & 1 & 1 & 1 \\
Agriculture & 0 & 1 & 1 \\
Grassland & 0 & 1 & 1 \\
\hline
\end{tabular}

Table 4.7 Example of conversion matrix with three land use types (Source: Own calculation)

\subsubsection{Accuracy assessment of model}

For accuracy assessment, we applied three different approaches. First, logistic regression model is assessed with the Relative Operating Characteristic (ROC) method. Second, we performed a visual comparison based on two pairs of maps: reference maps of year 1996 and 2003, reference map of year 1996 and simulated map of year 2003. Finally, simulation results were precisely evaluated with the corresponding values from a statistical database.

Rykiel (1996) asserted that any land-use change model system of specific region must be calibrated to improve its goodness of fit. Typically, land-use change model is calibrated upon the historical data. Hence, this process needs two land use/cover maps: one for the start of simulation period $\left(t_{0}\right)$ and one for the simulation period $\left(t_{1}\right)$. The simulated land-use map at $\left(t_{1}\right)$ is then compared with actual/reference land use/cover map at $\left(t_{1}\right)$. For validation, the simulated land-use map at $\left(t_{2}\right)$ is then compared with actual/reference land use/cover map at $\left(t_{2}\right)$. As can be seen, both calibration and 
validation process do the same activities in comparing simulated land use/cover map and actual/reference land use/cover map at the same period. However, these processes are different in other purpose. Calibration looks for opportunity to improve its accuracy by changing model's parameters, while validation is used for independently evaluating quality of simulated land use/cover maps.

\subsubsection{Relative operating characteristic (ROC)}

As mentioned above, it is necessary to evaluate the goodness of fit of logistic regression model prediction. For this purpose, the ROC method is chosen as the quantitative measurements (Verburg et al., 2005). A ROC curve is plotted by the True Positive Rate (TPR). The TPR defines the proportion of correct positive results occur among all positive samples available during the test, whereas False Positive Rate (FPR) defines the occurrence of the incorrect positive proportion among all negative samples available in the test. These results could be summarized based on a contingency table. As shown in Table 4.8, the columns indicate the occurrence of certain categories (event) and the rows indicate the output of model prediction (diagnosis). The occurrence of a certain land use/cover type is positive and the non-occurrence is negative. Pontius and Schneider (2001) asserted that "the entries are the number (or proportion) of cells that fall into each category combination”. Consequently, the correct proportion is calculated as $(\mathrm{A}+\mathrm{D}) /(\mathrm{A}+\mathrm{B}+\mathrm{C}+\mathrm{D})$.

\begin{tabular}{cccc}
\hline \multirow{2}{*}{ Diagnosis } & \multicolumn{3}{c}{ Event } \\
\cline { 2 - 4 } & Positive & Negative & Total \\
\hline Positive & $\mathrm{A}$ & $\mathrm{B}$ & $\mathrm{A}+\mathrm{B}$ \\
Negative & $\mathrm{C}$ & $\mathrm{D}$ & $\mathrm{C}+\mathrm{D}$ \\
Total & $\mathrm{A}+\mathrm{C}$ & $\mathrm{B}+\mathrm{D}$ & $\mathrm{A}+\mathrm{B}+\mathrm{C}+\mathrm{D}$ \\
\hline
\end{tabular}

Table 4.8 Two-by-two contingency table

Source from (Pontius and Schneider, 2001)

In which:
A: True-positive
B: False-positive 


\section{$\mathrm{C}$ : False-negative \\ D: True-negative}

The cells A and D are the ways that an event agrees with the prediction (positive or negative), while the cells $\mathrm{B}$ and $\mathrm{C}$ are the ways of disagreement of event to prediction (positive or negative). The true-positive proportion $(A / A+C)$ and the false-positive proportion $(\mathrm{B} / \mathrm{B}+\mathrm{D})$ are obtained on the vertical and the horizontal axes, respectively (Engelsman, 2002). Based on the results of each comparison in the sequence, the ROC curve is constructed by the area under the curve which is in a coordinate system with the FP-rate on the $\mathrm{x}$-axis and the TP-rate on the $\mathrm{y}$-axis. The ROC curve starts at the point $(\mathrm{FP}=0, \mathrm{TP}=0)$, and ends at the point $(\mathrm{FP}=1, \mathrm{TP}=1)(\mathrm{J}$. Koch, 2012). The area under the curve (AUC) is computed by trapezoidal approximation, as follows (Pontius and Schneider, 2001):

$$
\text { Area dunder curve }=\sum_{i=1}^{n}\left[x_{i+1}-x_{i}\right]\left[y_{i}+y_{i+1}-y_{i} / 2\right]
$$

In which:

$x_{i}$ : the rate of false-positives for scenarios $i$

$y_{i}$ : the rate of true-positives for scenarios $i$

$n$ : the number of suitability groups

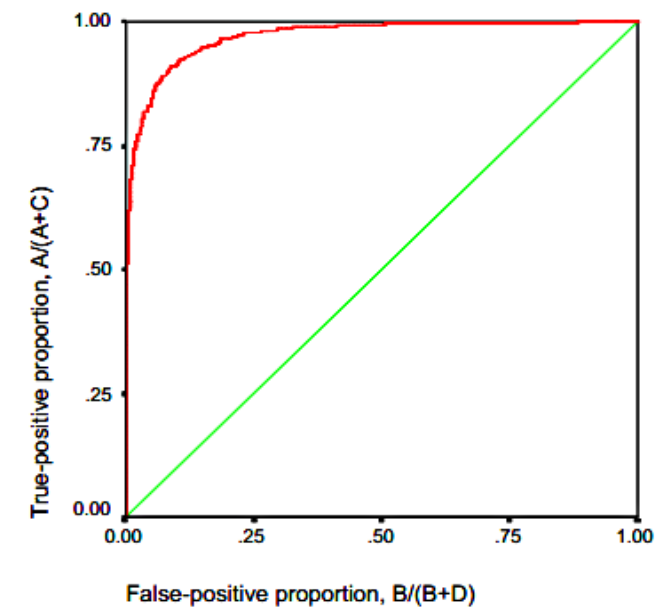

Figure 4.11 Example of ROC curve = 0.970, area under the curve (forest)

Source from (Engelsman, 2002) 
The value of AUC typically ranges from 0.5 to 1 as shown in Figure 4.11. If this area is equal to 1 (the true-positive rate is 1 and false-positive is 0 ), then the discrimination of logistic regression is perfect. On the other hand, if the ROC curve area is 0.5 (true and false-positive rates are equal), then the logistic regression model does not fully predict the changes better than any random approach (Orekan, 2007).

We performed separately ROC analyses for each land use/cover type. The higher the ROC value is, the better the fit of logistic regression is. The spatial distribution of land use/cover system within the study area can be determined by the selected driving factors at high ROC value.

\subsubsection{Visual comparison}

According to Pontius and Chen (2006), it is necessary to examine the simulation maps by visual comparison, which is the quickest way to have a glance at spatial pattern. By which, the user could decide to invest more time to improve the model or not. Pontius Jr et al. (2004) proposed some effective techniques in validating the spatially explicit of land use/cover change models, such as: three-way map comparison, error budget, multiple resolution comparison, null resolution. Accordingly, we carried out three-map comparison as visual approach, between the pair of land use/cover maps extracted from remote satellite data in year 1996 and 2003, which we considered as the actual or reference land use/cover maps. On the one hand, the second pair of maps is between the actual/reference map of year 1996 and the simulation map of year 2003. This was done by the aid of Map Comparison Kit (MCK) without area restriction (Visser and de Nijs, 2006).

\subsubsection{Model output validation}

In recent years, land-use change models have been increasingly used to analyze dynamic change of land use/cover system, by which spatial policy making could be supported (van Vliet et al., 2011). In this circumstance, it is important to comprehensively assess the accuracy of simulated maps for scientific use as well as policy analysis. Together with visual examination, simulated maps are comprehensively assessed how the model predicts correct location of land use/cover types. 
Validation of land-use change model is typically based on pixel-by-pixel comparison between simulated land use/cover map and reference land use/cover map. As mentioned in section 4.4.2, Kappa coefficient of agreement is well known as a common method in a long time. However, some authors recently argued that Kappa has not been the appropriate measure for accuracy any longer (van Vliet et al., 2011). Alternatively, Pontius Jr et al. (2004) presented a validation technique used to determine the agreement of land-change model between two pairs of maps, which are achieved over the combination of three maps: reference maps of from time $t_{1}$ to time $t_{2}$, simulated map of time $t_{2}$. The first comparison is based on the reference map of time $t_{1}$ and the reference map of time $t_{2}$. Continuously, the second comparison between predicted map of time $t_{2}$ and the reference map of time $t_{2}$ is calculated. To evaluate the performance of simulation model, the first comparison is examined with the second comparison upon the observed indicators, including: disagreement due to quantity, disagreement due to location, agreement due to location, agreement due to quantity, and agreement due to chance. Then, all three maps are coarsened the resolution by aggregation until the simulation result is more accurate than the no-change model and thus find the "null resolution". However, van Vliet et al. (2011) asserted that the given statistics do not include a reference level. Hence, it is not possible to know the absolute value of model's accuracy. Afterwards, alternative approaches in assessing accuracy of land-use change model were developed by Chen and Pontius (2010) and Hagen-Zanker and Lajoie (2008). However, these methods are still indirect measures. Therefore, van Vliet et al. (2011) introduced a direct measure based on $\mathrm{K}_{\text {simulation }}$ and its compositions ( $\mathrm{K}_{\text {transition, }} \mathrm{K}_{\text {tranloc }}$ ). This approach is chosen in accessing accuracy of land-use change model within the study and expressed as follows:

(1) $\quad K_{\text {Simulation }}=\frac{p_{o}-p_{e(\text { Transition })}}{1-p_{e(\text { Transition })}}$

Where:

$\mathrm{K}_{\text {simulation: }}$ coefficient of agreement between the simulated land use transition and the actual land use transition

Values of $\mathrm{K}_{\text {simulation }}$ range from -1 to 1 , as follows: 
$\mathrm{K}_{\text {simulation }}=1$ : perfect agreement,

$\mathrm{K}_{\text {simulation }}=0$ : the agreement as good as expected result

$\mathrm{K}_{\text {simulation }}<0$ : the agreement less good as expected result

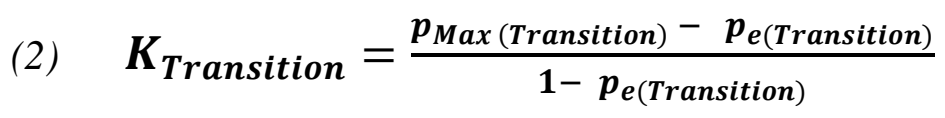

Where:

$\mathrm{K}_{\text {Transition }}$ : the agreement in quantity of land use transition

Values of $\mathrm{K}_{\text {Transition }}$ range from 0 to 1 , as follows:

$\mathrm{K}_{\text {Transition }}=1$ : the sizes of class transition in simulation are exactly in agreementwith the sizes of class transition in reality

$\mathrm{K}_{\text {Transition }}=0$ : there are no class transition appeared in simulated map and reality map as well

(3) $\quad K_{\text {Tranloc }}=\frac{p_{o}-p_{e(\text { Transition })}}{p_{M a x}(\text { Transition })-p_{e(\text { Transition })}}$

Where:

$\mathrm{K}_{\text {Transloc }}$ : the degree to which transition agree in their allocation

Values of $\mathrm{K}_{\text {Transloc }}$ range from -1 to 1 , as follows:

$\mathrm{K}_{\text {Transloc }}=0$ : the agreement in allocation can be expected by chance

$\mathrm{K}_{\text {Transition }}=1$ : high possible agreement in allocation

$\mathrm{K}_{\text {Transition }}<0$ : worse agreement in allocation

In which:

(3.1) $P_{o}$ : the observed fraction of agreement

$$
P_{o}=\sum_{i=1}^{c} p\left(a=i^{\wedge} s=i\right)
$$

(3.2) $P_{e(\text { Transition) }}$ : the expected fraction of agreement 


$$
P_{e(\text { Transition })}=\sum_{c=1}^{j} p(o=j) \cdot \sum_{c=1}^{j} p(a=i \mid o=j) \cdot p(s=i \mid o=j)
$$

(3.3) $P_{\text {Max (transition): }}$ the maximum accuracy

$P_{M a x(T r a n s i t i o n)}=\sum_{c=1}^{j} p(o=j) \cdot \sum_{c=1}^{j} \min (p(a=i \mid o=j), p(s=i \mid o=j))$

[4.62]

Where:

$i$ : land use classes $(i=1,2, . ., \mathrm{c})$

( $a=i^{\wedge} s=i$ ): cells on diagonal that have the same land use in both maps

a: cell in map A (actual map)

s: cell in map S (simulated map)

All comparisons are computed by the aid of Map Comparison Kit (http://www.riks.nl/mck/). More detailed of land-use change model's accuracy measures could be found at (van Vliet et al., 2011). 
The process of calibration and validation in this study is presented in Figure 4.12.

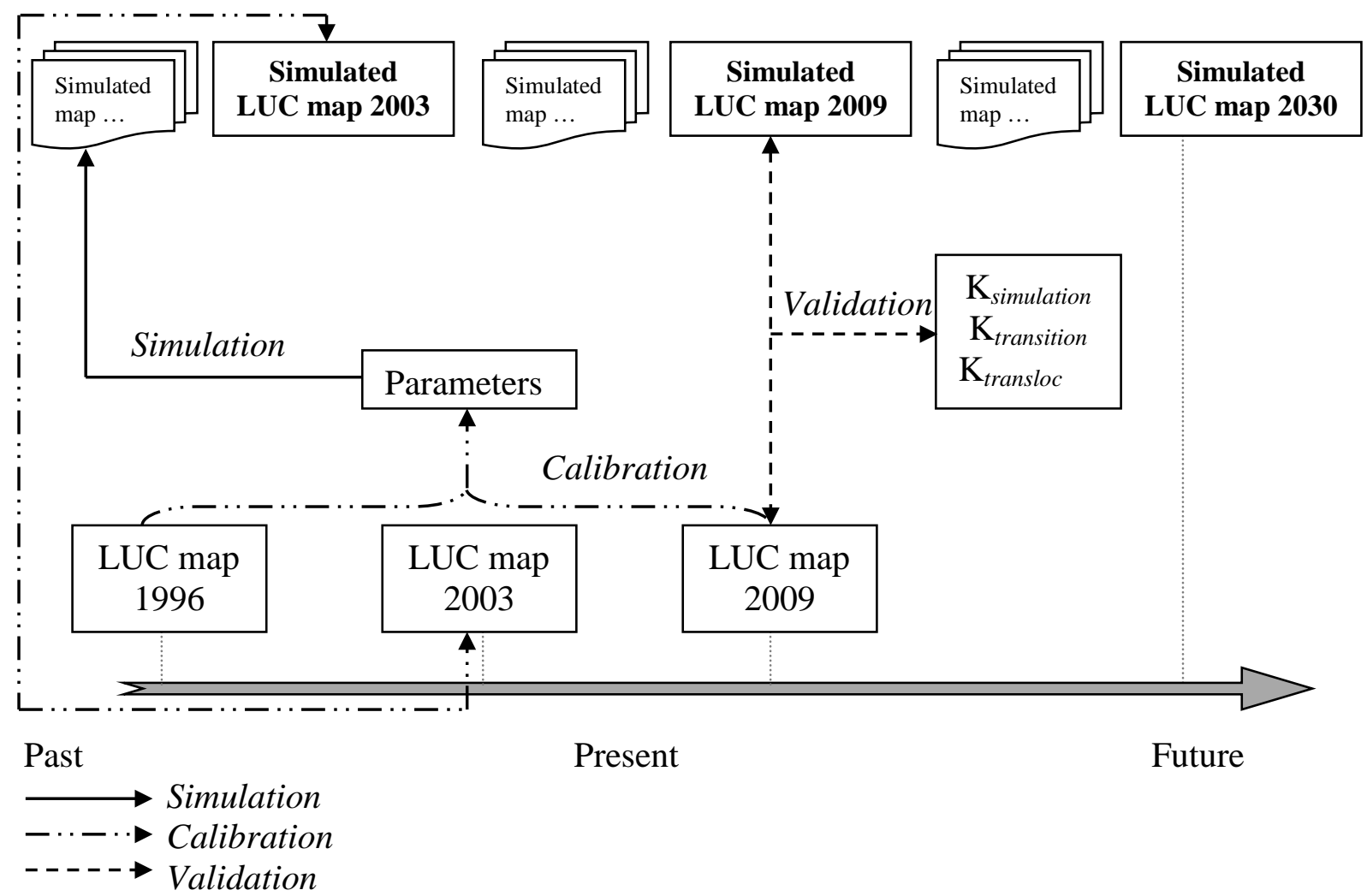

Figure 4.12 Flowchart of calibration and validation process

Adapted from (Estoque and Murayama, 2012)

\subsection{ANOVA analysis for landscape metrics under scenarios}

For further understanding, one-way Analysis Of Variance (ANOVA) was applied to examine if there were significant effects of different land use/cover scenarios to landscape metrics with the aid of IBM SPSS Statistics Version 20. Accordingly, the test employed on each landscape metric (NP, PD, PROX_MN, AREA_MN, IJI, LPI, LSI) with the using of the 22 simulation runs per scenario as independent variables. Since the one-way ANOVA is often followed up with post-hoc multiple comparisons, the Tukey’s post hoc test at significance level 0.05 was used. 


\section{CHAPTER 5}

\section{Land Use/Cover Changes}

Chapter 5 provides a historical view of the land use/cover types within Da Nang City over the past thirty years by multi-temporal images. The first part of this chapter describes the rate of land use and land cover changes, and explains the causes. Then it attempts to find out the changes in structure of landscape through the landscape metrics which will be presented in the second part.

\subsection{Spatial-temporal dynamics and evolution of LULC changes}

The accuracy of LULC maps in years 1979, 1996, 2003, and 2009 was evaluated by means of overall accuracy and various Kappa coefficients. From each LULC map, a total of 300 stratified random pixels was set up and then checked with reference data. The overall accuracies of Landsat MSS 1979, Landsat TM 1996, Landsat ETM+ 2003 and ASTER 2009 were 81.74\%, 80.33\% 84.44\% and 89.00\% respectively. Table $\mathbf{5 . 1}$ shows five variations of the kappa index of agreement $\left(\mathrm{K}_{n o}, \mathrm{~K}_{\text {allocation }}, \mathrm{K}_{\text {quantity }}, \mathrm{K}_{\text {histo }}\right.$, and $\mathrm{K}_{\text {standard }}$ ) for each land use map from 1979 to 2009.

In general, the results show that Kappa values of all LULC maps are over 0.6. Based on work of Pontius (2000), a Kappa value, which is higher than 0.5, can be considered “satisfactory” in comparison with reference data. In addition, Landis and Koch (1977) characterized the agreement of comparison between classified map and 
reference data as follows: values from 0.4 to 0.75 are fair to good, and values over 0.75 are good to excellent. Based on these criterions, LULC maps derived from remote satellite imagery can be used for further studying. As can be seen in Table 5.1, the traditional Kappa ( $\mathrm{K}_{\text {standard }}$ ) of ASTER has higher accuracy than the others. This could be explained by the better spatial, spectral and radiometric resolution of ASTER data. The result indicates that the LULC maps have high values of expected overall agreement $\left(\mathrm{K}_{n o}\right)$, high values of predicted quantity $\left(\mathrm{K}_{\text {quantity }}\right)$, and low but positive values of predicted allocation $\left(\mathrm{K}_{\text {allocation }}\right)$. More detail about the observed agreement and disagreement of the quantity and spatial allocation of the categories in LULC maps can be found in Appendix 1.

\begin{tabular}{lcccc}
\hline $\mathbf{K}_{\text {information }}$ & $\mathbf{1 9 7 9}$ & $\mathbf{1 9 9 6}$ & $\mathbf{2 0 0 3}$ & $\mathbf{2 0 0 9}$ \\
\hline $\mathrm{K}_{\text {no }}$ & 0.68 & 0.77 & 0.79 & 0.87 \\
$\mathrm{~K}_{\text {allocation }}$ & 0.67 & 0.81 & 0.87 & 0.86 \\
$\mathrm{~K}_{\text {quantity }}$ & 0.84 & 0.8 & 0.75 & 0.93 \\
$\mathrm{~K}_{\text {histo }}$ & 0.89 & 0.83 & 0.85 & 0.94 \\
$\mathrm{~K}_{\text {standard }}$ & 0.60 & 0.67 & 0.74 & 0.81 \\
\hline
\end{tabular}

Table 5.1 Kappa scores obtained from assessment of four different land use maps (Source: Own calculation)

For classification, a number of training pixels was set for each individual image. The number of pixels for Landsat 1979, Landsat 1996, Landsat 2003 and ASTER 2009 were 11701, 16389, 11927, and 10693, respectively. Based on supervised classification method using Maximum likelihood algorithm, six LULC types were derived from classification maps of years 1979, 1996, 2003, and 2009. The spatial distributions of the LULC classes for four periods of time are shown in Figure 5.1. The classification statistics are summarized in Table 5.2.

A more thorough insight into a quantitative assessment of the accuracy for entire LULC, products derived from remote sensing images was also compared with statistical data (Figure 5.2). According to the article 13 of Vietnamese Law on Land 2003, land use could be classified into new categories: agricultural land, non-agricultural land, and unused land based on the use purpose (Viet Nam Laws, 2003). Agricultural land 


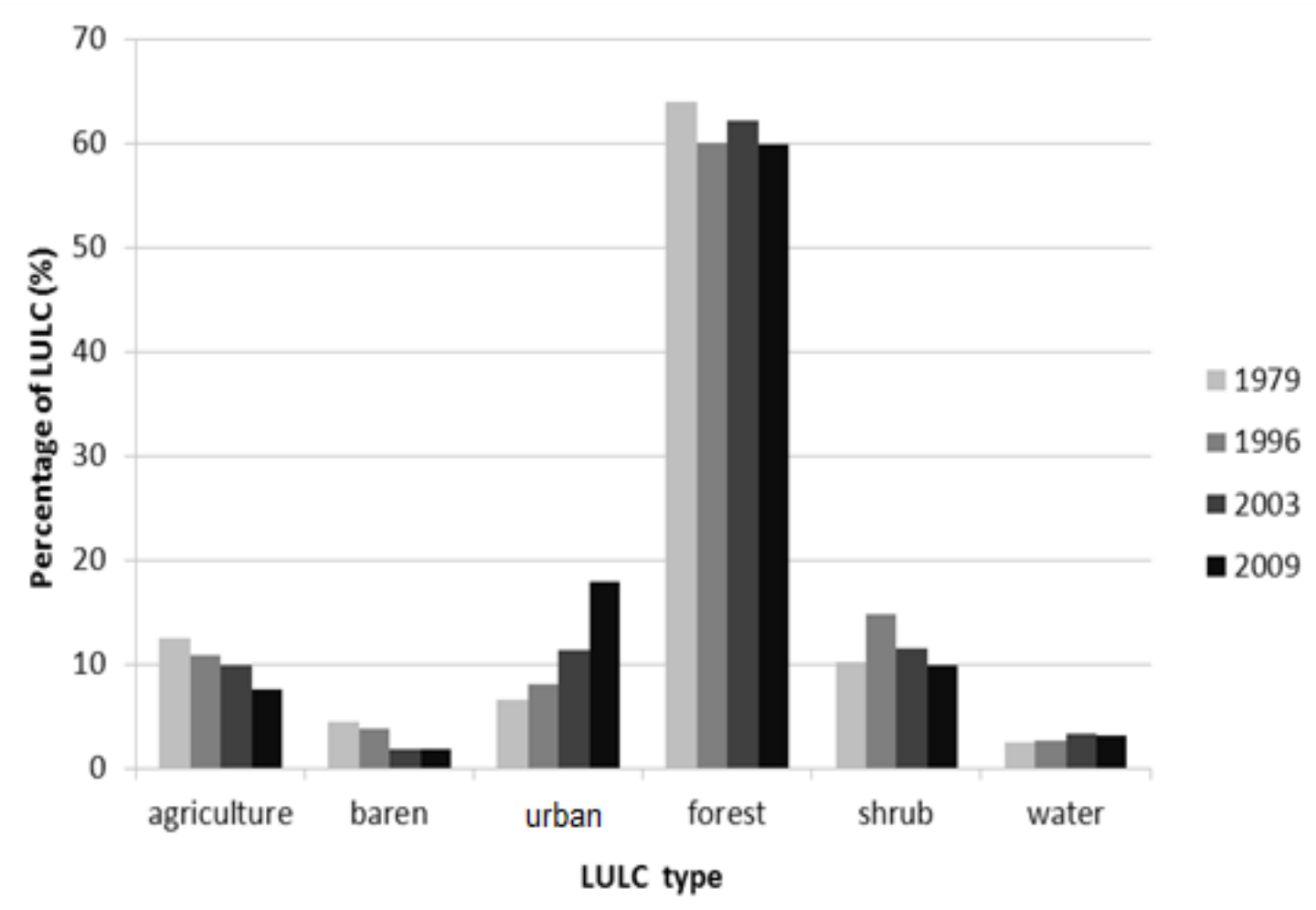

Figure 5.1 Percentage of land use/land cover extracted from remote sensing data (Source: Own calculation)

Unit:ha

\begin{tabular}{|c|c|c|c|c|c|c|c|c|}
\hline LULC & 1979 & & 1996 & & 2003 & & 2009 & \\
\hline & $\begin{array}{l}\text { Area } \\
\text { (ha) }\end{array}$ & (\%) & $\begin{array}{l}\text { Area } \\
\text { (ha) }\end{array}$ & (\%) & $\begin{array}{l}\text { Area } \\
\text { (ha) }\end{array}$ & (\%) & $\begin{array}{l}\text { Area } \\
\text { (ha) }\end{array}$ & $(\%)$ \\
\hline Agriculture & 12048.0 & 12.4 & 10416.7 & 10.8 & 8118.1 & 8.4 & 7294.7 & 7.5 \\
\hline Barren & 4312.2 & 4.5 & 3680.9 & 3.8 & 2487.2 & 2.6 & 1708.9 & 1.8 \\
\hline Urban & 6315.3 & 6.5 & 7791.5 & 8.0 & 11630.0 & 12.0 & 17298.5 & 17.9 \\
\hline Forest & 61972.0 & 64.0 & 58126.7 & 60.0 & 59467.1 & 61.4 & 57936.2 & 59.8 \\
\hline Shrub & 9785.2 & 10.1 & 14253.2 & 14.7 & 12335.9 & 12.7 & 9575.8 & 9.9 \\
\hline Water & 2384.6 & 2.5 & 2548.3 & 2.6 & 2779.0 & 2.9 & 3003.6 & 3.1 \\
\hline Total & 96817.2 & 100 & 96817.2 & 100.0 & 96817.2 & 100 & 96817.7 & 100 \\
\hline
\end{tabular}

Table 5.2 Land use/cover in Da Nang City from 1979 to 2009

(Source: Own calculation) 


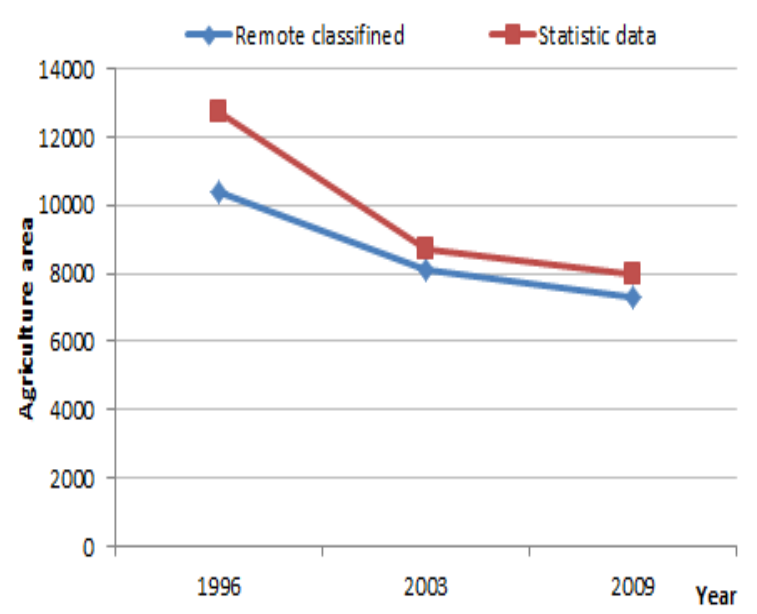

a)

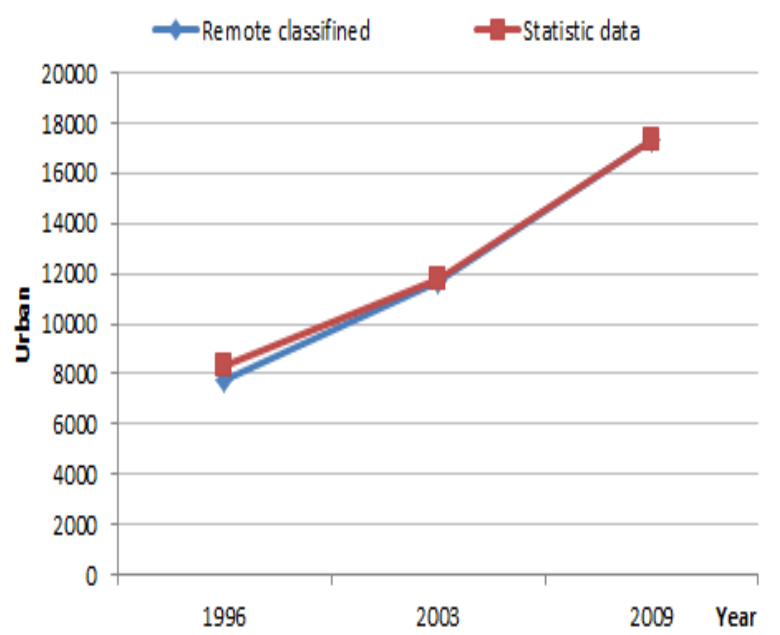

c)

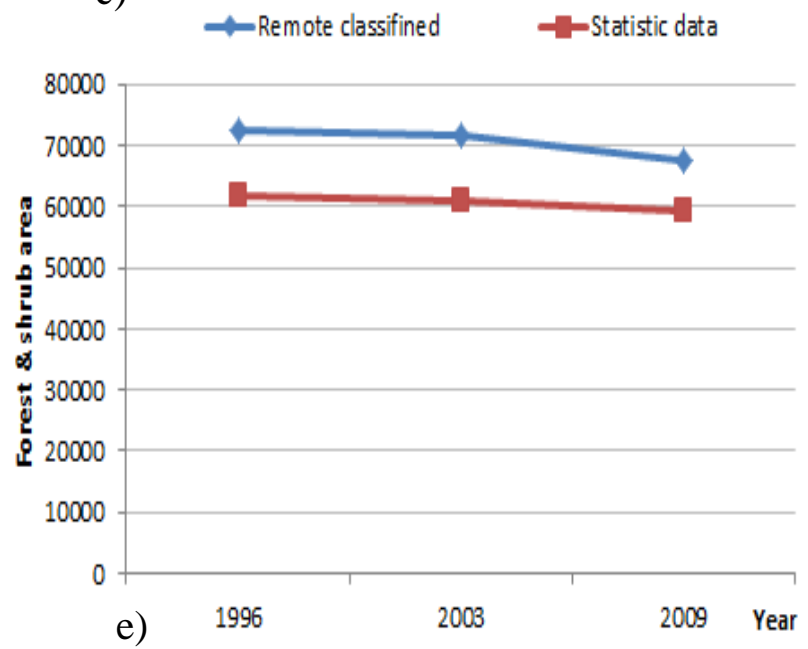

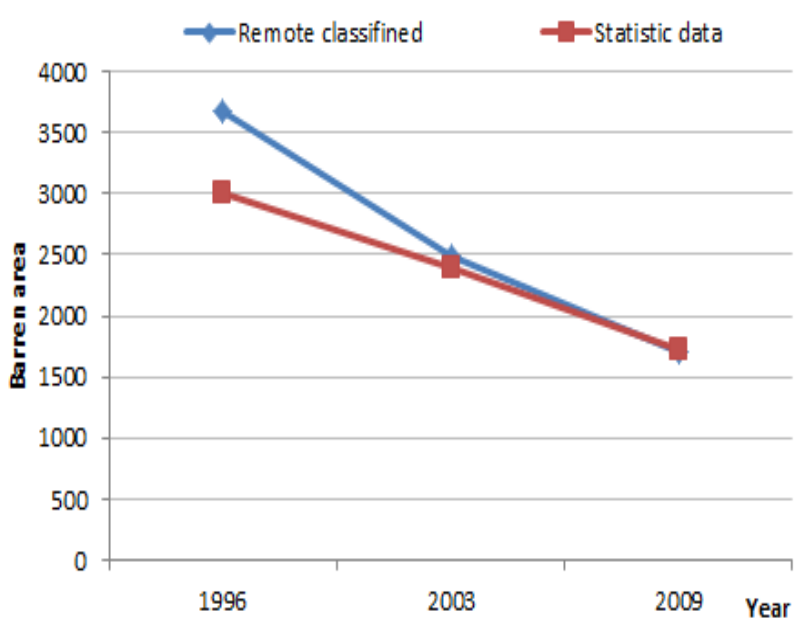

b)

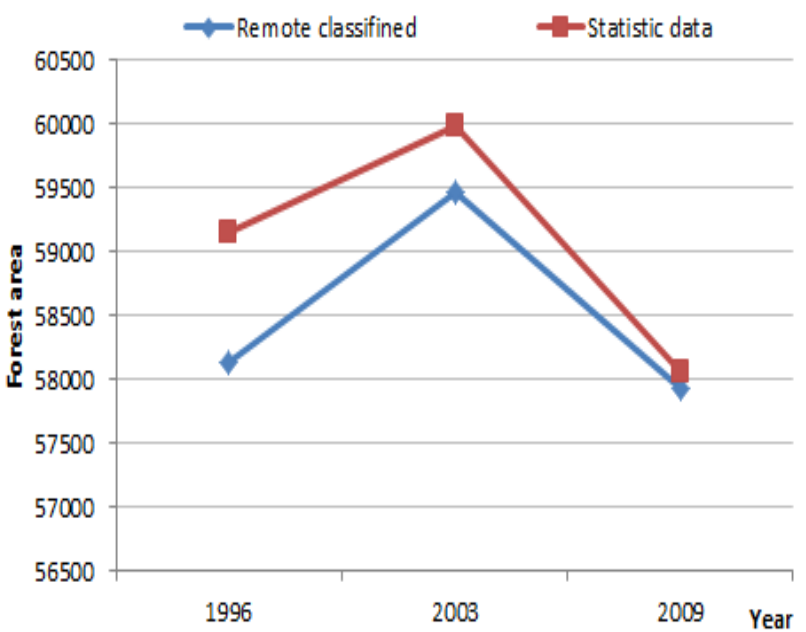

d)

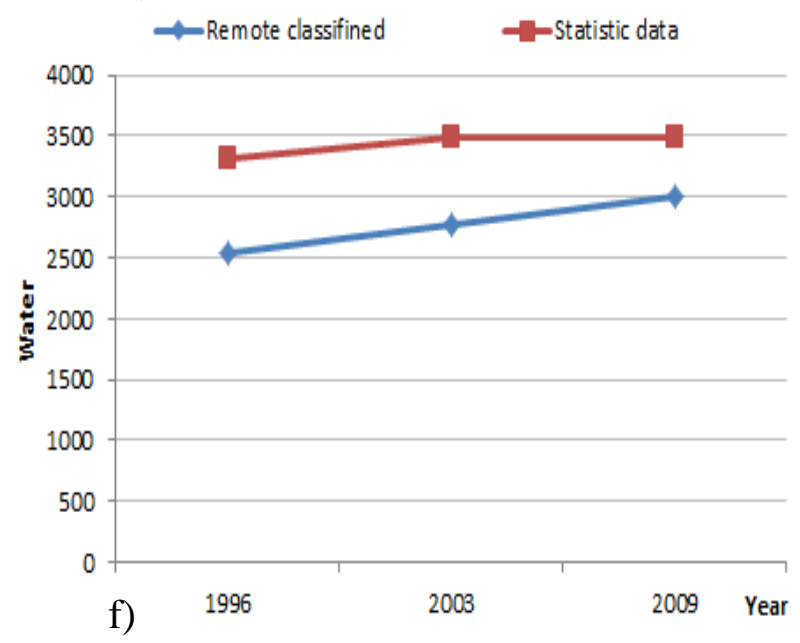

Figure 5.2 Trends of land use/covers from multi-temporal images and statistic data:

a) agriculture; b) barren; c) urban; d) forest; e) shrub and forest; f) water (Source: Own calculation) 
category comprises land for planting annual crops (rice, cultivation, pastoral, and other annual crops), land for planting perennial crops, forest land, land for aquaculture, land for salt production, and other agricultural land as stipulated by the Government. Nonagriculture land category comprises residential land, land for construction, land used for national defense and security purposes, business purposes, public purposes, religious establishments, and other non-agricultural land as stipulated by the Government. In which, forest land is defined as purpose of land use rather than land cover, including: “(1) protected forest, for the preservation of water resources, the prevention of erosion, natural disasters, climatic risks, and the overall protection of environment; (2) special use of forest to conserve nature, plant and animal species, to research, and protect historic, cultural, and tourist sites; (3) production forest, for supplying timber and other forest products, and associated with the other types of forest to protect environment" (Ducourtieux and Castella, 2006). This classification system is quite different in comparison with land use/cover classification scheme for use with remotely sensed data developed by Anderson et al.,(1976b). In this circumstance, there is no discrimination between forest and shrub class. Consequently, Figure5.2e is used to observe the trend of shrub. As mentioned above, due to the quality of images, Landsat TM 1996 was chosen instead of 1997. Nevertheless, there was no historic data about the state of land use/cover in this year. Therefore, land use/cover types extracted from Landsat TM 1996 were compared with statistic data in 1997. Although there were little differences in level, the trends of land use/cover obtained from satellite imagery were similar to those in statistic data.

Figure 5.1 shows that the dominant LULC classes in spatial distribution pattern were forest and urban. Accordingly, forest area was counted as 64\%, 60\%, 61.4\% and $59.8 \%$ of the total coverage in years 1979, 1996, 2003, and 2009, respectively; meanwhile, urban area was occupied $6.5 \%, 8.0 \%, 12 \%$, and $17.9 \%$ of the total coverage in 1979, 1996, 2003, and 2009. During the period from 1979 to 2009, the surface water body covered about $2.5 \%, 2.6 \%, 2.9 \%$, and $3.1 \%$ of in the study of the total region. The results are also shown that from 1979 to 2009 LULC units under shrub, agriculture and barren decreased from $10.1 \%$ to $9.9 \%, 12.4 \%$ to $7.5 \%$, and $4.5 \%$ to $1.8 \%$, respectively (Table 5.2). 


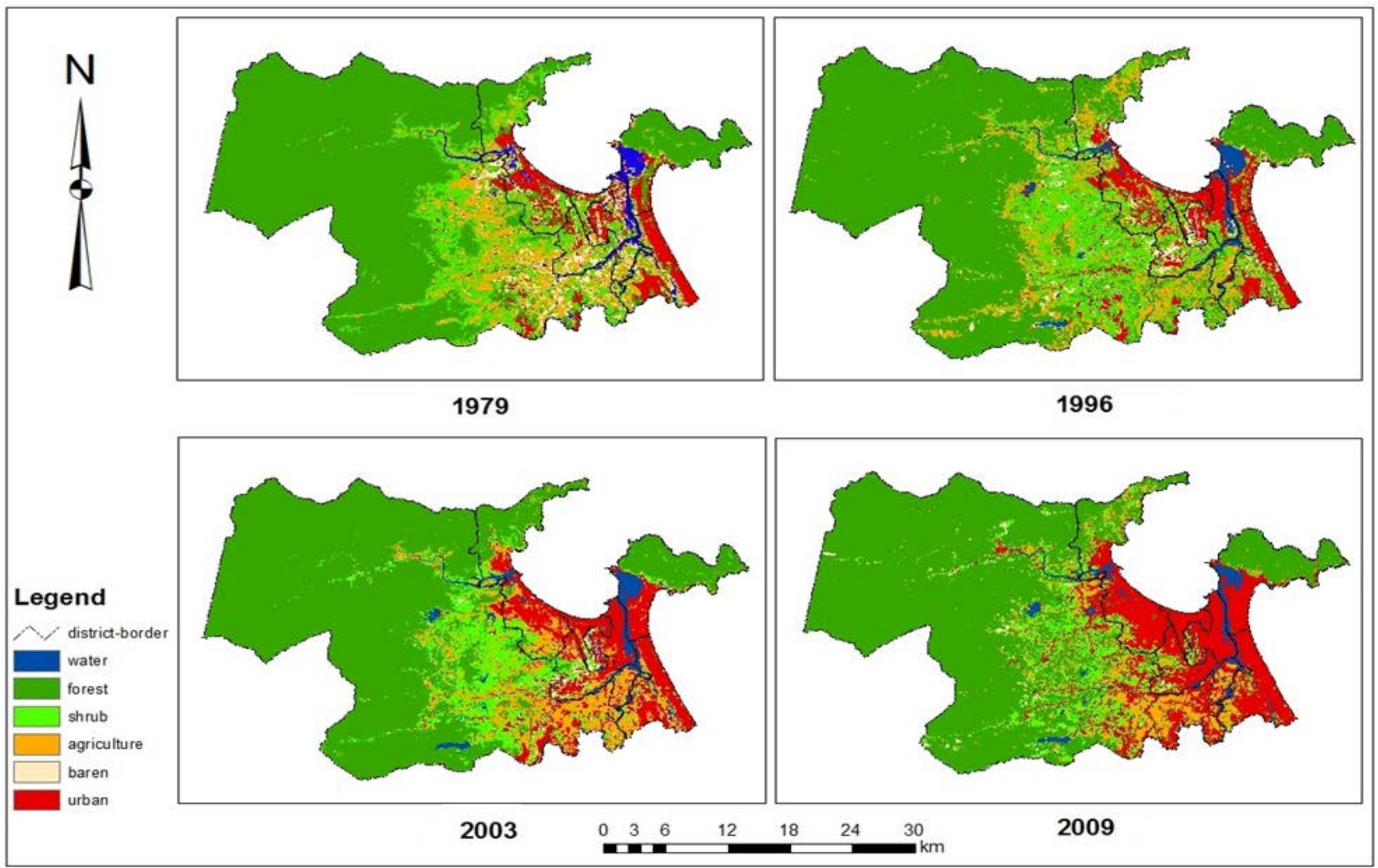

Figure 5.3 Classified land use/cover maps from multi-temporal images (Source: Own calculation) 
Figure 5.3 presents the LULC maps of study area generated from multi-temporal images for all four years 1979, 1996, 2003, and 2009. LULC areas were specified by multiplying the number of pixels and the spatial resolution of remote data (i.e. $30 \mathrm{~m}$ ), in which the pixel numbers were determined after applying post-classification analysis. The changes of LULC were measured by the difference of pixel numbers between two dates afterwards. Based on post-classification comparison, the from-to change matrices of LULC in Da Nang City were created in four intervals, 1979-1996, 1996-2003, 2003-2009 and 1979-2009 to provide a further comprehensive analyses in losing and gaining among the six LULC classes (Table 5.3). In cross tabulation, conversion values of classes were arranged in descending order while unchanged pixels were located along the major diagonal of the matrix.

\section{Urban}

Urban areas faced the most dramatic change. They increased from 6314.85 ha in 1979 to 17298.54 ha in 2009 (Table 5.2), thus representing an increase of $140 \%$ of total land use area. The expansion of urban area in Da Nang City is confirmed by the regional statistics. In the first period from 1979 to 1996, urban area grew up just 1476.2 ha, representing $13.4 \%$ of net increase of urban area. However, only in seven years (19962003), after separation from Quang Nam province and becoming a centrally governed city, the urban area expanded 3838.5 ha more, which was 35\% of net increase of urban area. Within six years later, from 2003 to 2009, the urban area incessantly increased and gained 5668.5 ha, which contributed $51.6 \%$ to net increase of urban area, experienced a remarkable change of the urban area with a rapid scale. The swift expansion of urban area in the last two periods is the result of rapid economic development. As can be seen in Figure 5.4, Gross Domestic Product (GDP) of Da Nang City increased steadily from 1990 to 2009, with an annual growth of GDP of 10.3\% (higher than nation's annual growth of GDP 7.2\%). In addition, the increase of population in Da Nang City could be seen as another reason for urban expansion, in which population increase from 679.7 thousand people in 1997 to 890.5 thousand people in 2009, representing an increase of 31\%. 
Chapter 5. LULC changes

\begin{tabular}{llllllll}
\hline & 1979 & & & & & & \\
\cline { 2 - 7 } 1996 & Agriculture & Barren & Urban & Forest & Shrub & Water & 1996 Total \\
\hline Agriculture & 2910.96 & 1062.45 & 202.32 & 3865.05 & 2238.21 & 125.1 & 10416.69 \\
Barren & 657.81 & 481.5 & 573.84 & 986.49 & 832.23 & 142.56 & 3680.91 \\
Urban & 486.54 & 834.48 & 4280.67 & 1408.77 & 577.62 & 189 & 7791.48 \\
Forest & 2797.47 & 711.99 & 324.81 & 52197.03 & 1878.3 & 118.62 & 58126.77 \\
Shrub & 5016.06 & 984.69 & 655.65 & 3294.27 & 4084.56 & 201.69 & 14253.21 \\
Water & 179.19 & 237.06 & 97.02 & 220.41 & 174.24 & 1607.58 & 2548.26 \\
1979 Total & 12048.03 & 4312.17 & 6314.85 & 61972.02 & 9785.16 & 2384.55 & \\
Change & & & & & & & \\
1979-1996 & -1631.34 & -631.26 & 1476.63 & -3845.25 & 4468.05 & 163.71 & \\
\hline
\end{tabular}

(a) 1979-1996

\begin{tabular}{|c|c|c|c|c|c|c|c|}
\hline \multirow[b]{2}{*}{2003} & \multicolumn{7}{|l|}{1996} \\
\hline & Agriculture & Barren & Urban & Forest & Shrub & Water & $\begin{array}{l}2003 \\
\text { Total }\end{array}$ \\
\hline Agriculture & 2244.51 & 282.87 & 575.01 & 2165.76 & 2782.44 & 61.2 & 8118.09 \\
\hline Barren & 325.98 & 532.08 & 414.09 & 360.45 & 803.7 & 44.91 & 2487.15 \\
\hline Urban & 1127.07 & 985.5 & 5867.1 & 1090.71 & 2187.63 & 310.86 & 11629.98 \\
\hline Forest & 4389.66 & 538.29 & 120.78 & 51701.94 & 2610.18 & 34.29 & 59466.78 \\
\hline Shrub & 2235.96 & 1169.46 & 578.43 & 2572.11 & 5698.53 & 74.79 & 12335.94 \\
\hline Water & 80.91 & 166.23 & 221.67 & 137.25 & 154.44 & 1989.45 & 2778.84 \\
\hline \multicolumn{8}{|l|}{ Change } \\
\hline 1996-2003 & -2298.6 & -1193.76 & 3838.5 & 1340.01 & -1917.27 & 230.58 & \\
\hline \multicolumn{8}{|c|}{ (b) 1996-2003 } \\
\hline \multicolumn{8}{|c|}{2003} \\
\hline 2009 & Agriculture & Barren & Urban & Forest & Shrub & Water & $\begin{array}{l}2009 \\
\text { Total }\end{array}$ \\
\hline Agriculture & 1858.68 & 177.66 & 711 & 2880.63 & 1645.38 & 15.03 & 7294.68 \\
\hline Barren & 86.76 & 121.86 & 148.14 & 860.58 & 464.04 & 24.93 & 1708.92 \\
\hline Urban & 3188.7 & 1188.27 & 9025.29 & 739.35 & 2673.81 & 458.55 & 17298.54 \\
\hline Forest & 1036.17 & 231.93 & 414.99 & 52503.66 & 3556.26 & 95.85 & 57935.79 \\
\hline Shrub & 1833.21 & 656.01 & 808.56 & 2364.21 & 3851.46 & 51.3 & 9575.82 \\
\hline Water & 108.27 & 105.48 & 460.89 & 46.71 & 138.33 & 2104.29 & 3003.57 \\
\hline 2003 Total & 8118.09 & 2487.15 & 11629.98 & 59466.78 & 12335.94 & 2778.84 & \\
\hline Change 2003-2009 & 9 & -778.23 & 5668.56 & -1530.99 & -2760.12 & 224.73 & \\
\hline
\end{tabular}

(c) 2003-2009

\begin{tabular}{llllllll}
\hline & 1979 & & & & & & \\
\cline { 2 - 7 } 2009 & Agriculture & Barren & Urban & Forest & Shrub & Water & $\begin{array}{l}\text { 2009 } \\
\text { Total }\end{array}$ \\
\hline Agriculture & 1779.21 & 991.26 & 110.79 & 2394.99 & 1950.3 & 61.83 & 7294.68 \\
Barren & 353.07 & 78.3 & 91.8 & 933.93 & 240.48 & 8.73 & 1708.92 \\
Urban & 2975.04 & 1933.56 & 5096.7 & 3898.26 & 2789.37 & 581.04 & 17298.54 \\
Forest & 3787.38 & 227.52 & 221.58 & 51584.22 & 1928.79 & 89.37 & 57935.79 \\
Shrub & 2895.48 & 747.45 & 430.47 & 2834.19 & 2589.48 & 67.68 & 9575.82 \\
Water & 257.85 & 334.08 & 182.97 & 326.43 & 286.74 & 1575.9 & 3003.57 \\
1979 Total & 12048.03 & 4312.17 & 6314.85 & 61972.02 & 9785.16 & 2384.55 & \\
Change & & & & & & & \\
1979-2009 & -4753.35 & -2603.25 & 10983.69 & -4036.23 & -209.34 & 619.02 & \\
\hline
\end{tabular}




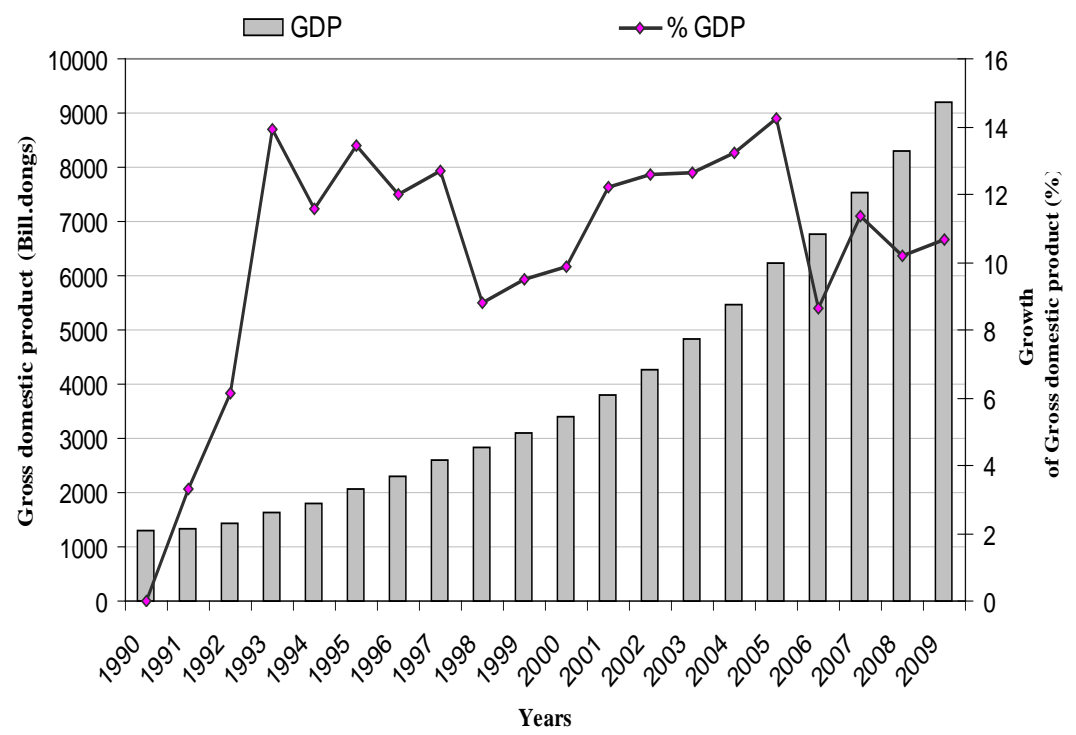

Figure 5.4 Gross Domestic Product and its growth in Da Nang City from 1990-2009 (Source: Statistical Year Books)

\begin{tabular}{|c|c|c|c|c|c|c|c|c|}
\hline \multirow{2}{*}{ Time } & \multirow{2}{*}{ Unit } & \multicolumn{7}{|c|}{ District } \\
\hline & & CL & HC & HV & LC & NHS & ST & TK \\
\hline \multirow[t]{2}{*}{1979} & $\begin{array}{l}\text { Area } \\
\text { (ha) }\end{array}$ & 316.3 & 653.8 & 866.5 & 1607.9 & 16745.0 & 685,08 & 286.3 \\
\hline & $(\%)$ & 9.1 & 30.0 & 1.2 & 19.6 & 42.2 & 11.0 & 30.4 \\
\hline \multirow[t]{2}{*}{1996} & $\begin{array}{l}\text { Area } \\
\text { (ha) }\end{array}$ & 484.9 & 1051.7 & 1492.3 & 1709.6 & 1890.4 & 839.43 & 535.3 \\
\hline & $(\%)$ & 14.0 & 48.4 & 2.1 & 20.8 & 47.7 & 13.4 & 56.7 \\
\hline \multirow[t]{2}{*}{2003} & $\begin{array}{l}\text { Area } \\
\text { (ha) }\end{array}$ & 1145.9 & 1248.0 & 2248.0 & 2123.91 & 2228.9 & 1185.0 & 725.2 \\
\hline & $(\%)$ & 33.0 & 57.3 & 3.1 & 25.9 & 56.2 & 19.0 & 77.0 \\
\hline \multirow[t]{2}{*}{2009} & $\begin{array}{l}\text { Area } \\
\text { (ha) }\end{array}$ & 1910.3 & 1595.3 & 5350.3 & 3287.16 & 2753.3 & 1569.4 & 835.3 \\
\hline & $(\%)$ & 55.1 & 73.4 & 7.5 & 40.0 & 69.4 & 25.0 & 88.4 \\
\hline
\end{tabular}

(CL: Cam Le; HC: Hai Chau; HV: Hoa Vang; LC: Lien Chieu; NHS: Ngu Hanh Son; ST: Son Tra; TK: Thanh Khe)

Table 5.4 Measuring the changes of urban area in different districts (Source: Own calculation) 
Further comparison with the classified land use/cover maps derived from multitemporal images in Figure 5.3, in which, the urban areas are displayed as red color. The spatial distribution and extent of urban area varied differently among the administrative districts within Da Nang City which is clearly presented in Table 5.4. In terms of percentage, the most intensive occurrence of urban area was in Thanh Khe district (88.4\% of its administrative area), followed by Hai Chau district (73.4\%), Ngu Hanh Son district (69.4\%), Cam Le district (55.1\%) and Lien Chieu district (40.0\%) over the past thirty years. As a city located close to the eastern seaboard, habitants of Da Nang city tended to live near the coast. In the period from 1979 to 1996, urban area distributed scattered in Ngu Hanh Son (42.2\%), Thanh Khe (30.4\%), Hai Chau (30\%), Lien Chieu (19.6\%) and a part of Son Tra districts (11\%). From 1996 to 2003, this area expanded and concentrated in these districts. As observed from Figure 5.3, the expansion of urban area tends to vary on the mainland instead of along the coastal line.

Cross tabulation shows that the increase of urban area gained from the conversions of forest, agriculture, shrub and barren to urban. Of the 10983.69 ha of total growth in urban area from 1979 to 2009, 33.5\% was converted from forest, 26.1\% from agriculture, 21.5\% from shrub and 16.8\% from barren. From 1979 to 2009, 3898.26 ha of forest were converted to urban, while 221.58 ha of urban were converted to forest at the same time. The later change may not reasonable and looks like the result of classification errors. According to Anderson et al., (1976a), park, garden, recreation, roads belong to urban LULC classification scheme level IV and V. However, when the trees in these places grew up, the pixels associated with tree canopies may be classified as forest. Similarly, these commission errors could be found also in the change of urban to agriculture or urban to shrub.

\section{Agriculture}

Table 5.2 shows that the agricultural area had an area of 12048.03 ha in 1979, 10416.7 ha in 1996, 8118.1 ha in 2003 and 7294.7 ha in 2009, representing by $12.4 \%, 10.8 \%, 8.4 \%$, and 7.5\%, respectively. From 1979 to 2009, agricultural area strongly decreased by 4753.35 ha (Table 5.3d), representing a net decrease of 39.5\%, the change of agriculture area 
altered considerably in different periods of time. Within a span of seventeen years, from 1979 to 1996, the agriculture area reduced 1631.34 ha, thus representing 13.5\%, whereas, from 1996 to 2003, within just seven years, the agriculture area reduced by 2298.6 ha, thus representing 19.1\%, and from 2003 to 2009, within six years, agricultural area reduced by 823.41 ha, which represented of 6.8\%. The loss of agriculture from 1979 to 2009 was mainly caused by the encroachment of urban areas and forestation. According to Table 5.3d, the agricultural area gained only 110.79 ha from urban areas, while it lost 2975.04 ha to urban areas, representing $60.3 \%$ of total decrease in agricultural land use. Likewise, 1392.39 ha of agriculture were converted to forest, representing $29.3 \%$ of total decrease in agricultural land use.

As mentioned above, the decrease in agricultural area could be the result of the rapid increase of urban area. Moreover, this trend was followed by the oriental economic structure as the overall long-term programming in developing economics and social of Da Nang City, in which the descending order of sectors was services, industry, and agriculture (Figure 5.5). The loss of agriculture to forest was the result of changes from crop land to orchard or artificial forest (e.g. Acacia mangium, Acacia auriculiformis, Eucalyptus camaldulensis). It has been noticed that the change from urban to agriculture was likely to be due to the classification errors. In classified LULC maps, these errors could be omission or commission errors.

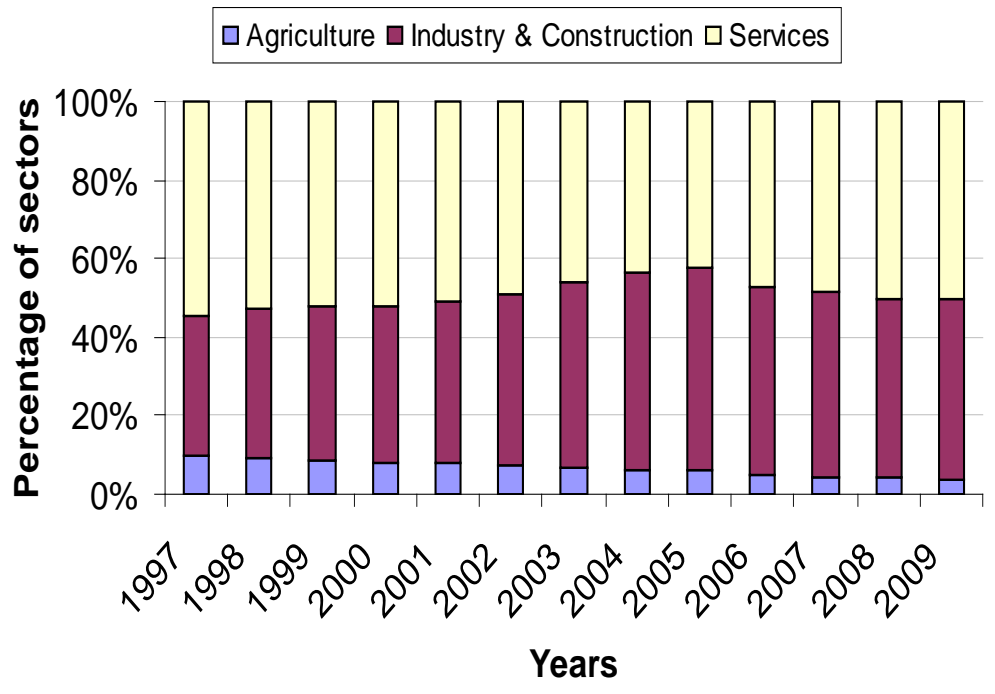

Figure 5.5 Development of the economic structure in Da Nang City from 1997 to 2009 (Source: Statistical Year Books) 
Chapter 5. LULC changes

\section{Forest}

Table 5.2 shows that forest area decreased in general over the study period. However, this area fluctuated variously in different periods. In quantitative terms, the forest area was detected as 61972 ha in 1979, 58126.7 ha in 1996, 59467.1 ha in 2003, and 57936.2 ha in 2009, thus representing 64\%,60\%, 61.4\% and 59.8\% of total area of Da Nang City, respectively. Until 2009, 83.2\% (51584.22 ha) of forests in 1979 that were still remained unchanged (Table 5.3.d). Results showed that the forest area lost 10387.8 ha of its 1979 area to other classes, in which 37.5\% (3898.26 ha) converted to urban, 27.3\% (2834.19 ha) to shrub and 23.1\% (2394.99 ha) to agriculture. The results also indicated that the gain of forest area mainly came from agriculture and shrub. From 1979 to 2009, 6254.64 ha were converted to forest, in which 60.5\% (3787.38 ha) from agriculture and 30.8\% (1928.79 ha) from shrub. The observed trends of decreasing and increasing of forest area in different periods of time in Da Nang City could be clarified by the following reasons. During the first period from1979 to 1996, like other provinces in Viet Nam, deforestation was mainly caused by the increasing demand of land for agriculture and timber products. Consequently, the "close the natural forest gate" policy to restrict the over-exploitation was promulgated by government in 1990. To continue supplying materials for timbers and paper industry, forestry productions were exploited from forest plantation (Van Loi, 2008). Therefore, forest cover area had been slightly increased in the second period from 1996 to 2003 by reforestation programs. However, in the third period from 2003 to 2009, forest area decreased once again (1.6\% of total area in Da Nang City) due to the rapid urbanization.

\section{Shrub}

Area of shrub cover class during the four periods is showed in Table 5.2. Shrub area occupied 9785.2 ha in 1979, 14253.2 ha in 1996, 12335.9 ha in 2003 and 9575.8 ha in 2009, which represented in $10.1 \%, 14.7 \%, 12.7 \%$, and $9.9 \%$ respectively. At the end of study period (2009), shrub area decreased by 209.34 ha. Of the 9575.82 ha of total area in shrub land use, 2589.48 ha shrub was still unchanged in 2009. As can be seen from statistics, the changes of shrub area were different through periods of times. The reasons 
Chapter 5. LULC changes

that caused the increase and decrease in area of shrub class might be similarly with the reasons mentioned in the changes of forest area.

\section{Barren}

In the same way, 2603.25 ha of barren area consistently decreased from 1979 to 2009, which represented that barren lost 60.4\% of its 1979 area by 2009 (Table 5.2). Based on Table 5.3d, only 78.3 ha of barren remained unchanged from 1979 to 2009. Barren lost $44.8 \%$ (1933.56 ha) to urban, 23\% (991.26 ha) to agriculture and 17.3\% (747.45 ha) to shrub in the same period. Meanwhile, 933.93 ha, 353.07 ha and 240.48 ha of barren areas were obtained from forest, agriculture and shrub. It is noted that the conversion between agriculture and barren might be influenced by acquisition of remotely sensed image in different seasons. It can be asserted that some agriculture plots had been harvested and fallowed during the time for operating of remote satellite.

\section{Water}

Water had been an area of 2384.55 ha in 1979, 2548.26 ha in 1996, 2778.84 ha in 2003, and 3003.57 ha in 2009 (Table 5.3). Note that water area in Da Nang City continuously increased from 1979 to 2009. It showed that the water area gained 26\% of its 1979 area by 2009. Table 5.3d shows, 1388.07 ha of land-to-water gained from other classes and lost 808.65 ha of its 1979 area to other classes. The 1388.07 ha which was belonged to water class, 24.1\% (334.08 ha) came from barren, 23.5\% (326.43 ha) from forest, 21\% (286.74 ha) from shrub and 18.6\% (257.85 ha) from agriculture. Around 808.65 ha of water area was lost from 1979 to 2009, 72\% (581.04 ha) transformed to urban area. The decrease of water pixels could be the results of the different resolution of the sensors used in this study, which caused consequently the omission errors. Besides, the seasonal changes in remotely sensed data may affect the accuracy of water class.

The increase of water in the study period resulted from construction of new reservoirs to collect water in the latter part of the 1980s. Besides the rivers and streams system, Da Nang has thirty reservoirs and lakes with capacity of 3.3 million $\mathrm{m}^{3}$ of water supplied for 4580 ha 
cultivated land. However, these reservoirs and lakes are not distributed equally; most of them are located within Hai Chau and Thanh Khe districts, in contrast to this, there are not many in Son Tra, Ngu Hanh Son and Lien Chieu; the two largest reservoirs are in Hoa Vang district, namely Dong Nghe and Hoa Trung (Thang, 2009). In the orientation of land use planning of Da Nang City, increasing water area is an important task to supply water not only for cultivated land but also for the demand of industry as well as residential area and conserving the ecological environment.

\subsection{Landscape pattern analysis at class level}

\begin{tabular}{lllllllll}
\hline Class & $\begin{array}{l}\text { PLAND } \\
(\mathbf{\%})\end{array}$ & $\begin{array}{l}\text { NP } \\
(\#)\end{array}$ & $\begin{array}{l}\text { LPI } \\
(\mathbf{\%})\end{array}$ & $\begin{array}{l}\text { AREA_ } \\
\mathbf{M N} \\
\mathbf{( h a )}\end{array}$ & $\begin{array}{l}\text { PD } \\
(\# / \mathbf{1 0 0 h a})\end{array}$ & $\begin{array}{l}\text { PROX_lN } \\
\mathbf{M N}\end{array}$ & $\begin{array}{l}\text { LSI } \\
(\#)\end{array}$ & $\begin{array}{l}\text { IJI } \\
(\mathbf{m})\end{array}$ \\
\hline 1979 & & & & & & & & \\
\hline Agriculture & 7.0 & 1240 & 2.7 & 10.0 & 0.7 & 491.2 & 50.8 & 71.1 \\
Urban & 3.7 & 682 & 1.0 & 9.2 & 0.4 & 67.1 & 41.2 & 62.5 \\
Forestry & 36.0 & 2180 & 29.4 & 28.4 & 1.3 & 2670.1 & 26.2 & 84.0 \\
\hline 2009 & & & & & & & & \\
\hline Agriculture & 3.6 & 3051 & 0.3 & 2.1 & 1.7 & 24.2 & 60.2 & 50.0 \\
Urban & 10.1 & 1771 & 4.6 & 10.2 & 1.0 & 1728.6 & 25.0 & 79.3 \\
Forestry & 33.2 & 1554 & 29.5 & 38.0 & 0.9 & 17985.4 & 24.8 & 82.3 \\
\hline
\end{tabular}

Table 5.5 Metrics of landscape structure at the class level (Source: Own calculation)

In order to have a more comprehensive analysis and focusing on spatial changes of classification maps of the years 1979 and year 2009, the three representative classes (agriculture, urban, and forest) were chosen to compute spatial landscape matrices. These landscape metrics indices were calculated and summarized in Table 5.5, through which a comprehensive overall picture of landscape structure (including: area, shape, isolation and proximity, and contagion/interspersion) could be revealed.

The dramatic changes of LULC stimulated by intensive development of economics in Da Nang City resulted in the intrinsic change of landscape structure from 1979 to 2009. Table 5.5 shows the relevant landscape metrics at class level for the three main classes: agriculture, urban and forestry. In Da Nang City, forestry area is the most dominant class of 
landscape due to its largest percentage of total area. This could be identified by the largest patch index (LPI), a specific measure used for observing the dominance of a land cover type. A comparison with agriculture and urban area, the largest patch index (LPI) of forest area is highest at rate of $29.4 \%$ and $29.5 \%$ in 1979 and 2009, respectively. During the whole period from 1979 to 2009, the statistic for the forestry class showed that the percentage of landscape (PLAND) index decreased from 36\% to 33.2\%, the number of patches (NP) decreased from 2180 to 1554 and the patch density index (PD) decreased softly from 1.3 per 100 ha to 0.9 per 100 ha. In contrast to this, the mean patch area index (AREA_MN) increased from 28.4 ha to 38.0 ha, which was supported by the increasing of the mean proximity index (PROX_MN) from $2670.1 \mathrm{~m}$ to $17985.4 \mathrm{~m}$. It can be assumed that forested patches increasingly occupied the neighborhood, defined by a search radius of $300 \mathrm{~m}$. It indicates that those forested patches were more contiguous in the domain of spatial distribution. As can be seen, the 1979 forest class had a high interspersion and juxtaposition index (84.0\%). This value indicated that the patches were well interspersed in the landscape. Or in short, these forest patches were adjacent to each other equally. In 2009, this index reduced slightly to $82.3 \%$, which characterized a disproportioned in distribution of patch type adjacencies. However, such changes could be generally negligible. The IJI index of forest patches was still high over $80 \%$. In addition, the landscape shape index (LSI) asserted also a slightly decreasing from 26.2 in 1979 to 24.8 in 2009; this might suggest a less dispersed in spatial distribution of forest patches.

In regard to agriculture area during the period from 1979 to 2009, Table 5.5 shows the decrease of this class by the percentage of landscape (PLAND) index, from $7.0 \%$ to 3.6\%. However, the results also show that the number of patches (NP) increased from 1240 to 3051, and the patch density index (PD) increased over twofold from 0.7 per 100 ha to 1.7 per 100 ha. In contrast to this, the mean patch area (AREA_MN) decreased from 10.0 ha to 2.1 ha and the largest patch index (LPI) lessened drastically from $2.7 \%$ to $0.3 \%$. Also, the mean proximity (PROX_MN) decreased strongly from $491.2 \mathrm{~m}$ to $24.2 \mathrm{~m}$. The combination of these values reveals that the agriculture patches in 2009 were smaller and more fragmented than the agriculture patches in 1979. As can be seen in Table 5.5, the 
1979 agricultural class has a higher interspersion and juxtaposition index (IJI) than the 2009 agricultural class (i.e. 18.1\%). Those values indicate that the spatial intermixing of agriculture patches in the landscape. Furthermore, the landscape shape index (LSI) supported this view by the increase from 50.8 to 60.2 within the 30-year study period, emphasizing a higher complexity of this class.

As mentioned above, urban area increased promptly from 6315.3 ha in 1979 to 17298.5 ha in 2009. Consequently, the spatial of urban areas showed the significant increasing of the percentage of landscape index (PLAND) from 3.7\% to 10.1\%. Likewise, the largest patch index (LPI) increased from $1.0 \%$ in 1979 to $4.6 \%$ in 2009, reflecting the encroachment of urban area in Da Nang City. It is further supported by the number of patches index (NP) increasing drastically from 682 to 1771 . The mean patch area (AREA_MN) of urban increased from 9.2 ha to 10.2 ha whereas the patch density (PD) increased from 0.4 per 100 ha to 1.0 per 100 ha. The agglomeration of new urban areas evidenced the rapid expansion of urban areas in landscape of Da Nang City during the span of thirty years. It can be seen from Table 5.5, the mean proximity (PROX_MN) of urban area increased substantially from $67.1 \mathrm{~m}$ to $1728.6 \mathrm{~m}$ and the interspersion and juxtaposition index (IJI) heightened 16.2 after 30-years. The first index showed a more uniform landscape configuration, in which urban patches became closer and less isolation. The next one presented that the urban patches were adjacent to each other and tended to take more clumped than before because of converting from other classes. The reduction of landscape shape index (LSI) from 41.2 to 25 illustrated a less complexity of this class.

\subsection{Discussions and conclusions}

By using Landsat and ASTER satellite images, this chapter presented the analysis of LULC and landscape change in the Da Nang region over the past thirty years (1979-2009). For detecting LULC changes, post-classification approach was applied. The results show the conspicuous changes of land use/cover, and thus substantial impact on landscape pattern. In general, a total of 35689.79 ha or $37 \%$ of the total land has undergone change. The analysis 
Chapter 5. LULC changes

indicates a notable decrease of agriculture, forest, barren, and shrub due to the expansion of urban.

The speed and transformation trends of LULC varied in different research periods. Before separating from Quang Nam Province (1979-1996), the LULC in Da Nang City changed gradually. However, after becoming an independent municipality, the LULC changed with rapid speed, especially urban area. Within thirteen years (1996-2009), urban area grew up $86.6 \%$. Spatially, it was shown that most of urban area occurred in Thanh Khe, Hai Chau, Ngu Hanh Son, and Cam Le districts. This could be caused by strong focus of economic development. From the following urban area, agriculture and forest had a high rate of change, with a decreasing trend. In the meantime, key landscape indices were performed for three main classes, viz., urban, agriculture and forest for further understanding in spatial distribution. Based on the analysis of landscape metrics, the different changes in landscape of Da Nang city were defined. The dynamic change of landscape indices at agriculture class revealed the break-up of the area into smaller patches. However, except agriculture, patches of forestry, and urban tended to have a uniform landscape configuration.

The study explored the changes of land use/land cover and spatial distribution of landscape in Da Nang City. This would help the decision maker and local authority have an overview in this area; it can integrate strategies into land use/cover planning which could be considered. However, this study has its own limitation. According to the results, it has been found that the number of patches (NP) of all classes changed dramatically over the past thirty years. Besides the fragmentation of patches due to the transformation of classes, such increase is probably due to the fact that ASTER image of 2009 with higher resolution could count small patches, compared to Landsat MSS image of 1979. 


\section{CHAPTER 6}

\section{Modeling Land Use/Cover Changes}

Chapter 6 deals with the simulation of land use/cover types in Da Nang City over periods of time (1996-2030). The first section presents the demand of land use/cover types for each year at the regional level as three specific scenarios based on SD modeling framework. These non-spatial scenarios are then used as one of the inputs of Dyna-CLUE. Regarding the parameters of Dyna-CLUE model, the relative settings are addressed in following sections. The results of running Dyna-CLUE model are explored through the allocation of land use/cover types within Da Nang City. The validations of models are assessed as well. Last section presents the effects of different scenarios to landscape structure within study area.

\subsection{Demands of land use/cover types}

\subsubsection{Demands of land use/cover types from 1996 to 2009}

As stated before, the demands of land use/cover types are simulated by using SD model under various parameters (Section 4.7.1.2). The results were examined and calibrated based on social-economic data in period of time from 1996 to 2009. Figure 6.1 shows the comparison between actual and predicted values of population, Gross Output Industry (GOI), and Fixed-Assets Investment construction (FAI) from 1996 to 2009. Figure 6.2 illustrates the comparison between actual values of land use/cover areas and their predicted values. 
Chapter 6. Modeling LULC Changes
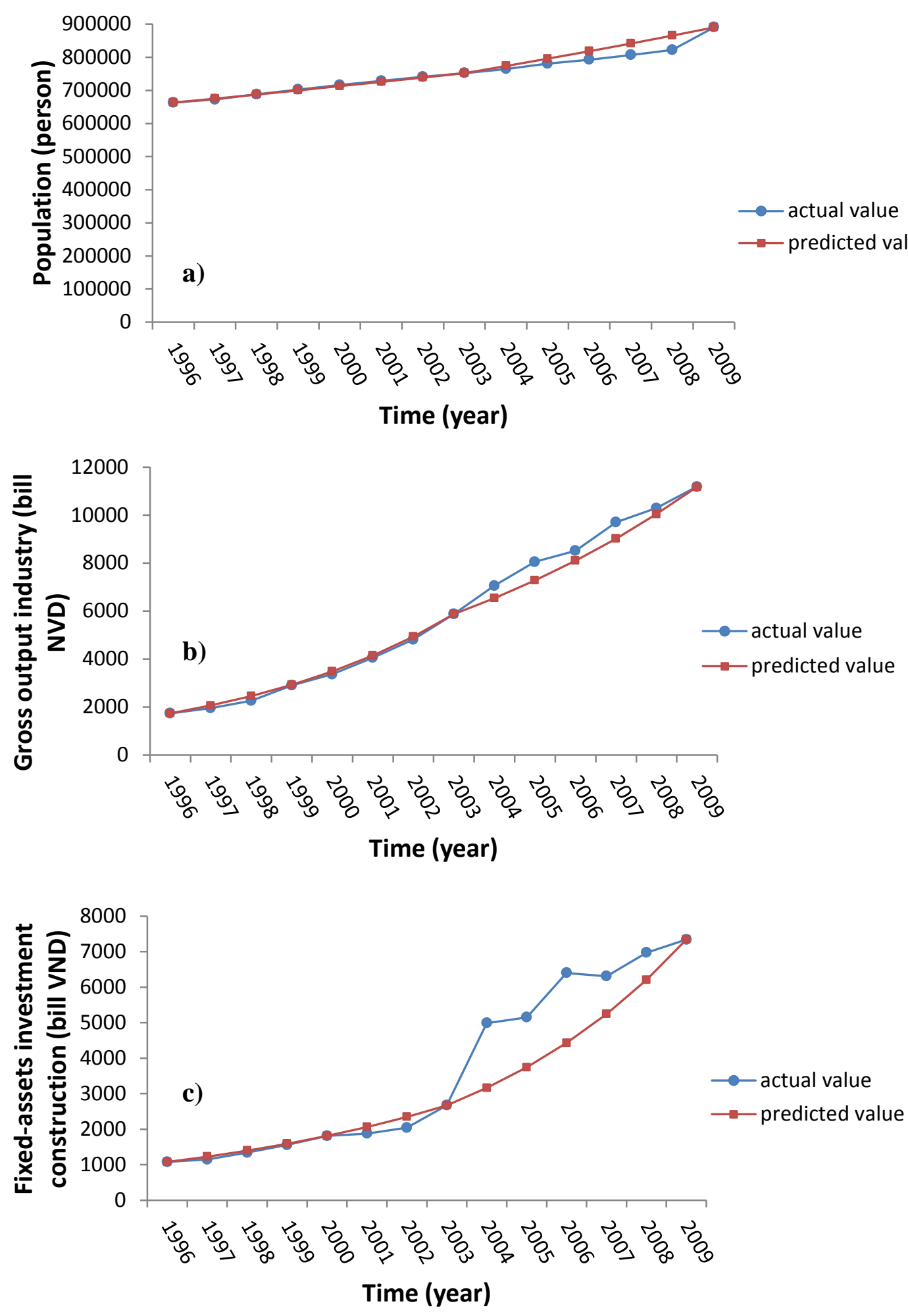

Figure 6.1 Comparison between actual and predicted values of a) Population, b) Gross output industry, and c) Fixed-assets investment construction

(Source: Own calculation) 
Chapter 6. Modeling LULC Changes

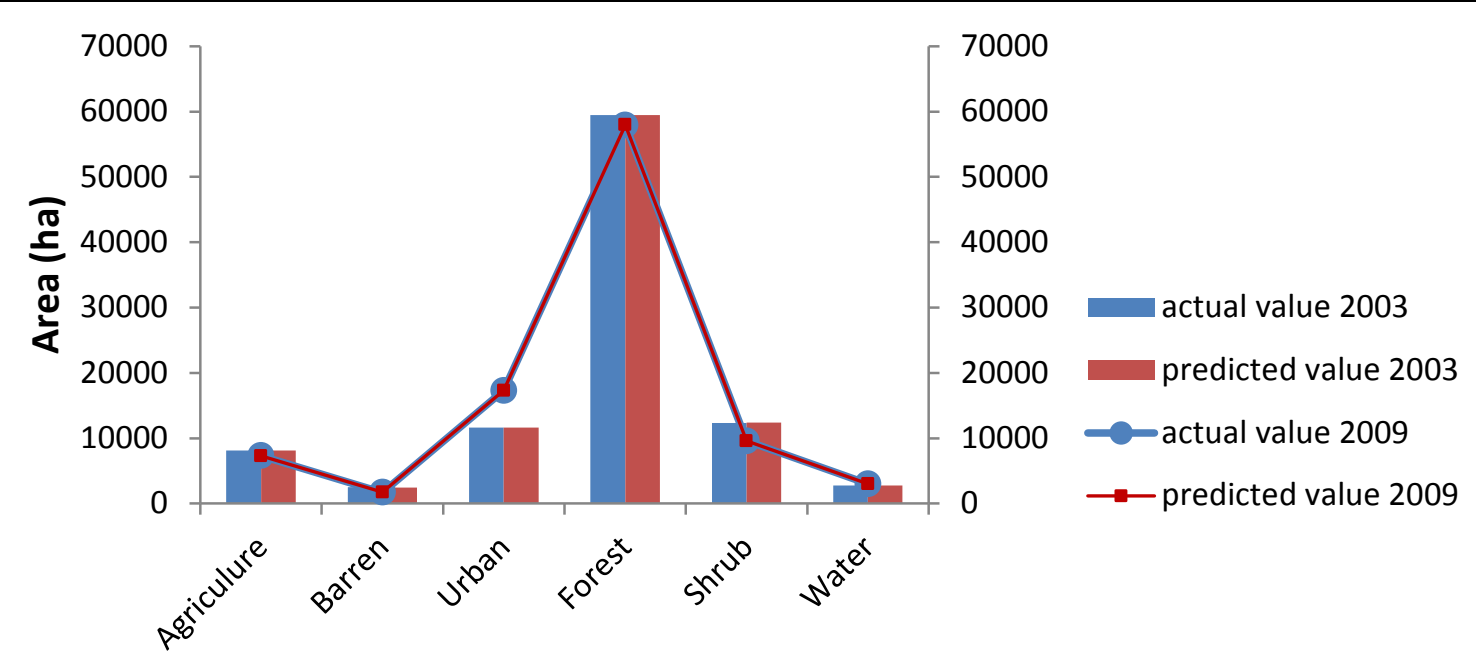

Land use/cover type

Figure 6.2 Comparison between actual and predicted values of land use/cover area (Source: Own calculation)

\begin{tabular}{lrrrr}
\hline Type & Year & Reference & Simulation & Error (\%) \\
\hline \multirow{2}{*}{ Population (person) } & 2003 & 752438 & 752438 & $\mathbf{0 . 0 0 0}$ \\
& 2009 & 890490 & 890489 & $\mathbf{0 . 0 0 0}$ \\
\hline \multirow{2}{*}{ GOI (bill VND) } & 2003 & 5874.59 & 5875.16 & $\mathbf{- 0 . 0 0 9}$ \\
& 2009 & 11179.48 & 11173.3 & $\mathbf{0 . 0 5 5}$ \\
\hline \multirow{2}{*}{ FAI (bill VND) } & 2003 & 2673.38 & 2673.53 & $\mathbf{- 0 . 0 0 6}$ \\
& 2009 & 7341.6 & 7345.89 & $\mathbf{- 0 . 0 5 8}$ \\
\hline \multirow{2}{*}{ Agriculture (ha) } & 2003 & 8118.1 & 8118.85 & $\mathbf{- 0 . 0 0 9}$ \\
& 2009 & 7294.7 & 7293.1 & $\mathbf{0 . 0 2 2}$ \\
\hline \multirow{2}{*}{ Barren (ha) } & 2003 & 2487.2 & 2457.83 & $\mathbf{1 . 1 8 1}$ \\
& 2009 & 1708.9 & 1723.53 & $\mathbf{- 0 . 8 5 6}$ \\
\hline \multirow{2}{*}{ Urban (ha) } & 2003 & 11630 & 11658.2 & $\mathbf{- 0 . 2 4 2}$ \\
& 2009 & 17298.5 & 17284.9 & $\mathbf{0 . 0 7 9}$ \\
\multirow{2}{*}{ Forest (ha) } & 2003 & 59467.1 & 59465.8 & $\mathbf{0 . 0 0 2}$ \\
& 2009 & 57936.2 & 57942.6 & $\mathbf{- 0 . 0 1 1}$ \\
\multirow{2}{*}{ Shrub (ha) } & 2003 & 12335.9 & 12364.9 & $\mathbf{- 0 . 2 3 5}$ \\
& 2009 & 9575.26 & 9568.29 & $\mathbf{0 . 0 7 3}$ \\
\multirow{2}{*}{ Water (ha) } & 2003 & 2779.0 & 2751.62 & $\mathbf{0 . 9 8 5}$ \\
& 2009 & 3003.6 & 3004.78 & $\mathbf{- 0 . 0 3 9}$ \\
\hline
\end{tabular}

Table 6.1 SD model results and validations (Source: Own calculation) 
A quantitative analysis of predicted parameter's accuracy in year of 2003 and 2009 is done and presented in Table 6.1. It indicates that the relative errors of simulation results in SD model are just around 1\%, compared with actual data. Hence, this model is reliable and can be used to forecast the future demand of land use/cover types.

\subsubsection{Demands of land use/cover types from 2009 to 2030}

\begin{tabular}{lrrr}
\hline Parameter (\%) & Scenario A & Scenario B & Scenario C \\
\hline Natural growth rate & 2.00 & 1.19 & 1.19 \\
Mechanical growth rate & 0.85 & 2.8 & 1.18 \\
GOI rate & 20.77 & 26.43 & 26.43 \\
FAI rate & 18.4 & 12.20 & 10.00 \\
\hline
\end{tabular}

Table 6.2 Setting parameters for three scenarios

Based on SD model which was presented in Figure 4.7, it is assumed that the scenarios would be distinguished by the change of four main parameters: natural growth rate, mechanical growth rate, Gross output industry (GOI) rate, and Fixed-assets investment construction (FAI) rate; while the other parameters in the model are maintained. These parameters were selected because they directly influence the changes of Population and Economic factors. In the next 22 years from the year of 2009, the designated main parameters are attained from Land use planning guideline, and General plan of socio and economic development of Da Nang City to 2020 (Table 6.2).

In this section, three different scenarios are presented. The first scenario is the baseline one so-called "development as usual", in which the simulation is based on the maintainable parameters obtained from historical statistics of Da Nang City (1996-2009). The second one is "aggressive development" which may speed up the growth rate of economic factors without considering environmental conditions. The last one is "optimal development”, in which both economic and environmental factors are noticed. The conditions of scenarios are presented as follows:

\section{Scenario A}


As can be seen in Table 6.2, the demand of land use/cover in this scenario is particularly based on the growth rate of the development between 1996 and 2009. It is assumed that the increase of population in Da Nang City is mainly due to the growth of natural rate (2\% per year). Being one of five centrally-controlled municipalities in Viet Nam in the early of year 1997, Da Nang city has moved into “a period of massive infrastructure building”. Besides, with the adopted of Law on Foreign Direct Investment, Da Nang City has attracted various invested projects (Nguyen, 2003). Consequently, the rate of Gross output industry and fixed-assets investment construction during this period is high. In scenario A, these rates are applied for simulating the demand of land use/cover area. It is also assumed that the water area (3003.79 ha in 2009) remained constant during the whole period of running the SD model.

\section{Scenario B}

In scenario $\mathrm{B}$, the simulation is made upon the assumption that the natural growth rate is $1.19 \%$ per year, while the mechanical growth rate is $2.8 \%$ per year. In addition, the rate of Gross output industry and Fixed-assets investment construction is $26.43 \%$ and $12.20 \%$, respectively. These rates are collected from the General orientation of socio-economic development in Da Nang City to 2020. In this scenario, the socio-economic condition of Da Nang City is supposed to be in a remarkable state; the infrastructure has been completed; and the policy on investment encouragement in Da Nang City is good as well. Hence, the mechanical growth rate is higher than in scenario A because of large-scale immigration to Da Nang City for finding jobs. Together with the increase of mechanical growth rate, the gross output industry rate of this scenario also increases to $26.43 \%$ per year. Out of the "period of massive infrastructure building", the fixed-asset investment construction of this scenario decreases to $12.20 \%$ per year. Similarly, the water area in this scenario also remains constant during the whole period of running the SD model.

\section{Scenario C}

In the third scenario, the supposed conditions of the model are almost as same as those in the second scenario. However, the mechanical growth and fixed-assets investment 
construction are lower at $1.18 \%$ per year and $10.0 \%$ per year, respectively. Importantly, this scenario focuses more on sustainable development according to the long term planning in Da Nang City. Accordingly, land use/cover types in Da Nang City must be considered more as protecting, sparely utilizing, and reasonably converting. By which, the socioeconomic component of city could be promoted to develop as a sustainable and stable strategy. In long term, the spatial pattern of city would be extended to the South, the West, and the North-west through developing the satellite towns. Restricting the conversion of agriculture area (especially, rice area) to other purposes is needed, in order to satisfy the society's demand for agricultural products, to supply the raw material for industry, and settle agricultural labors. Additionally, caring and protecting the actual forest area, and intensifying the afforestation play an important role in maintaining the ecological environment. Hence, it requires keeping the forest cover above $60 \%$ compared with total area in Da Nang City. In this scenario, the water area in year 2009 is also remained constant during the whole period of running the SD model.

Temporal simulation of land use/cover system in Da Nang City is presented in Table 6.3. Details about the predicted results of land use/cover area in Da Nang city as three scenarios could be found in Appendix 2.

Unit: ha

\begin{tabular}{rrrrrrrl}
\hline Year & Scenario & Agriculture & Barren & Urban & Forest & Shrub & water \\
\hline 2010 & 1 & 7054.52 & 1959.5 & 17934.5 & 57647.27 & 9218.1 & 3003.79 \\
& 2 & 6826.37 & 1538.11 & 18582.8 & 57686.9 & 9179.71 & 3003.79 \\
2020 & 3 & 7161.46 & 1538 & 18087.4 & 57936.2 & 9090.83 & 3003.79 \\
& 1 & 6094.01 & 0 & 24406.01 & 55183.5 & 8130.37 & 3003.79 \\
& 2 & 5287.91 & 536.3 & 24847.4 & 55253.8 & 7888.48 & 3003.79 \\
2030 & 3 & 6671.99 & 536.19 & 21734.28 & 57936.2 & 6935.23 & 3003.79 \\
& 1 & 4089.62 & 0 & 30884.66 & 52675.6 & 6164.01 & 3003.79 \\
& 2 & 1195.72 & 0 & 34451.24 & 52810.2 & 5356.73 & 3003.79 \\
& 3 & 5297.7 & 110.55 & 27092.77 & 57936.2 & 3376.67 & 3003.79 \\
\hline
\end{tabular}

Table 6.3 Temporal simulation of land use/cover system in Da Nang city

(Source: Own calculation) 


\subsection{Driving factors for allocation}

As stated in section 2.1.4, projecting the future changes of land use/cover types requires critical driving forces. According to the conditions of available data as well as the local features of the study area, seven factors were chosen to analyze the allocation of land use/cover in Da Nang City, including: extrinsic driving factors (urban rate, mean density of population), and intrinsic driving factors (slope, elevation, distance to road, distance to urban, and distance to water).

Each factor was prepared as grid map with a cell size of $30 \mathrm{~m}$ x $30 \mathrm{~m}$ (Figure 6.3). The two first factors (urban rate and mean density of population) were calculated according to collected data in the Yearly Statistics Book of Da Nang City, while the rest of the factors were computed with the grid cell as the basic unit. The elevation and slope factors were extracted from the Digital Elevation Model (DEM) of the study area by the tool in ArcGIS 10.1. The distance to urban, road, and water are Euclidean distances that were also generated upon the application of ArcGIS 10.1 package software. It is assumed that these driving factors contribute to the change of land use/cover in study area from 1996 to 2009 and will continue to do so over the next decades. 


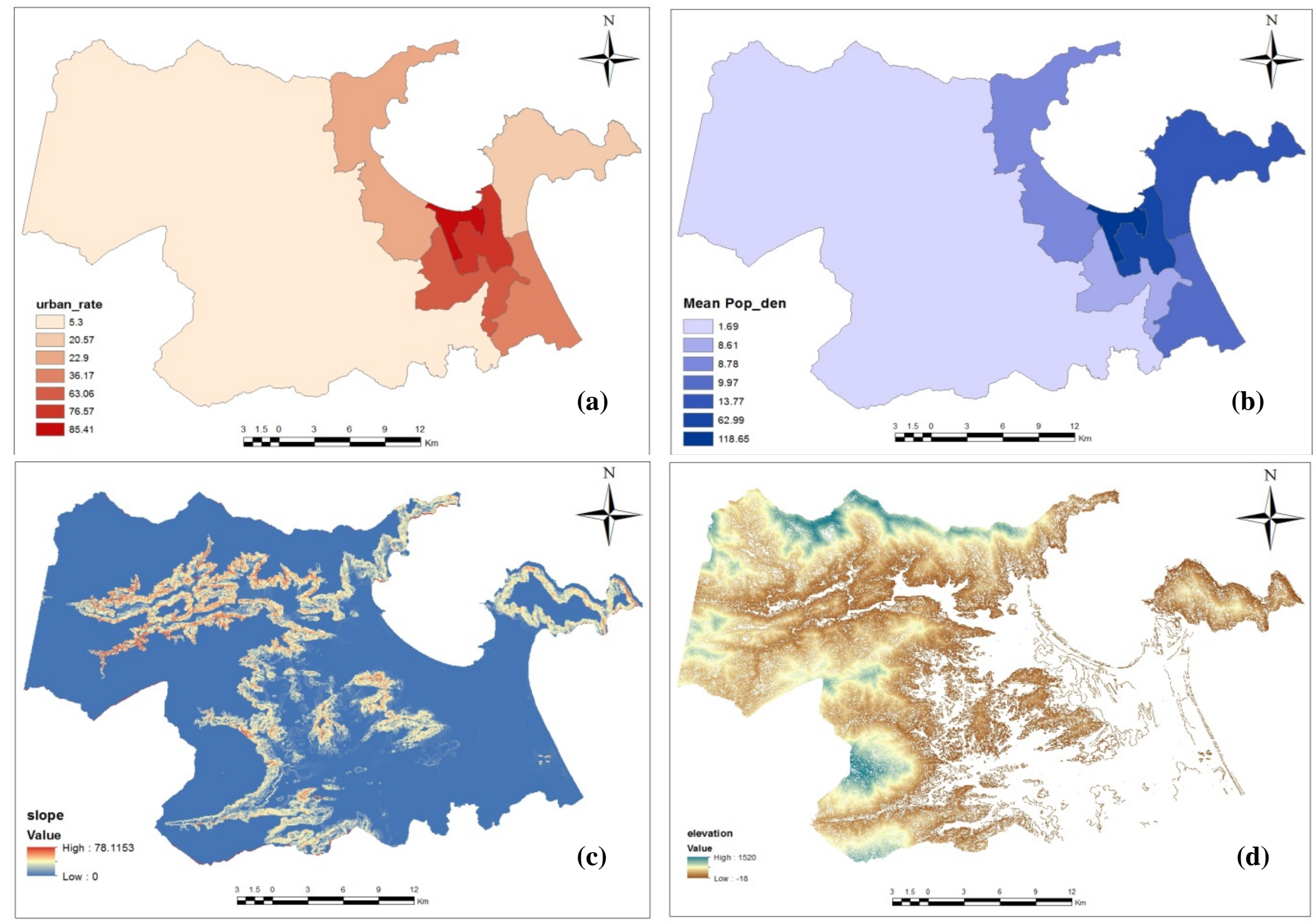

Figure 6.3 Driving factors a) Urban rate, b) Mean density of population, c) Slope, d) Elevation (Source: Own Calculation) 

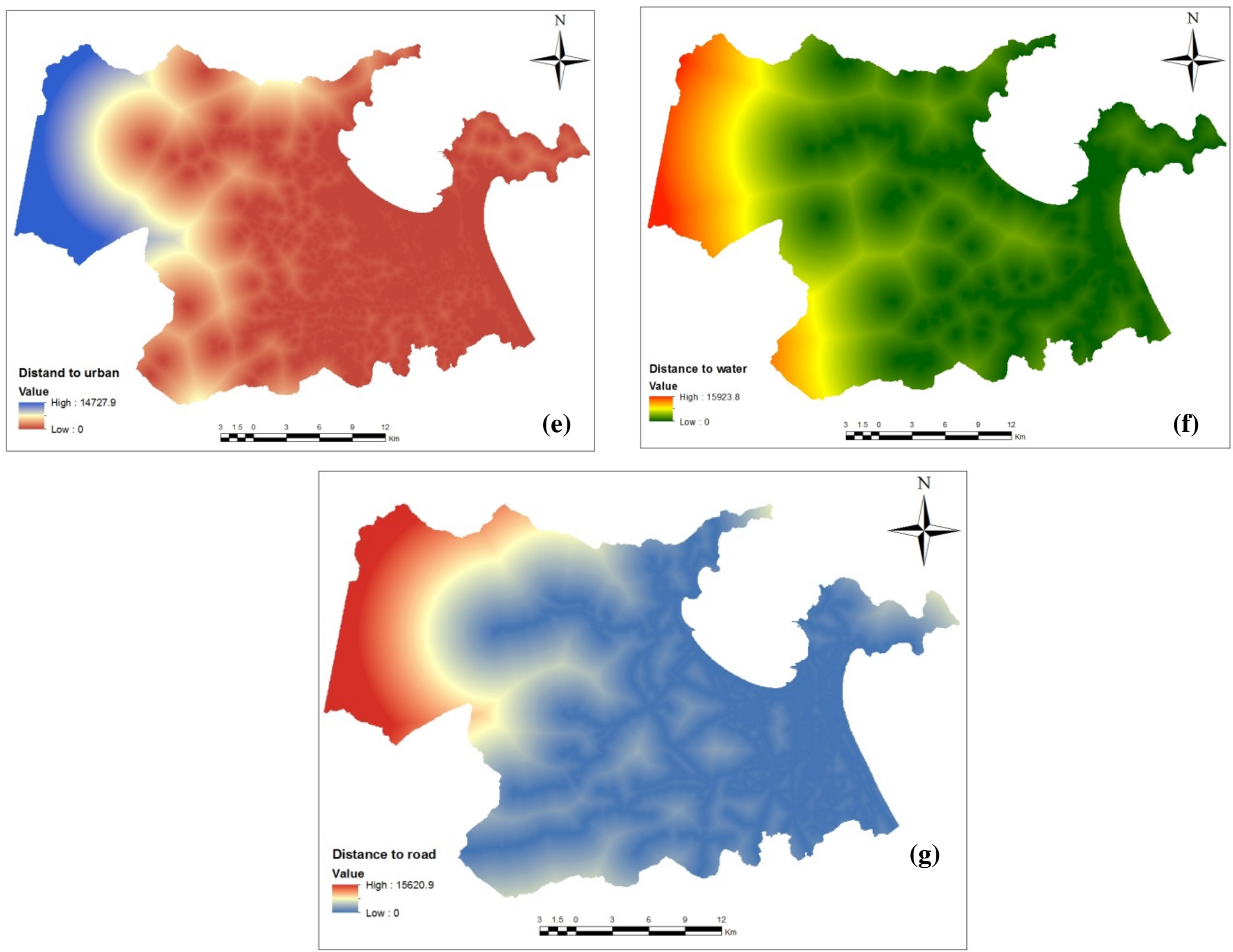

Figure 6.3 (continued) Driving factors e) Distance to urban, f) Distance to water, g) Distance to road (Source: Own calculation) 
Chapter 6. Modeling LULC Changes

\subsection{Logistic regression analysis}

\begin{tabular}{lrrrrrr}
\hline \multicolumn{1}{c}{ Land use/cover } & Agriculture & Barren & Urban & Forest & Shrub & Water \\
Driving factors & & & & & & \\
\hline Urban rate & -0.01492 & -0.00465 & 0.00645 & 0.01980 & -0.01848 & -0.00637 \\
Mean density of population & 0.01099 & -0.00867 & -0.01170 & -0.01485 & 0.02097 & -0.00949 \\
Slope & -0.00953 & 0.00556 & -0.00103 & 0.01690 & -0.01731 & 0.00650 \\
Elevation & -0.00026 & -0.00047 & 0.00036 & 0.00040 & -0.00054 & 0.00045 \\
Distance to road & -0.00034 & -0.00015 & -0.00023 & 0.00052 & -0.00030 & -0.00008 \\
Distance to urban & -0.00013 & -0.00088 & -0.02925 & 0.00118 & -0.00097 & 0.00017 \\
Distance to water & -0.00005 & -0.00007 & 0.00005 & 0.00018 & -0.00005 & -0.01899 \\
Constant & 0.94382 & 1.05483 & 2.63099 & -2.41997 & 1.41003 & 3.18663 \\
$\boldsymbol{R O C}$ & $\mathbf{0 . 6 9 7}$ & $\mathbf{0 . 7 8 0}$ & $\mathbf{0 . 9 9 0}$ & $\mathbf{0 . 9 1 3}$ & $\mathbf{0 . 7 8 0}$ & $\mathbf{0 . 9 9 8}$ \\
\hline
\end{tabular}

Table 6.4 Logistic regression of land use/cover type

(Source: Own calculation)

To examine the relation between land use/cover types and their potential driving factors, multivariate logistic regression model was conducted for LULC map of the year 1996 (the initial year of running Dyna-CLUE model). In this study, all the driving factors were chosen to assess the appropriateness of a special grid cell to be exerted to a certain land use/cover type. The logistic regression analysis was run with the statistic software IBM SPSS package 20. In which, land use/cover types were set as dependent variables, while driving factors were set as independent variables that influence spatial patterns. The regression confidence degree that was used in the analysis is set to $98 \%(\alpha=0.02)$. The results of logistic regression are presented in Table 6.4. More detail can be found in Appendix 3.

In this regression, seven variables are considered as driving factors. Each variable has its own effect on the spatial pattern of each land use type. The coefficient $\beta$ in logistic regression results is used to explain this correlation. Larger positive $\beta$ value reveals stronger positive correlation between driving factors and land use/cover type, whereas larger negative $\beta$ value reveals stronger negative correlation (Priyanto, 2010). Table 6.4 
Chapter 6. Modeling LULC Changes

shows the explanation how driving factors affect to the probable changes of land use/cover types in Da Nang City.

Regarding agricultural area, the finding shows that mean density population is the biggest positive determinant in allocation of this type of land use compared to the other driving factors. It has coefficient $\beta$ value at 0.01099 and exponential $\beta$ value at 1.011 (Appendix 3_Table A3.3), which means that the increase of 1 unit mean density population variable will influence 0.01099 unit of agriculture area to change with the probability value at 1.009 (or, in other words, 1 unit influence of mean density population has 91.99 probability of changing agricultural area). Other driving factors and other land use/cover types could be interpreted in the same way. Urban rate has a strong negative effect on allocation of agriculture area (-0.01492). The distance to water is shown to be the factor that has the lowest negative significance in the change of agriculture area $(-0.00005)$.

Similar to agricultural area, barren also has seven driving factors. However, only slope factor has a positive impact on the occurrence of this kind of land cover (0.00556). Urban rate is considered as the factor that has the largest negative effect to the change of barren (-0.00465). The results of logistic regression model are reasonable. Most of barren areas in Da Nang City are distributed in high slope positions which could be examined from image interpretation. In addition, barren area is seen as the expansive source of any kind of land use/cover type, especially urban area closely related with urban rate factor.

According to logistic regression for urban area, some driving factors were classified as positive variables, including urban rate, elevation, and distance to water. On other hand, four factors (mean density of population, slope, distance to road, and distance to urban) were considered as negative variables. The correlation of each driving factor with the probability change of urban area in this research is reasonable. As observed from remote satellite images, residential areas in Da Nang City tend to expand along the coastal line and river banks. Moreover, people prefer to concentrate their housing in central areas rather than in satellite towns. This could be explained by the psychology of most Vietnamese people liked to be in the existing central area where the public facilities and health facilities are obtained easier. Another interesting finding is that the elevation factor has a positive 
Chapter 6. Modeling LULC Changes

effect on the increase of urban area. It means that urban area tends to expand in the higher elevation. Most of existing urban built-up areas in Da Nang City have been located plentifully along the coastal line. In this case, new urban areas must be expanded inland where the elevation is higher. In addition, this could help to avoid sea level rise. Another reason is that lower areas are given priority for agriculture and aquaculture activities.

The model for forest area has just one negative factor (mean density of population), and six positive factors in contributing the allocation (urban rate, slope, elevation, distance to road, distance to urban, distance to water). The results denote that the increase of population and their demands are the main reasons of the loss of forest areas. In contrast to forest land, mean density of population is the positive factor in predicting the presence of shrub; all the rest of the factors are negative.

Related to water area, urban rate, mean density of population, distance to road, distance to water are the dependent factors that have negative values in logistic regression model. The others have positive effects to the change of water area. The negative relationships with the urban rate and mean density of population reveal that the increase of population may threaten the area of water because of the expansion of urban area.

The allocation of land use/cover types are well explained by the selected driving factors that have the high ROC test statistic. In this study, ROC values of logistic regression models ranges from 0.70 to 0.99 , depending on types of land use/cover. Based on the considering of (Pontius and Schneider, 2001), ROC values over 0.7 and less than 0.8 are acceptable, while ROC values over 0.8 are excellent. It can be concluded that the results of the logistic regression model are capable of explaining the spatial variation occurring in the different land use/cover types within the Da Nang City. The analytical results of the logistic regression model in Table $\mathbf{6 . 4}$ denoted that the allocations of all land use/cover types are jointly determined by biophysical elements (slope, elevation, etc.) and socio-economic elements (urban rate, mean density of population). These values could be used as input of the Dyna-CLUE model. More details about ROC curves are presented in Appendix 4. 
Chapter 6. Modeling LULC Changes

\subsection{Elasticity coefficients}

The codes of allowing changes and behavior of land use/cover types in the study area were specified by running the Dyna-CLUE model various times with sets of conversion elasticity specified by the user. After each run, the simulated maps in year 2003 and 2009 were converted from ASCII files to grid maps. These maps were assessed the accuracies with reference data in the same year, afterwards. It was found that the most reliable simulation results were generated from the following set of elasticity coefficients (Table 6.5).

\begin{tabular}{lr}
\hline Land use/cover type & Elasticity \\
\hline Agriculture & 0.4 \\
Barren & 0.2 \\
Urban & 1 \\
Forest & 0.9 \\
Shrub & 0.6 \\
Water & 1 \\
\hline
\end{tabular}

Table 6.5 Elasticity coefficient of land use/cover type

(Source: Own calculation)

Elasticity coefficient of urban is set the maximum value as 1 because it is assumed to have the highest conversion cost compared with other land use/cover types. Water is set to 1 because it is considered to have maintained the same size and location during the simulation period. Barren is believed as the most spatially dynamic land use, thus, its elasticity is set to 0.2. During the last two decades, urban areas in Da Nang City have mainly expanded at the expense of agriculture. Hence, its elasticity is supposed to be 0.4 . Shrub also could be considered the second source for expanding urban area. Consequently, its elasticity coefficient is assigned at 0.6 . Once an area is covered by forest, it is difficult to convert into other kinds of land use/cover; therefore, its elasticity coefficient is chosen as 0.9 . The value of 0.9 denotes that in the condition of net negative change of forest cover, the reforestation plays an important role in compensating the loss of forest area. These values would be used as one of the main parameters in the Dyna-CLUE model. More details could be found in Appendix 5. 
Chapter 6. Modeling LULC Changes

\subsection{Conversion matrix}

The conversion matrix is also generated to determine what the future land use is likely to be. Similar to the way in specifying elasticity coefficients, the conversion matrix was examined based on the knowledge about the changes of land use/cover types within the study area. After running the Dyna-CLUE model in various times, the land use/cover conversion matrix is determined in Table 6.6. In this matrix, the left side (column) is the current land use/cover types, and the right side (row) is the converted land use/cover types. If a conversion is supposed possible, then the value is set equal 1; if not, the value is set equal 0. Of the six land use/cover types used, changes are permitted for the following types: agriculture, barren, urban, forest, and shrub. As stated before, the size and location of water area is considered to fix at the temporal and spatial scale during the simulation period.

\begin{tabular}{lcccccc}
\hline Land use/cover type & Agriculture & Barren & Urban & Forest & Shrub & Water \\
\hline Agriculture & 1 & 1 & 1 & 1 & 1 & 1 \\
Barren & 1 & 1 & 1 & 1 & 1 & 1 \\
Urban & 0 & 0 & 1 & 0 & 0 & 1 \\
Forest & 1 & 1 & 1 & 1 & 1 & 1 \\
Shrub & 1 & 1 & 1 & 1 & 1 & 1 \\
Water & 0 & 0 & 0 & 0 & 0 & 1 \\
\hline
\end{tabular}

Table 6.6 Conversion matrix of land use/cover type (Source: Own calculation)

\subsection{Validation output from the Dyna-CLUE model}

\subsubsection{Visual comparison}

As stated before (section 4.7.3.2), visual comparison is the quickest way to access the spatial patterns of models. Consequently, the visual changes of land use/cover are computed through the following pairs of maps: reference maps of year 1996 and 2003, reference map of year 1996 and simulation map of year 2003. The left side of Figure 6.4 shows that there is a visual similarity between Dyna-CLUE's simulated map of year 2003 and the reference map of year 2003. 


\section{Chapter 6. Modeling LULC Changes}

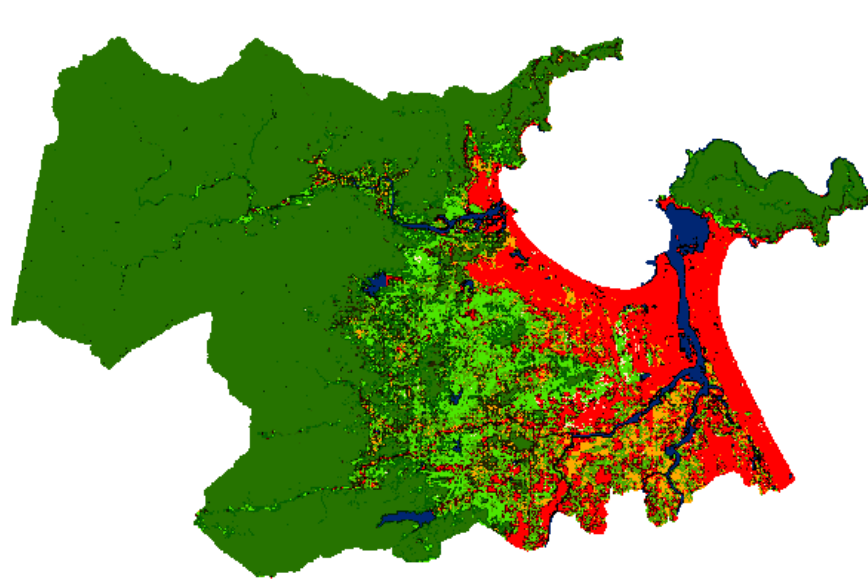

Reference 1996

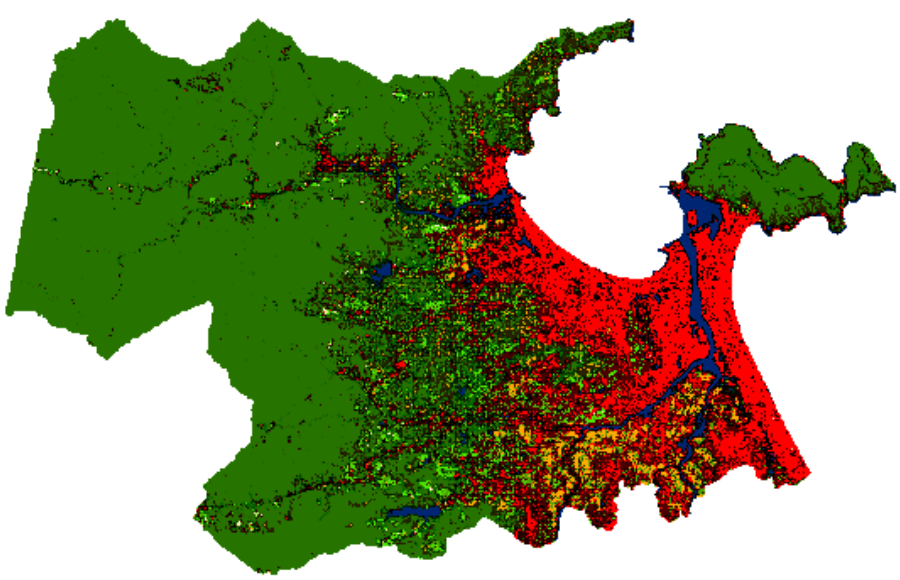

Reference 2003

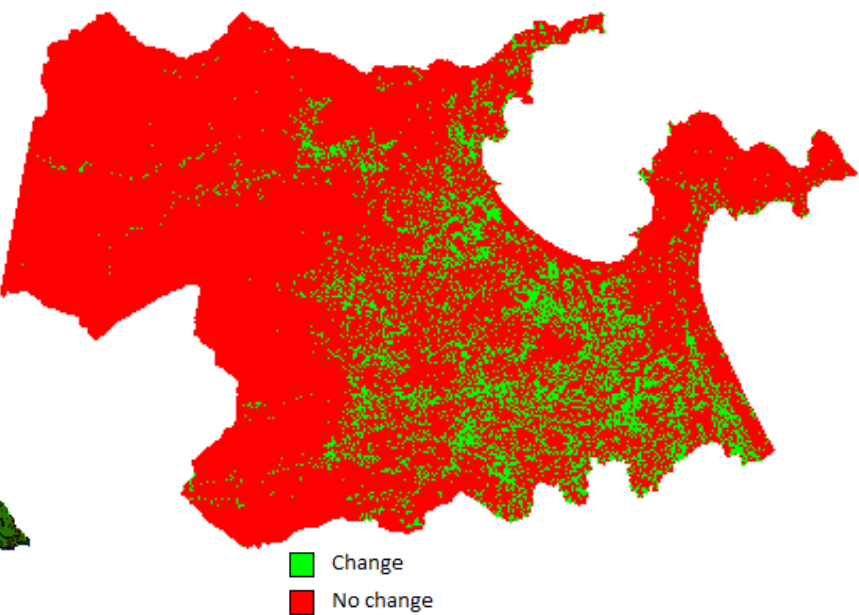

Actual change from 1996 to 2003
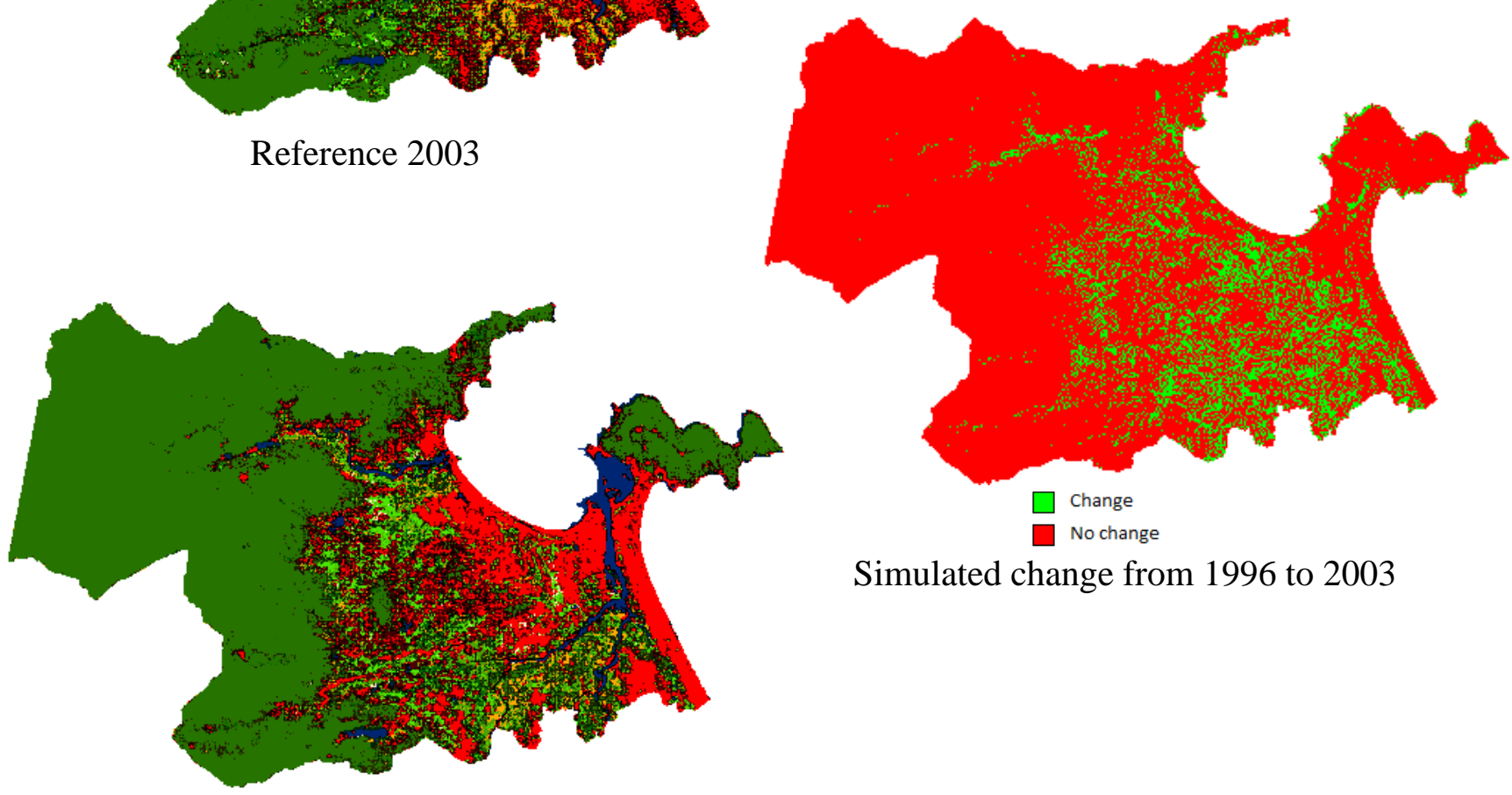

Simulated change from 1996 to 2003

Simulation 2003

Figure 6.4 Visual comparison between the pairs of maps (Source: Own calculation) 
Closer comparisons among the three maps are presented on the right side of Figure 6.4. The map on the upper right position of Figure 6.4 reveals the actual changes based on the reference data, while the map on the bottom right supposes the changes of land use/cover types in Da Nang City based on predictions of the Dyna-CLUE model. The areas of changes are displayed in green color while non-green color denotes the static characteristic of land use/cover over the space and time. These pair of maps shows some similarities between the actual and the simulation changes even though there are some differences. The simulated changes from 1996 to 2003 compared to actual changes in the same period show that the most concentrated conversions were in the south-east of Da Nang City.

The findings above demonstrate the capability of the Dyna-CLUE model in predicting approximately the land use/cover changes in Da Nang City. Upon this consideration, statistical techniques of comparison are applied to detect the complex patterns of change that are missed by human eyes (Pontius Jr et al., 2004).

\subsubsection{Agreements components}

The model creates a total of 35 simulated maps from the run of each scenario. In this case, to assess the accuracy of the model, the simulated land use maps at run 7 and run 13 were compared to the available land use maps extracted from remote satellite data in years 2003 and 2009, respectively. This would be done according to the validation processing steps mentioned in section 4.7.3.3.

\begin{tabular}{lcc}
\hline Index & $\mathbf{2 0 0 3}$ & $\mathbf{2 0 0 9}$ \\
\hline $\mathrm{K}_{\text {Simulation }}$ & 0.77 & 0.76 \\
$\mathrm{~K}_{\text {Transloc }}$ & 0.71 & 0.68 \\
$\mathrm{~K}_{\text {Transition }}$ & 0.96 & 0.93 \\
\hline
\end{tabular}

Table 6.7 Accuracy assessment indices of land use change modeling (Source: Own calculation)

Table 6.7 shows the indices in assessing the accuracy of model through the variation of agreement indices, including $K_{\text {Simulation }}, K_{\text {Transloc }}$, and $K_{\text {Transition. }}$. In general, the result 
Chapter 6. Modeling LULC Changes

indicates that the agreement of simulated and observed land use maps is more accurate at simulating the quantity than allocation of land use/cover types. Because, allocation of land use/cover types in the model were determined by the most appropriate of all factors, including quantity of land use/cover types, driving factors, elasticity, etc. $K_{\text {Transition }}$ index of both predicted maps in year 2003 and 2009 is above 90\%, whereas $K_{\text {Transloc }}$ index is around 70\%. According to (Pontius and Schneider, 2001), land use/cover change model which has Kappa index over 0.5 is considered satisfactory. Again, Landis and Koch (1977) asserted the characteristic agreement as follows: values of 0.4 or less reveal a poor model, values from 0.4 to 0.75 are fair to good, and values over 0.75 are very good to excellent. The Kappa values of this study are considered similar to the results of other literatures, such as the study of Verburg et al. (1999), who obtained an accuracy range of 71-90\% in modeling the change of land use in Ecuador by CLUE-S. In other words, the positive values of Kappa in this study assert a positive correlation between the simulated maps and the actual maps. As a result, the predefined rules were considered for running the prediction procedure (see Figure 4.6).

\subsection{Analysis the changes of scenarios}

\subsubsection{Land use/cover changes under different scenarios}

The results of the Dyna-CLUE model provide pictures of future land use/cover within the study area following three differing scenarios for the period 2009-2030 which were differentiated by demands of land use/cover types. Figure 6.5 presents land use/cover of scenario A in Da Nang City from 2009 to 2030, if the policy in developing economic is maintained. Between 2009 and 2030, scenario B represents the economic growth storyline with a huge increase of urban area in comparison to scenario $C$, the environmental emphasis storyline (Figure 6.6, 6.7). According to the simulated results, it is documented that land use/cover patterns created by the Dyna-CLUE model are consistent with those extracted in the historical maps. Figures 6.5-6.7 demonstrate that remarkable changed areas are frequently discovered in the south-east part of Da Nang City, especially where the areas have high rate of urban and low elevation. 

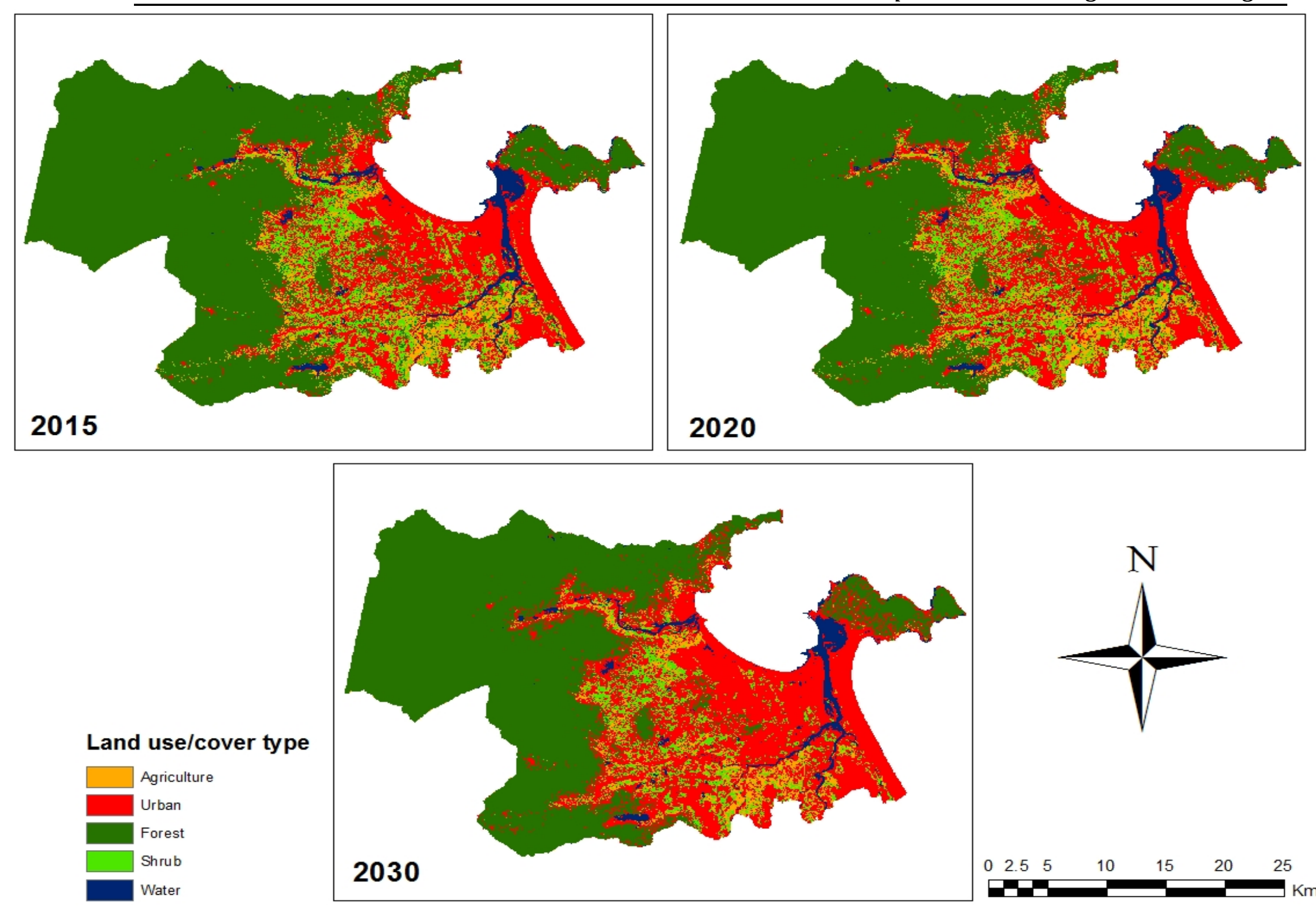

Figure 6.5 Simulated LULC maps in scenario A (Source: Own calculation)

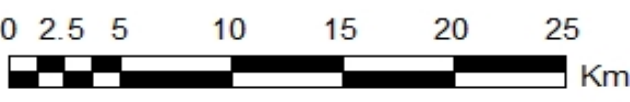



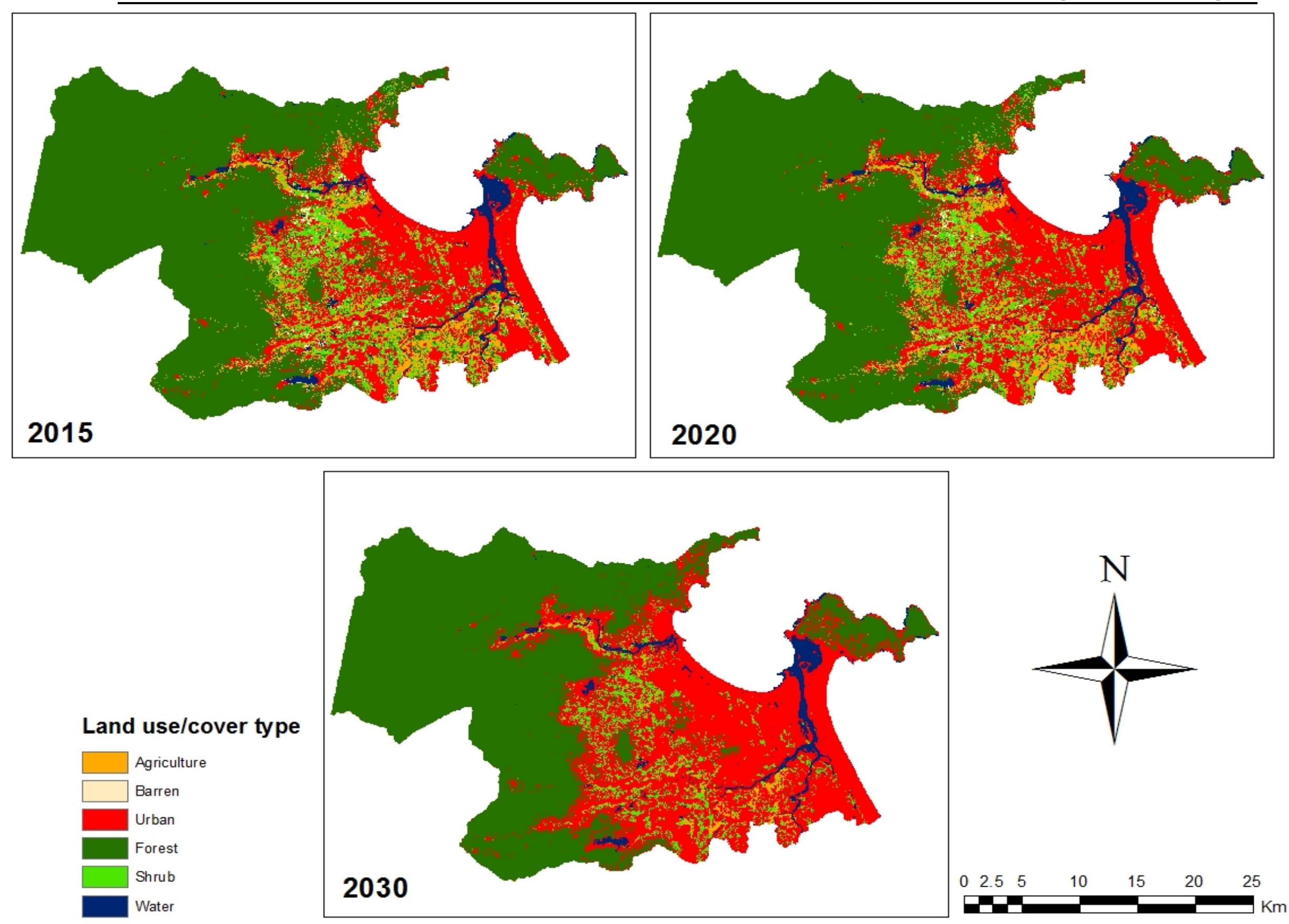

Figure 6.6 Simulated LULC maps in scenario B (Source: Own calculation) 

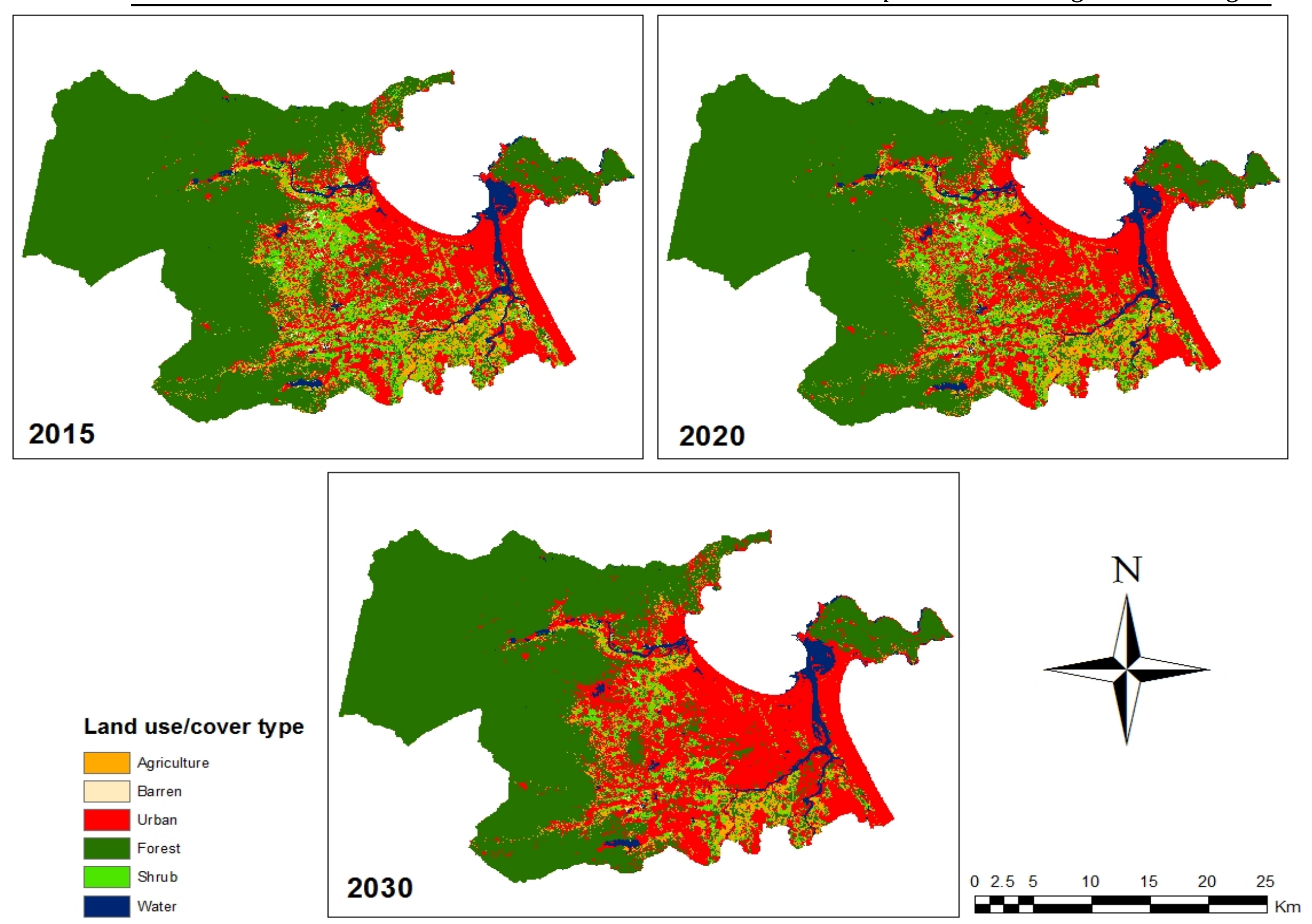

Figure 6.7 Simulated LULC maps in scenario C (Source: Own calculation) 
Chapter 6. Modeling LULC Changes

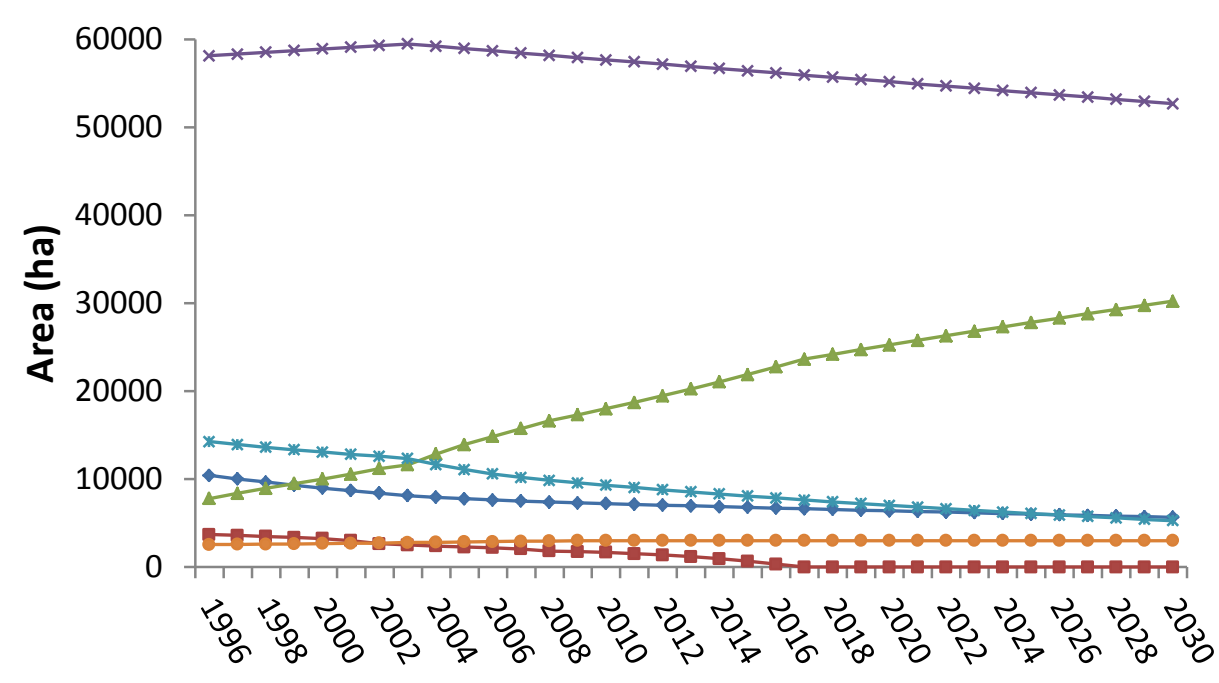

$\rightarrow$ Agriculture

$\rightarrow$ Barren

—Urban

$\rightarrow$ Forest

$\rightarrow$ - Shrub

$\because$ Water

(a) Scenario A

Time (year)

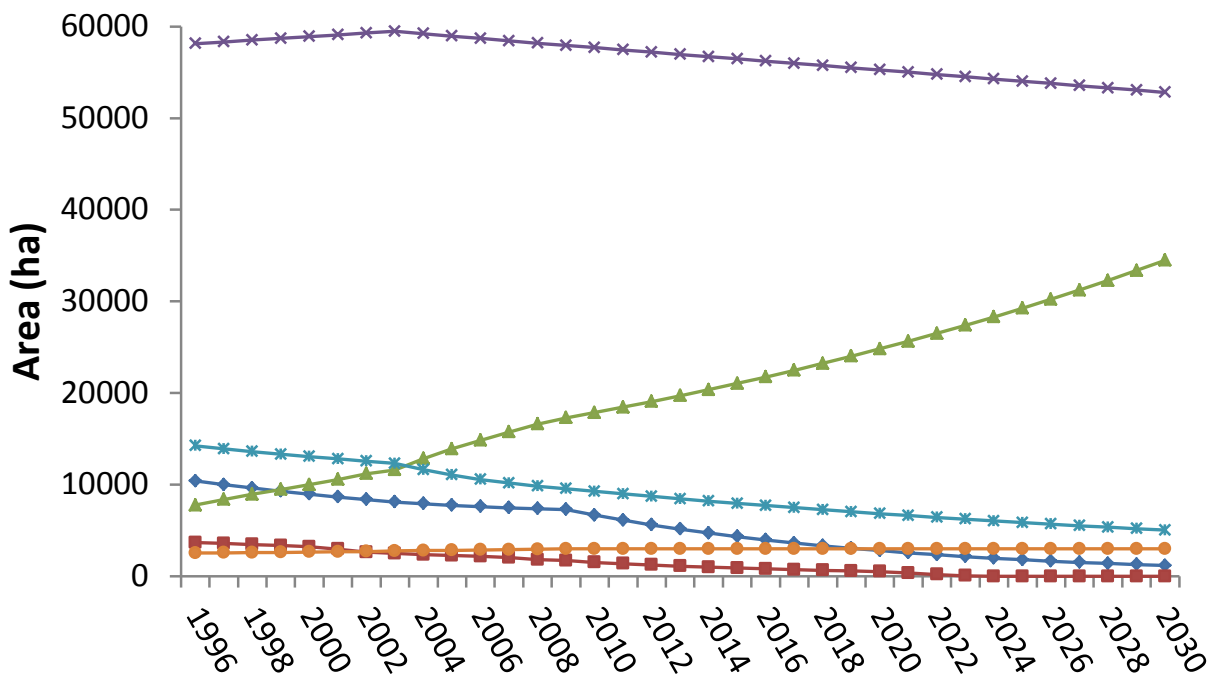

$\longrightarrow$ Agriculture

$\rightarrow$ Barren

$\longrightarrow$ Urban

$\rightarrow$ Forest

— Shrub

$\rightarrow$ Water

(b) Scenario B

Time (year)

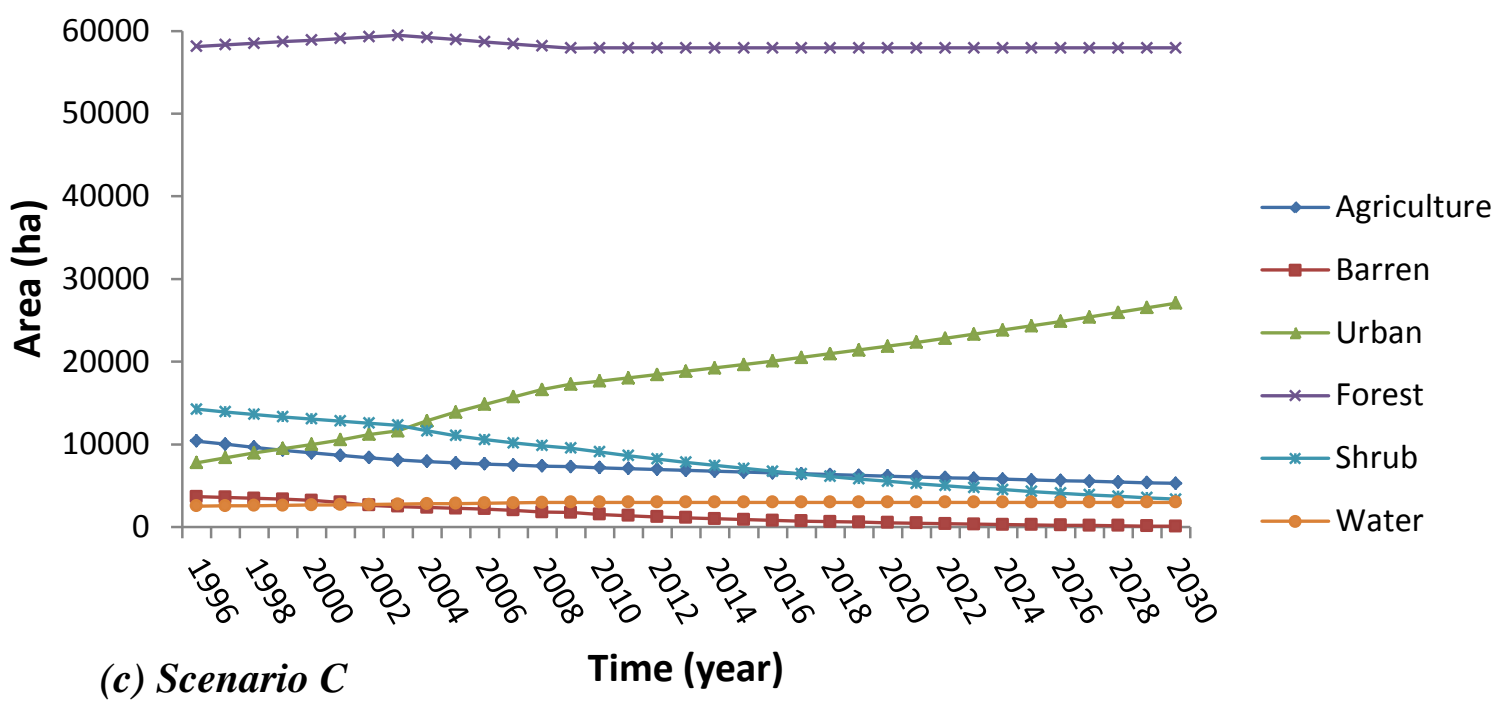

Figure 6.8 Land use/cover types under different scenarios (Source: Own calculation) 
Chapter 6. Modeling LULC Changes
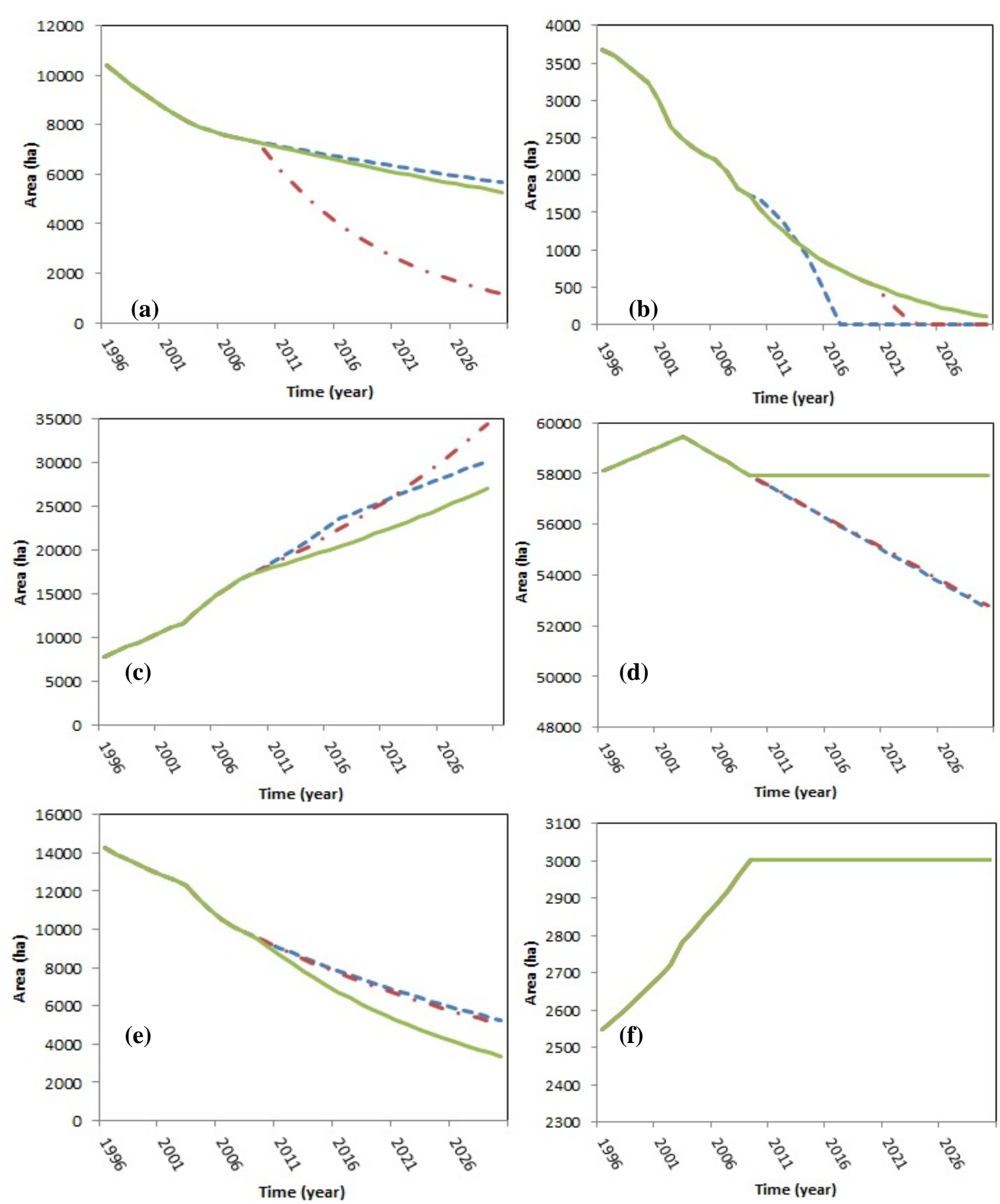

$$
\begin{array}{r}
-- \text { Scenario A } \\
- \text { Scenario B } \\
\text { Scenario C }
\end{array}
$$

Figure 6.9 Comparisons of land use/cover in three scenarios: a) Agriculture, b) Barren, c) Urban, d) Forest, e) Shrub, f) Water

(Source: Own Calculation) 
Chapter 6. Modeling LULC Changes

\begin{tabular}{|c|c|c|c|c|c|c|c|}
\hline \multirow{3}{*}{$\begin{array}{l}\text { Land } \\
\text { use/cover }\end{array}$} & \multirow{3}{*}{$\begin{array}{c}\text { Baseline } \\
2009 \\
\text { Area } \\
\text { (ha) }\end{array}$} & \multicolumn{6}{|c|}{ Scenario } \\
\hline & & \multicolumn{2}{|c|}{ A } & \multicolumn{2}{|c|}{ B } & \multicolumn{2}{|c|}{$\mathrm{C}$} \\
\hline & & $\begin{array}{l}\text { Area } \\
\text { (ha) }\end{array}$ & $\begin{array}{c}\Delta \text { Area } \\
\text { (ha in \%) }\end{array}$ & $\begin{array}{l}\text { Area } \\
\text { (ha) }\end{array}$ & $\begin{array}{c}\Delta \text { Area } \\
\text { (ha in \%) }\end{array}$ & $\begin{array}{l}\text { Area } \\
\text { (ha) }\end{array}$ & $\begin{array}{c}\Delta \text { Area } \\
\text { (ha in \%) }\end{array}$ \\
\hline Agriculture & 7294.68 & 4089.62 & $\begin{array}{c}-3205.06 \\
(43.94)\end{array}$ & 1195.72 & $\begin{array}{c}-6098.96 \\
(83.61)\end{array}$ & 5297.7 & $\begin{array}{c}-1996.98 \\
(27.40)\end{array}$ \\
\hline Barren & 1708.92 & 0 & $\begin{array}{c}-1708.92 \\
(100)\end{array}$ & 0 & $\begin{array}{c}-1708.92 \\
(100)\end{array}$ & 110.55 & $\begin{array}{r}-1598.37 \\
(93.53)\end{array}$ \\
\hline Urban & 17298.54 & 30884.66 & $\begin{array}{c}13586.12 \\
(78.54)\end{array}$ & 34451.24 & $\begin{array}{c}17152.7 \\
(99.16)\end{array}$ & 27092.77 & $\begin{array}{c}9794.23 \\
(56.62)\end{array}$ \\
\hline Forest & 57935.79 & 52675.6 & $\begin{array}{c}-5269.19 \\
(9,1)\end{array}$ & 52810.2 & $\begin{array}{c}-5125.59 \\
(8.85)\end{array}$ & 57936.2 & $\begin{array}{c}0,41 \\
(0.00007)\end{array}$ \\
\hline Shrub & 9575.82 & 6164.01 & $\begin{array}{c}-3411.81 \\
(35,63)\end{array}$ & 5356.73 & $\begin{array}{c}-4219.09 \\
(44.10)\end{array}$ & 3376.67 & $\begin{array}{c}-6199.15 \\
(64.74)\end{array}$ \\
\hline Water & 3003.57 & 3003.57 & $0(0.0)$ & 3003.57 & $0(0.0)$ & 3003.57 & $0(0.0)$ \\
\hline
\end{tabular}

Table 6.8 Comparison of land use/cover changes in 2030 under three scenarios

(Source: Own calculation)

The simulation results of each land use/cover type under different scenarios are presented in Figure 6.8 and Figure 6.9. The graphs indicate that only water area does not change during the whole period of running the model. Under the setting conditions of the three scenarios, urban area is the only one which increases at the expense of other land use/cover types. The urban class expands along costal region of Da Nang City in all three scenarios. In comparison, the growth of urban area in scenario $\mathrm{C}$ is more sustainable than in the other two scenarios. As can be seen in Table 6.8, the least expansion is by 27092.77 ha in 2030 under scenario C (56.62\% net increase compared to baseline 2009), with the environmental success storyline, and the highest one is 34451.24 ha in 2030 under scenario B (99.16\% net increase compared to baseline 2009), with less concern for environment issues. Overall, urban area in Da Nang City is developed by following a space-filling pattern tendency. In this sense, new developments are located around the existing urban areas.

With continuous acceleration of population and economics, the area of agriculture, barren, forest, and shrub will significantly decrease. Barren is considered to be a source for expanding other land use/cover types, such as urban. As a result, this 
area decreases strongly in all scenarios. With regards to agriculture, the scenario B with the assumption of rapid development, shows a decrease by 6098.96 ha (83.61\%) in agriculture area between 2009 and 2030. The agriculture area for the A and C scenario decreases by -3205.06 ha (43.94\%) and 1996.98 ha (27.40\%), respectively. Figures 6.5 and 6.7 show that good quality agriculture areas in scenarios $A$ and C are kept unchanged. Despite the fact that the remaining agriculture area is small in size, it is the important part contributed to ecosystem in the study area. Forest in scenarios A and B decreases approximately 9\% between 2009 and 2030. Meanwhile, scenario C, which is concerned with environmental issues, resulted in maintaining the forest cover over $60 \%$ of total area in Da Nang City. Therefore, the forest area in scenario C will be retained at 57936.2 ha during the whole period of running the model. Finally, the area of shrub in scenario C decreases strongly from 9575.82 ha in 2009to 3376.67 ha in 2030, showing a net decrease of $64.74 \%$ after 22 years of simulation.

Consequently, the B scenario, assuming rapid development in economics without regulation, resulted in the largest change in barren, urban and agriculture area. The $\mathrm{C}$ scenario, which is more concerned with environmental issues, resulted in the highest demand for forest area. Scenario A shows the baseline of development within Da Nang City which could be considered as the average level for comparing scenarios.

\subsubsection{Land use/cover changes according to administration boundary}

The distribution changes of land use/cover in 2030 under different scenarios are also summarized in relation to administrative district boundaries (Table 6.9). As stated before, water area is maintained during the simulated period. Therefore, the area of this land cover is stable in all districts under all scenarios. The B scenario, with the largest changes in urban area, shows the expansion of urban area as largest in Hoa Vang district with 12208.7 ha (225.3\%) in comparison to 2009. The increase of urban area in scenario $B$ in Hoa Vang district is approximately twofold the increase of this kind of land use in scenario C at 7064.5 ha (130.4\%). As presented in Table 5.4, urban areas in 2009 were highly concentrated in Thanh Khe, Hai Chau, and Ngu Hanh Son districts with 88.4\%, 73.4\%, and 69.4\%, respectively. Thus, very few new urban areas are distributed in these districts during simulated period. Besides the Hoa Vang district, this dynamic area is also allocated in the Son Tra, Lien Chieu, and Cam Le districts with 1105.9 ha (68.9\%), 
1545.9 ha (44.6\%), and 793.9 ha (38.4\%), respectively, under scenario B in 2030. The A scenario results in less change than do the B scenario. It can be interpreted that the simulated urban areas under all scenarios occur in districts where the urban rate is low, and conversely.

Table 6.9 shows that agriculture area in scenario B decreases in almost districts, except Thanh Khe where the agriculture area was too small (0.5 ha in 2009). Although, the percentage of change is just around $74.3 \%$, in comparison to other districts, the agriculture area in Hoa Vang has the highest decrease (-3364.5 ha). Agricultural area in the $\mathrm{C}$ scenario is forecast to decrease with lower percentage than in the B scenario between 2009 and 2030. For example, agriculture area under scenario C is suggested to decrease by 263 ha (32.2\%) in Lien Chieu district and 15.5 ha (16.3\%) in Son Tra district, while the percentage of these districts in B scenario is $100 \%$ and $97.5 \%$, respectively. Similar to urban area, the agriculture areas in the A scenario results less change than in the B scenario. As shown in Table 6.9, forest with large areas in 2009 were mostly distributed in Hoa Vang, Son Tra, and Lien Chieu districts with 52450.5 ha, 3682.4 ha, and 2744.6 ha, respectively. The A scenario resulted in the largest change in forest area, with the demand for forest area decreasing by 6286.7 ha in these three districts. Hoa Vang is the district with the greatest transition of forest area, where the area of forest is forecasted to decrease by 5174.8 ha between 2009 and 2030. Loss of forest areas is the smallest under the $\mathrm{C}$ scenario. In particular, the forest areas are well retained and not transformed into other land use/cover types in Cam Le and Hai Chau districts under all scenarios. 
Chapter 6. Modeling LULC Changes

\begin{tabular}{|c|c|c|c|c|c|c|c|}
\hline \multirow{3}{*}{ Region } & \multirow{3}{*}{$\begin{array}{c}\text { LUC } \\
2009 \\
\text { Area } \\
\text { (ha) }\end{array}$} & \multicolumn{6}{|c|}{ Scenario 2030} \\
\hline & & \multicolumn{2}{|c|}{$\mathbf{A}$} & \multicolumn{2}{|c|}{ B } & \multicolumn{2}{|c|}{$\mathrm{C}$} \\
\hline & & $\begin{array}{c}\Delta \text { Area } \\
\text { (ha) }\end{array}$ & $\begin{array}{c}\Delta \text { Rate } \\
(\%)\end{array}$ & $\begin{array}{c}\Delta \text { Area } \\
\text { (ha) }\end{array}$ & $\begin{array}{c}\Delta \text { Rate } \\
(\%)\end{array}$ & $\begin{array}{c}\Delta \text { Area } \\
\text { (ha) }\end{array}$ & $\begin{array}{c}\Delta \text { Rate } \\
(\%)\end{array}$ \\
\hline \multicolumn{8}{|l|}{ Cam Le } \\
\hline Agriculture & 532.1 & -531.8 & -99.9 & -532 & -100 & -492.1 & -92.5 \\
\hline Barren & 41.6 & -41.6 & -100 & -41.6 & -100 & -41.6 & -100 \\
\hline Urban & 2066.0 & 668.5 & 32.4 & 793.9 & 38.4 & 708.6 & 34.3 \\
\hline Forest & 90.5 & 0 & 0 & 0 & 0 & 0 & 0 \\
\hline Shrub & 415.4 & -95.2 & -22.9 & -220.4 & -53.1 & -175.5 & -42.2 \\
\hline Water & 310.4 & 0 & 0 & 0 & 0 & 0 & 0 \\
\hline
\end{tabular}

Hai Chau

Agriculture

$1.4-0$

Barren

24.8

$-24.8$

$\begin{array}{ll}0 & -1.4\end{array}$

$-100$

0

0

Urban

1689.8

101.1

$-100$

$-24.8$

$-100$

$-24.8$

$-100$

Forest

$6 \quad 124.8$

7.4

7.3

Shrub

2

0

$0 \quad 0$

0

123.3

0

Water

158

$-76.4$

$-48.3$

$-98.7$

$-62.5$

$-98.5$

$-62.3$

\section{Hoa Vang}

Agriculture

294.2

0

0

0

0

0

Barren

$4525.7 \quad-1138.9$

$-25.2 \quad-3364.5$

$-74.3 \quad-431.9$

$-9.5$

Urban

843.6

$-843.6$

$-100.0-843.6$

$-100.0 \quad-738.5$

$-87.5$

Forest

5419.6

9581.7

176.812208 .7

225.3

130.4

Shrub

$52450.5-5174.8$

$-9.9 \quad-5072.3$

$-9.7$

$-2.8$

Water

$\begin{array}{ll}-32.3 & -2928.3\end{array}$

$-39.0-4440.1$

$-59.2$

Lien Chieu

Agriculture

984.9

$-2424.5$

$0 \quad 0$

$0 \quad 0$

0

Barren

Urban

816.5

$-508.5$

$-62.3 \quad-816.4$

$-100 \quad-263$

$-32.2$

$31.1 \quad-31.1$

$-100$

$-31.1$

$-100$

$-27.9$

$-89.6$

Forest

3468.0

1171.6

$33.8 \quad 1545.9$

44.6

774.6

22.3

Shrub

$2744.6 \quad-199.3$

$-7.3 \quad-183.5$

$-6.7$

0

Water

$-432.7$

$-54.0 \quad-514.9$

$-64.3$

$-82.8$

Ngu Hanh Son

316.4

$0 \quad 0$

0

$-663.0$

0

Agriculture

$$
379.8
$$

-95.8
-12
151.3
-71.3
27.6
0

$\begin{array}{ll}-25.2 & -379.8\end{array}$

$-100$

$-100$

0

$-100-12$
5.1

15.9

$-12$

$-100$

Urban

2968.6

5.1

473.3

15.9
-90.8

$-122$

$-4.1$

Forest

78.5

$-90.8 \quad-71.3$

$-5.1$

$13.7-10.3$

-5.1
0

133.9

66.5

Water $\quad 316.1$

\section{Son Tra}

Agriculture

94.9

$-41.4$

$0 \quad 0$

0

3
0

0

Barren

19.7

$-19.7$

$-43.6$

$-92.5$

$-97.5$

$-15.5$

$-16.3$

Urban

1604.3

1070.7

66.7

$-19.7$

$-100.0$

$-17.3$

$-87.7$

26.7 
Chapter 6. Modeling LULC Changes

\begin{tabular}{|c|c|c|c|c|c|c|c|}
\hline \multirow{3}{*}{ Region } & \multirow{3}{*}{$\begin{array}{c}\text { LUC } \\
2009 \\
\text { Area } \\
\text { (ha) }\end{array}$} & \multicolumn{6}{|c|}{ Scenario 2030} \\
\hline & & \multicolumn{2}{|c|}{ A } & \multicolumn{2}{|c|}{ B } & \multicolumn{2}{|c|}{$\mathrm{C}$} \\
\hline & & $\begin{array}{c}\Delta \text { Area } \\
\text { (ha) }\end{array}$ & $\begin{array}{c}\Delta \text { Rate } \\
(\%)\end{array}$ & $\begin{array}{c}\Delta \text { Area } \\
\text { (ha) }\end{array}$ & $\begin{array}{c}\Delta \text { Rate } \\
(\%)\end{array}$ & $\begin{array}{c}\Delta \text { Area } \\
\text { (ha) }\end{array}$ & $\begin{array}{c}\Delta \text { Rate } \\
(\%)\end{array}$ \\
\hline Forest & 3682.4 & -912.6 & -24.8 & -886.7 & -24.1 & -272.9 & -7.4 \\
\hline Shrub & 135.8 & -96.9 & -71.4 & -106.9 & -78.7 & -122.0 & -89.9 \\
\hline Water & 689.2 & 0 & 0 & 0 & 0 & 0 & 0 \\
\hline \multicolumn{8}{|l|}{ Thanh Khe } \\
\hline Agriculture & 0.5 & 0 & 0 & 0 & 0 & 0 & 0 \\
\hline Barren & 1.4 & -1.4 & -100 & -1.4 & -100 & -1.4 & -100 \\
\hline Urban & 872.9 & 0 & 0 & 0 & 0 & 0 & 0 \\
\hline Forest & 2.3 & -2.0 & -88 & -2 & -88 & -1.5 & -68 \\
\hline Shrub & 41.4 & 3.4 & 8.2 & 3.4 & 8.2 & 3.0 & 7.2 \\
\hline Water & 22.1 & 0 & 0 & 0 & 0 & 0 & 0 \\
\hline
\end{tabular}

Table 6.9 Comparison of land use/cover types in 2030 under three scenarios according to administration boundary (Source: Own calculation)

\subsection{Landscape structure of scenarios}

\subsubsection{At landscape level}

In this section, we focus on studying the changes of landscape structure for three different scenarios. Hence, seven metrics (mentioned in section 4.6) were used to explore the temporal changes of spatial patterns at landscape-level for three scenarios across the entire landscape from 2009 to 2030, including the number of patches (NP), patch density (PD), mean proximity (PROX_MN), mean patch area (AREA_MN), interspersion and juxtaposition (IJI), largest patch index (LPI), largest shape index (LSI). In this case, the percentage of patches (PLAND) metric was not used because it does not exist at landscape level. The analytical metrics are presented in Figure 6.10. For the years observed in our analysis, the values of NP, PD, IJI, LPI, and LSI decrease for all scenarios (Figure 6.10a, b, e, $\mathbf{f}$, and g). Figure 6.10c, $\mathbf{d}$ show that the values of PROX_MN and AREA_MN of all scenarios increase during the simulated period (2009-2030).

In three scenarios, the values of NP substantially decreased from 2009 to 2030 indicating that many dispersive patches within the study area trends towards an increasingly large-grained pattern (Figure 6.10a). This is also supported by the 
Chapter 6. Modeling LULC Changes
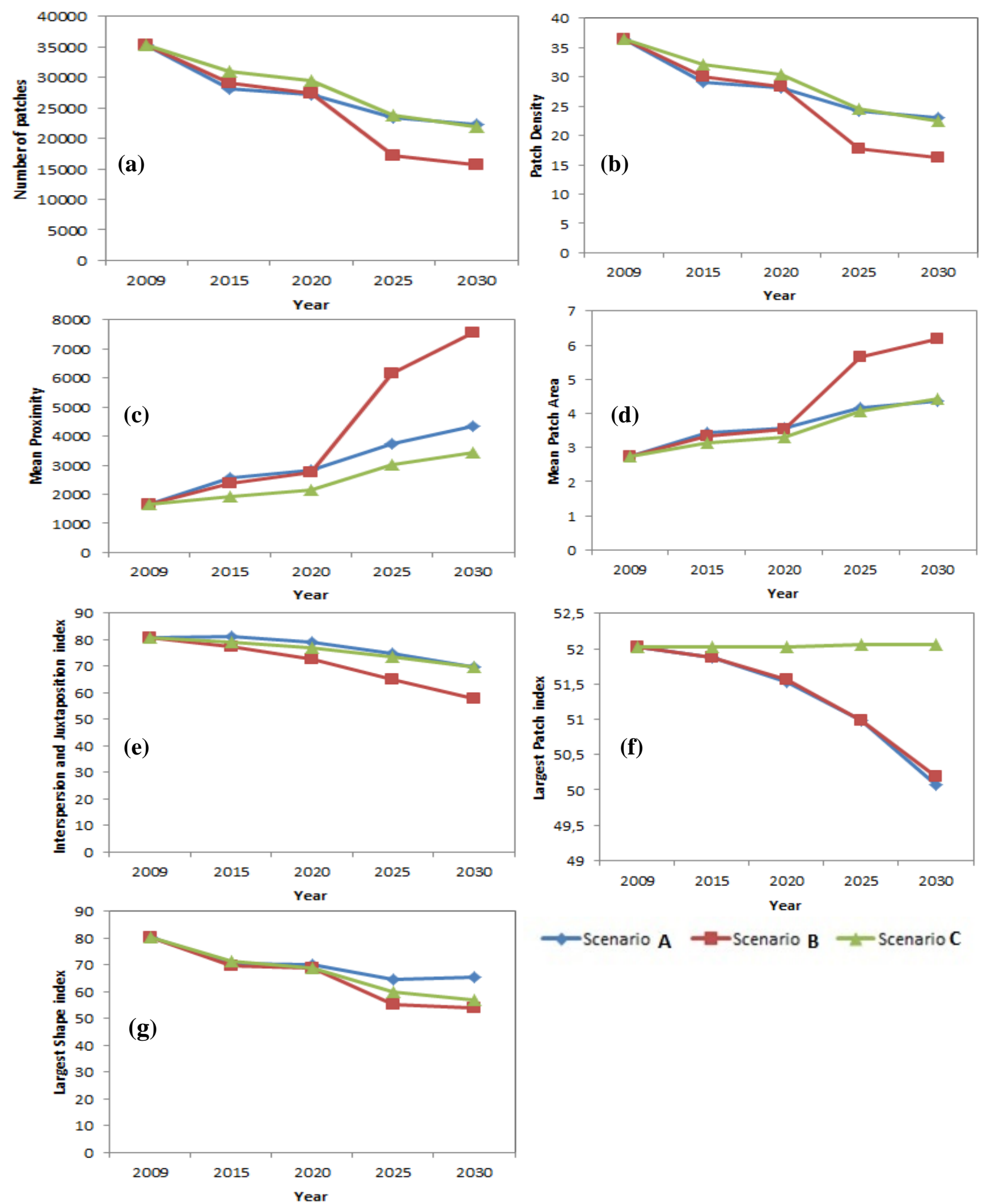

Figure 6.10 Landscape metrics at landscape level under scenarios (a) number of patches, (b) patch density, (c) mean proximity, d) mean patch area, (e) interspersion and juxtaposition index, (f) largest patch index, and (g) largest shape index 
decreasing tendency of PD (Figure 6.10b). In which, the values of NP and PD of landscape in scenarios A (the baseline policy) and C (sustainable development) are greater than those for scenario B (economic development). It is illuminating that landscape in scenario B is less heterogeneous than scenario A and C. It means that the patches are formed. Many dispersive patches would merge into large ones. Hence, the landscape heterogeneity declined. Again, this judgment could be proved by observing the distribution of urban area (the red color) from simulation scenarios in Figure 6.5, Figure 6.6 and Figure 6.7, respectively.

Correspondingly, the NP and AREA_MN of all scenarios had a negative relationship, which indicates that there are less patches in a landscape and that the mean patch sizes are larger. Similarly, the PROX_MEAN defined by a search radius of $300 \mathrm{~m}$ for all scenarios would continuously increase between 2009 and 2030. It can be assumed that patches in all scenarios would increasingly occupy the neighborhood. Figure 6.10c and $\mathbf{d}$ show that scenario B has the highest value by 2030, compared to scenarios $\mathrm{A}$ and $\mathrm{C}$.

In all scenarios, values of IJI within the study area slightly decrease between the years of 2009 and 2030 (Figure 6.10e), indicating that the landscape pattern would shift from dispersion a state to a distributed state, in which, scenario B has lower IJI values by 2030 than scenarios A and C. In other words, spatial distribution of various patches in scenario B would become more inter-conjugated and better connected than patches in other scenarios.

Regarding LPI, the value indicates the degree of control of large patches on the landscape. Our results show that the LPI values of scenarios A and B continuously decrease during the periods 2009-2030. The smaller LPI values by 2030 testify that the largest patch in the landscape of scenarios A and B lose their dominant place, while LPI values in scenario $\mathrm{C}$ are nearly constant. It is reflected that the landscape in scenario $\mathrm{C}$ is less affected by the changes of land use/cover types. In general, this finding is reasonable because it reflects the "optimal development" of scenario C as mentioned before. 
LSI of different scenarios is calculated by deviation between the patch area and the same square area for measuring the complexity of its shape. Our analytical results show that the values of LSI in the trio of scenarios are decreased within the study area. It is demonstrated that the landscape patches become less complex. Among them, scenario B has lower values during the periods 2020-2030 than scenarios A and C through human forward interference.

The above results reveal that contiguous processes in the three scenarios are strengthened temporally and spatially. The information underlines that spatial pattern within Da Nang City in scenario B would less heterogeneous compared to scenarios A and $\mathrm{C}$ on the one hand. On the other hand, it demonstrates that scenario B affects more the landscape than scenarios A and C through the interference of human activities.

\subsubsection{At class level}

Similarly, the calculation of seven landscape metrics for the three scenarios was also analyzed at class level. Figure 6.11- 6.16 show the differences of landscape metrics for the agriculture, barren, urban, forest, shrub, and water class under three scenarios. In this case, the percentage of landscape index (PLAND) was not examined, because it was explained in details at section 6.7.

In general, the values of NP, PD, PROX_MN, and IJI of agricultural class under all scenarios decrease during the period of simulation (Figure 6.11a, b and c). It indicates that agriculture land patches are distributed more isolated by the end of simulation in 2030. In addition, the smaller of LPI index also indicates that the largest patch of agriculture in the landscape lost its dominant place. Moreover, the LSI values of agriculture decrease continuously. It reveals that agriculture land patches become regular and less complex after implementing the land use/cover model. Our results show that the values of NP, PD, PROX_MN, LPI, and LSI of agricultural class in the C scenario are greater than those in the A and B scenarios. It means that agriculture land patches in scenario $\mathrm{C}$ are affected less compared to those in other scenarios. This finding is reasonable with the policy of scenario $\mathrm{C}$ in sustainable development; especially agriculture land always comes high on the list of priority preservation. 
Among all landscape types, barren within the study area is a special one, which is considered as source for expansion of other landscape types. Hence, Figure 6.12 shows that values of all landscape metrics of this barren land tend to move towards or approximate to 0 at the end of simulation period. As mentioned above, the $\mathrm{C}$ scenario tries to develop in a sustainable way. Consequently, the values of all landscape metrics in this scenario are always higher than in scenarios A and B.

The changes of landscape metrics at urban class from 2009 to 2030 are presented in Figure 6.13. Our results show that urban land is the most variable landscape patch type. For instance, the number of patches in scenario A are considered bigger after 2009, increasing from approximately 4500 patches in 2009 to over 8000 patches in 2030. In addition, values of PD increase greatly from 45 patches per 100 ha to 80 patches per 100 ha. PROX_MN and LPI both strongly increase which indicates that urban land patches become dominant within the study area during the simulation period. In contrast to agriculture and barren, values of landscape metrics in scenario $\mathrm{C}$ are mostly lower than scenarios A and B.

Forest is the landscape type that also has notable variation. The trends of all landscape metrics at this kind class are similar to those at the landscape level (section 6.8.1). Since the land use/cover in Da Nang City is dominated by forest. Because of the requirement in keeping the forest cover above 60\% compared with total area in Da Nang City during the simulation periods, almost landscape metrics of forest in scenario $\mathrm{C}$ remain as constant, whereas in scenarios A and B they change significantly during 2009-2030 (Figure 6.14). At the end of simulation period, NP in Da Nang City of both scenarios A and B decrease almost two-fold from 5000 to 2500 in value. Meanwhile, PD of forest land patches in these scenarios shows the same trend. This indicates that large and continuous areas of forest land patches in Da Nang City are formed. Correspondingly, AREA_MN of forest patches take on an expanding trend (Figure 6.14d). Values of LSI in both scenarios decrease from 400 to 270 which represent the shape of forest land patches in Da Nang City become less complex (Figure 6.14g). 
Chapter 6. Modeling LULC Changes
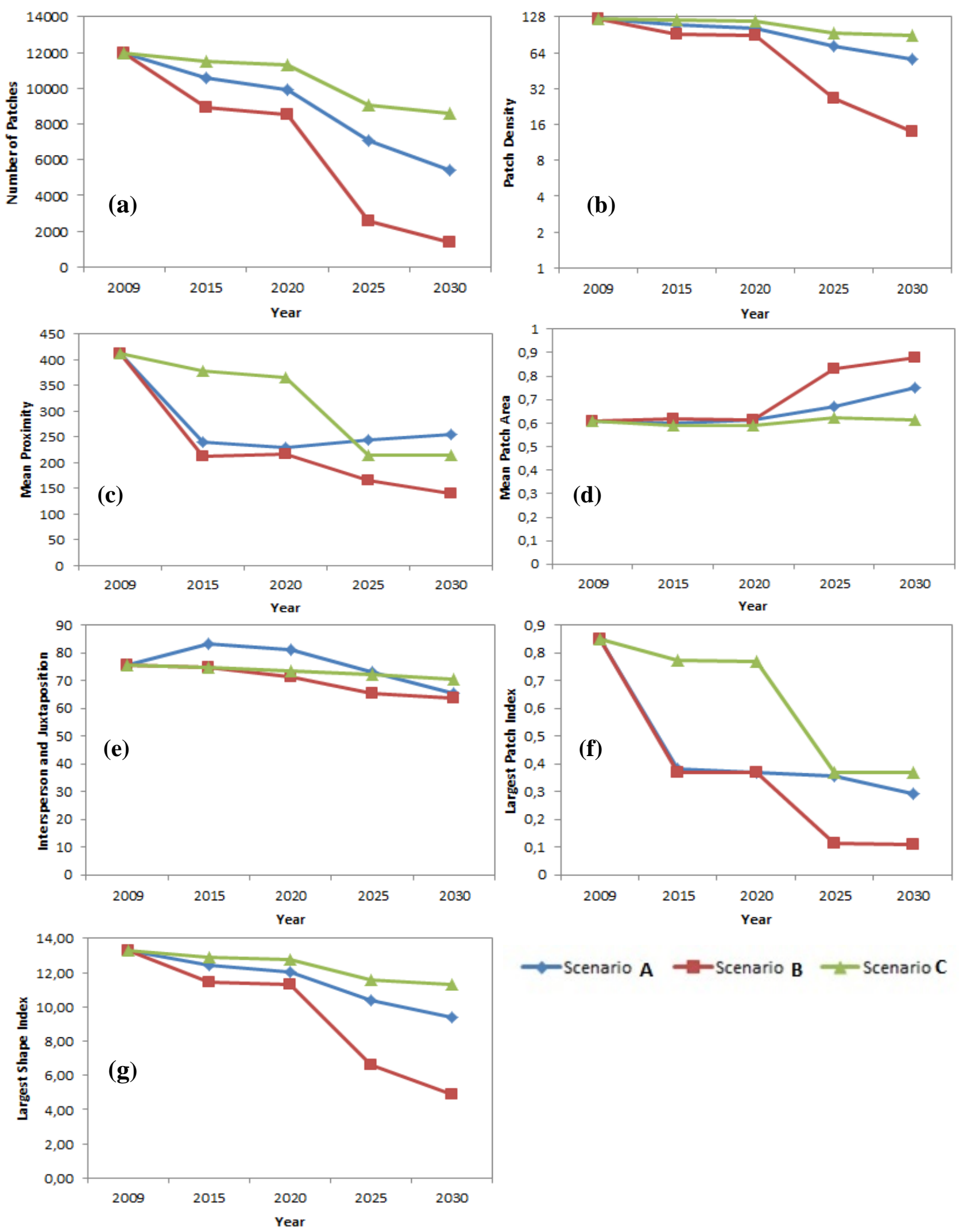

Figure 6.11 Landscape metrics at agriculture class under scenarios (a) number of patches, (b) patch density, (c) mean proximity, (d) mean patch area, (e) interspersion and juxtaposition index, $(f)$ largest patch index, and (g) largest shape index 


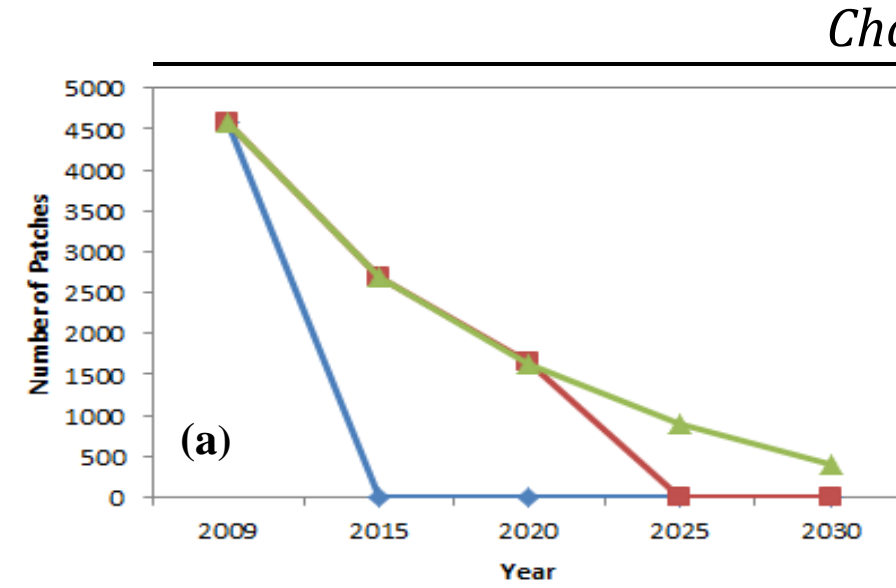

Chapter 6. Modeling LULC Changes
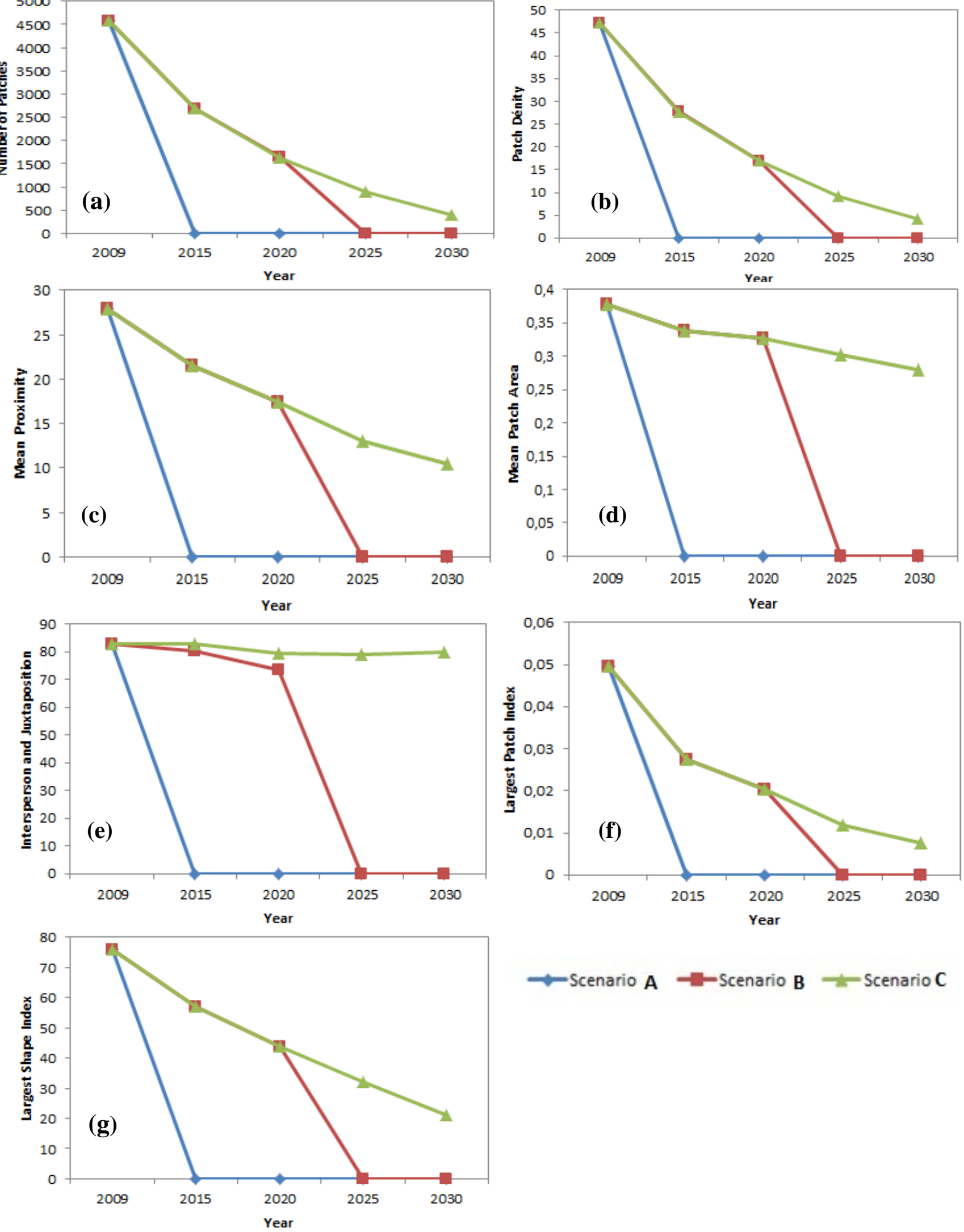

$\leadsto$ Scenario A - Scenario B $\longrightarrow$ Scenario C

Figure 6.12 Landscape metrics at barren class under scenarios (a) number of patches, (b) patch density, (c) mean proximity, (d) mean patch area, (e) interspersion and juxtaposition index, (f) largest patch index, and (g) largest shape index 
Chapter 6. Modeling LULC Changes
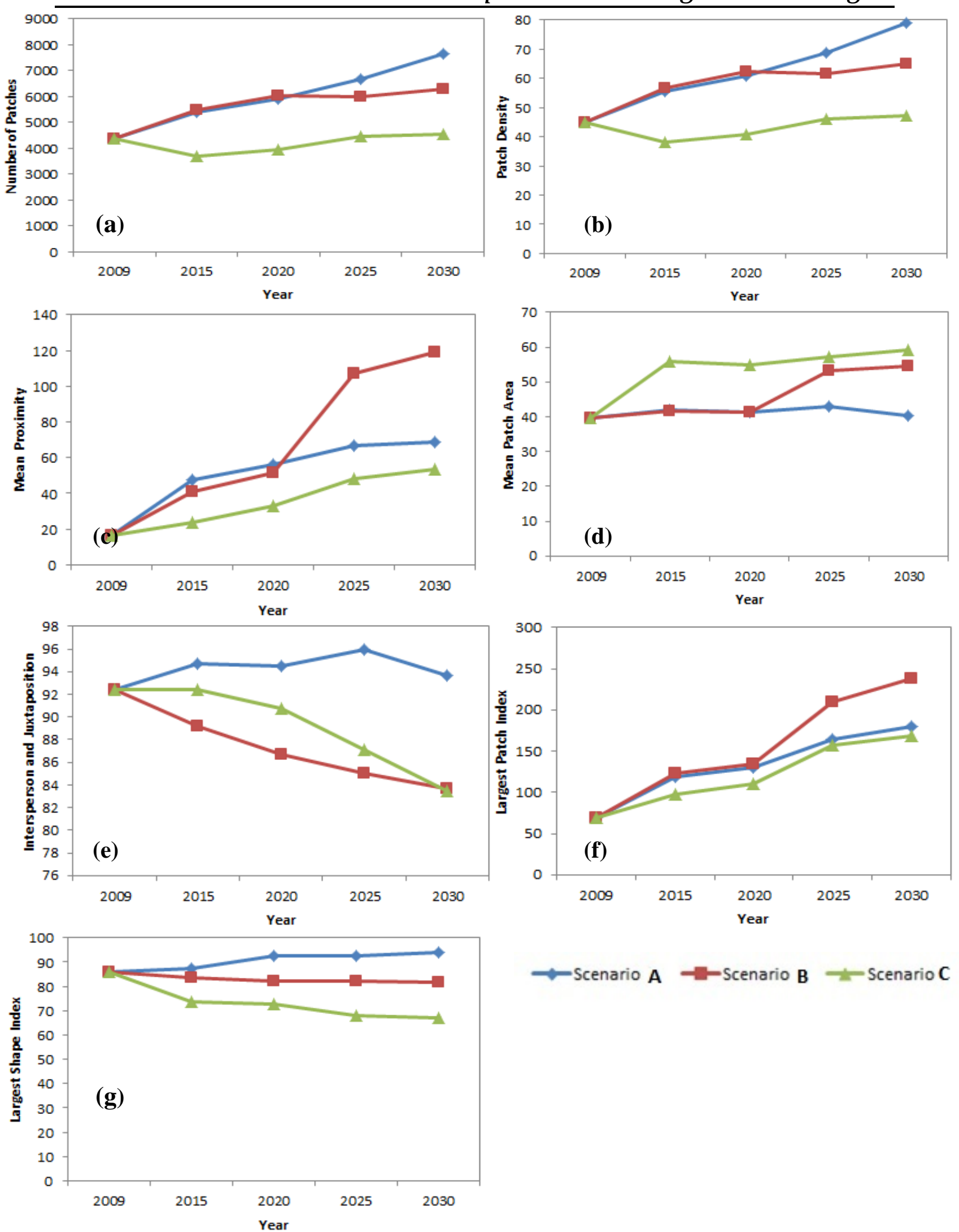

$\longrightarrow$ Scenario A - Scenario B $\longrightarrow$ Scenario C

Figure 6.13 Landscape metrics at urban class under scenarios (a) number of patches,

(b) patch density, (c) mean proximity, (d) mean patch area, (e) interspersion and juxtaposition index, $(f)$ largest patch index, and (g) largest shape index 
Chapter 6. Modeling LULC Changes
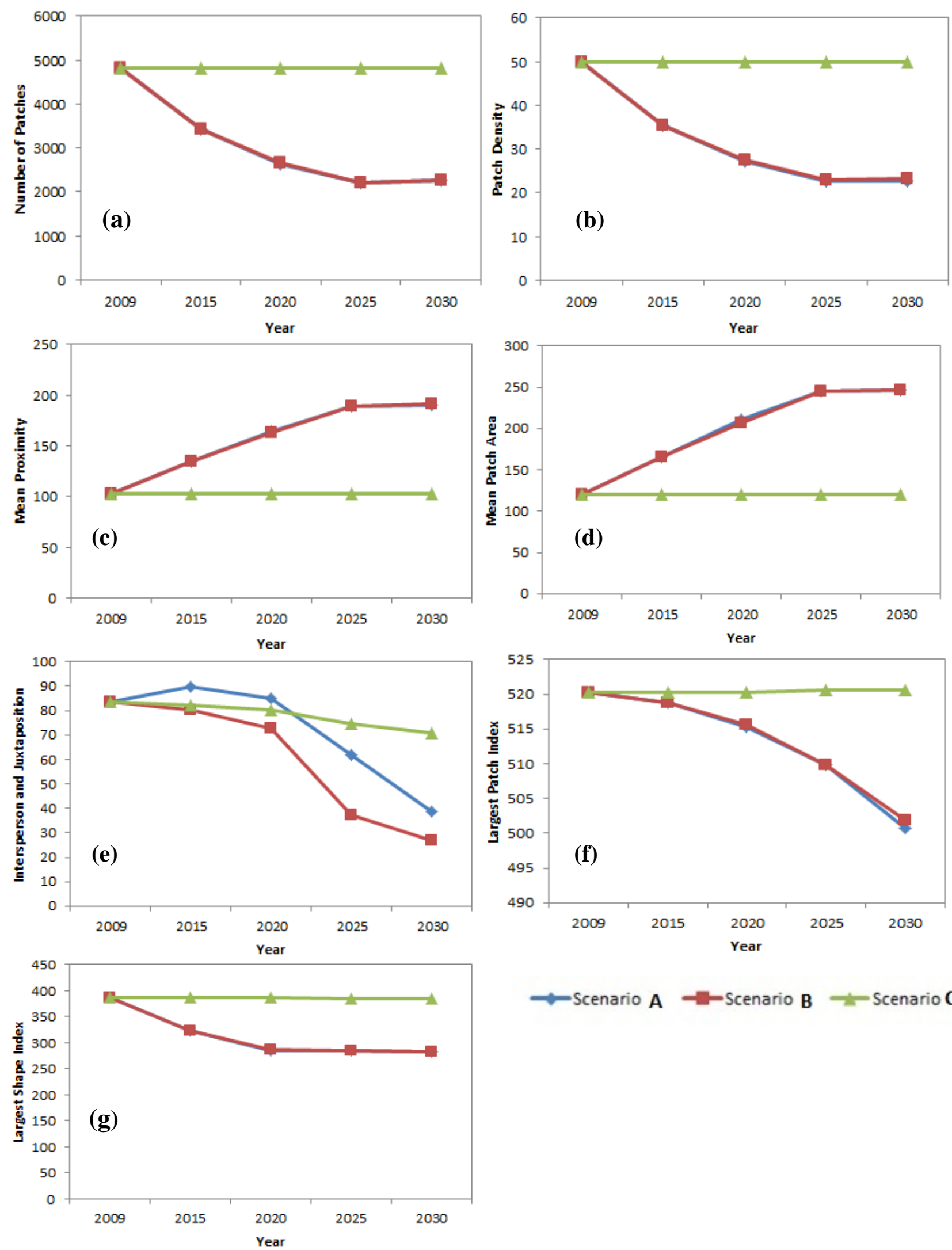

-Scenario A $=$ Scenario B $\longrightarrow$ Scenario C

Figure 6.14 Landscape metrics at forest class under scenarios (a) number of patches, (b) patch density, (c) mean proximity, (d) mean patch area, (e) interspersion and juxtaposition index, (f) largest patch index, and (g) largest shape index 
Chapter 6. Modeling LULC Changes
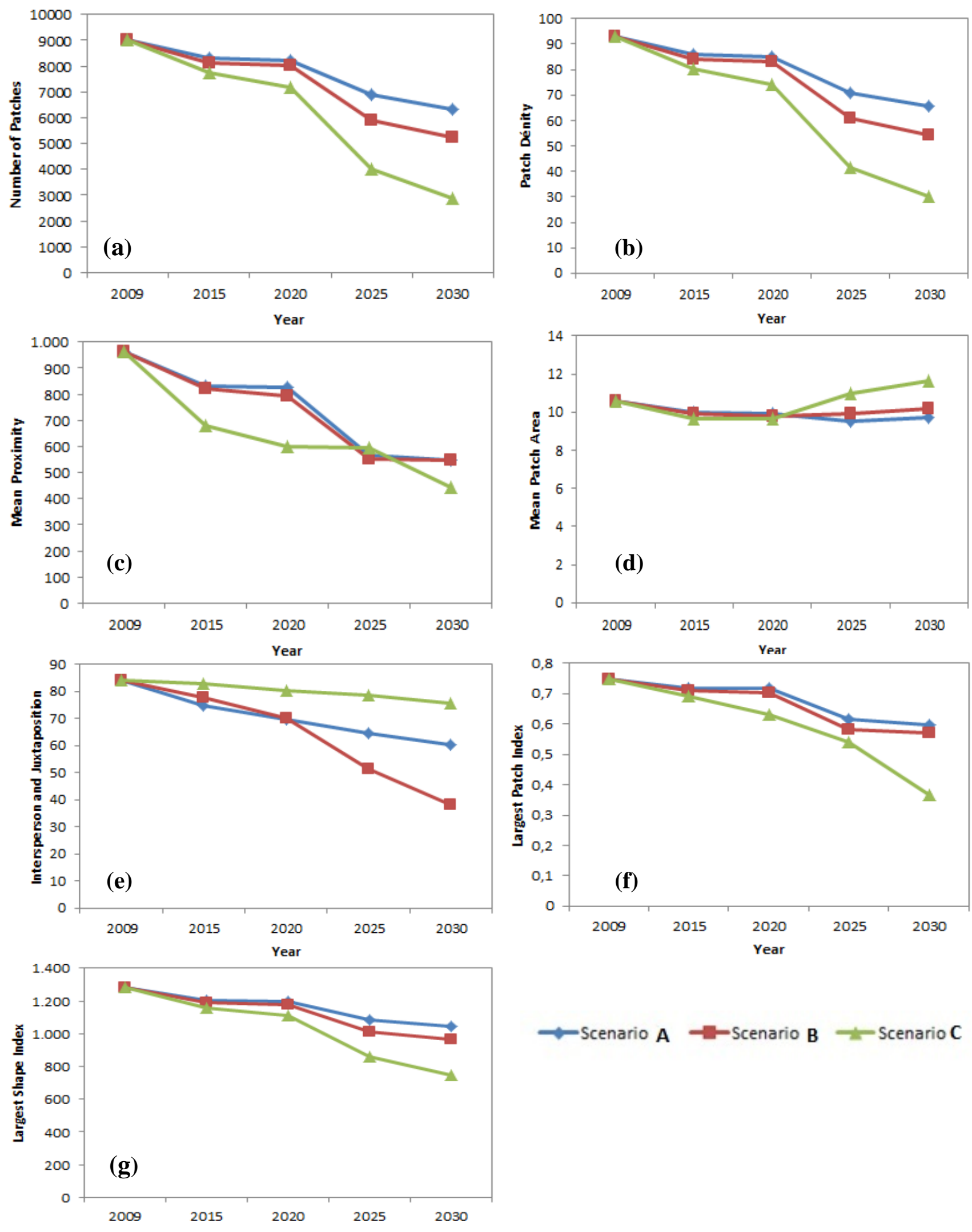

$\longrightarrow$ Scenario A - Scenario B $\longrightarrow$ Scenario C

Figure 6.15 Landscape metrics at shrub class under scenarios (a) number of patches, (b) patch density, (c) mean proximity, (d) mean patch area, (e) interspersion and juxtaposition index, (f) largest patch index, and (g) largest shape index 
Chapter 6. Modeling LULC Changes
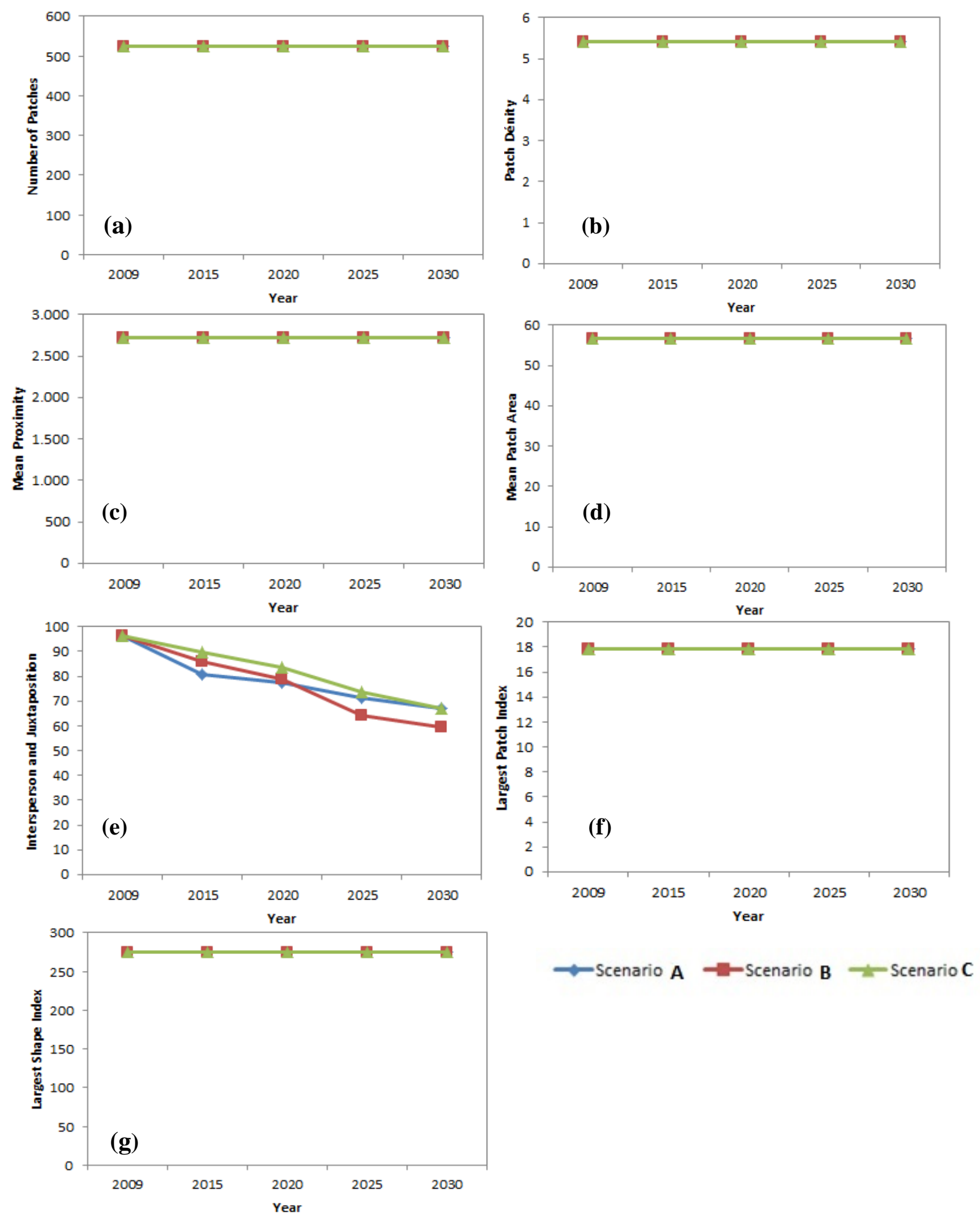

Figure 6.16 Landscape metrics at water class under scenarios (a) number of patches, (b) patch density, (c) mean proximity, (d) mean patch area, (e) interspersion and juxtaposition index, (f) largest patch index, and (g) largest shape index 
Shrub is another highly variable patch type. During the simulation period, its patches decrease dramatically (Figure 6.15a). It happens similarly with PD of shrub land patches. In general, the changes of shrub land, compared to the expansion of urban land, display a contrary degradation process in the region. Those results at the class level suggest that the heterogeneity of shrub significantly decrease from 2009 to 2030.

As noted above, water areas would be retained during the simulation period. Hence, most of the landscape metrics of water patches in the three scenarios are stable during the simulation period, except IJI index. As can be seen from Figure 6.16e, the IJI values of water class in all scenarios have the same decreasing tendency. It testifies that water areas are aggregated in a particular area. The changes of this index are caused by the spatial variations of other classes within study area, in which, IJI values of the B scenario are lower than those for the A and C scenarios.

\subsubsection{Effects of land use scenarios to landscape structure}

\begin{tabular}{lccccccc}
\hline \multirow{2}{*}{ Level } & \multicolumn{7}{c}{$\boldsymbol{F}$ value } \\
\cline { 2 - 8 } & NP & PD & PROX_MN & AREA_MN & IJI & LPI & LSI \\
\hline Landscape & $2.46^{*}$ & $2.46^{*}$ & 6.57 & 4.28 & 7.72 & 13.37 & $2.12^{*}$ \\
\hline Agriculture & 12.85 & 136.49 & 9.42 & 10.75 & 11.87 & 10.58 & 10.58 \\
Barren & 4.18 & 4.18 & 12.19 & 22.93 & 27.66 & 6.15 & 10.27 \\
Urban & 37.10 & 37.10 & 8.14 & 41.93 & 31.73 & 3.29 & 100.31 \\
Forest & 52.30 & 23.25 & 33.47 & 34.27 & 5.96 & 13.37 & 55.38 \\
Shrub & 5.83 & 5.83 & 2.23 & 5.68 & 12.22 & 4.69 & 5.83 \\
Water & $0.000^{*}$ & $0.000^{*}$ & $0.000^{*}$ & $0.000^{*}$ & $1.5 *$ & $0.000^{*}$ & $0.000 *$ \\
\hline
\end{tabular}

*: not significant at the 0.05 level

Table 6.10 The differences of landscape metrics under three scenarios (Source: Own calculation)

For further understanding, the study would test if there is significant difference in landscape structure under different modeled scenarios. In this case, we employed the test of variance (one-way ANOVA) on each landscape metrics (NP, PD, Prox_MN, Area_MN, JIJ, LPI, LSI), using each of 22 simulation runs (from 2009 to 2030) per scenario as independent value. Tukey's post hoc test was set at $\alpha=0.05$. 
Table 6.10 presents the results of one-way ANOVA in analyzing effects of different land use/cover scenarios to landscape structure within the entire study area. At landscape level, it indicates that the landscape metrics LPI and IJI of all scenarios differ significantly with the changes of land use/cover during the period of simulation for the entire study area. Meanwhile, the landscape metrics for NP, PD, and LSI do not significantly differ for all scenarios.

At class level, the analytical results show that the landscape metric NP of forest has the highest significant difference for all scenarios during the simulated period. Continuously, this metric also differ significantly with demand for urban and agriculture classes in the trio of scenarios. Regarding the landscape metric PD, the ANOVA results show that PD at agriculture class differs significantly by demand of land use/cover for all scenarios, which is approximately fourfold the number of difference in urban class and six fold the number of difference in forest class. Again, the landscape metrics of PROX_MN and LPI under three scenarios are different by the changes of demand in forest class. In the AREA_MN landscape metric, urban class is considered to have the highest significant difference than the other classes. Similar to AREA_MN, the landscape metrics IJI and LSI of urban class in all scenarios have the highest values. The landscape metric LSI particularly, varies significantly with the demands of land use/cover for all scenarios throughout the simulation period. The significant difference of this landscape metric is approximately twofold the value of forest class, tenfold the value of agriculture class, and seventeen fold the value of shrub class. Because of the stability during the simulated period, all landscape metrics of water class do not significantly differ for all land use/cover scenarios.

With respect to the spatial configuration of land use/cover scenarios, main results of landscape metrics, which are obtained by running one-way ANOVA for 22 simulations (from 2009 to 2030), are presented in Table 6.11. The results show that the mean values of landscape metrics under three scenarios do not differ significantly, except NP and PROX_MN. As can be seen from Table 6.11, mean value of landscape metric NP in scenario B is the lowest one, compared to scenario A and C. It reveals that the spatial configuration in scenario B is less heterogeneous than scenarios A and C. In addition, the value of landscape metric PROX_MN in scenario B is the highest one, 
which indicates that there are more patches in a search radius of $300 \mathrm{~m}$ of scenario $\mathrm{B}$ than scenarios A and C. More details could be found in Appendix 6.

\begin{tabular}{lrrrrrr}
\hline \multirow{2}{*}{$\begin{array}{l}\text { Landscape } \\
\text { metrics }\end{array}$} & \multicolumn{2}{c}{ Scenario A } & \multicolumn{2}{c}{ Scenario B } & \multicolumn{2}{c}{ Scenario C } \\
\cline { 2 - 7 } & \multicolumn{1}{c}{ Mean } & \multicolumn{1}{c}{ SD } & \multicolumn{1}{c}{ Mean } & \multicolumn{1}{c}{ SD } & Mean & \multicolumn{1}{c}{ SD } \\
\hline NP & 27035.50 & 4059.21 & 24819.00 & 6755.59 & 28256.36 & 4391.18 \\
PD & 27.92 & 4.19 & 25.63 & 7.00 & 29.19 & 4.50 \\
PROX_MN & 2996.57 & 849.70 & 3903.40 & 2159.67 & 2397.63 & 621.24 \\
AREA_MN & 3.65 & 0.52 & 4.22 & 1.30 & 3.51 & 0.567 \\
IJI & 77.59 & 3.88 & 71.54 & 7.65 & 76.22 & 3.50 \\
LPI & 51.37 & 0.61 & 51.42 & 0.57 & 52.04 & 0.16 \\
LSI & 69.51 & 4.81 & 65.06 & 8.73 & 67.26 & 7.40 \\
\hline
\end{tabular}

Table 6.11 Obtained descriptive values of landscape metrics

(Source: Own calculation)

\subsection{Discussions and conclusions}

\subsubsection{Discussions}

According to the findings and interpretations above, it can be concluded that the integration of SD and Dyna-CLUE models is capable of predicting the future land use/cover distributions within the study area. However, there are some issues, involved driving factors, scale of input data, and elasticity parameters which should be considered to get a deep understanding the models.

Priyanto (2010) asserted that the shortage of input data could give an inaccuracy in estimating the changes of land use/cover based on causative effects of driving factors. Similarly, too many variables without significant effects could not well explain the behavior of land use/cover changes. In addition, Verburg and Veldkamp (2004) stated that the number of involved driving factors should be selected upon the extent and actual conditions of the research area. Large areas need more variety of driving factors to describe the distribution of land use/cover over a period of time, whereas small areas, liked Da Nang City, needs fewer variables. Consequently, seven driving factors, evaluated by measuring the goodness of logistic regression for every land use/cover type (ROC values from 0.7 to 0.9 ), are believed to reflect the dynamics of Da Nang 
City. If the Dyna-CLUE model has more socio-economic data such as the preference of society in choosing new urban locations with high business potential, it could improve the capability of the model in simulating land use/cover behavior. Unfortunately, this data is unavailable. Hence, if the data becomes available, it should be incorporated in to future work.

As mentioned in section 4.3.1, all images used in this study were resampled to scale resolution of $30 \mathrm{~m}$. In the CLUE-S model, this cell size is considered as a large grid based system (Verburg et al., 2002). If input data is acquired at higher spatial resolution, more detailed information could be revealed, thus it has the possibility to improve the understanding of dynamic changes within the study area (Cheng, 2003). However, Priyanto (2010) noticed that more capacity and time are required for iteration processes when the model is running with data at a larger resolution.

The elasticity parameters of this study (detail in section 6.4) are defined upon experiments getting from historical dynamic changes within study area and arranged from 0.2 to 1 . According to Carlson (2004), it is feasible to access more reasonable parameters by trying many times. Hence, it is essential to choose and test other different elasticity values to evaluate the simulation results of the Dyna-CLUE model in our future research.

\subsubsection{Conclusions}

Understanding the changes of land use/cover types as well as their future distribution in a particular region plays an important role in helping land use planners and managers adjust their spatial planning decisions and avoid inappropriate decisions (Pontius and Neeti, 2010). By modeling the changes of land use/cover, a depicted future of land use distribution can be empirically tested through developed scenarios. It means that the results of modeling can provide insights in to the future occurrence and configuration of land use/cover. Also, it is necessary to consider the relation among natural, socioeconomic conditions and dynamic transitions of land use/cover type sunder different scenarios. Therefore, this study developed scenarios with different mission storylines to simulate the future changes of land use/cover in Da Nang City by using the DynaCLUE model from 2009 to 2030. 
First, all three scenarios were calibrated based on observed changes of land use/cover types in Da Nang City in the 1996 -2009 period and this was used to simulate the dynamics in the period 2009-2030. Seven exogenous explanatory variables, including urban rate, mean density of population, slope, elevation, distance to road, distance to urban, and distance to water were analyzed by binary logistic regression model in order to simulate 35 probability maps. The ROC values of logistic regression models, ranged from 0.70 to 0.99 based on types of land use/cover, indicate that these driving factors can be used to explain the spatial pattern within study area.

Second, all scenarios (A, B, and C) give a continuous increase in urban area, and a gradual decrease in agriculture area, barren, and shrub. The change of urban area in 2030 is the highest under scenario B with 17152.7 ha (99.16\%), the lowest under scenario C with 9794.23 ha (56.62\%). Visually, the urban areas mostly occur in the adjacent of existing urban area in the south-east part of Da Nang City, and densely along the coastal zone. Around these parts, urban areas also tend to expand to the western part of this zone. Consequently, the expansion of urban areas causes the conversion of agriculture area and other land use/cover types. The B scenario results in the most loss of agriculture area 6098.96 ha (83.61\%), while the C scenario shows the least loss of agriculture area 1996.98 ha (27.40\%) during the simulated period. Particularly, forest areas decease by 5269.19 ha (9.1\%), 5125.59 ha (8.85\%) under scenarios $\mathrm{A}$ and $\mathrm{B}$, respectively; meanwhile, the $\mathrm{C}$ scenario, emphasized the environmental issue, which shows no change in forest (57936.2 ha) during the simulated period. Overall, urban areas increase the most in Hoa Vang district, by 9581.7 ha (176.8\%), 12208.7 ha (225.3\%), 7064.5 ha (130.4\%) under scenarios A, B, and C, respectively, while Thanh Khe is shown to have the least change in land use/cover, compared to other districts.

Finally, one-way ANOVA analysis shows that landscape metrics LPI and IJI at the landscape level under scenarios differ significantly with the changes of land use/cover during simulated period within entire study area. At class level, the results show that the forest class has high differences with landscape metrics NP, PROX_MN and LPI. Meanwhile, the landscape metrics AREA_MN, IJI and LSI of urban class are considered to have the highest significant difference than the others. Regarding agriculture, the ANOVA results show that PD at agriculture class level differs 
significantly by demand of land use/cover for all scenarios, which is approximately fourfold the number of difference in urban class level and six fold the number of difference in forest class level. For analyzing the spatial configuration of land use/cover under scenarios, one-way ANOVA results also show that mean value of landscape metrics under scenarios do not differ significantly, except NP and PROX_MN. The value of NP in scenario B is the lowest one, compared to scenarios A and C. It reveals that the spatial configuration in scenario B is less heterogeneous than scenarios A and C. This conclusion is supported by the highest value of PROX_MN in scenario B.

According to the analysis above, the results of scenario prediction would provide a guide for land-use-planners and decision-makers in Da Nang City. In this case, an optimal strategy for sustainable development is chosen, it would be most suitable for planners and decision-makers to seek the $\mathrm{C}$ scenario for the best land use plan. It is the most plausible plan to constrain the dynamic growth of urban area to protect land resources and promote sustainable strategy. 


\section{CHAPTER 7}

\section{Conclusions}

Chapter 7 provides remarkable conclusions of the research based on the main results and analysis obtained from previous chapters. Hence, an insight about the research objectives is presented. This chapter is also concerned with some certain advisory ideas arising from the results of the research. Furthermore, it will emphasize the probable future works according to this perspective.

\subsection{General conclusions}

The key objective of this research is to address and simulate the changes of land use/cover in Da Nang City. Land use/cover changes are well known as the results of spatial-temporal interactions between bio-physical and human activities at various scales (Veldkamp A, 2001; Verburg et al., 2004). The changes of land use/cover affect the environment of a region in different ways. Therefore, it is necessary to define and simulate the changes of land use/cover in a spatial-temporal pattern. Through this examination, the causes and consequences, as well as ecological impacts could be revealed, in order to support decision-makers and land-use-planner in making betterinformed decisions (Luo et al., 2010).

Based on land use/cover maps obtained from satellite imagery, the study has explored the potential of SD and Dyna-CLUE models in examining the future of land use/cover changes in Da Nang City under different scenarios. In this thesis, we accomplished these following missions: 
- $\quad$ “Assessing the change of land use/cover, in particular urban land use under the impacts of urbanization by using time series remotely sensed images from 1979 to 2009”

From satellite imagery, land use/cover maps of Da Nang City in 1979, 1996, 2003, and 2009 were established. It was found that the changes of land use/cover within Da Nang City were mainly occurred due to the expansion of urban area which had a net increase, $140 \%$ of total area of Da Nang City over the past thirty years (1979-2009). In the first eighteen years (1979-1996), urban area increased 13.4\%. However, only in seven years (1996-2003), after separation from Quang Nam province and becoming a centrally governed city, the urban area had a net increase of 35\%. Within the six years later (2003-2009), the urban area incessantly increased and contributed 51.6\% to net increase of urban area. Besides, water area increased with annual rate of change $0.87 \%$ in the same period. Conversely, barren and agriculture consistently lost $60.4 \%$ and $39.5 \%$ of their 1979 area, respectively. In addition, forest and shrub decreased 6.5\% and 2.1\% in the same period, respectively. Given the results shown in this research, urbanization has significantly modified the land use/cover in Da Nang City during the entire study period. Urban area is markedly distributed in Thanh Khe, Hai Chau, Ngu Hanh Son, and Cam Le districts. Hence, it could cause pressures on coastal plain in Da Nang City.

- $\quad$ "Analysing patterns of changes in landscape within the study area during the last three decades”

To have an intrinsic evaluation about spatial changes of land use/cover, three representative classes (urban, agriculture, and forest) were chosen to compute spatial landscape matrices, namely: percentage of landscape (PLAND), number of patches (NP), largest patch index (LPI), average size of patches (AREA_MN), patch density (PD), proximity index (PROX_MN, interspersion and juxtaposition index (IJI), and landscape shape index (LSI). These metrics were chosen for analysis based on actual conditions of the study area as well as own background knowledge. As mentioned above, urban area grew up rapidly from 1979 to 2009. It was reflected by the increase of LPI. Furthermore, the landscape metrics of urban class showed the increase of NP, AREA_MN, and PD as the evidence of expanded urban during the span of thirty years. Based on these findings, the values of PROX_MN, IJI, and LSI presented in this thesis 
show that configuration of urban class became more uniform and less complex. Regarding to agriculture class, although its NP and PD increased during the period from 1979 to 2009, the relevant landscape metrics (AREA_MN, LPI, and PROX_MN) decreased strongly. The combination of these values revealed that agriculture class in 2009 became more fragmented than in 1979, also, it was supported by the decrease of the IJI index. Forest class was the most dominant land use/cover in Da Nang City until 2009; hence, the LPI of forest was the highest, compared to other classes. However, the decrease of NP and PD gave evidence about the change of forest class. In contrast to this, the results showed the increase of AREA_MN and PROX_MN as well, which indicated that forested patches became more contiguous in the domain of spatial distribution. It was supported again by high value of IJI. From a landscape point of view, it can be documented that the coastal landscape characteristics in Da Nang City were affected strongly after three decades.

- "Determining the underlying and proximate causes of land use/land cover changes"

The findings of this study revealed that the growth of population (31\%), the increase of economics, especially annual growth rate of GDP (10.3\% from 1990 to 2009), and the focus on development of Industry \& Construction, Services sectors were the main causes of land use/cover changes in Da Nang City over the past thirty years (19792009).

- $\quad$ "Simulating and locating the changes of land use/cover within the study area during the period 2009 to 2030"

Based on targets obtained from strategic development of Da Nang City in next 20 years, the SD model was applied to predict the demands of land use/cover changes within Da Nang City under three different scenarios, namely, scenario A “development as usual”, scenario B "aggressive development", and scenario C "optimal development". The A scenario is predefined by retaining all conditions, so these conditions are same as those in the historical data. The B scenario corresponds to a vigorous development with the consideration of high investment in industry. The $\mathrm{C}$ scenario constrains the development of land use/cover within the study area by projecting population, as well as protecting the actual forest area, sparely utilizing, and reasonably converting land 
use/cover. In further steps of modeling, the three scenarios were used to allocate the spatial pattern with the Dyna-CLUE model. The changes of land use/cover generated under three scenarios are consistent with those detected from historical maps. It means that the increase of urban area and decrease of agriculture would still be the main tendency of land use/cover types in Da Nang City. The results show that urban area has an increase of $99.16 \%$ under the B scenario, 78.54\% under the A scenario, and 56.62\% under the C scenario. The B scenario generates a substantial increase of urban area at the expense of agriculture, and other land use/cover types, compared to the other two scenarios. Thus, the B scenario results in the most loss of agriculture area (83.61\%), while the $\mathrm{C}$ scenario shows the least loss of $27.4 \%$. Particularly, forest area in the $\mathrm{C}$ scenario is retained during the simulated period. Overall, the changes of urban area mostly occur in Hoa Vang, Son Tra, and Lien Chieu districts, where the urban rate is low before simulating. Also, these changes of land use/cover types affect landscape structure in various ways. Of which, urban class is considered to have the highest change at AREA_MN, IJI, and LSI metrics. As stated above, the expansion of urban area causes the decrease of agriculture area. Consequently, the PD metric of agriculture class differs significantly for all scenarios. Meanwhile, the NP, PROX_MN, and LPI metrics of forest show a large difference. The analysis also reveals that spatial configuration under the $\mathrm{B}$ scenario would lead to the least heterogeneous landscape compared to the other two scenarios on the one hand. On the other hand, scenario B shows evidence of serious interference of human activities on landscape structure. In this sense, the $\mathrm{C}$ scenario suggests an effective way to develop Da Nang City in the next 20 years.

In general, my thesis exhibited a significant contribution to land use planning process in Da Nang City by predicting the changes of land use/cover in spatial-temporal pattern. Also, it helps local decision-makers better comprehend the complexity of land use/cover system. The simulated results could give anticipative information around coastal region in the future, which could be considered as consultative strategies for land use planning. The most important contribution of this thesis is that the framework of used models could provide a serviceable and scientific tool for planners at the initial stage of the planning process. Practically, the study of my thesis can be applied not only in Da Nang city, but also in other similar regions with rapid urbanization in Viet Nam. 


\subsection{Future works}

Generally, the results within this thesis indicate that the integration of the SD model and Dyna-CLUE model has capability to explain land use/cover behavior by using significant factors as a complete process. According to Pijanowski et al. (2000), the use of the cause-effects relationship created from driving factors and land use/cover change in CLUE model could prevent spurious interpretation and subjective human intervention. However, further improvements of this research could be implemented.

The study was completely done as a process for supporting land use planning from initial data. Due to the conditions of research, available data used for analysis are different at acquisition sources and spatial resolution. This would cause some inaccuracies in interpreting data. Thus, if one kind of higher spatial resolution data could be accessed (e.g. Vietnamese first satellite VNREDSat-1, 07/05/2013), it would overcome this restriction. Consequently, more information explored from the specific region could enhance the understanding the real situation.

As can be seen from historical data, the transportation network significantly influences to the urbanization process. Currently, the actual road network was used as one of critical driving factors in the Dyna-CLUE model. In addition, constraint factors such as the price of an area, or an area in good condition for business were not included in the model. Hence, if future transportation network information and related data could be identified and inserted into model, it may improve the simulated outcomes.

In section 6.9.1, it is discussed that land use/cover conversion elasticity were defined based on empirical assessment. In this sense, it is possible to investigate the elasticity from local planners or managements. Furthermore, the cooperation could help in various ways, including more relevant data could be easily accessed and used, more practical policy could be established in models and it is the shortest way to let local planners and managers know and apply the models to their usual works. 


\section{References}

Agarwal, C., Green, G. M., Grove, J. M., Evans, T. P., and Schweik, C. M., 2002, A Review and Assessment of Land-Use Change Models: Dynamics of Space, Time, and Human Choice, Gen. Tech. Rep. NE-297. Newton Square, PA: U.S. Department of Agriculture, Forest Service, Northeastern Research Station, p. 61.

Ahmed, B., Ahmed, R., and Zhu, X., 2013, Evaluation of Model Validation Techniques in Land Cover Dynamics: ISPRS International Journal of Geo-Information, v. 2, no. 3, p. 577-597.

Anderson, J. R., Hardy, E. E., Roach, J., and Witmer, R. E., 1976a, A land use/cover classification system for use with remote sensor data: US Geological Survey Professional p. 964: Sious Falls, SD.

Anderson, J. R., Hardy, E. E., Roach, J. T., and Witmer, R. E., 1976b, A land use and land cover classification system for use with remote sensor data: Tech.rep., U.S. Geological Survey Professional Paper, p. 964.

Angel, D. P., Attoh, S., Kromm, D., Dehart, J., Slocum, R., and White, S., 1998, The drivers of greenhouse gas emissions: What do we learn from local case studies?: Local Environment: The International Journal of Justice and Sustainability, v. 3, no. 3, p. 263-277.

Antrop, M., and Van Eetvelde, V., 2000, Holistic aspects of suburban landscapes: visual image interpretation and landscape metrics: Landscape and Urban Planning, v. 50, no. 1-3, p. 43-58.

Apan, A., Raine, S. R., and Paterson, Image analysis techniques for assessing landscape structural change: a case study of the Lockyer Valley catchment, Queensland, in Proceedings 10th Australasian Remote Sensing and Photogrammetry Conference2000, p. 438-455.

Bakr, N., Weindorf, D. C., Bahnassy, M. H., Marei, S. M., and El-Badawi, M. M., 2010, Monitoring land cover changes in a newly reclaimed area of Egypt using multitemporal Landsat data: Applied Geography, v. 30, no. 4, p. 592-605.

Bhatta, B., 2010, Analysis of urban growth and sprawl from remote sensing data, Springer Heidelberg Dordrecht London New York, 191 p.:

Braimoh, A. K., and Onishi, T., 2007, Geostatistical techniques for incorporating spatial correlation into land use change models: International Journal of Applied Earth Observation and Geoinformation, v. 9, no. 4, p. 438.

Brooks, D., A. Baudin, and P. Schwarzbauer., 1995, Modelling forest products demand, supply and trade, UN-ECE/FAO Timber and Forest Discussion Papers, ETTS V Working Paper, ECE/TIM/DP/5.

Brown, D. G., Walker, R., Manson, S., and Seto, K., 2004, Modeling land use and land cover change, in Garik Gutman, Anthony C. Janetos, Christopher O. Justice, Emilio F. Moran, John F. Mustard, Ronald R. Rindfuss, David Skole, Billy Lee Turner II, and Cochrane, M. A., eds., Land Change Science: Observing, Monitoring and Understanding Trajectories of Change on the Earth's Surface Springer, p. 482.

Campbell, B. J., 1996, Introduction to Remote Sensing , 2nd Edition, Guilford Press, New York.

-, 2002, Introduction to Remote Sensing , 3nd Edition, Guilford Press, New York.

Campbell, J. B., 2007, Introduction to Remote Sensing, The Guilford Press. 
Canty, M. J., and Nielsen, A. A., 2008, Automatic radiometric normalization of multitemporal satellite imagery with the iteratively re-weighted MAD transformation: Remote Sensing of Environment, v. 112, no. 3, p. 1025-1036.

Canty, M. J., Nielsen, A. A., and Schmidt, M., 2004, Automatic radiometric normalization of multitemporal satellite imagery: Remote Sensing of Environment, v. 91, no. 3-4, p. 441-451.

Carlson, T. N., 2004, Analysis and prediction of surface funoff in an urbanizing watershed using satellite imagery: Journal of the American Water Resources Association, v. 40, no. 4, p. 1087-1098.

Caselles, V., and García, M. J. L., 1989, An alternative simple approach to estimate atmospheric correction in multitemporal studies International Journal of Remote Sensing v. 10, no. 6, p. 1127 - 1134

Chase, T. N., Pielke Sr, R. A., Kittel, T. G. F., Nemani, R. R., and Running, S. W., 2000, Simulated impacts of historical land cover changes on global climate in northern winter: Climate Dynamics, v. 16, no. 2-3, p. 93-105.

Chen, H., and Pontius, R., Jr., 2010, Diagnostic tools to evaluate a spatial land change projection along a gradient of an explanatory variable: Landscape Ecology, v. 25, no. 9, p. 1319-1331.

Chen, X., Vierling, L., and Deering, D., 2005, A simple and effective radiometric correction method to improve landscape change detection across sensors and across time: Remote Sensing of Environment, v. 98, no. 1, p. 63-79.

Chen, Z., and Wang, J., 2010, Land use and land cover change detection using satellite remote sensing techniques in the mountainous Three Gorges Area, China: International Journal of Remote Sensing, v. 31, no. 6, p. 1519-1542.

Cheng, J., 2003, Modelling the spatial and temporal land use growth [Doctoral Dissertation: Utretch University, Utrech, The Netherlands.

Chorley, R. J., and Haggett, P., 1967, Models in geography.

-, 2013, Integrated models in geography, Routledge, Taylor \& Francis group.

Colgalton, R. G., and Green, K., 1999, Assessing the accuracy of remotely sensed data: principles and practices, CRC Lewis Publishers.

Collier, U., 1997, Local authorities and climate protection in the European union: Putting subsidiarity into practice?: Local Environment: The International Journal of Justice and Sustainability, v. 2, no. 1, p. 39-57.

Collier, U., and Löfstedt, R. E., 1997, Think globally, act locally? : Local climate change and energy policies in Sweden and the UK: Global Environmental Change, v. 7, no. 1, p. 25-40.

Committee on Global Change Research, 1999, Global Environmental Change: Research pathways for the next decade, National Academy Press, Washington, DC, 596 p.:

Conel, J. E., 1990, Determination of surface reflectance and estimates of atmospheric optical depth and single scattering albedo from Landsat Thematic Mapper data International Journal of Remote Sensing, v. 11, no. 5, p. 783 - 828.

Conghe Song, Curtis E. Woodcock, Karen C. Seto, Mary Pax Lenney, and Macomber, S. A., 2001, Classification and change detection using landsat tm data when and how to correct atmospheric effects?: Remote Sensing of Environment, v. 75, p. 230-244.

Crocetto, N., and Tarantino, E., 2009, A Class-Oriented Strategy for Features Extraction from Multidate ASTER Imagery: Remote Sensing, v. 1, no. 4, p. 1171-1189. 
Curran, P. J., 1987, Review Article Remote sensing methodologies and geography: International Journal of Remote Sensing, v. 8, no. 9, p. 1255-1275.

Da Nang' s committee, 2012, Population planning and developing in Da Nang city from 2011 to 2020. Assessed on

12/11/2012 http://dhtp.vn/img/uploads/Van\%20ban\%20dieu\%20hanh/UBND\% 20TP\%20DN/QD5882-UBtp.pdf.

Danang' statistical office, 2009, Statistical yearbook, Danang publishing house, 118 p.:

Danang Info, 2012, Danang overview. Accessed on 03/18/2013 http://www.danangcity.gov.vn/portal/page/portal/danang/english/da nang info/ove.

de Koning, G. H. J., Verburg, P. H., Veldkamp, A., and Fresco, L. O., 1999, Multi-scale modelling of land use change dynamics in Ecuador: Agricultural Systems, v. 61, no. 2, p. 77-93.

DeAngelo, B. J., and Harvey, L. D. D., 1998, The jurisdictional framework for municipal action to reduce greenhouse gas emissions: Case studies from Canada, the USA and Germany: Local Environment: The International Journal of Justice and Sustainability, v. 3, no. 2, p. 111-136.

Deng, J. S., Wang, K., Hong, Y., and Qi, J. G., 2009, Spatio-temporal dynamics and evolution of land use change and landscape pattern in response to rapid urbanization: Landscape and Urban Planning, v. 92, no. 3-4, p. 187-198.

Dewan, A. M., and Yamaguchi, Y., 2009, Land use and land cover change in Greater Dhaka, Bangladesh: Using remote sensing to promote sustainable urbanization: Applied Geography, v. 29, no. 3, p. 390-401.

Dietzel, C., Herold, M., Hemphill, J. J., and Clarke, K. C., 2005, Spatio-temporal dynamics in California's Central Valley: empirical links urban theory: International Journal of Geographic Information Sciences, v. 19, no. 2, p. 175195.

Ding, H., Wang, R. C., Wu, J. P., Zhou, B., Shi, Z., and Ding, L. X., 2007, Quantifying Land Use Change in Zhejiang Coastal Region, China Using Multi-Temporal Landsat TM/ETM+ Images: Pedosphere, v. 17, no. 6, p. 712-720.

Du, Y., Teillet, P. M., and Cihlar, J., 2002, Radiometric normalization of multitemporal high-resolution satellite images with quality control for land cover change detection: Remote Sensing of Environment, v. 82, no. 1, p. 123-134.

Ducourtieux, O., and Castella, J. C., 2006, Land reforms and impact on land use in the uplands of Vietnam and Laos: Environmental protection or poverty alleviation? , At the frontier of land issues: Social embeddedness of rights and public policy: Montpellier, France, Assessed 09/07/2012 http://www.mpl.ird.fr/colloque_foncier/Communications/PDF/Duco urtieux.pdf.

Dunn, C. P., Sharpe, D. M., Guntensbergen, G. R., Stearns, F., and \& Yang, Z., 1991, Methods for analyzing temporal changes in landscape pattern in Turner, M. G., and Gardner, R. H., eds., Quantitative methos in landscape ecology: the analysis and interpretation of landscape heterogeneity New York: Springer Verlag, p. 173-198.

Ehlers, M., Jadkowski, M. A., Howard, R. R., and Brostuen, D. E., 1990, Application of SPOT data for regional growth analysis and local planning: Photogrammetric Engineering and Remote Sensing, v. 56, p. 175-180.

Ellis, E., 2010, Land-use and land-cover change. Accessed on 14/03/2013 http://www.eoearth.org/article/Land-use_and_land-cover_change. 
Elvidge, C. D., Sutton, P. C., Wagner, T. W., RHONDA RYZNER, J. E. V., SCOTT J. GOETZ, ANDREW J., SMITH, C. J., KAREN C. SETO, MARC L. IMHOFF, Y.Q. WANG,, and CRISTINA MILESI, R. N., 2004, Urbanization Land change science: Observing, Monitoring and Understanding Trajectories of Change on the Earth's Surface, Volume Remote Sensing and Digital Image Processing, Kluwer academic publishers, p. 315-328.

Engelsman, W., 2002, Simulating land use changes in an urbanising are in Malaysia: An application of the CLUE-S model in the Selangor river basin [Master Thesis: Wageningen University, $67 \mathrm{p}$.

Estoque, R. C., and Murayama, Y., 2012, Examining the potential impact of land use/cover changes on the ecosystem services of Baguio city, the Philippines: A scenario-based analysis: Applied Geography, v. 35, no. 1-2, p. 316-326.

FAO, 1995, Planning for sustainable use of land resources: Towards a new approach, Food and Agriculture Organization of the United Nations.

Forman, R. T. T., and Gordon, M., 1986, Landscape ecology, Wiley, New York.

Forrester, J. W., 1961, Industrial Dynamics, Pegasus Communications.

Fragkias, M., Langanke, T., Boone, C.G., Haase, D., Marcotullio, P.J., Munroe, D., Olah, B., Reenberg, A., Seto, K.C., Simon, D. , 2012, Land Teleconnections in an Urbanizing World.

Hagen-Zanker, A., and Lajoie, G., 2008, Neutral models of landscape change as benchmarks in the assessment of model performance: Landscape and Urban Planning, v. 86, no. 3-4, p. 284-296.

Haines-Young, R. H., 1989, Modelling geographical knowledge, in Macmillan, W., ed., Remodelling geography, Oxford: Basil Blackwell, p. 22-39.

Haines-Young, R. H., and Petch, J. H., 1986, Physical geography: its nature and methods, London: Harper \& Row, 230 p.:

Hall, F. G., Strebel, D. E., Nickeson, J. E., and Goetz, S. J., 1991, Radiometric rectification: Toward a common radiometric response among multidate, multisensor images: Remote Sensing of Environment, v. 35, no. 1, p. 11-27.

Hargis, C., Bissonette, J., and David, J., 1998, The behavior of landscape metrics commonly used in the study of habitat fragmentation: Landscape Ecology, v. 13, no. 3, p. 167-186.

Harris, P. M., and Ventura, S. J., 1995, The integration of geographic data with remotely sensed imagery to improve classification in an urban area: Photogrammetric Engineering and Remote Sensing, v. 61, p. 993-998.

Harvey, L. D. D., 1993, Tackling urban Co2 emissions in Toronto: Environment, v. 35, no. 7, p. 16-20.

He, C., Okada, N., Zhang, Q., Shi, P., and Zhang, J., 2006, Modeling urban expansion scenarios by coupling cellular automata model and system dynamic model in Beijing, China: Applied Geography, v. 26, no. 3-4, p. 323-345.

Heo, J., and FitzHugh, T. W., 2000, A standardized radiometric normalization method for change detection using remotely sensed imagery Photogrammetric Engineering and Remote Sensing, v. 66, no. 2, p. 173-181.

Herold, M., Couclelis, H., and Clarke, K. C., 2005, The role of spatial metrics in the analysis and modeling of urban land use change: Computers, Environment and Urban Systems, v. 29, no. 4, p. 369-399.

Hinton, J. C., 1996, GIS and remote sensing integration for environmental applications: International Journal of Geographical Information Systems, v. 10, no. 7, p. 877890. 
Houghton, R. A., Hackler, J. L., and Lawrence, K. T., 1999, The U.S. Carbon Budget: Contributions from Land-Use Change: Science, v. 285, no. 5427, p. 574-578.

Huang, J., Lin, J., and Tu, Z., 2010, Detecting spatiotemporal change of land use and landscape pattern in a coastal gulf region, southeast of China: Environment, Development and Sustainability, v. 12, no. 1, p. 35-48.

IDS, 2007, Governance screening for urban climate change resilience building and adaptation strategies in asia: Assessment of Danang, Vietnam, http://www.ids.ac.uk/files/dmfile/DaNang.pdf, accessed on 09/03/2013.

J. Koch, F. W., R. Schaldach, J. Onigkeit, 2012, An Integrated Land-Use System Model for the Jordan River Region, in Appiah-Opoku, S., ed., Environmental Land Use Planning: Intech, p. 87-116.

Janzen, D. T., Fredeen, A. L., and Wheate, R. D., 2006, Radiometric correction techniques and accuracy assessment for Landsat TM data in remote forested regions: Canadian Journal of Remote Sensing v. 32, no. 5, p. 330-340.

Jat, M. K., Garg, P. K., and Khare, D., 2008, Monitoring and modelling of urban sprawl using remote sensing and GIS techniques: International Journal of Applied Earth Observation and Geoinformation, v. 10, no. 1, p. 26-43.

Jensen, J. R., 2000, Remote sensing of the environment: An earth resource perspective, New Jersey, Prentice Hall 544 p.:

Jensen, J. R., 2005, Introductory digital image processing: a remote sensing perspective, New Jersey: Prentice-Hall, 545 p.:

Ji, W., Ma, J., Twibell, R. W., and Underhill, K., 2006, Characterizing urban sprawl using multi-stage remote sensing images and landscape metrics: Computers, Environment and Urban Systems, v. 30, no. 6, p. 861-879.

Johannsen, C. J., Petersen, G. W., Carter, P. G., and Morgan, M. T., 2003, Remote sensing changing natural resource management: Journal of Soil and Water Conservation, v. 58, no. 2, p. 42A-45A.

Jokar Arsanjani, J., 2012, Dynamic land use/cover change modelling: Geosimulation and multiagent-based modelling, Berlin, Heidelberg : Springer-Verlag Berlin Heidelberg.

Kangas, K., and Baudin, A., 2003, Modelling and projections of forest productions demand, supply and trade in Europe, UN-ECE/FAO Geneva Timber and Forest discussion paper 30.

Kashaigili, J. J., and Majaliwa, A. M., 2010, Integrated assessment of land use and cover changes in the Malagarasi river catchment in Tanzania: Physics and Chemistry of the Earth, Parts A/B/C, v. 35, no. 13-14, p. 730-741.

Käyhkö, N., Fagerholm, N., Asseid, B. S., and Mzee, A. J., 2011, Dynamic land use and land cover changes and their effect on forest resources in a coastal village of Matemwe, Zanzibar, Tanzania: Land Use Policy, v. 28, no. 1, p. 26-37.

Keleş, S., Sivrikaya, F., Çakir, G., and Köse, S., 2008, Urbanization and forest cover change in regional directorate of Trabzon forestry from 1975 to 2000 using landsat data: Environmental Monitoring and Assessment, v. 140, no. 1-3, p. 114.

Khoury, A. E., 2012, Modeling land use changes in the South Nation watershed using Dyna-CLUE [Master thesis]: University of Ottawa, 104 p.

Kok, K., and Winograd, M., 2002, Modelling land-use change for Central America, with special reference to the impact of hurricane Mitch: Ecological Modelling, v. 149, no. 1-2, p. 53-69. 
Koomen, E. S., J.; Bakema, A.; Scholten, H.J. (Eds.), 2007, Modelling Land-use change: Progress and Applications, P.O. Box 17, 3300 AA Dordrecht, The Netherlands., Springer,, GeoJournal Library.

Kyriakidis, P. C., Liu, X., and Goodchild, M. F., 2004, Geostatistical Mapping of Thematic Classification Uncertainty, Remote Sensing and GIS Accuracy Assessment, CRC Press, p. 145-162.

Lambin, E. F., 2004, Modelling land use change, John Wiley \& Sons, Inc., West Sussex, Lon, Environmental modelling: fiding simplicity in complexity, 342 p.:

Lambin, E. F., Geist, H. J., and Lepers, E., 2003, Dynamics of land use and land cover change in tropical regions: Annual Review of Environment and Resources, v. 28, no. 1, p. 205-241.

Lambin, E. F., Rounsevell, M. D. A., and Geist, H. J., 2000, Are agricultural land-use models able to predict changes in land-use intensity?: Agriculture, Ecosystems \& Environment, v. 82, no. 1-3, p. 321-331.

Lambin, E. F., Turner, B. L., Geist, H. J., Agbola, S. B., Angelsen, A., Bruce, J. W., Coomes, O. T., Dirzo, R., Fischer, G., Folke, C., George, P. S., Homewood, K., Imbernon, J., Leemans, R., Li, X., Moran, E. F., Mortimore, M., Ramakrishnan, P. S., Richards, J. F., Skånes, H., Steffen, W., Stone, G. D., Svedin, U., Veldkamp, T. A., Vogel, C., and Xu, J., 2001, The causes of land-use and landcover change: moving beyond the myths: Global Environmental Change, v. 11, no. 4, p. 261-269.

Lambright, W. H., Changnon, S. A., and Harvey, L. D. D., 1996, Urban reactions to the global warning issue: agenda setting in Toronto and Chincago: Climate Change, v. 34, p. 463-478.

Landis, J. R., and Koch, G. G., 1977, The Measurement of Observer Agreement for Categorical Data: Biometrics, v. 33, p. 159-174.

Lawgali, F. F., 2008, Forestcasting water demand for agricultural, industrial and domestic use in Libya: International Review of Business Papers, v. 4, no. 5, p. 231-248.

Lee, C.-L., Huang, S.-L., and Chan, S.-L., 2009, Synthesis and spatial dynamics of socio-economic metabolism and land use change of Taipei Metropolitan Region: Ecological Modelling, v. 220, no. 21, p. 2940-2959.

Leinenkugel, P., 2010, The combined use of optical and SAR data for large area impervious surface mapping [Msc: Paris-Lodron Salzburg University, $121 \mathrm{p}$.

Leitao, A. B., and Ahern, J., 2002, Applying landscape ecological concepts and metrics in sustainable landscape planning: Landsc. Urban Plan., v. 59, no. 2, p. 65-93.

Lin, Y.-P., Hong, N.-M., Wu, P.-J., Wu, C.-F., and Verburg, P. H., 2007, Impacts of land use change scenarios on hydrology and land use patterns in the $\mathrm{Wu}-\mathrm{Tu}$ watershed in Northern Taiwan: Landscape and Urban Planning, v. 80, no. 1-2, p. 111-126.

Liu, Y., 2009, Modelling urban development with geographical information systems and cellular automata, CRC Press, Taylor \& Francis group, 204 p.:

Lunetta, R. S., and Elvidge, C. D., 1998, Remote sensing change detection: environmental monitoring methods and applications. , Taylor \& Francis, London.

Luo, G., Yin, C., Chen, X., Xu, W., and Lu, L., 2010, Combining system dynamic model and CLUE-S model to improve land use scenario analyses at regional scale: A case study of Sangong watershed in Xinjiang, China: Ecological Complexity, v. 7, no. 2, p. 198-207. 
Lyons, M. B., Phinn, S. R., and Roelfsema, C. M., 2012, Long term land cover and seagrass mapping using Landsat and object-based image analysis from 1972 to 2010 in the coastal environment of South East Queensland, Australia: ISPRS Journal of Photogrammetry and Remote Sensing, v. 71, no. 0, p. 34-46.

M. Batty, Yichun Xie, and Sun, Z., 1999, Modeling urban dynamics through GIS-based cellular automata: Computers, Environment and Urban Systems, v. 23, p. 205233.

M. Caprioli, B. Figorito, and Tarantino, E., 2006, Radiometric normalization of Landsat Etm+ data for multitemporal analysis: Proceedings of ISPRS Commision VII Mid-term Symposium on " Remote sensing: From pixels to Process" v. 34, no. Part XXX.

-, Radiometric calibration methods for change detection analysis of satellite data aimed at environmental risk monitoring, in Proceedings The International Archives of the Photogrammetry, Remote Sensing and Spatial Information Sciences, Beijing, 2008, Volume XXXVII. Part 8, p. 397-402.

McEvoy, D., Gibbs, D. C., and Longhurst, J. W. S., 1999, The Prospects for Improved Energy Efficiency in the UK Residential Sector: Journal of Environmental Planning and Management, v. 42, no. 3, p. 409-424.

McGarigal, K., and Mark, B. J., 1995, FRAGSTATS: Spatial pattern analysis progam for quantifying lanscape structure.

McGarigal, K., and Marks, B. J., 1995, Fragstats: spatial pattern analysis program for quantifying landscape structure U. S. Forest Service General Technical Report, Portland, OR, USA.

McGarigal, K., SA Cushman, and E Ene., 2012, FRAGSTATS v4: Spatial Pattern Analysis Program for Categorical and Continuous Maps. Computer software program produced by the authors at the University of Massachusetts, Amherst. Available at the following web site: http://www.umass.edu/landeco/research/fragstats/fragstats.html.

McGarigal, K., SA Cushman, MC Neel, and Ene., E., 2002, FRAGSTATS: Spatial Pattern Analysis Program for Categorical Maps. Available at the following web site: http://www.umass.edu/landeco/research/fragstats/fragstats.html.

McGarigal, K., SA Cushman, MC Neel, and E Ene, 2002, FRAGSTATS: Spatial Pattern Analysis Program for Categorical Maps. Computer software program produced by the authors at the University of Massachusetts, Amherst. Available at the following web site: http://www.umass.edu/landeco/research/fragstats/fragstats.html.

Meadows, D. H., 2008, Thinking in Systems: A Primer, Chelsea Green Publishing, White River Junction, Vermont.

Men Ke-pei, and Kai, Z., 2010, Grey correlation between agriculture input factors and regional GDP growth in Anhui Province: Asian Agriculture Research v. 2, no. 4, p. 31-33.

Mesev, V., 1998, The use of census data in urban image classification: Photogrammetric Engineering and Remote Sensing, v. 64, p. 431-438.

Michalak, W. Z., 1993, GIS in land use change analysis: integration of remotely sensed data into GIS: Applied Geography, v. 13, no. 1, p. 28-44.

Mondal, S. M., Sharma, N., Kappas, M., and Garg, P. K., 2012, Modeling of spatiotemporal dynamics of land use land cover - a review and assessment: Jour-nal of Geomatics, v. 6, no. 2, p. 29-39. 
Moran, M. S., Jackson, R. D., Slater, P. N., and Teillet, P. M., 1992, Evaluation of simplified procedures for retrieval of land surface reflectance factors from satellite sensor output: Remote Sensing of Environment, v. 41, no. 2-3, p. 169184.

Muchoney, D. M., and Strahler, A. H., 2002, Pixel- and site-based calibration and validation methods for evaluating supervised classification of remotely sensed data: Remote Sensing of Environment, v. 81, no. 2-3, p. 290-299.

Müller, D., 2003, Land use change in the central highlands of Vietnam: A spatial econometric model combining satellite imagery and village survey data $[\mathrm{PhD}$ PhD]: Georg-August-University at Göttingen, 190 p.

Mulligan, M., and Wainwright, J., 2004, Modelling and model building, in Wainwright, J., and Mulligan, M., eds., Environmental modelling: finding simplicity in complicity, John Wiley \& Sons, Inc., West Sussex, London, p. 432.

Myint, S. W., and Wang, L., 2006, Multicriteria decision approach for land use land cover change using Markov chain analysis and a cellular automata approach: Canadian of Remote Sensing, v. 32, no. 6, p. 390-404.

Nguyen, X. T., 2003, Danang: policy otions for investment and economic development: http://agro.gov.vn/images/2007/04/Danang\%20Policy\%20Options \%20for\%20Investment\%20and\%20Economic\%20Development.pdf, accessed on 03/09/2013.

O'Neill, R. V., Krummel, J. R., Gardner, R. H., Sugihara, G., Jackson, B., DeAngelis, D. L., Milne, B. T., Turner, M. G., Zygmunt, B., Christensen, S. W., Dale, V. H., and Graham, R. L., 1988, Indices of landscape pattern: Landscape Ecology, v. 1 , no. 3, p. 153-162.

O'Neill, R. V., Riitters, K. H., Wickham, J. D., and Jones, K. B., 1999, Landscape Pattern Metrics and Regional Assessment: Ecosystem Health, v. 5, no. 4, p. 225233.

OECD, 2006, Competitive Cities in the Global Econom: OECD, Paris.

-, 2009, Regions at Glance 2009: OECD, Paris.

Olsen, L. M., Virginia H. Dale, and Thomas Foster, 2007, Landscape patterns as indicators of ecological change at Fort Benning, Georgia, USA: Landscape and Urban Planning, v. 79, p. 137-149.

Orekan, V. O. A., 2007, Implementaion of the local land use and land cover change model CLUE-s for Central Bennin by using socio-economic and remote sensing data [PhD: Rheinischen Friedrich-Wilhelms-Universität Bonn, 204 p.

Parker, D. C., Tom Evans, and Meretsky, V., 2001, Measuring Emergent Properties of Agent-Based Landcover/Landuse Models using Spatial Metrics, Seventh annual conference of the international society for compuational economics.

Peng, H., and Lu, H., 2007, Study on the Impacts of Urban Density on the Travel Demand Using GIS Spatial Analysis: Journal of Transportation Systems Engineering and Information Technology, v. 7, no. 4, p. 90-95.

People's committee Danang city, 2010, Planning social-seconomic developing to 2020.

Pijanowski, B. C., Gage, S. H., Long, D. T., and Cooper, W. C., 2000, A land transformation model for the Saginaw Baywatershed, in Sanderon, J., and Harris, L. D., eds., Landsape ecology: a top-down approach, Lewis Publishers, p. 246.

Pontius Jr, R. G., Huffaker, D., and Denman, K., 2004, Useful techniques of validation for spatially explicit land-change models: Ecological Modelling, v. 179, no. 4, p. 445-461. 
Pontius, J. R. G., 2000, Quantification error vesus location error in comparison of categorical maps: Photogrammetric Engineering and Remote Sensing, v. 66, no. 8, p. 1011-1016.

-, 2002, Statistical methods to partition effects of quantity and location during comparison of categorical maps at multiple resolutions: Photogrammetric Engineering and Remote Sensing, v. 68, no. 10, p. 1041-1049.

Pontius, J. R. G., Huffaker, D., and Denman, K., 2004, Useful techniques of validation for spatially explicit land-change models: Ecological Modelling, v. 179, no. 4, p. 445-461.

Pontius, J. R. G., and Millones, M., 2011, Death to Kappa: birth of quantity disagreement and allocation disagreement for accuracy assessment: International Journal of Remote Sensing, v. 32, no. 15, p. 4407-4429.

Pontius, J. R. G., and Schneider, L. C., 2001, Land-cover change model validation by an ROC method for the Ipswich watershed, Massachusetts, USA: Agriculture, Ecosystems \& Environment, v. 85, no. 1-3, p. 239-248.

Pontius, R., Jr., and Neeti, N., 2010, Uncertainty in the difference between maps of future land change scenarios: Sustainability Science, v. 5, no. 1, p. 39-50.

Pontius, R. G. J., and Chen, H., 2006, GEOMOD Modeling. Land-use and cover change modeling. Note on GEOMOD modeling available within IDRISI Andes package. : http://clarklabs.org, Clark Labs, Clark University, USA.

Priyanto, A. T., 2010, The impact of human activities on coastal zones and strategies towards sustainable development: a case study in Pekalongan, Indonesia [Master of science: University of Twente, $88 \mathrm{p}$.

Quan, B., Chen, J. F., Qiu, H. L., Römkens, M. J. M., Yang, X. Q., Jiang, S. F., and Li, B. C., 2006, Spatial-Temporal Pattern and Driving Forces of Land Use Changes in Xiamen: Pedosphere, v. 16, no. 4, p. 477-488.

Que, T. T., and Phuc, T. X., 2003, The Doi Moi policy and its impact on the poor, Accessed on 19/07/2012, http://www.socialwatch.org/node/10854

Radzicki, M., and Taylor, R., 2008, Origin of System Dynamics: Jay W. Forrester and the History of System Dynamics, U.S. Department of Energy's Introduction to System Dynamics. Accessed on 24/05/2013 http://www.systemdynamics.org/DL-IntroSysDyn/start.htm. .

Rafiee, R., Mahiny, A. S., Khorasani, N., Darvishsefat, A. A., and Danekar, A., 2009, Simulating urban growth in Mashad City, Iran through the SLEUTH model (UGM): Cities, v. 26, no. 1, p. 19-26.

Riitters, K. H., O'Neill, R. V., Hunsaker, C. T., Wickham, J. D., Yankee, D. H., Timmins, S. P., Jones, K. B., and Jackson, B. L., 1995, A factor analysis of landscape pattern and structure metrics: Landscape Ecology, v. 10, no. 1, p. 2339.

Rogan, J., and Chen, D., 2004, Remote sensing technology for mapping and monitoring land-cover and land-use change: Progress in Planning, v. 61, no. 4, p. 301-325.

Roy, P. S., and Tomar, S., 2001, Landscape cover dynamics pattern in Meghalaya: International Journal of Remote Sensing, v. 22, no. 18, p. 3813-3825.

Rykiel, E. J., 1996, Testing ecological models: The meaning of validation: Ecol. Model., v. 90, no. 3, p. 229-244.

Sala, O. E., Stuart Chapin , F., III, Armesto, J. J., Berlow, E., Bloomfield, J., Dirzo, R., Huber-Sanwald, E., Huenneke, L. F., Jackson, R. B., Kinzig, A., Leemans, R., Lodge, D. M., Mooney, H. A., Oesterheld, M. n., Poff, N. L., Sykes, M. T., 
Walker, B. H., Walker, M., and Wall, D. H., 2000, Global Biodiversity Scenarios for the Year 2100: Science, v. 287, no. 5459, p. 1770-1774.

Schott, J. R., Salvaggio, C., and Volchok, W. J., 1988, Radiometric scene normalization using pseudoinvariant features: Remote Sensing of Environment, v. 26, no. 1, p. 1-14, IN11, 15-16.

Shalaby, A., and Tateishi, R., 2007, Remote sensing and GIS for mapping and monitoring land cover and land-use changes in the Northwestern coastal zone of Egypt: Applied Geography, v. 27, no. 1, p. 28-41.

Shao, J. Y., Wang, K., Xiao, X. H., and Zhao, X. M., 2006, A study on prediction methods for urban construction land: Acta Agriculture Universitis Jiangxiensis, v. 28, no. 3, p. 472-476.

Silva, E., and Wu, N., 2012, Surveying Models in Urban Land Studies: Journal of Planning Literature, v. 27, no. 2, p. 139-152.

Sloke, D. l., 1994, Data on global land cover change: aquisition, assessment and analysis, in Meyer, W. B., and Turner II, B. L., eds., Changes in land use and land cover: A global perspective: Cambridge: Cambridge University Press, p. 437-471.

Stefanov, W. L., Ramsey, M. S., and Christensen, P. R., 2001, Monitoring urban land cover change: An expert system approach to land cover classification of semiarid to arid urban centers: Remote Sensing of Environment, v. 77, no. 2, p. 173-185.

Steven N. Durlauf, and Blume, L. E., 2008, The New Palgrave Dictionary of Economics, Palgrave Macmillan.

Thang, L. A., 2009, Studying and assessing the natural resources of Da Nang region for suitable development [Master Thesis: Vietnam national university, University of science, $106 \mathrm{p}$.

The Statistics department, 2005, Danang city - 30 years construction and development, in Statistics, ed.: Danang City.

Tolba, M. K., and El-Kholy, O. A., 1992, the world environment 1972-1992: two decades of challenge Chapman \& Hall, London.

Treitz, P., and Rogan, J., 2004, Remote sensing for mapping and monitoring land-cover and land-use change--an introduction: Progress in Planning, v. 61, no. 4, p. 269279.

Treitz, P. M., Howard, P. J., and Gong, P., 1992, Application of satellite and GIS technologies for land-cover and land-use mapping at the rural-urban fringe: A case study: Photogrammetric Engineering and Remote Sensing, v. 58, p. 439448.

Turner, B. L., 1994, Local faces, global flows: The role of land use and land cover in global environmental change: Land Degradation and Development, v. 5, no. 2, p. 71-78.

Turner, B. L. I., Sloke, D., Sanderson, S., Fisher, G., Freso, L., and Leemans, R., 1995, Land use and land cover change, IGBP Report, v. 35, HDP Report, v. 7. Stockholm and Geneva, IGBP and HDP.

Turner, M. G., 1989, Landscape Ecology: The Effect of Pattern on Process: Annual Review of Ecology and Systematics, v. 20, no. 1, p. 171-197.

Turner, M. G., Gardner, R. H., and O’Neill, R. V., 2001, Landscape Ecology in Theory and Practice: Pattern and Process, Springer, New York, 401 p.:

UN, 2008, State of the World's Cities 2008/2009: Harmonious Cities: United Nations Human Settlements Programme, Nairobi, Kenya 
USGS, 2009, News archive: change in status alert for the ASTER SWIR detector. Accessed on $26 / 03 / 2011$ https://lpdaac.usgs.gov/about/news_archive/wednesday_july_01_2009.

Van Loi, N., 2008, Use of GIS modelling in assessment of forestry land's potential in Thua Thien Hue province of central Vietnam [PhD thesis: Georg-August Goettingen University, 220 p.

van Vliet, J., Bregt, A. K., and Hagen-Zanker, A., 2011, Revisiting Kappa to account for change in the accuracy assessment of land-use change models: Ecological Modelling, v. 222, no. 8, p. 1367-1375.

Veldkamp, A., and Fresco, L. O., 1996, CLUE-CR: an integrated multi-scale model to simulate land use change scenarious in Costa Rica: Ecological Modelling, v. 91, p. 231-248.

Veldkamp A, L. F. F., 2001, Editorial: predicting land use change: Agriculture, Ecosystems and Environment v. 85, p. 1-6.

Verburg, P., 2010, The Clue modeling framework. Accessed 18/10/2012 http://www.ivm.vu.nl/en/Images/Exercises_tcm53-284019.pdf.

Verburg, P., and Overmars, K., 2009, Combining top-down and bottom-up dynamics in land use modeling: exploring the future of abandoned farmlands in Europe with the Dyna-CLUE model: Landscape Ecology, v. 24, no. 9, p. 1167-1181.

Verburg, P., Schot, P., Dijst, M., and Veldkamp, A., 2004, Land use change modelling: current practice and research priorities: GeoJournal, v. 61, no. 4, p. 309-324.

Verburg, P., Tom Veldkamp, and Lesschen, J. P., 2008, Exercises for the CLUE-S model,

UseChange/ExerciseClues.pdf, http://www.feweb.vu.nl/gis/ModellingLand18/09/2012:

Accessed

on

UseChange/ExerciseClues.pdf.

http://www.feweb.vu.nl/gis/ModellingLand-

Verburg, P., Van de Steeg, J., and Schulp, N., 2005, Manual for the CLUE-Kenya application. Accessed

on

27/02/2013 http://www.trajectories.org/download/CLUE_manual.pdf

Trajectories of Change.

Verburg, P., and Veldkamp, A., 2004, Projecting land use transitions at forest fringes in the Philippines at two spatial scales: Landscape Ecology, v. 19, no. 1, p. 77-98.

Verburg, P. H., Chen, Y., and Veldkamp, T., 2000, Spatial explorations of land use change and grain production in China: Agriculture, Ecosystems \& Environment, v. 82, no. 1-3, p. 333-354.

Verburg, P. H., de Koning, G. H. J., Kok, K., Veldkamp, A., and Bouma, J., 1999, A spatial explicit allocation procedure for modelling the pattern of land use change based upon actual land use: Ecological Modelling, v. 116, no. 1, p. 45-61.

Verburg, P. H., and Overmars, K. P., 2007, Dynamic simulation of land-use change trajectories with the CLUE-S model, in Koomen, E., Stillwell, J., Bakema, A., and Scholten, H. J., eds., Modelling land-use change: , Springer, p. 321-355.

Verburg, P. H., Soepboer, W., Veldkamp, A., Limpiada, R., Espaldon, V., and Mastura, S. S. A., 2002, Modeling the Spatial Dynamics of Regional Land Use: The CLUE-S Model: Environmental Management, v. 30, no. 3, p. 391-405.

Viet Nam Laws, 2003, Law on Land: Vietnam Laws Home Page, www.vietnamlaws.com/freelaws/Lw13na26Nov03Land[X2865].pdf.

Visser, H., and de Nijs, T., 2006, The Map Comparison Kit: Environmental Modelling \& Software, v. 21, no. 3, p. 346-358. 
Vitousek, P. M., Mooney, H. A., Lubchenco, J., and Melillo, J. M., 1997, Human Domination of Earth's Ecosystems: Science, v. 277, no. 5325, p. 494-499.

Wang, H., Li, X., Long, H., Qiao, Y., and Li, Y., 2011, Development and application of a simulation model for changes in land-use patterns under drought scenarios: Computers \& Geosciences, v. 37, no. 7, p. 831-843.

Weng, Q., 2002, Land use change analysis in the Zhujiang Delta of China using satellite remote sensing, GIS and stochastic modelling: Journal of Environmental Management, v. 64, no. 3, p. 273-284.

-, 2010, Remote sensing and GIS integration: theories, methods and applications, The McGraw-Hill Companies, Inc., 383 p.:

Wilbanks, T. J., and Kates, R. W., 1999, Global change in local places:How scale matters: Climate Change, v. 43, p. 601-628.

Wilkinson, G. G., 1996, A review of current issues in the integration of GIS and remote sensing data: International Journal of Geographical Information Systems, v. 10, no. 1 , p. 85-101.

Wilson, E. H., Hurd, J. D., Civco, D. L., Prisloe, M. P., and Arnold, C., 2003, Development of a geospatial model to quantify, describe and map urban growth: Remote Sensing of Environment, v. 86, no. 3, p. 275-285.

Wu, J., Jelinski, D. E., Luck, M., and Tueller, P. T., 2000, Multiscale Analysis of Landscape Heterogeneity: Scale Variance and Pattern Metrics: Geographic Information Sciences, v. 6, no. 1, p. 6-19.

Wu, Q., Li, H.-q., Wang, R.-s., Paulussen, J., He, Y., Wang, M., Wang, B.-h., and Wang, Z., 2006, Monitoring and predicting land use change in Beijing using remote sensing and GIS: Landscape and Urban Planning, v. 78, no. 4, p. 322333.

Xiao, J., Shen, Y., Ge, J., Tateishi, R., Tang, C., Liang, Y., and Huang, Z., 2006, Evaluating urban expansion and land use change in Shijiazhuang, China, by using GIS and remote sensing: Landscape and Urban Planning, v. 75, no. 1-2, p. 69-80.

Xinping Ye, 2008, Characterizing the Spatial Distribution of Giant Pandas in China using MODIS data and landscape metrics. Accessed on 21/02/2013 http://www.itc.nl/library/papers_2008/msc/gem/xingpingye.pdf [Msc thesis], $54 \mathrm{p}$.

Yang Long-fei, Zhao Qiao-gui, and Yang Zi-sheng, 2010, Prediction on the farmland demand of Yunnan province in 2020 based on food security: Asian Agriculture Research, v. 2, no. 3, p. 58-61.

Yang, X., and Lo, C. P., 2002, Using a time series of satellite imagery to detect land use and land cover changes in the Atlanta, Georgia metropolitan area: International Journal of Remote Sensing, v. 23, no. 9, p. 1775-1798.

Yuan, D., and Elvidge, C. D., 1996, Comparison of relative radiometric normalization techniques: ISPRS Journal of Photogrammetry and Remote Sensing, v. 51, no. 3, p. 117-126.

Zhan, Q., 2003, A hieracrchical oject-based approach for urban land-use classification from Remote sensing data [PhD Thesis PhD Thesis]: Wageningen University.

Zheng, X.-Q., Zhao, L., Xiang, W.-N., Li, N., Lv, L.-N., and Yang, X., 2012, A coupled model for simulating spatio-temporal dynamics of land-use change: A case study in Changqing, Jinan, China: Landscape and Urban Planning, v. 106, no. 1, p. 51-61. 


\section{Appendices}

\section{Appendix 1}

\section{Accuracy assessment error matrices}

\section{LULC 1979}

Sample Matrix

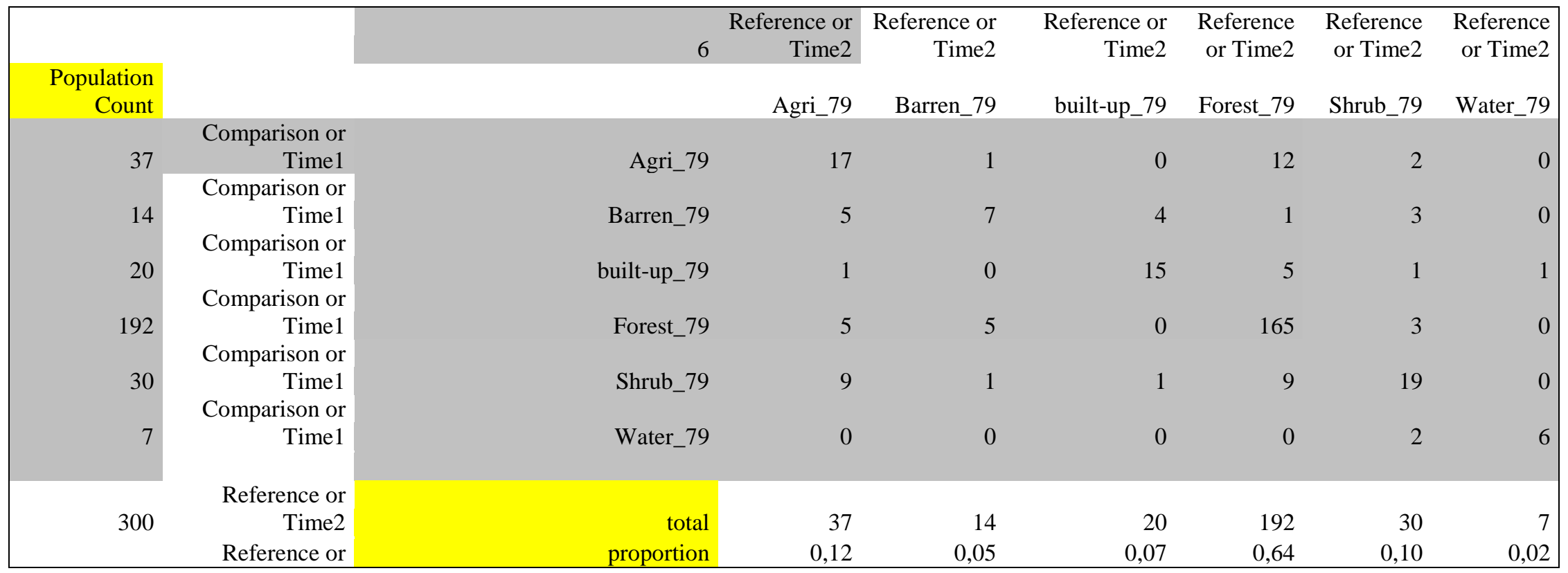




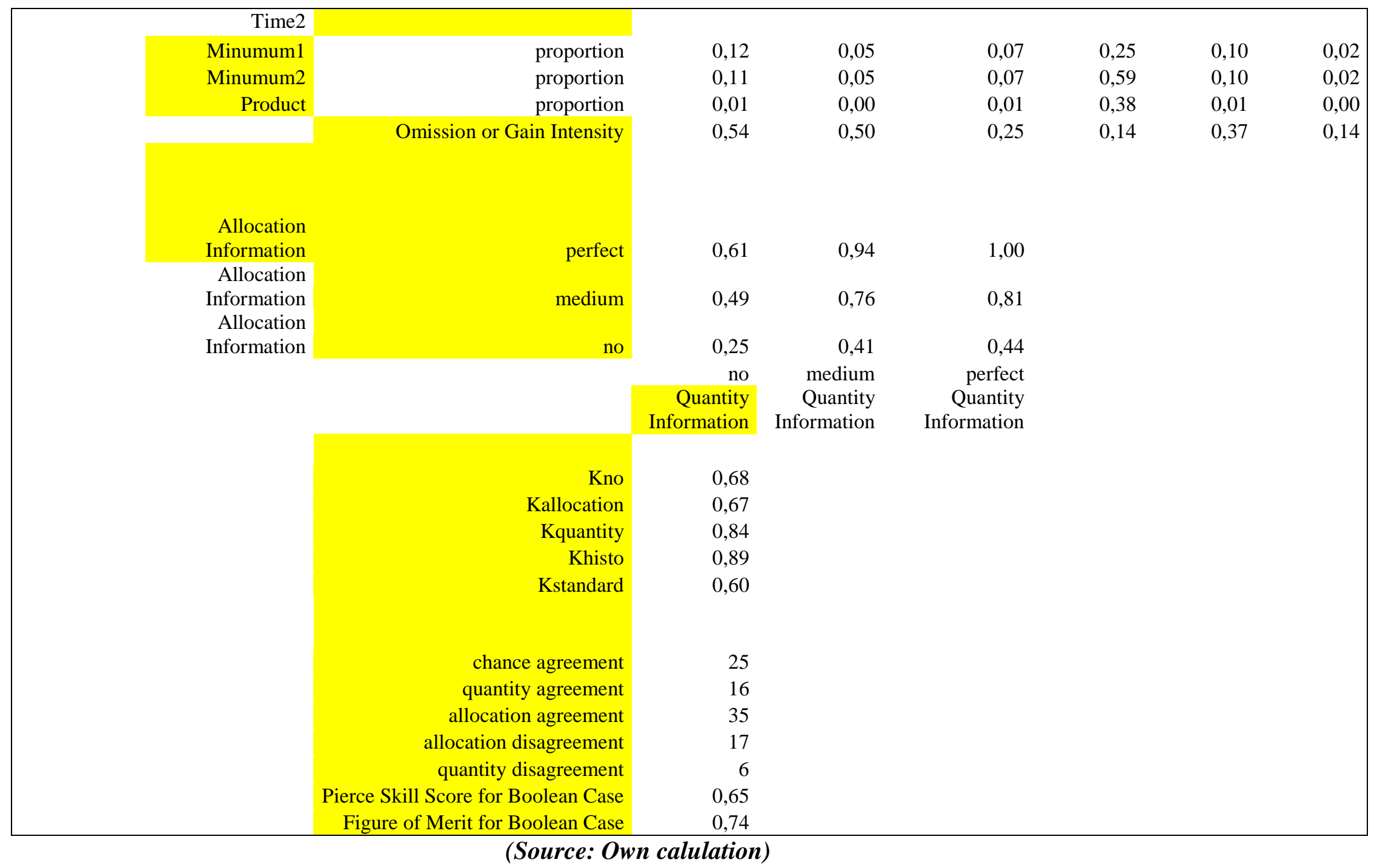




\section{Components}

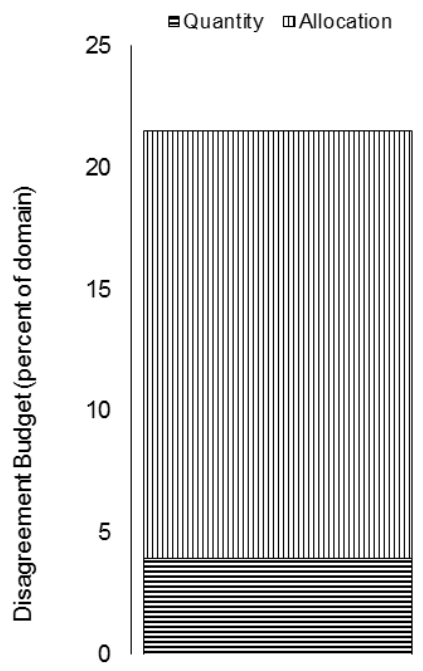

\section{Agreement-Disagreement}

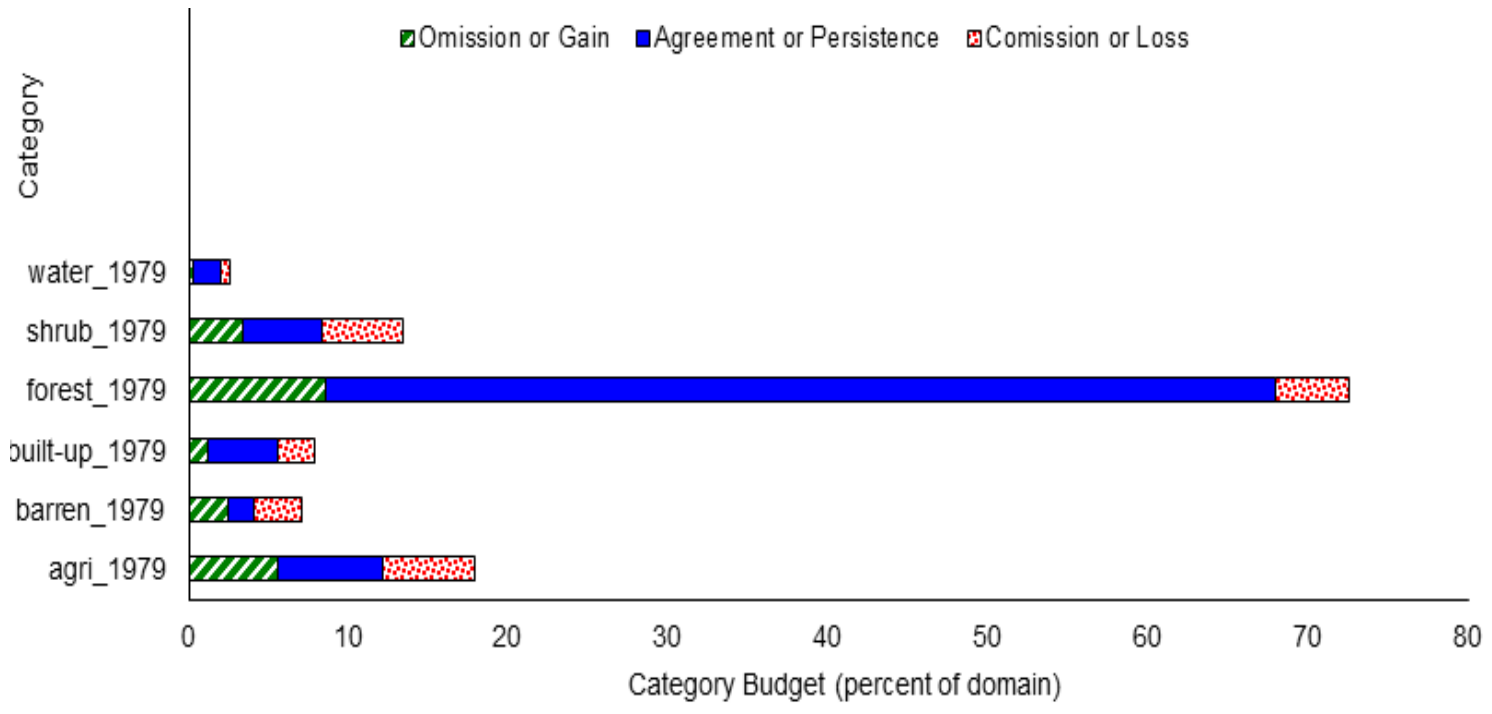

\section{Intensity}

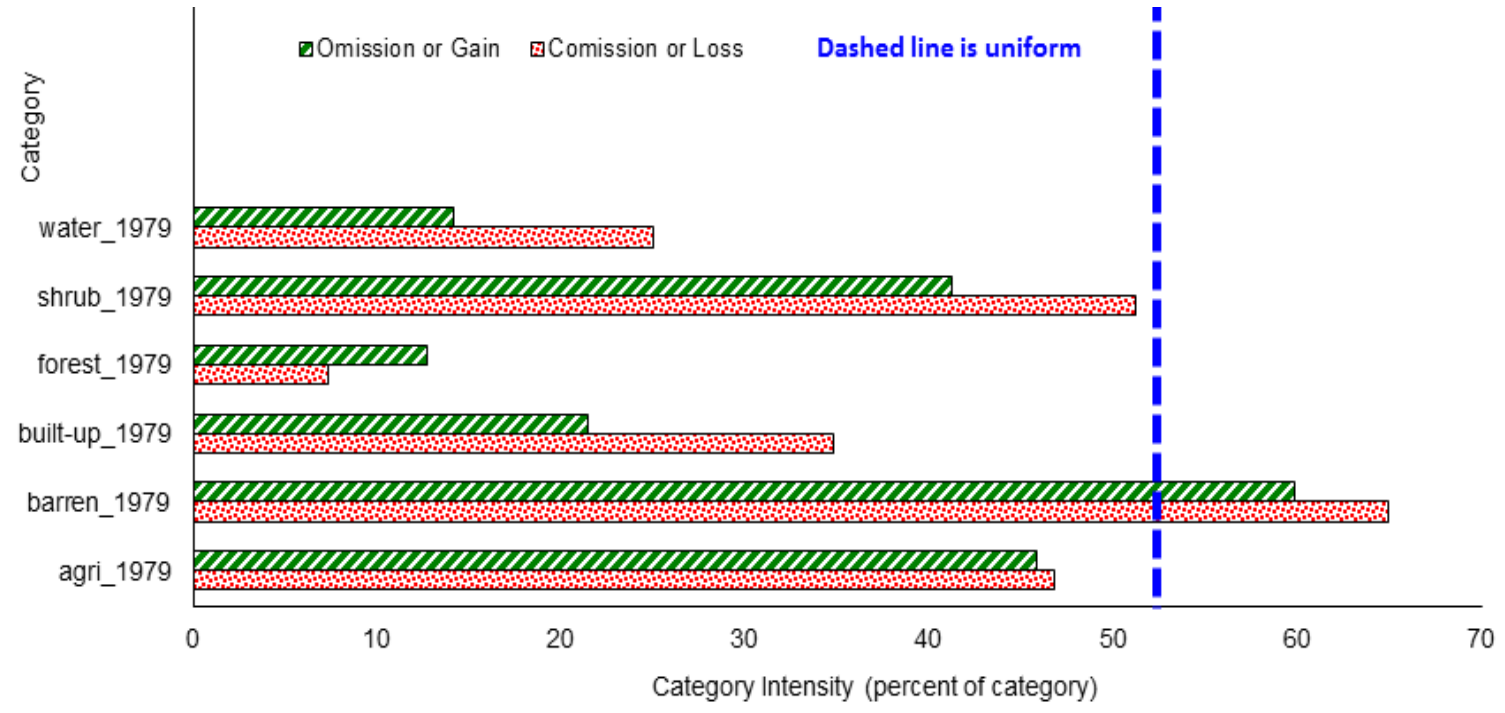

(Source: Own calulation) 


\section{LULC 1996}

\section{Sample Matrix}

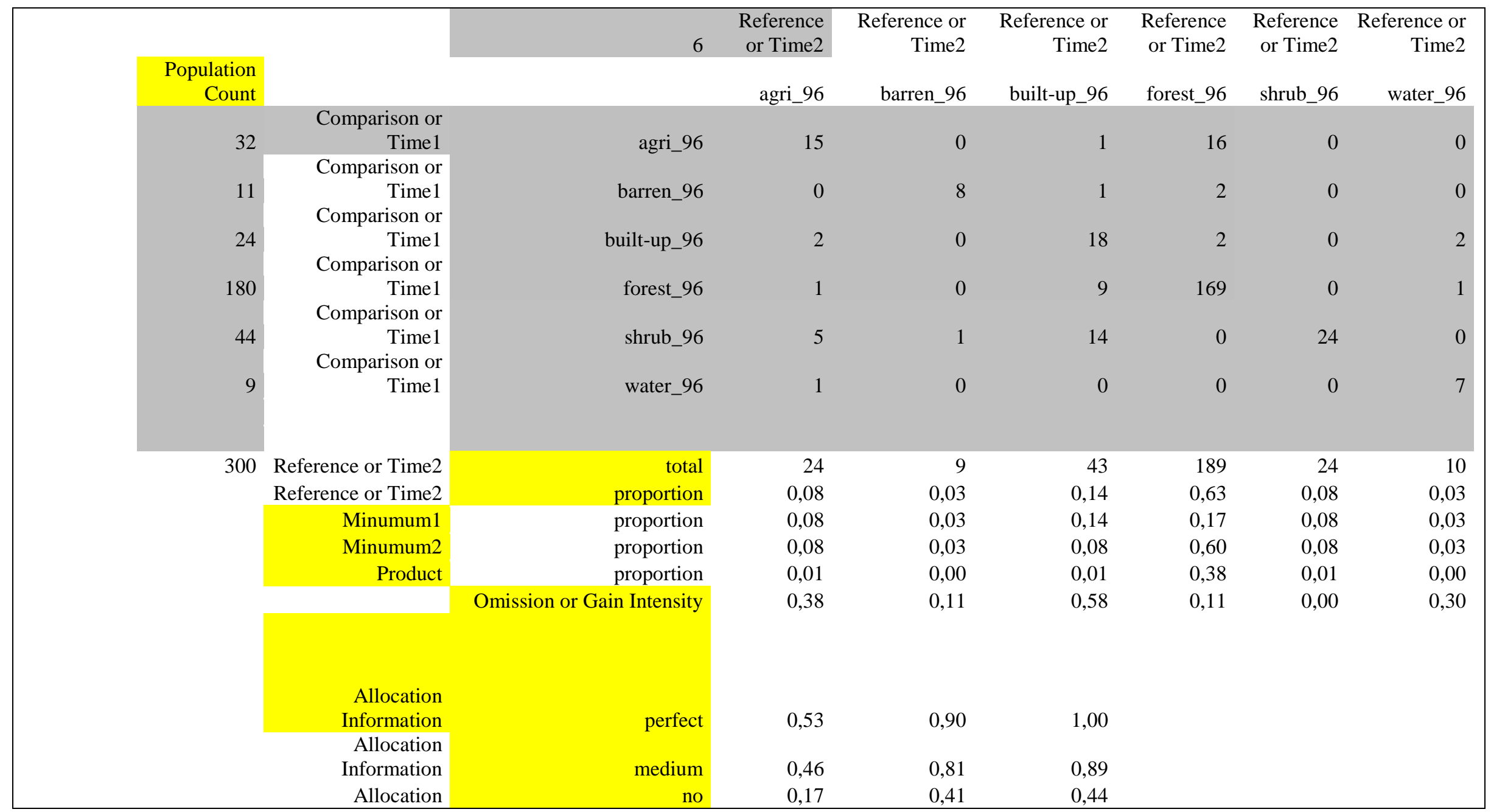




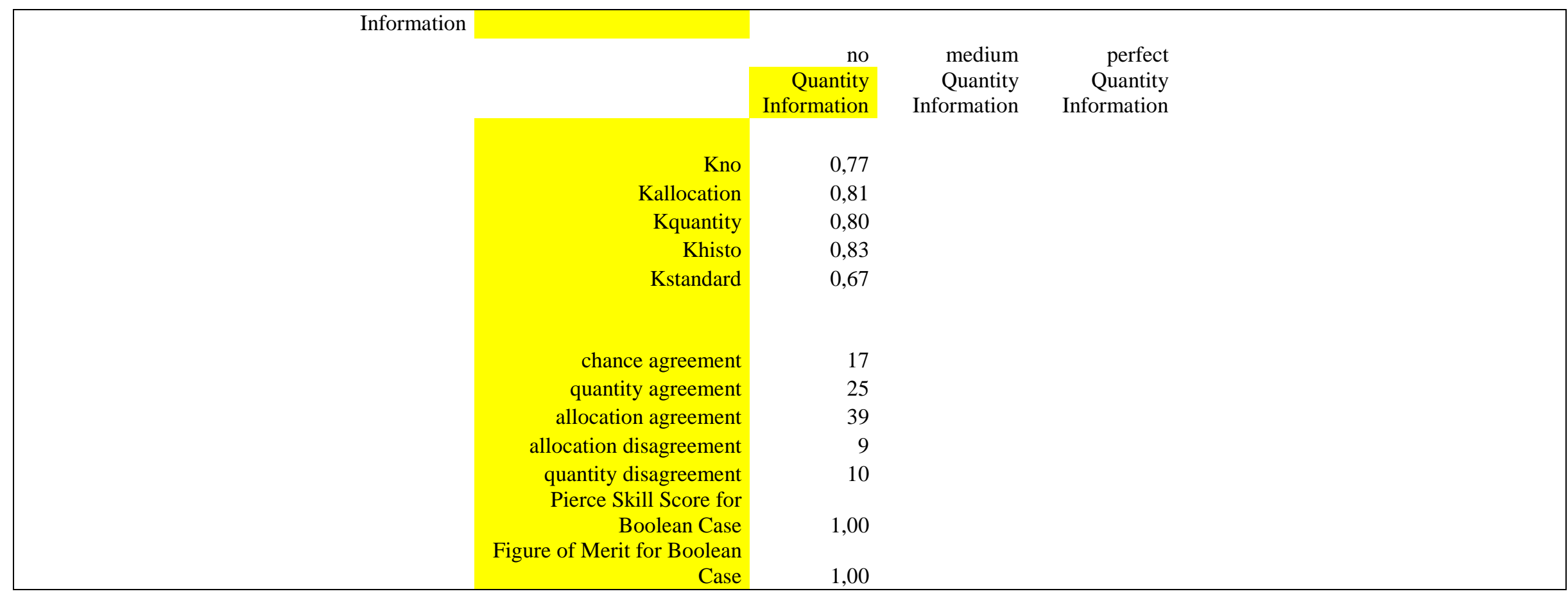

\section{(Source: Own calulation)}




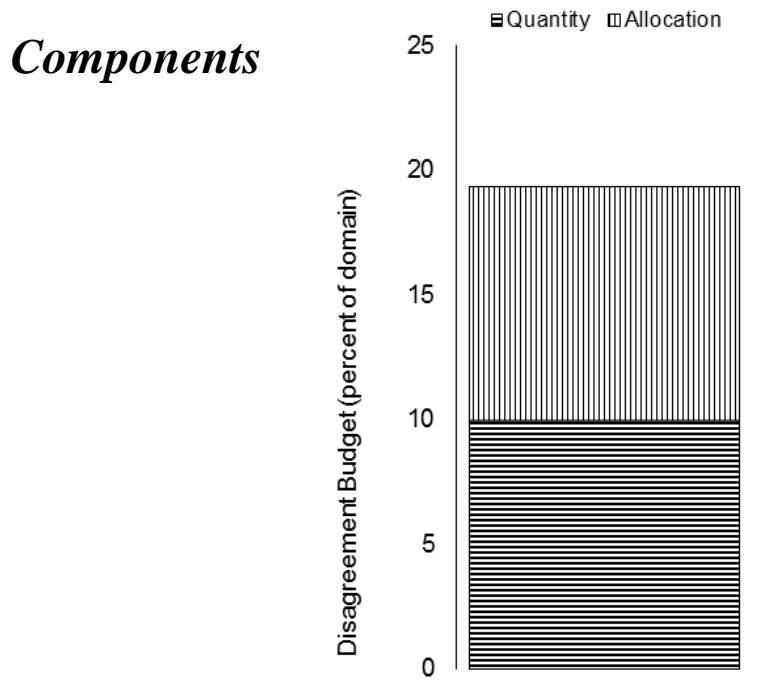

\section{Agreement - Disagreement}

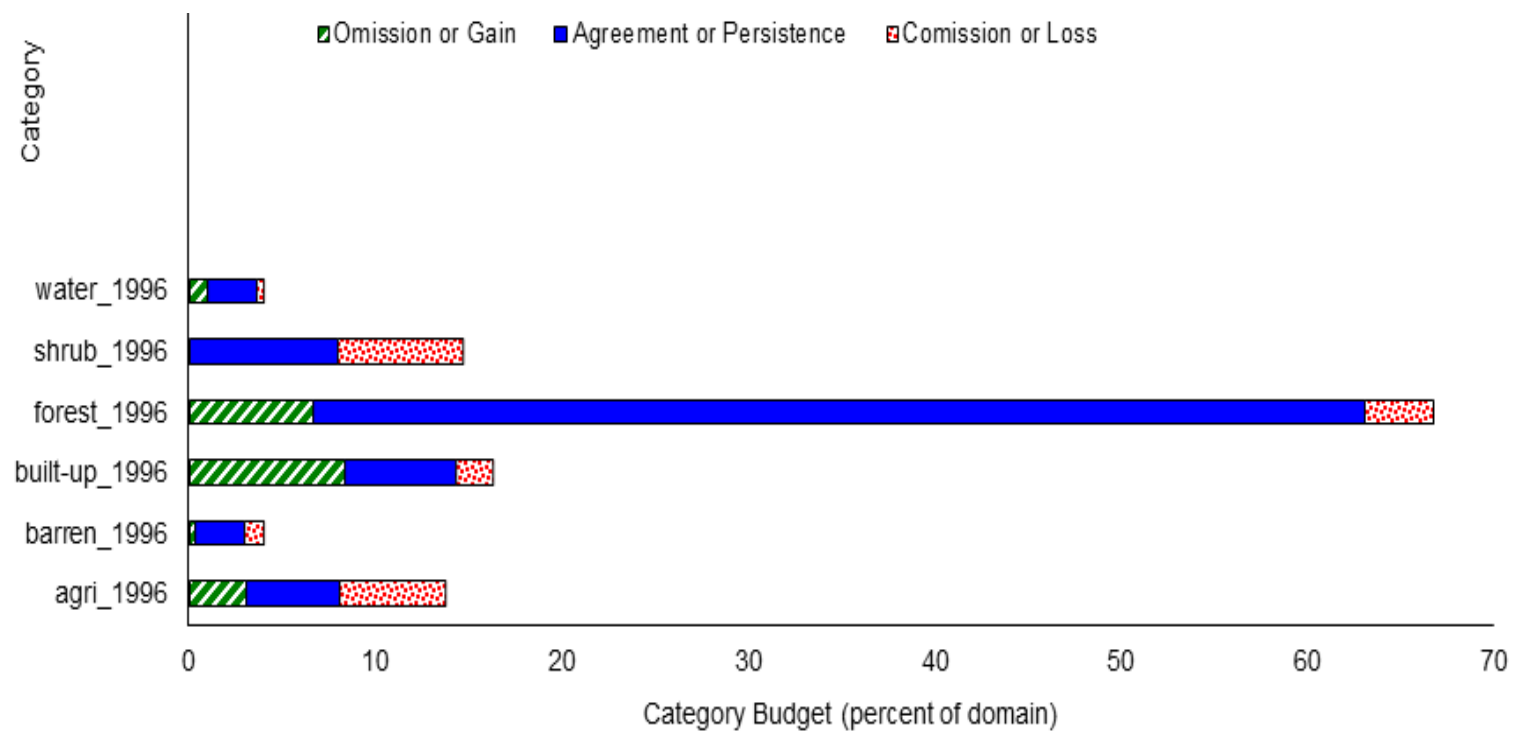

\section{Intensity}

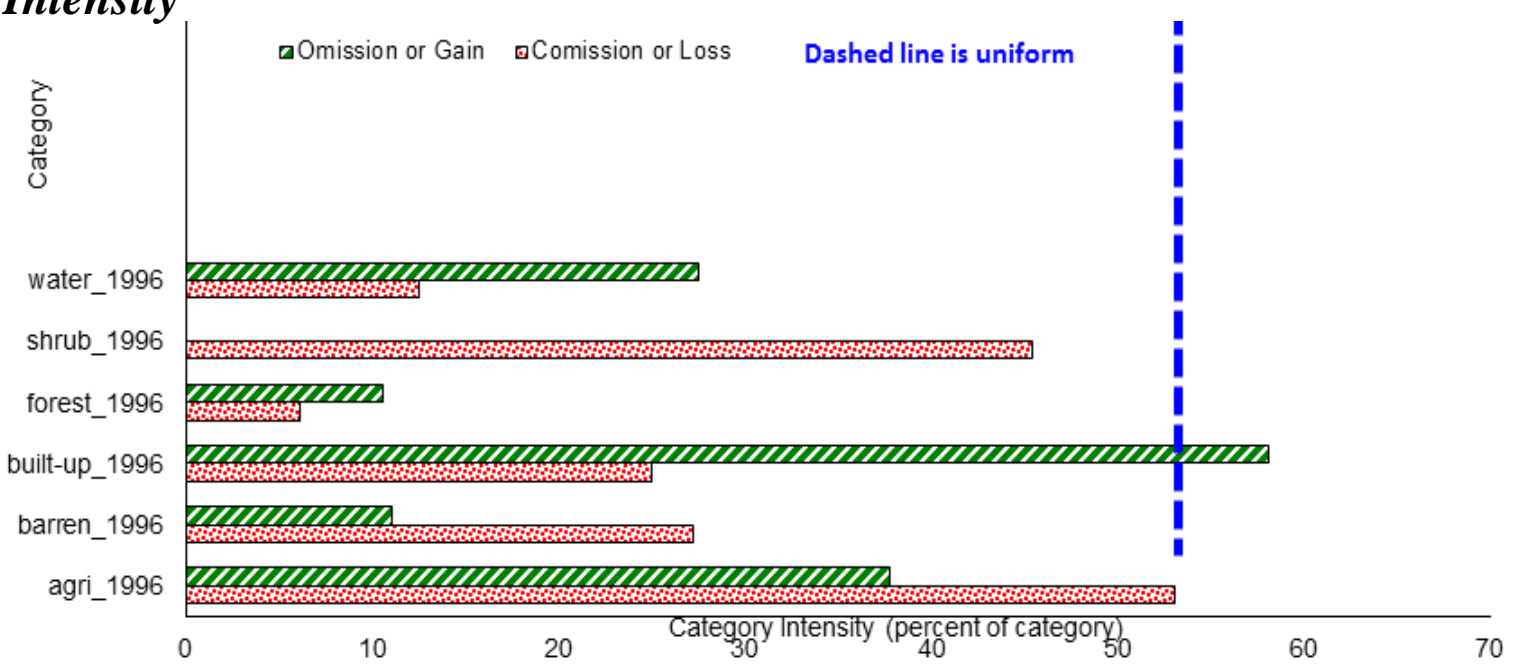

(Source: Own calulation) 


\section{LULC 2003}

\section{Sample Matrix}

\begin{tabular}{|c|c|c|c|c|c|c|c|c|}
\hline & & 6 & $\begin{array}{r}\text { Reference or } \\
\text { Time2 }\end{array}$ & $\begin{array}{r}\text { Reference or } \\
\text { Time2 }\end{array}$ & $\begin{array}{r}\text { Reference or } \\
\text { Time2 }\end{array}$ & $\begin{array}{r}\text { Reference } \\
\text { or Time2 }\end{array}$ & $\begin{array}{r}\text { Reference } \\
\text { or Time2 }\end{array}$ & $\begin{array}{l}\text { Reference } \\
\text { or Time2 }\end{array}$ \\
\hline $\begin{array}{r}\text { Population } \\
\text { Count }\end{array}$ & & & agri_03 & barren_03 & built-up_03 & forest_03 & shrub_03 & water_03 \\
\hline 29 & $\begin{array}{r}\text { Comparison or } \\
\text { Time1 }\end{array}$ & agri_03 & 21 & 3 & 1 & 4 & 0 & 0 \\
\hline 5 & $\begin{array}{r}\text { Comparison or } \\
\text { Time } 1\end{array}$ & barren_03 & 2 & 3 & 0 & 0 & 0 & 0 \\
\hline 34 & Time1 & built-up_03 & 9 & 0 & 25 & 0 & 0 & 0 \\
\hline 187 & $\begin{array}{r}\text { Comparison or } \\
\text { Time1 }\end{array}$ & forest_03 & 7 & 8 & 1 & 171 & 0 & 0 \\
\hline 35 & $\begin{array}{r}\text { Comparison or } \\
\text { Time } 1\end{array}$ & shrub_03 & 7 & 0 & 0 & 0 & 26 & 2 \\
\hline 10 & Time 1 & water_03 & 0 & 1 & 1 & 1 & 0 & 7 \\
\hline 300 & $\begin{array}{r}\text { Reference or } \\
\text { Time } 2 \\
\text { Reference }\end{array}$ & total & 46 & 15 & 28 & 176 & 26 & 9 \\
\hline & Time2 & proportion & 0,15 & 0,05 & 0,09 & 0,59 & 0,09 & 0,03 \\
\hline & Minumum1 & proportion & 0,15 & 0,05 & 0,09 & 0,25 & 0,09 & 0,03 \\
\hline & Minumum2 & proportion & 0,10 & 0,02 & 0,09 & 0,59 & 0,09 & 0,03 \\
\hline & Product & proportion & 0,01 & 0,00 & 0,01 & 0,37 & 0,01 & 0,00 \\
\hline & & $\begin{array}{r}\text { Omission or Gain } \\
\text { Intensity }\end{array}$ & 0,54 & 0,80 & 0,11 & 0,03 & 0,00 & 0,22 \\
\hline & $\begin{array}{r}\text { Allocation } \\
\text { Information }\end{array}$ & perfect & 0,66 & 0,91 & 1,00 & & & \\
\hline & Allocation & medium & 0,61 & 0,84 & 0,92 & & & \\
\hline
\end{tabular}




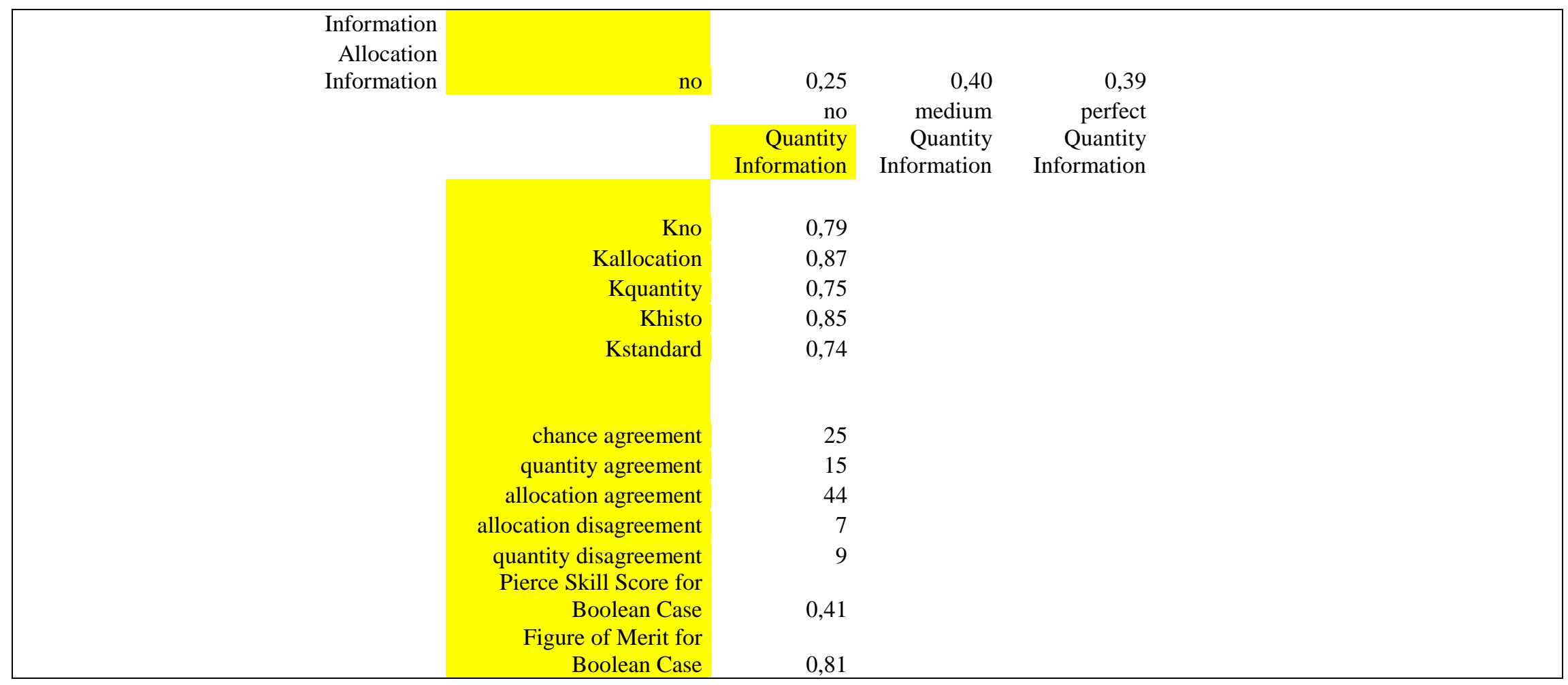

\section{(Source: Own calulation)}




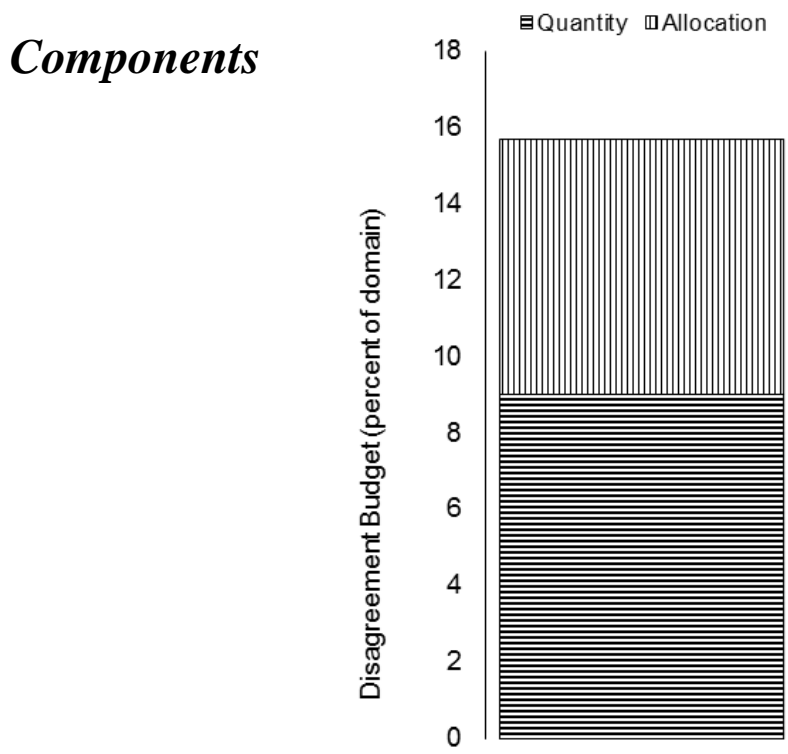

\section{Agreement - Disagreement}
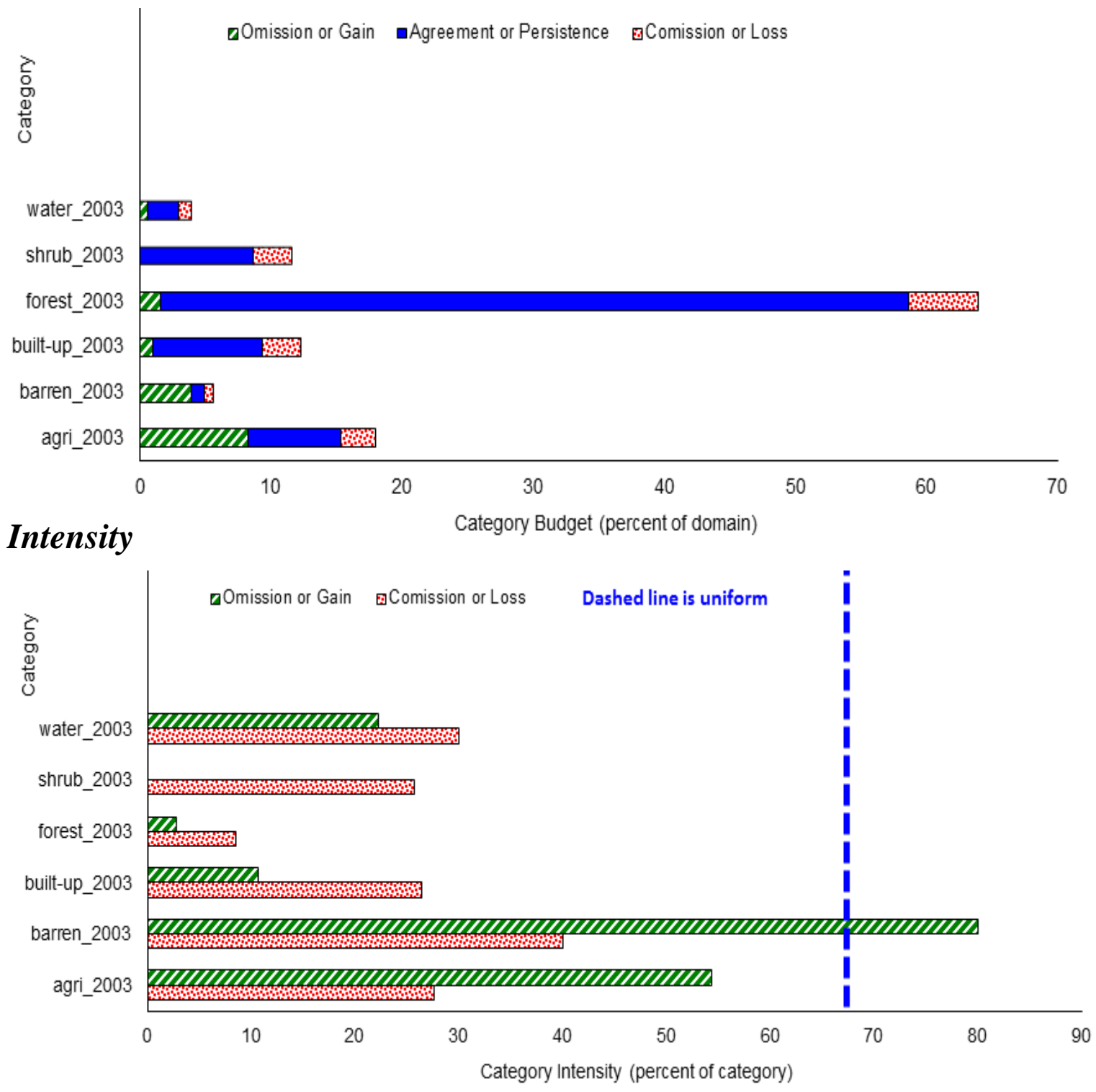

(Source: Own calulation) 


\section{LULC 2009}

\section{Sample Matrix}

\begin{tabular}{|c|c|c|c|c|c|c|c|c|}
\hline & & 6 & $\begin{array}{r}\text { Reference } \\
\text { or Time2 }\end{array}$ & $\begin{array}{r}\text { Reference or } \\
\text { Time2 }\end{array}$ & $\begin{array}{r}\text { Reference or } \\
\text { Time2 }\end{array}$ & $\begin{array}{r}\text { Reference } \\
\text { or Time2 }\end{array}$ & $\begin{array}{r}\text { Reference } \\
\text { or Time2 }\end{array}$ & $\begin{array}{r}\text { Reference or } \\
\text { Time2 }\end{array}$ \\
\hline \multirow{2}{*}{\multicolumn{9}{|c|}{ Population }} \\
\hline & & & agri_09 & barren_09 & built-up_09 & forest_09 & shrub_09 & water_2009 \\
\hline \multirow{3}{*}{23} & Comparison or & & & & & & & \\
\hline & Time1 & agri_09 & 14 & 0 & 1 & 8 & 0 & 0 \\
\hline & Comparison or & & & & & & & \\
\hline \multirow[t]{2}{*}{5} & Time1 & barren_09 & 1 & 4 & 0 & 0 & 0 & 0 \\
\hline & Comparison or & & & & & & & \\
\hline \multirow[t]{2}{*}{54} & Time1 & built-up_09 & 4 & 0 & 47 & 2 & 0 & 1 \\
\hline & Comparison or & & & & & & & \\
\hline \multirow[t]{2}{*}{179} & Time1 & forest_09 & 2 & 0 & 1 & 174 & 0 & 2 \\
\hline & Comparison or & & & & & & & \\
\hline \multirow[t]{2}{*}{30} & Time1 & shrub_09 & 6 & 0 & 3 & 0 & 21 & 0 \\
\hline & Comparison or & & & & & & & \\
\hline 9 & Time1 & water_09 & 0 & 0 & 2 & 0 & 0 & 7 \\
\hline \multirow[t]{11}{*}{300} & Reference or Time2 & total & 27 & 4 & 54 & 184 & 21 & 10 \\
\hline & Reference or Time2 & proportion & 0,09 & 0,01 & 0,18 & 0,61 & 0,07 & 0,03 \\
\hline & Minumum1 & proportion & 0,09 & 0,01 & 0,17 & 0,17 & 0,07 & 0,03 \\
\hline & Minumum2 & proportion & 0,08 & 0,01 & 0,18 & 0,60 & 0,07 & 0,03 \\
\hline & Product & proportion & 0,01 & 0,00 & 0,03 & 0,37 & 0,01 & 0,00 \\
\hline & & Omission or Gain Intensity & 0,48 & 0,00 & 0,13 & 0,05 & 0,00 & 0,30 \\
\hline & Allocation & & & & & & & \\
\hline & Information & perfect & 0,54 & 0,97 & 1,00 & & & \\
\hline & Allocation & & & & & & & \\
\hline & $\begin{array}{r}\text { Information } \\
\text { Allocation }\end{array}$ & medium & 0,49 & 0,89 & 0,92 & & & \\
\hline & Information & no & 0,17 & 0,41 & 0,42 & & & \\
\hline
\end{tabular}




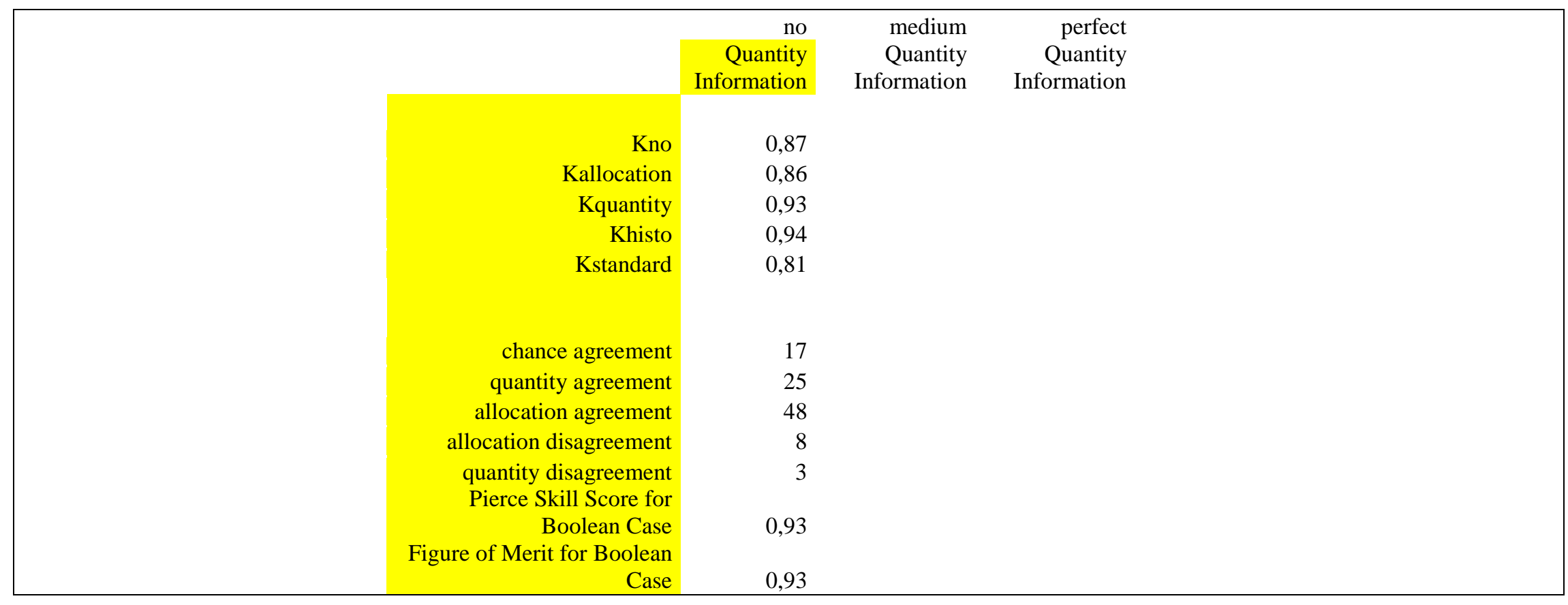

(Source: Own calulation) 


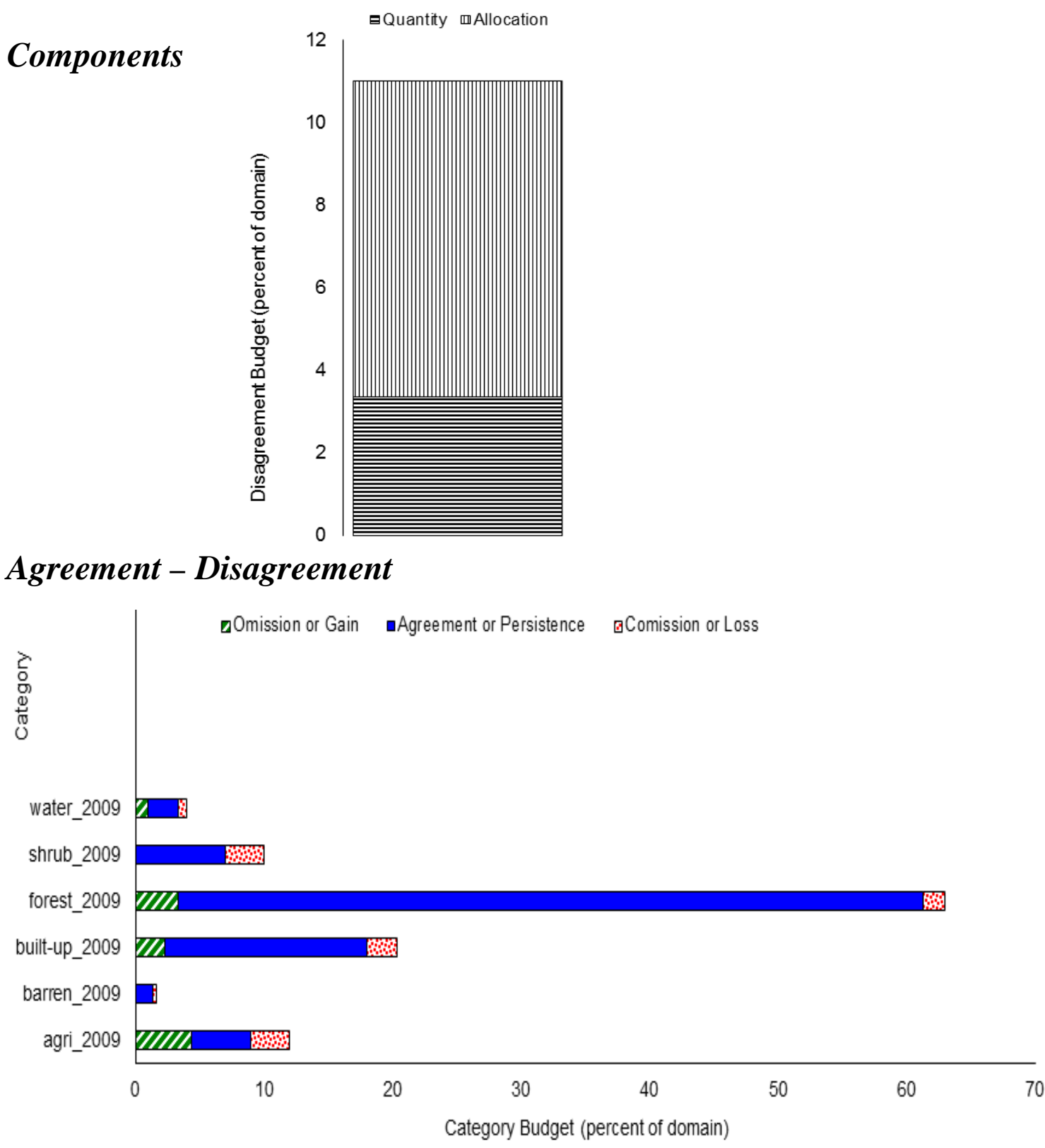

\section{Intensity}

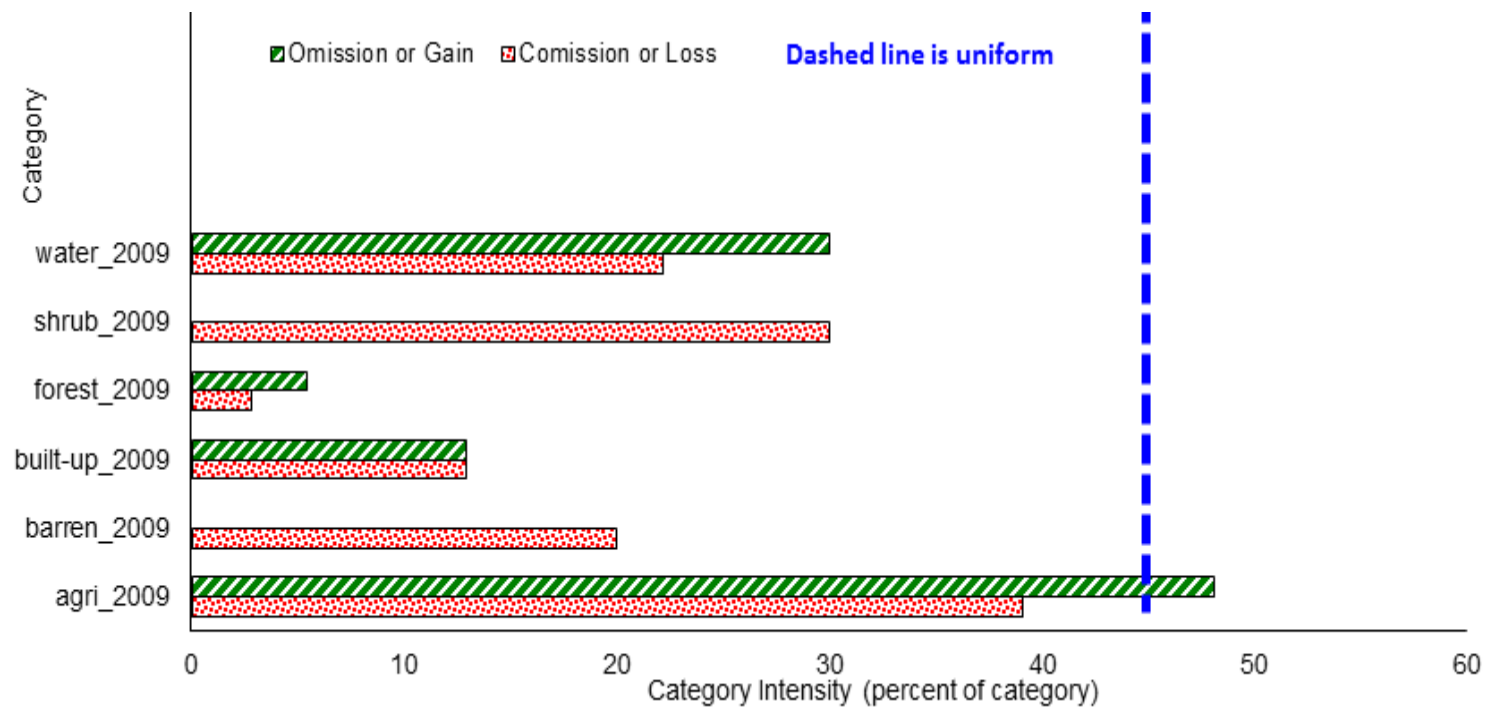

(Source: Own calulation) 


\section{Appendix 2}

\section{Scenarios of land use/cover types from 1996 to 2030}

\begin{tabular}{rrrrrrr}
\hline Year & Agriculture & \multicolumn{1}{c}{ Barren } & \multicolumn{1}{c}{ Urban } & \multicolumn{1}{c}{ Forest } & \multicolumn{1}{c}{ Shrub } & \multicolumn{1}{c}{ Water } \\
\hline 1996 & 10416.69 & 3680.91 & 7791.48 & 58127.13 & 14253.21 & 2548.26 \\
1997 & 10016.5 & 3592.7 & 8387.11 & 58318.4 & 13927.5 & 2575.47 \\
1998 & 9643.6 & 3483.79 & 8956.09 & 58509.6 & 13621.8 & 2602.8 \\
1999 & 9296.48 & 3362.66 & 9491.52 & 58700.8 & 13335.3 & 2630.92 \\
2000 & 8973.66 & 3226.05 & 9998.91 & 58892.1 & 13067.1 & 2659.86 \\
2001 & 8673.75 & 2989.03 & 10565.59 & 59083.3 & 12816.4 & 2689.61 \\
2002 & 8395.47 & 2641.51 & 11203.31 & 59274.6 & 12582.6 & 2720.19 \\
2003 & 8118.04 & 2497.3 & 11630 & 59467.3 & 12322.9 & 2782.14 \\
2004 & 7932.48 & 2377.14 & 12843.38 & 59205.7 & 11644.4 & 2814.58 \\
2005 & 7767.48 & 2275.5 & 13911.62 & 58945.3 & 11069 & 2848.78 \\
2006 & 7621.99 & 2199.49 & 14841.04 & 58686 & 10584.4 & 2884.76 \\
2007 & 7495.09 & 2043.68 & 15748.54 & 58427.8 & 10180 & 2922.57 \\
2008 & 7385.89 & 1823.01 & 16629.49 & 58170.8 & 9846.26 & 2962.23 \\
2009 & 7293.57 & 1733.46 & 17296.7 & 57914.9 & 9575.26 & 3003.79 \\
2010 & 7054.52 & 1959.5 & 17934.5 & 57647.27 & 9218.1 & 3003.79 \\
2011 & 6903.43 & 1582.59 & 18921.6 & 57426.1 & 8980.17 & 3003.79 \\
2012 & 6740.37 & 839.22 & 20305.8 & 57172.6 & 8755.9 & 3003.79 \\
2013 & 6597.62 & 0 & 21722.78 & 56920.2 & 8573.29 & 3003.79 \\
2014 & 6474.22 & 0 & 22243.05 & 56668.9 & 8427.72 & 3003.79 \\
2015 & 6369.27 & 0 & 22710.9 & 56418.6 & 8315.12 & 3003.79 \\
2016 & 6281.93 & 0 & 23130.5 & 56169.5 & 8231.96 & 3003.79 \\
2017 & 6211.43 & 0 & 23505.89 & 55921.4 & 8175.17 & 3003.79 \\
2018 & 6157.04 & 0 & 23840.36 & 55674.4 & 8142.09 & 3003.79 \\
2019 & 6118.1 & 0 & 24129.4 & 55428.4 & 8137.99 & 3003.79 \\
2020 & 6094.01 & 0 & 24406.01 & 55183.5 & 8130.37 & 3003.79 \\
2021 & 5759.51 & 0 & 25437.79 & 54927.8 & 7688.79 & 3003.79 \\
2022 & 5458.89 & 0 & 26362.16 & 54673.3 & 7319.54 & 3003.79 \\
2023 & 5190.43 & 0 & 27189.34 & 54419.8 & 7014.32 & 3003.79 \\
2024 & 4952.51 & 0 & 27928.13 & 54167.4 & 6765.85 & 3003.79 \\
2025 & 4743.64 & 0 & 28586.34 & 53916.1 & 6567.81 & 3003.79 \\
2026 & 4562.44 & 0 & 29170.97 & 53665.8 & 6414.68 & 3003.79 \\
2027 & 4407.59 & 0 & 29687.94 & 53416.7 & 6301.66 & 3003.79 \\
2028 & 4277.91 & 0 & 30142.82 & 53168.6 & 6224.56 & 3003.79 \\
2029 & 4172.26 & 0 & 30540.3 & 52921.6 & 6179.73 & 3003.79 \\
2030 & 4089.62 & 0 & 30884.66 & 52675.6 & 6164.01 & 3003.79 \\
\hline & & & & & &
\end{tabular}

Table A3.1 Demand of land use/cover types in scenario 1 


\begin{tabular}{rrrrrrr}
\hline Year & Agriculture & \multicolumn{1}{c}{ Barren } & \multicolumn{1}{l}{ Urban } & \multicolumn{1}{c}{ Forest } & \multicolumn{1}{l}{ Shrub } & \multicolumn{1}{l}{ Water } \\
\hline 1996 & 10416.69 & 3680.91 & 7791.48 & 58127.13 & 14253.21 & 2548.26 \\
1997 & 10016.5 & 3592.7 & 8387.11 & 58318.4 & 13927.5 & 2575.47 \\
1998 & 9643.6 & 3483.79 & 8956.09 & 58509.6 & 13621.8 & 2602.8 \\
1999 & 9296.48 & 3362.66 & 9491.52 & 58700.8 & 13335.3 & 2630.92 \\
2000 & 8973.66 & 3226.05 & 9998.91 & 58892.1 & 13067.1 & 2659.86 \\
2001 & 8673.75 & 2989.03 & 10565.59 & 59083.3 & 12816.4 & 2689.61 \\
2002 & 8395.47 & 2641.51 & 11203.31 & 59274.6 & 12582.6 & 2720.19 \\
2003 & 8118.04 & 2497.3 & 11630 & 59467.3 & 12322.9 & 2782.14 \\
2004 & 7932.48 & 2377.14 & 12843.38 & 59205.7 & 11644.4 & 2814.58 \\
2005 & 7767.48 & 2275.5 & 13911.62 & 58945.3 & 11069 & 2848.78 \\
2006 & 7621.99 & 2199.49 & 14841.04 & 58686 & 10584.4 & 2884.76 \\
2007 & 7495.09 & 2043.68 & 15748.54 & 58427.8 & 10180 & 2922.57 \\
2008 & 7385.89 & 1823.01 & 16629.49 & 58170.8 & 9846.26 & 2962.23 \\
2009 & 7293.57 & 1733.46 & 17296.7 & 57914.9 & 9575.26 & 3003.79 \\
2010 & 6826.37 & 1538.11 & 18582.8 & 57686.9 & 9179.71 & 3003.79 \\
2011 & 6436.61 & 1384.27 & 19705.1 & 57438.8 & 8849.11 & 3003.79 \\
2012 & 6116.92 & 1245.91 & 20682.6 & 57191.8 & 8576.66 & 3003.79 \\
2013 & 5859.01 & 1121.28 & 21531.6 & 56945.9 & 8356.1 & 3003.79 \\
2014 & 5655.71 & 1009.17 & 22266 & 56701 & 8182.01 & 3003.79 \\
2015 & 5500.82 & 908.19 & 22898 & 56457.2 & 8049.68 & 3003.79 \\
2016 & 5388.95 & 817.34 & 23438.1 & 56214.5 & 7955 & 3003.79 \\
2017 & 5315.46 & 735.72 & 23895.6 & 55972.7 & 7894.41 & 3003.79 \\
2018 & 5276.35 & 662 & 24278.6 & 55732.1 & 7864.84 & 3003.79 \\
2019 & 5268.15 & 595.92 & 24593.8 & 55492.4 & 7863.62 & 3003.79 \\
2020 & 5287.91 & 536.3 & 24847.4 & 55253.8 & 7888.48 & 3003.79 \\
2021 & 4405.16 & 365.4 & 26735.64 & 55004.7 & 7302.99 & 3003.79 \\
2022 & 3664.49 & 211.59 & 28367.2 & 54756.6 & 6814.01 & 3003.79 \\
2023 & 3048.67 & 73.16 & 29771.28 & 54509.6 & 6411.18 & 3003.79 \\
2024 & 2542.73 & 0 & 30922.45 & 54263.7 & 6085.01 & 3003.79 \\
2025 & 2133.65 & 0 & 31833.87 & 54018.8 & 5827.57 & 3003.79 \\
2026 & 1810.17 & 0 & 32596.85 & 53775 & 5631.87 & 3003.79 \\
2027 & 1562.53 & 0 & 33227.21 & 53532.3 & 5491.85 & 3003.79 \\
2028 & 1382.27 & 0 & 33738.87 & 53290.5 & 5402.25 & 3003.79 \\
2029 & 1262.1 & 0 & 34143.37 & 53049.9 & 5358.52 & 3003.79 \\
2030 & 1195.72 & 0 & 34451.24 & 52810.2 & 5356.73 & 3003.79 \\
\hline & & & & & &
\end{tabular}

Table A3.2 Demand of land use/cover types in scenario 2

(Source: Own calulation) 


\begin{tabular}{|c|c|c|c|c|c|c|}
\hline Year & Agriculture & Barren & Urban & Forest & Shrub & Water \\
\hline 1996 & 10416.69 & 3680.91 & 7791.48 & 58127.13 & 14253.21 & 2548.26 \\
\hline 1997 & 10016.5 & 3592.7 & 8387.11 & 58318.4 & 13927.5 & 2575.47 \\
\hline 1998 & 9643.6 & 3483.79 & 8956.09 & 58509.6 & 13621.8 & 2602.8 \\
\hline 1999 & 9296.48 & 3362.66 & 9491.52 & 58700.8 & 13335.3 & 2630.92 \\
\hline 2000 & 8973.66 & 3226.05 & 9998.91 & 58892.1 & 13067.1 & 2659.86 \\
\hline 2001 & 8673.75 & 2989.03 & 10565.59 & 59083.3 & 12816.4 & 2689.61 \\
\hline 2002 & 8395.47 & 2641.51 & 11203.31 & 59274.6 & 12582.6 & 2720.19 \\
\hline 2003 & 8118.04 & 2497.3 & 11630 & 59467.3 & 12322.9 & 2782.14 \\
\hline 2004 & 7932.48 & 2377.14 & 12843.38 & 59205.7 & 11644.4 & 2814.58 \\
\hline 2005 & 7767.48 & 2275.49 & 13911.62 & 58945.3 & 11069 & 2848.78 \\
\hline 2006 & 7621.99 & 2199.48 & 14841.04 & 58686 & 10584.4 & 2884.76 \\
\hline 2007 & 7495.09 & 2043.67 & 15748.54 & 58427.8 & 10180 & 2922.57 \\
\hline 2008 & 7385.89 & 1823.01 & 16629.49 & 58170.8 & 9846.26 & 2962.23 \\
\hline 2009 & 7293.57 & 1733.46 & 17296.7 & 57914.9 & 9575.26 & 3003.79 \\
\hline 2010 & 7161.46 & 1538 & 18087.4 & 57936.2 & 9090.83 & 3003.79 \\
\hline 2011 & 7048.16 & 1384.19 & 18771.91 & 57936.2 & 8673.43 & 3003.79 \\
\hline 2012 & 6952.82 & 1245.76 & 19363.38 & 57936.2 & 8315.73 & 3003.79 \\
\hline 2013 & 6874.66 & 1121.17 & 19871.01 & 57936.2 & 8010.85 & 3003.79 \\
\hline 2014 & 6812.94 & 1009.04 & 20302.93 & 57936.2 & 7752.78 & 3003.79 \\
\hline 2015 & 6767 & 908.12 & 20666.28 & 57936.2 & 7536.28 & 3003.79 \\
\hline 2016 & 6736.22 & 817.3 & 20967.43 & 57936.2 & 7356.74 & 3003.79 \\
\hline 2017 & 6720.01 & 735.56 & 21211.96 & 57936.2 & 7210.16 & 3003.79 \\
\hline 2018 & 6703.87 & 661.99 & 21418.81 & 57936.2 & 7093.02 & 3003.79 \\
\hline 2019 & 6687.59 & 595.78 & 21592.05 & 57936.2 & 7002.27 & 3003.79 \\
\hline 2020 & 6671.99 & 536.19 & 21734.28 & 57936.2 & 6935.23 & 3003.79 \\
\hline 2021 & 6411.41 & 470.93 & 22730.71 & 57936.2 & 6264.63 & 3003.79 \\
\hline 2022 & 6181.66 & 412.1 & 23596.45 & 57936.2 & 5687.47 & 3003.79 \\
\hline 2023 & 5981.29 & 359.16 & 24344.38 & 57936.2 & 5192.86 & 3003.79 \\
\hline 2024 & 5808.91 & 311.5 & 24985.98 & 57936.2 & 4771.29 & 3003.79 \\
\hline 2025 & 5663.26 & 268.61 & 25531.36 & 57936.2 & 4414.45 & 3003.79 \\
\hline 2026 & 5543.17 & 230.02 & 25989.43 & 57936.2 & 4115.07 & 3003.79 \\
\hline 2027 & 5447.53 & 195.28 & 26368.07 & 57936.2 & 3866.81 & 3003.79 \\
\hline 2028 & 5375.35 & 164.01 & 26674.2 & 57936.2 & 3664.12 & 3003.79 \\
\hline 2029 & 5325.69 & 135.87 & 26913.97 & 57936.2 & 3502.15 & 3003.79 \\
\hline 2030 & 5297.7 & 110.55 & 27092.77 & 57936.2 & 3376.67 & 3003.79 \\
\hline
\end{tabular}

Table A3.3 Demand of land use/cover types in scenario 3

(Source: Own calulation) 


\section{Appendix 3}

\section{Logistic regression of land use/cover types}

\begin{tabular}{cll}
\hline Value & $\begin{array}{c}\text { Land use/cover } \\
\text { type }\end{array}$ & $\begin{array}{c}\text { CLUE } \\
\text { name }\end{array}$ \\
\hline 0 & Agriculture & Cov1_0.0 \\
1 & Barren & Cov2_0.0 \\
2 & Urban & Cov3_0.0 \\
3 & Forest & Cov4_0.0 \\
4 & Shrub & Cov5_0.0 \\
5 & Water & Cov6_0.0
\end{tabular}

Table A3.1 Available land use/cover types in logistic regression mode

\begin{tabular}{cll}
\hline Value & \multicolumn{1}{c}{ Driving factor } & $\begin{array}{c}\text { CLUE } \\
\text { name }\end{array}$ \\
\hline 0 & Urban rate & Sc1gr0.fil \\
1 & Mean density of population & Sc1gr1.fil \\
2 & Slope & Sc1gr2.fil \\
3 & Elevation & Sc1gr3.fil \\
4 & Distance to road & Sc1gr4.fil \\
5 & Distance to urban & Sc1gr5.fil \\
6 & Distance to water & Sc1gr6.fil \\
\hline
\end{tabular}

Table A3.2 Available driving factors in logistic regression mode

\begin{tabular}{|rr|r|r|r|r|r|r|}
\hline & \multicolumn{1}{|c|}{ B } & S.E. & Wald & df & \multicolumn{1}{c|}{ Sig. } & $\operatorname{Exp(B)}$ \\
\hline Step $1^{\text {a }}$ & sc1gr0.fil & -0.0149190854 & .001 & 513.110 & 1 & .000 & .985 \\
& sc1gr1.fil & 0.0109944723 & .001 & 218.169 & 1 & .000 & 1.011 \\
& sc1gr2.fil & -0.0095273290 & .001 & 144.636 & 1 & .000 & .991 \\
sc1gr3.fil & -0.0002644512 & .000 & 99.782 & 1 & .000 & 1.000 \\
sc1gr4.fil & -0.0003383414 & .000 & 1907.158 & 1 & .000 & 1.000 \\
sc1gr5.fil & -0.0001319261 & .000 & 155.916 & 1 & .000 & 1.000 \\
sc1gr6.fil & -0.0000494684 & .000 & 127.386 & 1 & .000 & 1.000 \\
Constant & 0.9438244201 & .012 & 6038.416 & 1 & .000 & 2.570 \\
\hline
\end{tabular}

a. Variable(s) entered on step 1: sc1gr0.fil, sc1gr1.fil, sc1gr2.fil, sc1gr3.fil, sc1gr4.fil, sc1gr5.fil, sc1gr6.fil.

Table A3.3 Logistic regression for Agriculture 


\begin{tabular}{|rr|r|r|r|r|r|r|}
\hline & \multicolumn{1}{|c|}{ B } & S.E. & Wald & df & \multicolumn{1}{c|}{ Sig. } & $\operatorname{Exp}(\mathrm{B})$ \\
\hline Step $1^{\text {a }}$ & sc1gr0.fil & -0.0046540920 & .001 & 31.345 & 1 & .000 & .995 \\
& sc1gr1.fil & -0.0086689189 & .001 & 45.522 & 1 & .000 & .991 \\
& sc1gr2.fil & 0.0055618135 & .001 & 36.023 & 1 & .000 & 1.006 \\
sc1gr3.fil & -0.0004720580 & .000 & 189.136 & 1 & .000 & 1.000 \\
sc1gr4.fil & -0.0001496706 & .000 & 193.121 & 1 & .000 & 1.000 \\
sc1gr5.fil & -0.0008809770 & .000 & 2507.818 & 1 & .000 & .999 \\
sc1gr6.fil & -0.0000688887 & .000 & 124.537 & 1 & .000 & 1.000 \\
Constant & 1.0548256000 & .015 & 5240.184 & 1 & .000 & 2.871 \\
\hline
\end{tabular}

a. Variable(s) entered on step 1: sc1gr0.fil, sc1gr1.fil, sc1gr2.fil, sc1gr3.fil, sc1gr4.fil, sc1gr5.fil, sc1gr6.fil.

\section{Table A3.4 Logistic regression for Barren}

\begin{tabular}{|rr|r|r|r|r|r|r|}
\hline & B & S.E. & Wald & df & Sig. & $\operatorname{Exp}(\mathrm{B})$ \\
\hline Step $1^{\text {a }}$ & sc1gr0.fil & 0.0064498058 & .002 & 16.480 & 1 & .000 & 1.006 \\
& sc1gr1.fil & -0.0117015352 & .003 & 18.827 & 1 & .000 & .988 \\
& sc1gr2.fil & -0.0010296843 & .002 & .422 & 1 & .516 & .999 \\
sc1gr3.fil & 0.0003574733 & .000 & 35.477 & 1 & .000 & 1.000 \\
sc1gr4.fil & -0.0002257239 & .000 & 66.420 & 1 & .000 & 1.000 \\
sc1gr5.fil & -0.0292470249 & .000 & 12556.409 & 1 & .000 & .971 \\
sc1gr6.fil & 0.0000518170 & .000 & 8.491 & 1 & .004 & 1.000 \\
Constant & 2.6309852354 & .029 & 8045.194 & 1 & .000 & 13.887 \\
\hline
\end{tabular}

a. Variable(s) entered on step 1: sc1gr0.fil, sc1gr1.fil, sc1gr2.fil, sc1gr3.fil, sc1gr4.fil, sc1gr5.fil, sc1gr6.fil.

Table A3.5 Logistic regression for Urban

\begin{tabular}{|rr|r|r|r|r|r|r|}
\hline & \multicolumn{1}{|c|}{ B } & S.E. & Wald & df & \multicolumn{1}{c|}{ Sig. } & $\operatorname{Exp(B)}$ \\
\hline Step $1^{\text {a }}$ & sc1gr0.fil & 0.0198023206 & .001 & 553.806 & 1 & .000 & 1.020 \\
& sc1gr1.fil & -0.0148509094 & .001 & 225.312 & 1 & .000 & .985 \\
& sc1gr2.fil & 0.0168966457 & .001 & 312.608 & 1 & .000 & 1.017 \\
& sc1gr3.fil & 0.0003982220 & .000 & 132.819 & 1 & .000 & 1.000 \\
sc1gr4.fil & 0.0005154539 & .000 & 2400.376 & 1 & .000 & 1.001 \\
sc1gr5.fil & 0.0011781218 & .000 & 4849.269 & 1 & .000 & 1.001 \\
sc1gr6.fil & 0.0001809166 & .000 & 888.721 & 1 & .000 & 1.000 \\
Constant & -2.4199720631 & .018 & 18539.638 & 1 & .000 & .089 \\
\hline
\end{tabular}

a. Variable(s) entered on step 1: sc1gr0.fil, sc1gr1.fil, sc1gr2.fil, sc1gr3.fil, sc1gr4.fil, sc1gr5.fil, sc1gr6.fil.

Table A3.6 Logistic regression for Forest 


\begin{tabular}{|rr|r|r|r|r|r|r|}
\hline & \multicolumn{1}{|c|}{ B } & S.E. & Wald & df & \multicolumn{1}{c|}{ Sig. } & Exp(B) \\
\hline Step $1^{\text {a }}$ & sc1gr0.fil & -0.0184782530 & .001 & 523.355 & 1 & .000 & .982 \\
& sc1gr1.fil & 0.0209688198 & .001 & 528.641 & 1 & .000 & 1.021 \\
& sc1gr2.fil & -0.0173097013 & .001 & 410.354 & 1 & .000 & .983 \\
sc1gr3.fil & -0.0005373425 & .000 & 325.167 & 1 & .000 & .999 \\
sc1gr4.fil & -0.0003007638 & .000 & 893.759 & 1 & .000 & 1.000 \\
sc1gr5.fil & -0.0009743441 & .000 & 3569.740 & 1 & .000 & .999 \\
sc1gr6.fil & -0.0000489223 & .000 & 72.376 & 1 & .000 & 1.000 \\
Constant & 1.4100301112 & .014 & 10456.760 & 1 & .000 & 4.096 \\
\hline
\end{tabular}

a. Variable(s) entered on step 1: sc1gr0.fil, sc1gr1.fil, sc1gr2.fil, sc1gr3.fil, sc1gr4.fil, sc1gr5.fil, sc1gr6.fil.

\section{Table A3.7 Logistic regression for Shrub}

\begin{tabular}{|c|c|c|c|c|c|c|c|}
\hline & & B & S.E. & Wald & $\mathrm{df}$ & Sig. & $\operatorname{Exp}(B)$ \\
\hline \multirow[t]{8}{*}{ Step $1^{\mathrm{a}}$} & sc1gr0.fil & -0.0063667786 & .004 & 2.123 & 1 & .145 & .994 \\
\hline & sc1gr1.fil & -0.0094942927 & .006 & 2.555 & 1 & .110 & .991 \\
\hline & sc1gr2.fil & 0.0064991753 & .003 & 5.074 & 1 & .024 & 1.007 \\
\hline & sc1gr3.fil & 0.0004453436 & .000 & 20.077 & 1 & .000 & 1.000 \\
\hline & sc1gr4.fil & -0.0000805535 & .000 & 6.308 & 1 & .012 & 1.000 \\
\hline & sc1gr5.fil & 0.0001696889 & .000 & 4.135 & 1 & .042 & 1.000 \\
\hline & sc1gr6.fil & -0.0189878414 & .000 & 4605.810 & 1 & .000 & .981 \\
\hline & Constant & 3.1866314025 & .045 & 4923.557 & 1 & .000 & 24.207 \\
\hline
\end{tabular}

a. Variable(s) entered on step 1: sc1gr0.fil, sc1gr1.fil, sc1gr2.fil, sc1gr3.fil, sc1gr4.fil, sc1gr5.fil, sc1gr6.fil.

\section{Table A3.8 Logistic regression for Water}

\section{(Source: Own calulation)}




\section{Appendix 4}

\section{Area under curve of Land use/cover types}
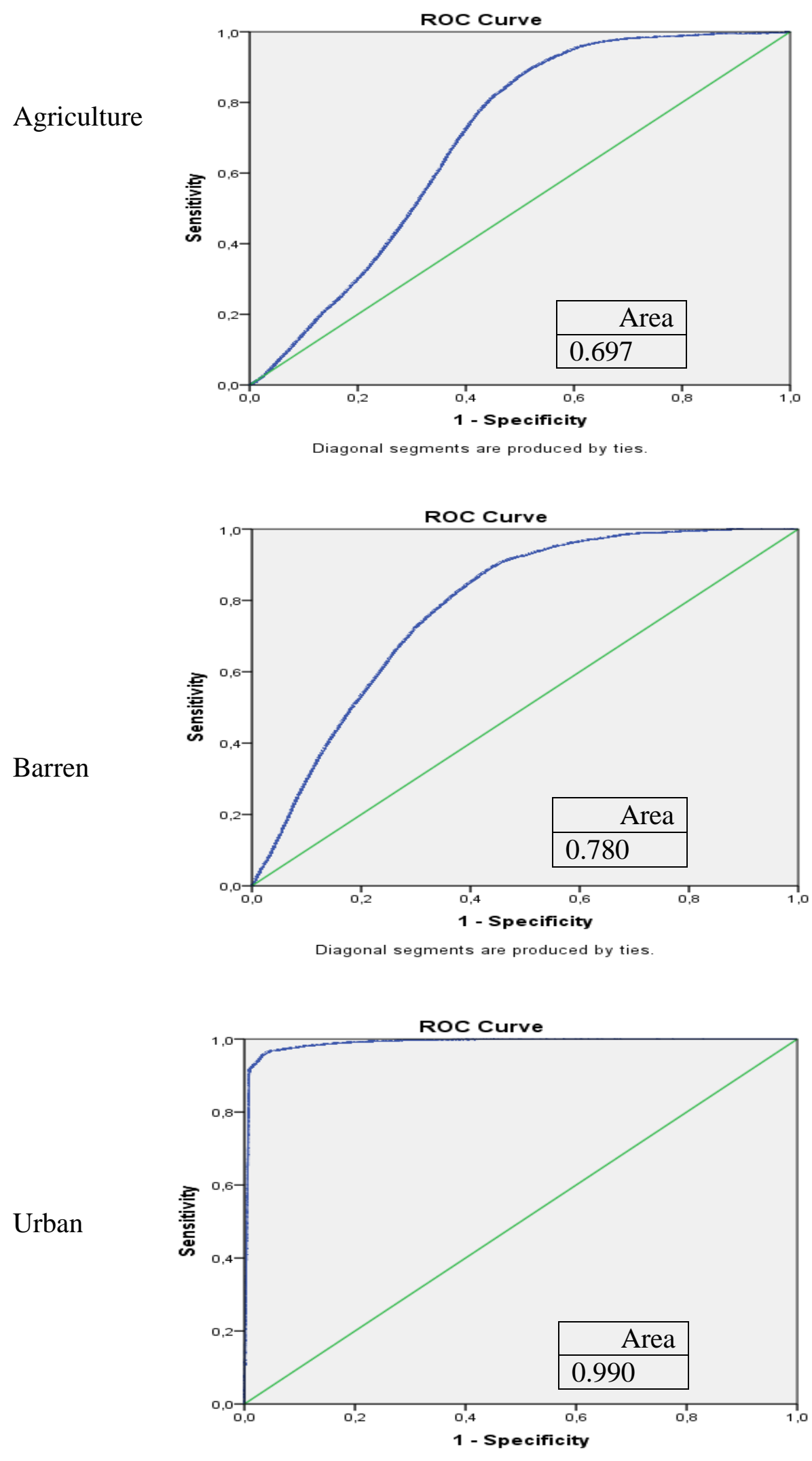

Diagonal segments are produced by ties. 


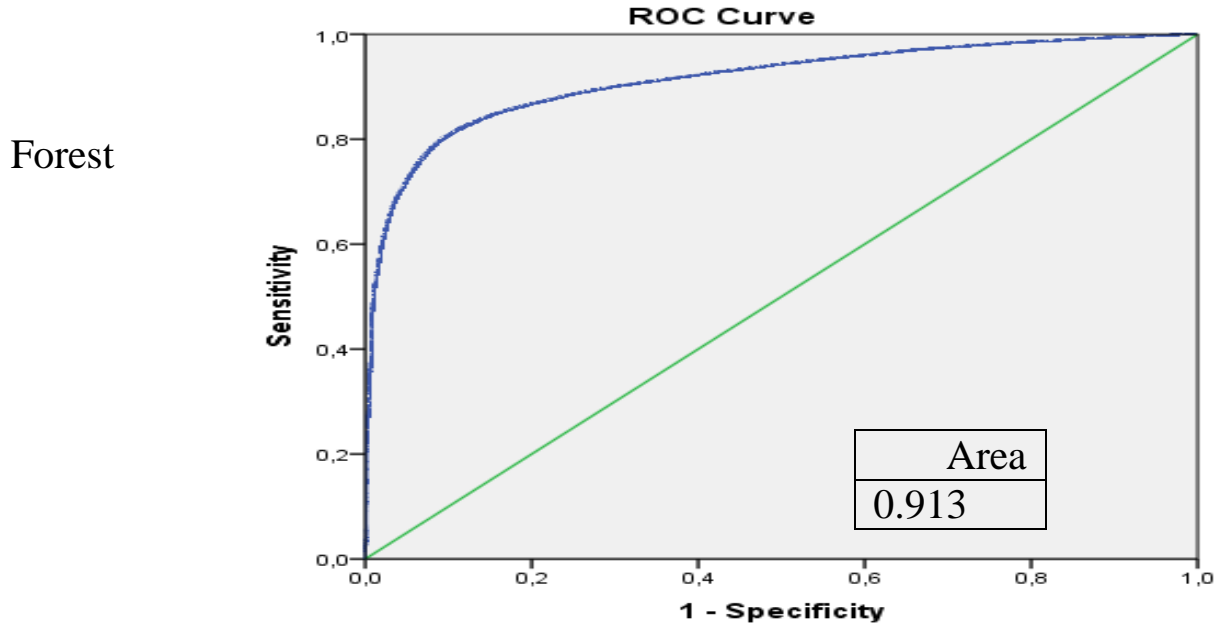

Diagonal segments are produced by ties.

Shrub

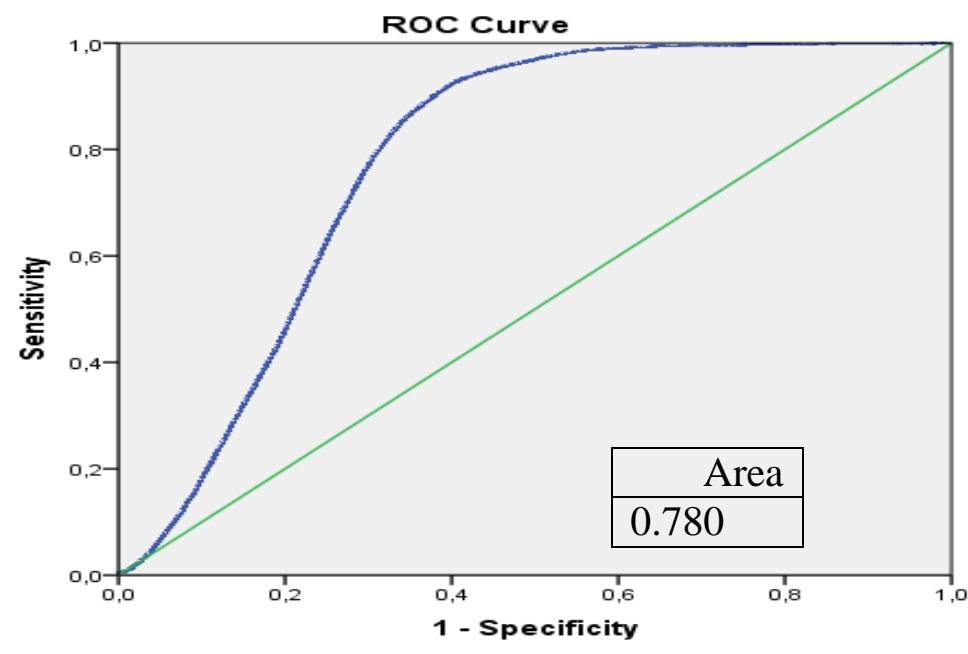

Diagonal segments are produced by ties.

Water

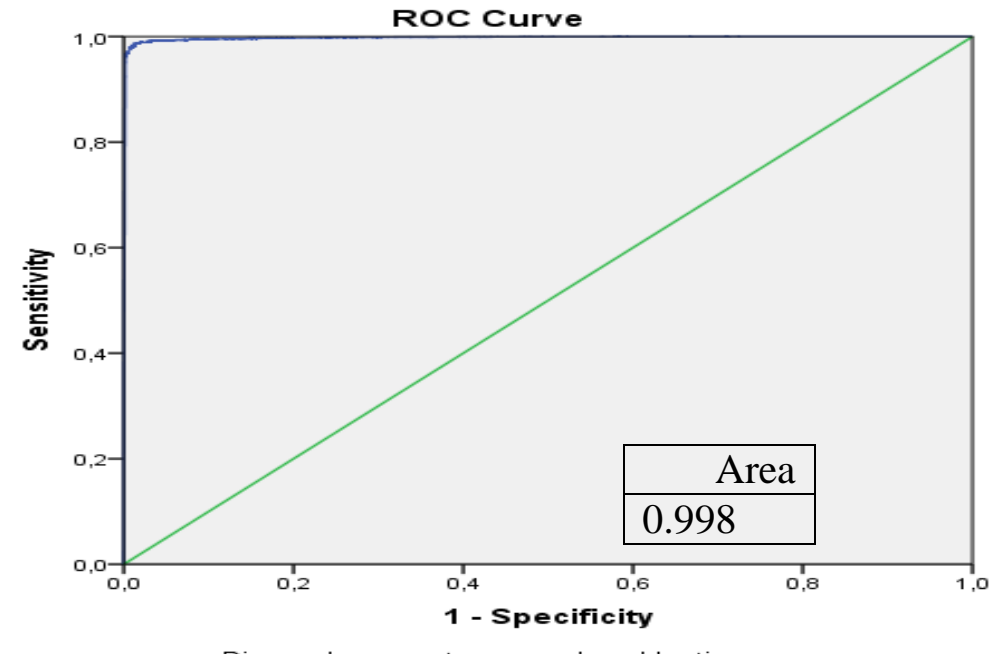

(Source: Own calulation) 


\section{Appendix A5}

\section{Main parameters of Dyna-CLUE model}

\begin{tabular}{|c|c|c|c|c|}
\hline Line & Codes & & Format & Description \\
\hline 1 & 6 & & Integer & $\begin{array}{l}\text { Number of land use/cover type. Maximum } 12 \\
\text { different land use types can be identified. }\end{array}$ \\
\hline 2 & 1 & & Integer & $\begin{array}{l}\text { Number of regions. Default is } 1 \text { and the } \\
\text { maximum number of region is } 3 \text {. }\end{array}$ \\
\hline 3 & 7 & & Integer & $\begin{array}{l}\text { Maximum number of independent variables in } \\
\text { logistic regression equation. The model can } \\
\text { handle } 20 \text { variables as maximum. }\end{array}$ \\
\hline 4 & 7 & & Integer & $\begin{array}{l}\text { Total number of driving factors. The model can } \\
\text { handle } 30 \text { variables as maximum. }\end{array}$ \\
\hline 5 & 1100 & & Integer & Number of rows of input grids. \\
\hline 6 & 1800 & & Integer & Number of columns \\
\hline 7 & 0.09 & & Float & Cell area (ha) of the grid cells \\
\hline 8 & 803145 & & Float & X-coordinate of the lower left corner \\
\hline 9 & 1762185 & & Float & Y-coordinate of the lower left corner \\
\hline 10 & $\begin{array}{llll}0 & 1 & 2 & 3 \\
\end{array}$ & $\begin{array}{ll}4 & 5 \\
\end{array}$ & Integer & Number coding of the land use/cover type \\
\hline 11 & $\begin{array}{llll}0.4 & 0.2 & 1 & 0.9\end{array}$ & 0.61 & Float & $\begin{array}{l}\text { Code for conversion elasticity ranges between } 0 \\
\text { and } 1 \text {. } \\
0: \text { all changes of land use/cover type are allowed } \\
>0 \ldots<1 \text { : changes are allowed, however, the } \\
\text { higher value, the higher the preference given to } \\
\text { location } \\
\text { 1: grid cell under one land use type can never } \\
\text { added and removed at the same time. }\end{array}$ \\
\hline 12 & 0.353 & & Float & $\begin{array}{l}\text { Iteration variables for output: } \\
\text { Iteration mode. Options: } 0 \text { (convergence criteria } \\
\text { are expressed as a percentage of the demand), } 1 \\
\text { (convergence criteria are expressed as absolute } \\
\text { values) } \\
\text { First convergence criterium: average deviation } \\
\text { between demanded changes and actually } \\
\text { allocated changes (default for \%: } 0.35 \text { ) } \\
\text { Second convergence criterium: maximum } \\
\text { deviation between demanded changes and } \\
\text { actually allocated changes (default for \%: } 3 \text { ) }\end{array}$ \\
\hline 13 & $1996 \quad 2030$ & & Integer & Start and end year of simulation \\
\hline 14 & 0 & & Integer & $\begin{array}{l}\text { Number and coding of explanatory factors that } \\
\text { change every year }\end{array}$ \\
\hline 15 & 1 & & Integer & $\begin{array}{l}\text { Output/input file choice } \\
\text { 1: ArcView headers will be printed in output } \\
\text { files; }\end{array}$ \\
\hline
\end{tabular}




\begin{tabular}{|c|c|c|c|}
\hline Line & Codes & Format & Description \\
\hline & & & $\begin{array}{l}\text { 0: No headers in output files (suited for e.g., } \\
\text { IDRISI) } \\
\text {-2: No headers in output files } \\
\text { 2: ArcView -ArcGIS header will be printed in } \\
\text { output files } \\
\text { 3: ArcGIS/ArcMap extension }\end{array}$ \\
\hline 16 & 0 & Integer & $\begin{array}{l}\text { Choice for a region specific regression } \\
\text { 0: No different regression for different regions } \\
\text { 1: Different regression for different regions } \\
\text { 2: Different regression with different demands }\end{array}$ \\
\hline 17 & 15 & Integer & $\begin{array}{l}\text { Initialization of land use history. } \\
\text { 0: The initial land use history will be reach from } \\
\text { file age.0 } \\
\text { 1: A random number will be assigned to all } \\
\text { pixels to represent the number of years that } \\
\text { current land use type is already found at that } \\
\text { location according to the standard seed for the } \\
\text { random number generator. } \\
\text { 2: A random number will be assigned to all } \\
\text { pixels to represent the number of years that } \\
\text { current land use type is already found at that } \\
\text { location with a different random number } \\
\text { generator. } \\
\text { For option } 1 \text { or } 2 \text { an addition number is added to } \\
\text { indicate the maximum number of years that can } \\
\text { be generated by the random (default: } 5 \text { ) }\end{array}$ \\
\hline 18 & 0 & Integer & $\begin{array}{l}\text { Choice for using the neighborhood function: } \\
\text { 0: Neighborhood function is not used } \\
\text { 1: Neighborhood function is used in simulation } \\
\text { 2: Only the influences are calculated, the } \\
\text { influence files are saved directly, no simulation }\end{array}$ \\
\hline 19 & 0 & Integer & $\begin{array}{l}\text { Variables for location specific preference } \\
\text { addition: } \\
0 \text { : not activate the function } \\
\text { 1: activate function }\end{array}$ \\
\hline 20 & 0.06 & Float & $\begin{array}{l}\text { Option iteration parameter. The parameter ranges } \\
\text { between } 0.001 \text { and } 0.1 \text {. With a somewhat higher } \\
\text { value (e.g.0.06) the iteration is more stability and } \\
\text { more likely to find a solution. A lower value } \\
\text { (e.g. } 0.01 \text { ) will give a faster convergence } \\
\text { although instability is more likely. }\end{array}$ \\
\hline
\end{tabular}

Source: according to Verburg et al. (2005) 


\section{Appendix 6}

\section{Main results obtained with ANOVA}

\section{A7.1 Landscape level}

\section{A7.1.1 Number of patches (NP)}

\begin{tabular}{|c|c|c|c|c|c|c|c|c|}
\hline & \multirow[b]{2}{*}{$\mathrm{N}$} & \multirow[b]{2}{*}{ Mean } & \multirow[b]{2}{*}{$\begin{array}{l}\text { Std. } \\
\text { Deviation }\end{array}$} & \multirow[b]{2}{*}{ Std. Error } & \multicolumn{2}{|c|}{$\begin{array}{c}\text { 95\% Confidence Interval } \\
\text { for Mean }\end{array}$} & \multirow[b]{2}{*}{ Minimum } & \multirow[b]{2}{*}{ Maximum } \\
\hline & & & & & $\begin{array}{l}\text { Lower } \\
\text { Bound }\end{array}$ & $\begin{array}{l}\text { Upper } \\
\text { Bound }\end{array}$ & & \\
\hline 1.00 & 22 & 27035,50 & 4059,21 & 2753 & 25235.7449 & 28835.2551 & 22219.00 & 35300.00 \\
\hline 2.00 & 22 & 24819,00 & 6755,59 & 1440.29595 & 21823.7406 & 27814.2594 & 15533.00 & 35300.00 \\
\hline 3.00 & 22 & 28256,36 & 4391,18 & 936.20356 & 26309.4218 & 30203.3055 & 21819.00 & 35300.00 \\
\hline Total & 66 & 26703,62 & 5324,77 & 655.43382 & 25394.6295 & 28012.6129 & 15533.00 & 35300.00 \\
\hline
\end{tabular}

\section{ANOVA}

value

\begin{tabular}{|c|c|c|c|c|c|}
\hline & $\begin{array}{c}\text { Sum of } \\
\text { Squares }\end{array}$ & $\mathrm{df}$ & Mean Square & $\mathrm{F}$ & Sig. \\
\hline $\begin{array}{l}\text { Between } \\
\text { Groups } \\
\text { Within } \\
\text { Groups } \\
\text { Total }\end{array}$ & $\begin{array}{l}1.336 \mathrm{E} 8 \\
1.709 \mathrm{E} 9 \\
1.843 \mathrm{E} 9\end{array}$ & $\begin{array}{r}2 \\
63 \\
65\end{array}$ & $\begin{array}{l}66802446.470 \\
27132558.422\end{array}$ & 2.462 & .093 \\
\hline
\end{tabular}

\section{A7.1.2 Patch Density (PD)}

value

\section{Descriptives}

\begin{tabular}{|c|c|c|c|c|c|c|c|c|}
\hline & \multirow[b]{2}{*}{$\mathrm{N}$} & \multirow[b]{2}{*}{ Mean } & \multirow[b]{2}{*}{$\begin{array}{c}\text { Std. } \\
\text { Deviation }\end{array}$} & \multirow[b]{2}{*}{ Std. Error } & \multicolumn{2}{|c|}{$\begin{array}{l}\text { 95\% Confidence Interval } \\
\text { for Mean }\end{array}$} & \multirow[b]{2}{*}{ Minimum } & \multirow[b]{2}{*}{ Maximum } \\
\hline & & & & & $\begin{array}{l}\text { Lower } \\
\text { Bound }\end{array}$ & $\begin{array}{l}\text { Upper } \\
\text { Bound }\end{array}$ & & \\
\hline 1.00 & 22 & 27.9241 & 4.19264 & .89387 & 26.0652 & 29.7831 & 22.95 & 36.46 \\
\hline 2.00 & 22 & 25.6348 & 6.97763 & 1.48764 & 22.5411 & 28.7285 & 16.04 & 36.46 \\
\hline 3.00 & 22 & 29.1851 & 4.53552 & .96698 & 27.1742 & 31.1961 & 22.54 & 36.46 \\
\hline Total & 66 & 27.5813 & 5.49979 & .67698 & 26.2293 & 28.9334 & 16.04 & 36.46 \\
\hline
\end{tabular}

$$
\text { ANOVA }
$$

value

\begin{tabular}{|l|r|r|r|r|l|}
\hline & Sum of Squares & \multicolumn{1}{c|}{$\mathrm{df}$} & Mean Square & $\mathrm{F}$ & Sig. \\
\hline Between & 142.531 & 2 & 71.266 & 2.462 & .093 \\
Groups & 1823.567 & 63 & 28.946 & & \\
$\begin{array}{l}\text { Within } \\
\text { Groups } \\
\text { Total }\end{array}$ & 1966.098 & 65 & & & \\
\hline
\end{tabular}


A7.1.3 Mean Proximity (PROX_MN)

Descriptives

\begin{tabular}{|c|c|c|c|c|c|c|c|c|}
\hline & \multirow[b]{2}{*}{$\mathrm{N}$} & \multirow[b]{2}{*}{ Mean } & \multirow[b]{2}{*}{$\begin{array}{l}\text { Std. } \\
\text { Deviation }\end{array}$} & \multirow[b]{2}{*}{ Std. Error } & \multicolumn{2}{|c|}{$\begin{array}{l}\text { 95\% Confidence Interval } \\
\text { for Mean }\end{array}$} & \multirow[b]{2}{*}{ Minimum } & \multirow[b]{2}{*}{ Maximum } \\
\hline & & & & & $\begin{array}{l}\text { Lower } \\
\text { Bound }\end{array}$ & $\begin{array}{l}\text { Upper } \\
\text { Bound }\end{array}$ & & \\
\hline 1.00 & 22 & 2996.5684 & 849.69193 & 181.15493 & 2619.8361 & 3373.3007 & 1634.17 & 4349.57 \\
\hline 2.00 & 22 & 3903.4050 & $\begin{array}{r}2159.6713 \\
8\end{array}$ & 460.44348 & 2945.8603 & 4860.9496 & 1650.94 & 7562.04 \\
\hline 3.00 & 22 & 2397.6292 & 621.24526 & 132.44993 & 2122.1845 & 2673.0739 & 1650.94 & 3419.89 \\
\hline Total & 66 & 3099.2009 & $\begin{array}{r}1501.2954 \\
5\end{array}$ & 184.79670 & 2730.1364 & 3468.2653 & 1634.17 & 7562.04 \\
\hline
\end{tabular}

ANOVA

\begin{tabular}{|c|c|c|c|c|c|}
\hline & $\begin{array}{c}\text { Sum of } \\
\text { Squares }\end{array}$ & $\mathrm{df}$ & $\begin{array}{c}\text { Mean } \\
\text { Square }\end{array}$ & $\mathrm{F}$ & Sig \\
\hline $\begin{array}{l}\text { Between } \\
\text { Groups } \\
\text { Within } \\
\text { Groups } \\
\text { Total }\end{array}$ & $\begin{array}{r}25288570.038 \\
1.212 \mathrm{E} 8 \\
1.465 \mathrm{E} 8\end{array}$ & $\begin{array}{r}2 \\
63 \\
65\end{array}$ & $\begin{array}{r}1264428 \\
5.019 \\
1924034 . \\
170\end{array}$ & 6.572 & .003 \\
\hline
\end{tabular}

A7.1.4 Mean Area (AREA_MN)

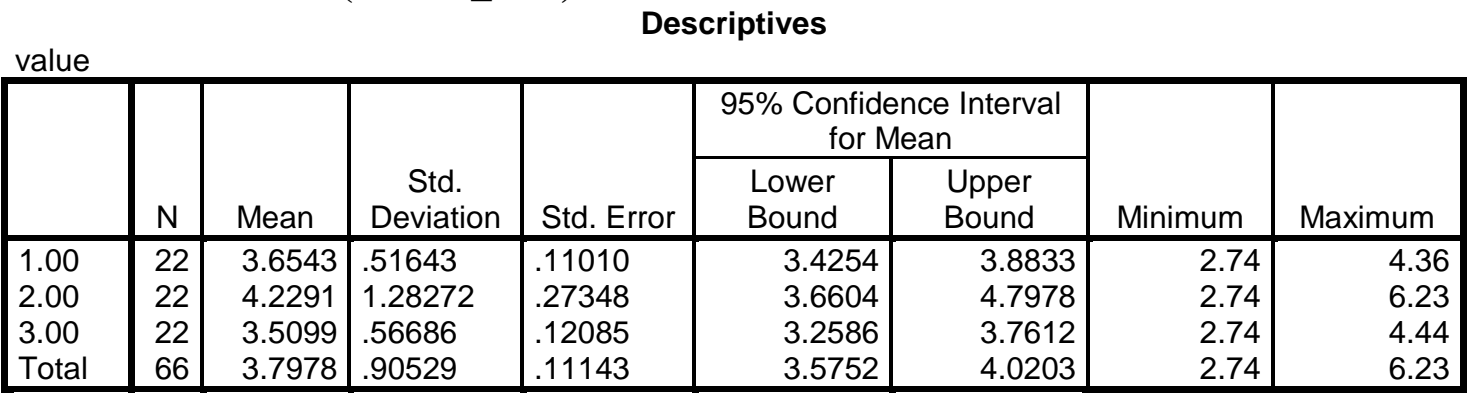

value

\section{ANOVA}

\begin{tabular}{|c|c|c|c|c|c|}
\hline & $\begin{array}{l}\text { Sum of } \\
\text { Squares }\end{array}$ & $\mathrm{df}$ & Mean Square & $\mathrm{F}$ & Sig. \\
\hline $\begin{array}{l}\text { Between } \\
\text { Groups } \\
\text { Within } \\
\text { Groups } \\
\text { Total }\end{array}$ & $\begin{array}{r}6.369 \\
46.901 \\
53.271\end{array}$ & $\begin{array}{r}2 \\
63 \\
65\end{array}$ & .744 & 4.278 & .018 \\
\hline
\end{tabular}

\section{A7.1.5 Interspersion and Juxtaposition (IJI)}

Descriptives

\begin{tabular}{|c|c|c|c|c|c|c|c|c|}
\hline & \multirow[b]{2}{*}{$\mathrm{N}$} & \multirow[b]{2}{*}{ Mean } & \multirow[b]{2}{*}{$\begin{array}{l}\text { Std. } \\
\text { Deviation }\end{array}$} & \multirow[b]{2}{*}{ Std. Error } & \multicolumn{2}{|c|}{$\begin{array}{l}\text { 95\% Confidence Interval } \\
\text { for Mean }\end{array}$} & \multirow[b]{2}{*}{ Minimum } & \multirow[b]{2}{*}{ Maximum } \\
\hline & & & & & $\begin{array}{l}\text { Lower } \\
\text { Bound }\end{array}$ & $\begin{array}{l}\text { Upper } \\
\text { Bound }\end{array}$ & & \\
\hline 1.00 & 22 & 77.5856 & 3.87455 & .82606 & 75.8677 & 79.3035 & 69.84 & 82.18 \\
\hline 2.00 & 22 & 71.5428 & 7.64642 & 1.63022 & 68.1525 & 74.9330 & 57.93 & 80.95 \\
\hline 3.00 & 22 & 76.2220 & 3.47201 & .74024 & 74.6826 & 77.7614 & 69.86 & 80.95 \\
\hline Total & 66 & 75.1168 & 5.86806 & .72231 & 73.6742 & 76.5593 & 57.93 & 82.18 \\
\hline
\end{tabular}




ANOVA
\begin{tabular}{|l|r|r|r|r|r|}
\hline & value \\
\hline Between Groups & Sum of Squares & df & Mean Square & F & Sig. \\
Within Groups & 441.986 & 2 & 220.993 & 7.751 & .001 \\
Total & 1796.231 & 63 & 28.512 & & \\
\hline
\end{tabular}

\section{A7.1.6 Largest Patch Index (LPI)}

\begin{tabular}{|c|c|c|c|c|c|c|c|c|}
\hline \multicolumn{9}{|c|}{ Descriptives } \\
\hline & \multirow[b]{2}{*}{$N$} & \multirow[b]{2}{*}{ Mean } & \multirow[b]{2}{*}{$\begin{array}{c}\text { Std. } \\
\text { Deviation }\end{array}$} & \multirow[b]{2}{*}{ Std. Error } & \multicolumn{2}{|c|}{$\begin{array}{l}\text { 95\% Confidence } \\
\text { Interval for Mean }\end{array}$} & \multirow[b]{2}{*}{ Minimum } & \multirow[b]{2}{*}{ Maximum } \\
\hline & & & & & $\begin{array}{l}\text { Lower } \\
\text { Bound }\end{array}$ & $\begin{array}{l}\text { Upper } \\
\text { Bound }\end{array}$ & & \\
\hline 1.00 & 22 & 51.3747 & .60625 & .12925 & 51.1059 & 51.6435 & 50.07 & 52.03 \\
\hline 2.00 & 22 & 51.4215 & .56660 & .12080 & 51.1703 & 51.6727 & 50.20 & 52.03 \\
\hline 3.00 & 22 & 52.0439 & .01637 & .00349 & 52.0366 & 52.0511 & 52.03 & 52.06 \\
\hline Total & 66 & 51.6134 & .56304 & .06931 & 51.4750 & 51.7518 & 50.07 & 52.06 \\
\hline
\end{tabular}

ANOVA

\begin{tabular}{|c|c|c|c|c|c|}
\hline & Sum of Squares & df & Mean Square & $\mathrm{F}$ & Sig \\
\hline $\begin{array}{l}\text { Between } \\
\text { Groups } \\
\text { Within } \\
\text { Groups } \\
\text { Total }\end{array}$ & $\begin{array}{r}6.141 \\
14.466 \\
20.606\end{array}$ & $\begin{array}{r}2 \\
63 \\
65\end{array}$ & .230 & $\begin{array}{r}13.3 \\
72\end{array}$ & .000 \\
\hline
\end{tabular}

\section{A7.1.7 Largest shape Index (LSI)}

\begin{tabular}{|c|c|c|c|c|c|c|c|c|}
\hline \multicolumn{9}{|c|}{ Descriptives } \\
\hline & \multirow[b]{2}{*}{$\mathrm{N}$} & \multirow[b]{2}{*}{ Mean } & \multirow[b]{2}{*}{$\begin{array}{c}\text { Std. } \\
\text { Deviation }\end{array}$} & \multirow[b]{2}{*}{ Std. Error } & \multicolumn{2}{|c|}{$\begin{array}{l}95 \% \text { Confidence } \\
\text { Interval for Mean }\end{array}$} & \multirow[b]{2}{*}{ Minimum } & \multirow[b]{2}{*}{ Maximum } \\
\hline & & & & & $\begin{array}{l}\text { Lower } \\
\text { Bound }\end{array}$ & $\begin{array}{l}\text { Upper } \\
\text { Bound }\end{array}$ & & \\
\hline 1.00 & 22 & 69.5057 & 4.81447 & 1.02645 & 67.3711 & 71.6403 & 64.20 & 80.23 \\
\hline 2.00 & 22 & 65.0616 & 8.73264 & 1.86180 & 61.1897 & 68.9334 & 53.19 & 80.23 \\
\hline 3.00 & 22 & 67.2625 & 7.38207 & 1.57386 & 63.9895 & 70.5355 & 56.78 & 80.23 \\
\hline Total & 66 & 67.2766 & 7.28524 & 89675 & 65.4857 & 69.0675 & 53.19 & 80.23 \\
\hline
\end{tabular}

ANOVA

\begin{tabular}{|l|r|r|r|r|r|}
\hline value & Sum of Squares & \multicolumn{1}{c|}{ df } & Mean Square & \multicolumn{1}{c|}{ F } & Sig. \\
\hline $\begin{array}{l}\text { Between } \\
\text { Groups }\end{array}$ & 217.263 & 2 & 108.631 & 2.11 & .129 \\
Within & 3232.594 & 63 & 51.311 & & \\
Groups & 3449.857 & 65 & & & \\
Total & & & & \\
\hline
\end{tabular}




\section{A7.2 Class level}

A7.2.1 Agriculture

\section{A7.2.1.1 Number of patches (NP)}

ANOVA
\begin{tabular}{|l|r|r|r|r|r|}
\hline value & Sum of Squares & df & Mean Square & F & Sig. \\
\hline Between Groups & 174265131,848 & 2 & 87132565,924 & 12,847 &, 000 \\
Within Groups & 427293152,091 & 63 & 6782430,986 & & \\
Total & 601558283,939 & 65 & & & \\
\hline
\end{tabular}

\section{A7.2.1.2 Patch Density (PD)}

Aalue
\begin{tabular}{|l|c|r|r|r|r|}
\hline & Sum of Squares & \multicolumn{1}{|c|}{ df } & Mean Square & \multicolumn{1}{c|}{ F } & Sig. \\
\hline Between Groups & 796869636034,576 & 2 & 398434818017,288 & 136,492 &, 000 \\
Within Groups & 183903391208,955 & 63 & 2919101447,761 & & \\
Total & 980773027243,530 & 65 & & & \\
\hline
\end{tabular}

\section{A7.2.1.3 Mean Proximity (PROX_MN)}

value

\begin{tabular}{|l|c|r|r|r|r|}
\hline & Sum of Squares & df & Mean Square & F & Sig. \\
\hline Between Groups & 103203134871,121 & 2 & 51601567435,561 & 9,416 &, 000 \\
Within Groups & 345256010274,409 & 63 & 5480254131,340 & & \\
Total & 448459145145,530 & 65 & & & \\
\hline
\end{tabular}

\section{A7.2.1.4 Mean Area (AREA_MN)}

ANOVA

value

\begin{tabular}{|l|r|r|r|r|r|}
\hline & Sum of Squares & \multicolumn{1}{|c|}{ df } & Mean Square & \multicolumn{1}{c|}{ S } & \multicolumn{1}{c|}{ Sig. } \\
\hline Between Groups & 11865783,545 & 2 & 5932891,773 & 10,751 &, 000 \\
Within Groups & 34767550,409 & 63 & 551865,880 & & \\
Total & 46633333,955 & 65 & & & \\
\hline
\end{tabular}

\section{A7.2.1.5 Interposition and Juxtaposition (IJI)}

ANOVA

value
\begin{tabular}{|l|r|r|r|c|r|}
\hline & \multicolumn{1}{|c|}{ Sum of Squares } & \multicolumn{1}{|c|}{ df } & \multicolumn{1}{c|}{ Mean Square } & \multicolumn{1}{c|}{ F } & Sig. \\
\hline Between Groups & 54455645558,273 & 2 & 27227822779,136 & 11,874 &, 000 \\
Within Groups & 144458339717,318 & 63 & 2292989519,323 & & \\
Total & 198913985275,591 & 65 & & & \\
\hline
\end{tabular}

\section{A7.2.1.6 Largest Patch Index (LPI)}

ANOVA

\begin{tabular}{|c|c|c|c|c|c|}
\hline & Sum of Squares & $\mathrm{df}$ & Mean Square & $F$ & Sig. \\
\hline Between Groups & 91694116,455 & 2 & 45847058,227 & 10,579 & ,000 \\
\hline Within Groups & 273029797,136 & 63 & 4333806,304 & & \\
\hline Total & 364723913,591 & 65 & & & \\
\hline
\end{tabular}


A7.2.1.7 Largest Shape Index (LSI)

ANOVA

value

\begin{tabular}{|l|r|r|r|r|r|}
\hline & Sum of Squares & df & Mean Square & F & Sig. \\
\hline Between Groups & 91694116,455 & 2 & 45847058,227 & 10,579 &, 000 \\
Within Groups & 273029797,136 & 63 & 4333806,304 & & \\
Total & 364723913,591 & 65 & & & \\
\hline
\end{tabular}

A7.2.2 Barren

A7.2.2.1 Number of patches (NP)

ANOVA

value

\begin{tabular}{|l|r|r|r|r|r|}
\hline & Sum of Squares & df & Mean Square & F & \multicolumn{1}{c|}{ Sig. } \\
\hline Between Groups & 18891431,545 & 2 & 9445715,773 & 4,176 &, 020 \\
Within Groups & 142492906,955 & 63 & 2261792,174 & & \\
Total & 161384338,500 & 65 & & & \\
\hline
\end{tabular}

\section{A7.2.2.2 Patch Density (PD)}

ANOVA
\begin{tabular}{|l|r|r|r|r|r|}
\hline & \multicolumn{1}{|c|}{ Sulue } \\
\hline Between Groups & 2015361908,576 & 2 & 1007680954,288 & 4,176 &, 020 \\
Within Groups & 15201468397,364 & 63 & 241293149,165 & & \\
Total & 17216830305,939 & 65 & & & \\
\hline
\end{tabular}

\section{A7.2.2.3 Mean Proximity (PROX_MN)}

ANOVA

value
\begin{tabular}{|l|r|r|r|r|r|}
\hline & Sum of Squares & \multicolumn{1}{|c|}{ df } & Mean Square & \multicolumn{1}{c|}{ F } & \multicolumn{1}{c|}{ Sig. } \\
\hline Between Groups & 2003805662,939 & 2 & 1001902831,470 & 12,186 &, 000 \\
Within Groups & 5179593535,318 & 63 & 82215770,402 & & \\
Total & 7183399198,258 & 65 & & & \\
\hline
\end{tabular}

\section{A7.2.2.4 Mean Area (AREA_MN)}

ANOVA

value
\begin{tabular}{|l|r|r|r|r|r|}
\hline & Sum of Squares & \multicolumn{1}{|c|}{ df } & Mean Square & F & \multicolumn{1}{c|}{ Sig. } \\
\hline Between Groups & 75186612,091 & 2 & 37593306,045 & 22,955 &, 000 \\
Within Groups & 103174174,273 & 63 & 1637685,306 & & \\
Total & 178360786,364 & 65 & & & \\
\hline
\end{tabular}

\section{A7.2.2.5 Interposition and Juxtaposition (IJI)}

ANOVA
\begin{tabular}{|l|r|r|r|r|r|}
\hline & \multicolumn{1}{|c|}{ Sulue } \\
\hline Between Groups & 4700137146865,728 & 2 & 2350068573432,864 & 27,675 &, 000 \\
Within Groups & 5349774565454,272 & 63 & 84917056594,512 & & \\
Total & 10049911712320,000 & 65 & & & \\
\hline
\end{tabular}


A7.2.6.6 Largest Patch Index (LPI)

ANOVA

value

\begin{tabular}{|l|r|r|r|r|r|}
\hline & Sum of Squares & df & Mean Square & F & \multicolumn{1}{c|}{ Sig. } \\
\hline Between Groups & 247403,273 & 2 & 123701,636 & 6,152 &, 004 \\
Within Groups & 1266727,227 & 63 & 20106,781 & & \\
Total & 1514130,500 & 65 & & & \\
\hline
\end{tabular}

\section{A7.2.2.7 Largest Shape Index (LSI)}

ANOVA

value

\begin{tabular}{|l|c|r|r|r|r|}
\hline & Sum of Squares & \multicolumn{1}{|c|}{ df } & Mean Square & F & Sig. \\
\hline Between Groups & 1289420321581,303 & 2 & 644710160790,651 & 10,269 &, 000 \\
Within Groups & 3955111043733,182 & 63 & 62779540376,717 & & \\
Total & 5244531365314,484 & 65 & & & \\
\hline
\end{tabular}

\section{A7.2.3 Urban}

\section{A7.2.3.1 Number of patches (NP)}

ANOVA

value
\begin{tabular}{|l|r|r|r|r|l|}
\hline & Sum of Squares & df & Mean Square & F & Sig. \\
\hline Between Groups & 39903841.303 & 2 & 19951920.652 & 37.100 & .000 \\
Within Groups & 33880550.227 & 63 & 537786.512 & & \\
Total & 73784391.530 & 65 & & & \\
\hline
\end{tabular}

\section{A7.2.3.2 Patch Density (PD)}

ANOVA
\begin{tabular}{|l|r|r|r|r|r|}
\hline & Sum of Squares & df & Mean Square & F & Sig. \\
\hline Between Groups & 4257.005 & 2 & 2128.503 & 37.100 & .000 \\
Within Groups & 3614.483 & 63 & 57.373 & & \\
Total & 7871.488 & 65 & & & \\
\hline
\end{tabular}

\section{A7.2.3.3 Mean Proximity (PROX_MN)}

value

\section{ANOVA}

\begin{tabular}{|l|r|r|r|r|l|}
\hline & Sum of Squares & df & Mean Square & F & Sig. \\
\hline Between Groups & 9848.483 & 2 & 4924.241 & 8.143 & .001 \\
Within Groups & 38098.396 & 63 & 604.736 & & \\
Total & 47946.878 & 65 & & & \\
\hline
\end{tabular}

\section{A7.2.3.4 Mean Area (AREA_MN)}

ANOVA

\begin{tabular}{|l|r|r|r|r|l|}
\hline value & Sum of Squares & df & Mean Square & F & Sig. \\
\hline Between Groups & 1712.009 & 2 & 856.005 & 41.929 & .000 \\
Within Groups & 1286.190 & 63 & 20.416 & & \\
Total & 2998.199 & 65 & & & \\
\hline
\end{tabular}


A7.2.3.5 Interposition and Juxtaposition (IJI)

ANOVA

\begin{tabular}{l|r|r|r|r|l|}
\hline value & Sum of Squares & df & Mean Square & F & Sig. \\
\hline Between Groups & 50394.215 & 2 & 25197.108 & 31.733 & .000 \\
Within Groups & 50024.886 & 63 & 794.046 & & \\
Total & 100419.102 & 65 & & & \\
\hline
\end{tabular}

\section{A7.2.3.6 Largest Patch Index (LPI)}

ANOVA

value
\begin{tabular}{|l|r|r|r|r|l|}
\hline & Sum of Squares & df & Mean Square & F & Sig. \\
\hline Between Groups & 11641.065 & 2 & 5820.533 & 3.293 & .044 \\
Within Groups & 111357.387 & 63 & 1767.578 & & \\
Total & 122998.452 & 65 & & & \\
\hline
\end{tabular}

\section{A7.2.3.7 Largest Shape Index (LSI)}

ANOVA

\begin{tabular}{|c|c|c|c|c|c|}
\hline & Sum of Squares & $\mathrm{df}$ & Mean Square & $\mathrm{F}$ & Sig. \\
\hline $\begin{array}{l}\text { Between Groups } \\
\text { Within Groups }\end{array}$ & $\begin{array}{l}330149.812 \\
103673.758\end{array}$ & $\begin{array}{r}2 \\
63\end{array}$ & $\begin{array}{r}165074.906 \\
1645.615\end{array}$ & 100.312 & .000 \\
\hline Total & 433823.570 & 65 & & & \\
\hline
\end{tabular}

\section{A7.2.4 Forest}

\section{A7.2.4.1 Number of patches (NP)}

value
\begin{tabular}{|l|r|r|r|r|l|}
\hline & Sum of Squares & df & Mean Square & F & Sig. \\
\hline Between Groups & 49541580.636 & 2 & 24770790.318 & 52.297 & .000 \\
Within Groups & 29840375.136 & 63 & 473656.748 & & \\
Total & 79381955.773 & 65 & & & \\
\hline
\end{tabular}

\section{A7.2.4.2 Patch Density (PD)}

ANOVA
\begin{tabular}{|l|r|r|r|r|r|}
\hline & value \\
\hline Between Groups & Sum of Squares & df & Mean Square & F & Sig. \\
Within Groups & 4099.111 & 2 & 2049.555 & 23.245 & .000 \\
Total & 9554.893 & 63 & 88.173 & & \\
\hline
\end{tabular}

\section{A7.2.4.3 Mean Proximity (PROX_MN) \\ ANOVA}

\begin{tabular}{|c|c|c|c|c|c|}
\hline & Sum of Squares & df & Mean Square & $\mathrm{F}$ & Sig \\
\hline $\begin{array}{l}\text { Between Groups } \\
\text { Within Groups }\end{array}$ & $\begin{array}{l}43088.591 \\
40558.896\end{array}$ & $\begin{array}{r}2 \\
63\end{array}$ & $\begin{array}{r}21544.296 \\
643.792\end{array}$ & 33.465 & .000 \\
\hline Total & 83647.487 & 65 & & & \\
\hline
\end{tabular}


A7.2.4.4 Mean Area (AREA_MN)

ANOVA

\begin{tabular}{|l|r|r|r|r|l|}
\hline & Sum of Squares & df & Mean Square & F & Sig. \\
\hline Between Groups & 85704.203 & 2 & 42852.102 & 34.269 & .000 \\
Within Groups & 78779.983 & 63 & 1250.476 & & \\
Total & 164484.186 & 65 & & & \\
\hline
\end{tabular}

\section{A7.2.4.5 Interposition and Juxtaposition (IJI)}

ANOVA

\begin{tabular}{|c|c|c|c|c|c|}
\hline & Sum of Squares & $\mathrm{df}$ & Mean Square & $\mathrm{F}$ & Sig. \\
\hline $\begin{array}{l}\text { Between Groups } \\
\text { Within Groups }\end{array}$ & $\begin{array}{r}333278.779 \\
1761889.863\end{array}$ & $\begin{array}{r}2 \\
63\end{array}$ & $\begin{array}{r}166639.389 \\
27966.506\end{array}$ & 5.959 & .004 \\
\hline Total & 2095168.641 & 65 & & & \\
\hline
\end{tabular}

\section{A7.2.4.6 Largest Patch Index (LPI)}

\section{ANOVA}

\begin{tabular}{|l|r|r|r|r|l|}
\hline & value \\
\hline Between Groups & Sum of Squares & df & Mean Square & F & Sig. \\
Within Groups & 613.801 & 2 & 306.900 & 13.366 & .000 \\
Total & 1446.576 & 63 & 22.962 & & \\
\hline
\end{tabular}

\section{A7.2.4.7 Largest Shape Index (LSI)}

\section{ANOVA}

value
\begin{tabular}{|l|r|r|r|r|r|}
\hline & Sum of Squares & df & Mean Square & F & Sig. \\
\hline Between Groups & 76627.413 & 2 & 38313.706 & 55.378 & .000 \\
Within Groups & 43587.039 & 63 & 691.858 & & \\
Total & 120214.452 & 65 & & & \\
\hline
\end{tabular}

\section{A7.2.5 Shrub}

\section{A7.2.5.1 Number of patches (NP)}

ANOVA
\begin{tabular}{|l|r|r|r|r|r|}
\hline value & Sum of Squares & df & Mean Square & F & Sig. \\
\hline Between Groups & 27406294.576 & 2 & 13703147.288 & 5.825 & .005 \\
Within Groups & $1.482 \mathrm{E} 8$ & 63 & 2352467.721 & & \\
Total & $1.756 \mathrm{E} 8$ & 65 & & & \\
\hline
\end{tabular}

\section{A7.2.5.2 Patch Density (PD)}

\begin{tabular}{l|r|r|r|r|r|}
\hline value & Sum of Squares & df & Mean Square & F & Sig. \\
\hline Between Groups & 2923.824 & 2 & 1461.912 & 5.825 & .005 \\
Within Groups & 15810.893 & 63 & 250.967 & & \\
Total & 18734.717 & 65 & & & \\
\hline
\end{tabular}


A7.2.5.3 Mean Proximity (PROX_MN)

ANOVA

\begin{tabular}{|l|r|r|r|r|l|}
\hline value & Sum of Squares & df & Mean Square & F & Sig. \\
\hline Between Groups & 98737.931 & 2 & 49368.965 & 2.228 & .116 \\
Within Groups & 1396115.475 & 63 & 22160.563 & & \\
Total & 1494853.406 & 65 & & & \\
\hline
\end{tabular}

A7.2.5.4 Mean Area (AREA_MN)

value

ANOVA

\begin{tabular}{|c|c|c|c|c|c|}
\hline & Sum of Squares & $\mathrm{df}$ & Mean Square & $\mathrm{F}$ & Sig. \\
\hline $\begin{array}{l}\text { Between Groups } \\
\text { Within Groups }\end{array}$ & $\begin{array}{r}2.731 \\
15.158\end{array}$ & $\begin{array}{r}2 \\
63\end{array}$ & 1.366 & 5.676 & .005 \\
\hline Total & 17.890 & 65 & & & \\
\hline
\end{tabular}

A7.2.5.5 Interposition and Juxtaposition (IJI) ANOVA

\begin{tabular}{|l|r|r|r|r|l|}
\hline value & Sum of Squares & df & Mean Square & F & Sig. \\
\hline Between Groups & 255842.186 & 2 & 127921.093 & 12.220 & .000 \\
Within Groups & 659474.231 & 63 & 10467.845 & & \\
Total & 915316.418 & 65 & & & \\
\hline
\end{tabular}

\section{A7.2.5.6 Largest Patch Index (LPI)}

value

ANOVA

\begin{tabular}{|c|c|c|c|c|c|}
\hline & Sum of Squares & df & Mean Square & $\mathrm{F}$ & Sig. \\
\hline $\begin{array}{l}\text { Between Groups } \\
\text { Within Groups }\end{array}$ & $\begin{array}{r}7.296 \\
48.973\end{array}$ & $\begin{array}{r}2 \\
63\end{array}$ & 3.648 & 4.693 & .013 \\
\hline Total & 56.269 & 65 & & & \\
\hline
\end{tabular}

A7.2.5.7 Largest Shape Index (LSI)

ANOVA

\begin{tabular}{|l|r|r|r|r|l|}
\hline & value \\
\hline Between Groups & 187964.401 & df & Mean Square & F & Sig. \\
Within Groups & 1015710.376 & 2 & 93982.201 & 5.829 & .005 \\
Total & 1203674.777 & 63 & 16122.387 & & \\
\hline
\end{tabular}

\section{A7.2.6 Water}

\section{A7.2.6.1 Number of patches (NP)}

ANOVA

\begin{tabular}{|l|l|r|l|l|l|}
\hline value & Sum of Squares & df & Mean Square & F & Sig. \\
\hline Between Groups & .000 & 2 & .000 &. &. \\
Within Groups & .000 & 63 & .000 & & \\
Total & .000 & 65 & & & \\
\hline
\end{tabular}


A7.2.6.2 Patch Density (PD)

ANOVA
\begin{tabular}{|l|l|r|l|l|r|}
\hline value & Sum of Squares & df & Mean Square & F & Sig. \\
\hline Between Groups & .000 & 2 & .000 & .000 & 1.000 \\
Within Groups & .000 & 63 & .000 & & \\
Total & .000 & 65 & & & \\
\hline
\end{tabular}

\section{A7.2.6.3 Mean Proximity (PROX_MN)}

ANOVA

value
\begin{tabular}{|l|l|r|l|l|r|}
\hline & Sum of Squares & df & Mean Square & F & Sig. \\
\hline Between Groups & .000 & 2 & .000 & .000 & 1.000 \\
Within Groups & .000 & 63 & .000 & & \\
Total & .000 & 65 & & & \\
\hline
\end{tabular}

\section{A7.2.6.4 Mean Area (AREA_MN)}

\section{ANOVA}

\begin{tabular}{|l|l|r|l|l|r|}
\hline & value \\
\hline Between Groups & .000 & df & Mean Square & F & Sig. \\
Within Groups & .000 & 2 & .000 & .000 & 1.000 \\
Total & .000 & 63 & .000 & & \\
\hline
\end{tabular}

\section{A7.2.6.5 Interposition and Juxtaposition (IJI)}

ANOVA

\begin{tabular}{|l|l|r|l|l|r|}
\hline \multicolumn{1}{|l|}{ value } & Sum of Squares & df & Mean Square & F & Sig. \\
\hline Between Groups & .000 & 2 & .000 & .000 & 1.000 \\
Within Groups & .000 & 63 & .000 & & \\
Total & .000 & 65 & & & \\
\hline
\end{tabular}

\section{A7.2.6.6 Largest Patch Index (LPI)}

ANOVA

\begin{tabular}{|l|l|r|l|l|r|}
\hline & value \\
\hline & Sum of Squares & df & Mean Square & F & Sig. \\
\hline Between Groups & .000 & 2 & .000 & .000 & 1.000 \\
Within Groups & .000 & 63 & .000 & & \\
Total & .000 & 65 & & & \\
\hline
\end{tabular}

\section{A7.2.6.7 Largest Shape Index (LSI)}

ANOVA

\begin{tabular}{|l|l|r|l|l|r|}
\hline \multicolumn{1}{|c|}{ value } & Sum of Squares & df & Mean Square & F & Sig. \\
\hline Between Groups & .000 & 2 & .000 & .000 & 1.000 \\
Within Groups & .000 & 63 & .000 & & \\
Total & .000 & 65 & & & \\
\hline
\end{tabular}

(Source: Own calulation) 


\section{Curriculum Vitae}

\section{Personal information}

Full Name

Sex:

Date of birth:

Nationality:

E-mail:
NGUYEN, HOANG KHANH LINH

Female

12.01.1980

Vietnamese

klinhhue@gmail.com

\section{Academic background}

$1998-2002$

Bachelor of Land Management, Hue University of Agriculture and Forestry, Viet Nam

$2004-2006$

Master of Land Science, Hue University of Agriculture and Forestry, Viet Nam

2009 - now

$\mathrm{PhD}$ student at Cartography, Remote Sensing, and GIS department, Geography Institute, Georg-August Göttingen University, Germany

\section{Conferences within the framework of thesis}

\section{Oral presentation}

Nguyen Hoang Khanh Linh, Stefan Erasmi, Martin Kappas, (2012), Quangtifying land use/cover change and landscape fragmentaion in Danang city, Vietnam: 19792009, XXII International Society for Photogrametry \& Remote Sensing Congress, Melbourne, Australia, 25 ${ }^{\text {th }}$ August $-1^{\text {st }}$ September 2012

\section{Poster presentation}

Nguyen Hoang Khanh Linh, Stefan Erasmi, Martin Kappas, (2010), Assessment land use/cover change of urbanization for sustainable development with the supporting of satellite remote sensed data: a case study in Danang city, Vietnam, Deutsche Gesellschaft für Geographie (DGfG), Arbeitskreis Fernerkundung, Heidelberg, Germany, $7^{\text {th }}-8^{\text {th }}$ October 2010

Nguyen Hoang Khanh Linh, Stefan Erasmi, Martin Kappas, (2012), Detecting forest cover change and fragmentation in Danang City by Landsat and ASTER data, International Scientific Conference on "Sustainable Land Use and Rural Development in Mountain Areas” at Hohenheim University, Stuttgart, Germany: $16^{\text {th }}-18^{\text {th }}$ April 2012

\section{Attendance}


$31^{\text {st }}$ Asian Conference on Remote Sensing 2010 (ACRS 2010), Hanoi, Vietnam, $1^{\text {st }}-5^{\text {th }}$ November 2010

$4^{\text {th }}$ Vietnam International Conference 2012, “Vietnam on integration and sustainable development”, $26^{\text {th }}-28^{\text {th }}$ November 2012

\section{Working experience}

2003-now Lecturer at Faculty of Land Resources and Agricultural Environment, Hue University of Agriculture and Forestry

\section{Published Articles}

2011 Nguyen Hoang Khanh Linh. Automatically creating land use map by IBI index from remote satellite data: a case study in Hue city- Thua Thien Hue province. Proceeding of GIS Nation, 2011 (In Vietnamese).

2012 Nguyen Hoang Khanh Linh. Assessing change of land use and urban land surface temperature by remote sensing data: a case study in Hue city -Thua Thien Hue provinve. Journal of Soil Science, Vietnam. Nr. 40, ISSN 08683743 (In Vietnamese).

2012 Nguyen Hoang Khanh Linh, Nguyen Thi Hai, Martin Kappas. Analysis the relationship between NDVI and land surface temperature by remote satellite data: A case study in Hue city- Thua Thien Hue province. Journal of Agriculture and Rural Development, Vietnam. Nr.14/2012.P. 132 - 146. ISSN 0866 - 7020 (In Vietnamese).

2012 Nguyen Hoang Khanh Linh, S. Erasmi, M. Kappas. Quantifying land use/cover change and landscape fragmentation in Danang city, Vietnam: 19792009. Proceedings of International Archives of the Photogrammetry, Remote Sensing and Spatial Information Sciences, Volume XXXIX-B8, 2012, p 501 506 (In English).

\section{Scholarship awarded}

- Government of Vietnam (PhD degree).

- German Academic Exchange Service (German education).

- ERASMUS (Intensive Program)

\section{Travel Grant}

Georg - August Göttingen University (2012), ERASMUS (2012)

\section{Specialized Training}

- Summer School, course of “Advanced Remote Sensing for Mapping, Monitoring \& Management of Environment”, $6^{\text {th }}-10^{\text {th }}$ November 2010, Vietnam Institute of Geodesy and Cartography (VIGAC), Hanoi, Vietnam.

- Weekend Seminar of German Academic Exchange Service, course of "Climate change Meeting the Challenge", $11^{\text {th }}-13^{\text {th }}$ March 2011, Goslar, Germany.

- E-Learning Course, “Cities and Climate Change”, $14^{\text {th }}-25^{\text {th }}$ November, 2011, The World Bank Institute.

- Training session, "Agents-based modeling for spatial processes in landscape geography”, $19^{\text {th }}$ February $-3^{\text {rt }}$ March 2012, Angers, France. 